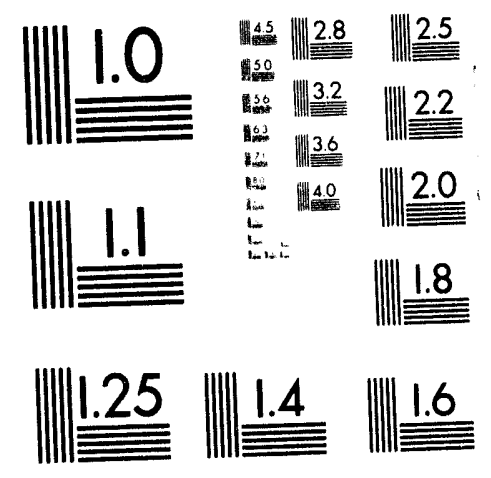




$$
\frac{\overrightarrow{0}}{\omega}
$$




\section{TOPICAL REPORT ON A PRECONCEPTUAL DESIGN FOR THE SPALLATION-INDUCED LITHIUM CONVERSION (SILC) TARGET FOR THE ACCELERATOR PRODUCTION OF TRITIUM (APT)}

Gregory J. Van Tuyle, Project Manager

Dimitrios M. Cokinos, Group Leader

Carl Czajkowski, Eena-Mai Franz, Peter Kroeger, Michael Todosow, Robert Youngblood, and Martin Zucker

Principal Investigators

September 1993

ACCELERATOR PRODUCTION OF TRITIUM

APPLIED TECHNOLOGIES DIVISION

DEPARTMENT OF ADVANCED TECHNOLOGY

P.O. BOX 5000

BROOKHAVEN NATIONAL LABORATORY, UPTON, NY 11973-5000

CONTRACT NO. DE-AC02-76CHOOO16

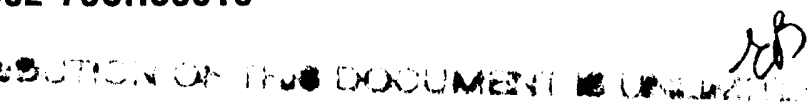





\begin{abstract}
The preconceptual design of the APT Li-Al target system, also referred to as the Spallation-Induced Lithium Conversion (SILC), target system, is summarized in this report. The system has been designed to produce a "3/8 Goal" quantity of tritium using the 200-mA, 1.0$\mathrm{GeV}$ proton beam emerging from the LANL-designed LINAC. The SILC target system consists of a beam expander, a heavy-water-cooled lead spallation neutron source assembly surrounded by light-water-cooled Li-Al blankets, a target window, heat removal systems, and related safety systems. The preconceptual design of each of these major components is described. Descriptions are also provided for the target fabrication, tritium extraction, and waste-steam processes. Performance characteristics are presented and discussed.
\end{abstract}




\section{CONTENTS}

PAGE

ABSTRACT $\ldots \ldots \ldots \ldots \ldots \ldots \ldots \ldots \ldots \ldots \ldots \ldots \ldots \ldots \ldots$

LIST OF FIGURES $\ldots \ldots \ldots \ldots \ldots \ldots \ldots \ldots \ldots \ldots \ldots \ldots \ldots$

LIST OF TABLES $\ldots \ldots \ldots \ldots \ldots \ldots \ldots \ldots \ldots \ldots \ldots \ldots \ldots \ldots \ldots \ldots \ldots \ldots$

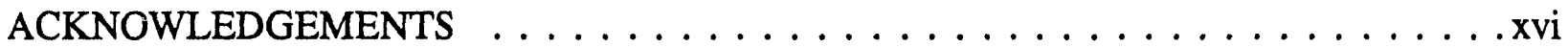

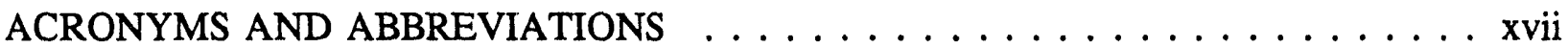

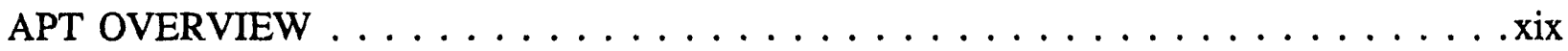

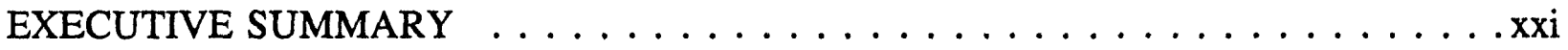

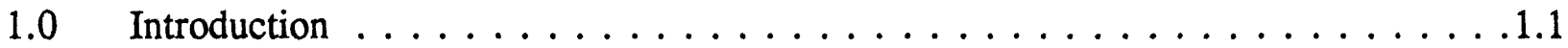

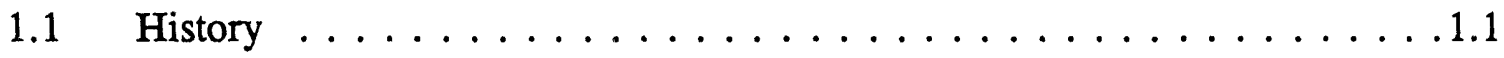

2.0 The Beam Expander for the Lithium-Aluminum Target . . . . . . . . . . . 2.1

Principal Investigator - M. Zucker

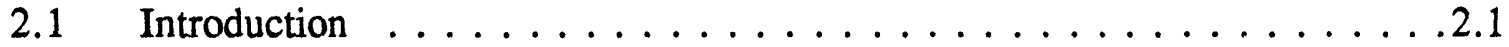

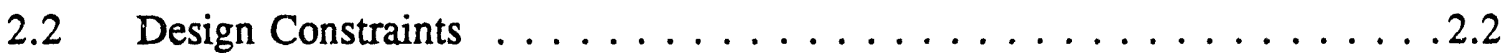

2.3 Considerations Relating to Safety and Equipment Protection . . . . . . . 2.5

2.4 Nominal Magnet Specifications . . . . . . . . . . . . . . . . 2.7

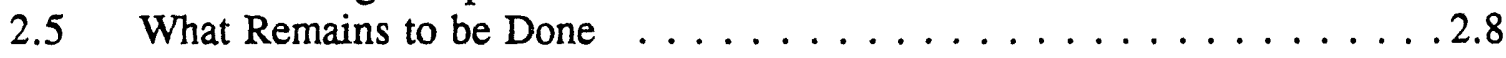

3.0 Lithium-Aluminum Target Design (WBS 5.1.3.1.1.2) $\ldots \ldots \ldots \ldots . \ldots \ldots$

Principal Investigator - M. Todosow

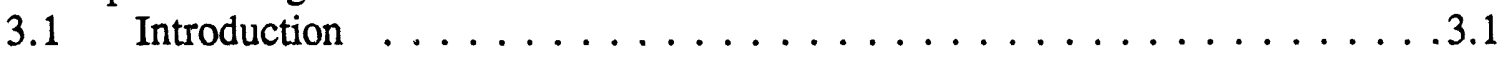

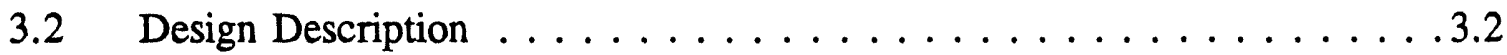

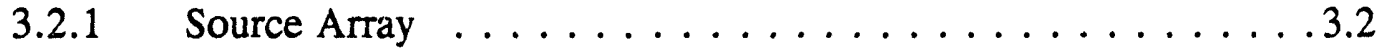

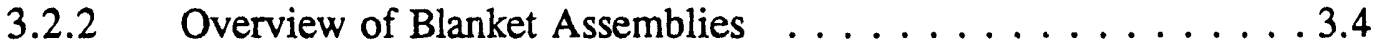

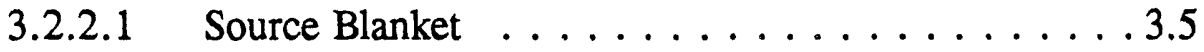

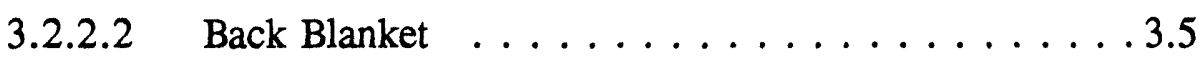

3.2.2.3 Expander Tube Blankets . . . . . . . . . . 3.6

3.2.2.4 Beam Window/Expander Tube . . . . . . . . 3.7

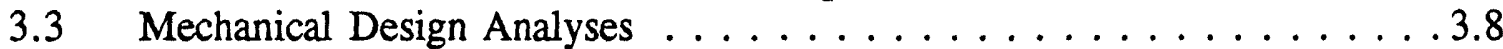

3.3.1 Blanket Assemblies . . . . . . . . . . . . . . 3.8

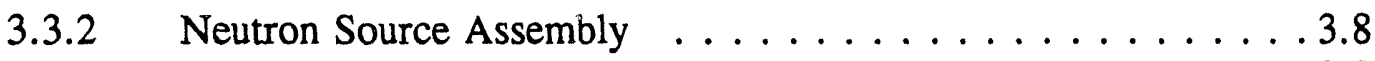

3.3 .3 Beam Window/Expander Tube . . . . . . . . . . . 3.8

3.4 Nuclear Design Analyses . . . . . . . . . . . . . . . . 3.9

3.4.1 Nuclear Design Methodology . . . . . . . . . . . . 3.9

3.4 .2 Validation of Methodology .................... 3.11

3.4.3 Selected Results of Nuclear Design Calculations . . . . . . . . 3.12

3.5 Design Options/Optimization . . . . . . . . . . . . 3.14

References . . . . . . . . . . . . . . . . . . . . 3.17 
4.0 Heat Removal System Design and Target Window Design (WBS 5.1.3.1.2.1 and WBS 5.1.3.1.4.1) $\ldots \ldots \ldots \ldots \ldots \ldots . \ldots \ldots$ Principal Investigator - P. Kroeger

4.1 Introduction $\ldots \ldots \ldots \ldots \ldots \ldots \ldots \ldots \ldots \ldots \ldots \ldots \ldots$

4.2 Component Cooling System Design $\ldots \ldots \ldots \ldots \ldots \ldots \ldots \ldots .1$

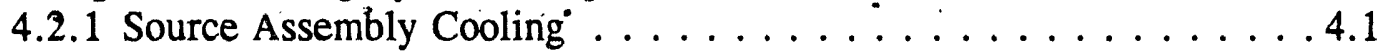

4.2.1.1 Source Assembly Description . . . . . . . . 4.1

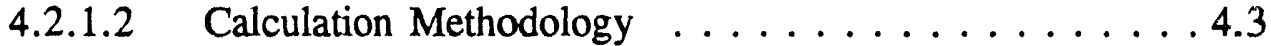

4.2.1.3 Analysis Results . . . . . . . . . . . . . . 4.5

4.2.2 Blanket Assembly Cooling . . . . . . . . . . . . . 4.13

4.2.2.1 Blanket Assembly Description . . . . . . . . 4.13

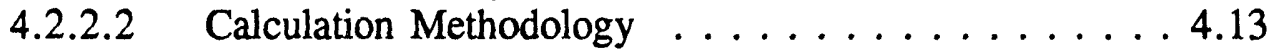

4.2.2.3 Analysis Results . . . . . . . . . . . . . . . 4.14

4.2.3 Target Window and Beam Expander Cooling . . . . . . . . 4.17

4.2.3.1 Cooling System Loop Description . . . . . . . . . 4.17

4.2.3.2 Window Cooling ... . . . . . . . . 4.17

4.2.3.2.1 Thermal Requirements . . . . . . . . . 4.17

4.2.3.2.2 Configuration . . . . . . . . . . 4.22

4.2.3.2.3 Predicted Operating Parameters . . . . 4.22

4.2.3.2.4 Analysis Methodology . . . . . . . . 4.23

4.2.3.2.5 Future Thermal Design Needs . . . . . . 4.23

4.2.3.3 Expander Cooling . . . . . . . . . . . . 4.23

4.2.3.3.1 Thermal Requirements . . . . . . . . . . 4.23

4.2.3.3.2 Configuration ... . . . . . . 4.23

4.2.3.3.3 Operating Parameters . . . . . . . . . . 4.24

4.2.3.3.4 Methodology . . . . . . . . . . . . . 4.24

4.2.3.3.5 Future Thermal Design Effort . . . . . . 4.24

4.2.3.4 Partition Closing . . . . . . . . . . . . . . . . 4.24

4.3 Heat Removal System Design . . . . . . . . . . . . . 4.26

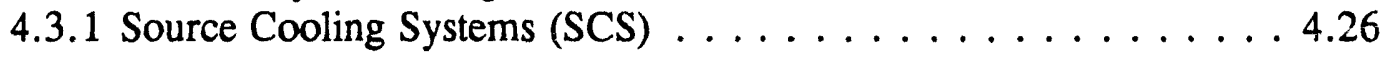

4.3.1.1 Source Primary Cooling System (SPCS) . . . . . . 4.26

4.3.1.1.1 General Description . . . . . . . . . . 4.26

4.3.1.1.2 Pumps . . . . . . . . . . . 4.27

4.3.1.1.3 Heat Exchangers . . . . . . . . . . 4.28

4.3.1.1.4 Pressurizer and Accumulator ........ 4.28

4.3.1.1.5 Piping and Valves ............ . 4.29

4.3.1.1.6 Instrumentation . . . . . . . . . . . . 4.29

4.3.1.2 Source Secondary Cooling System (SSCS) . . . . . 4.31

4.3.1.2.1 General Description . . . . . . . . . . 4.31

4.3 .1 .2 .2 Pumps . . . . . . . . . . . . . 4.32

4.3.1.2.3 Heat Exchangers . . . . . . . . . . . . 4.32

4.3.1.2.4 Natural Draft Water-to-Air Heat

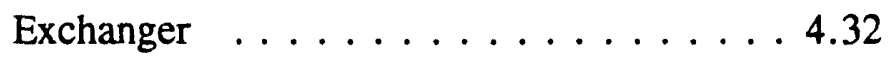

4.3.1.2.5 Surge Tank . . . . . . . . . . . . 4.32 
4.3.1.3 Source Circulating Water System (SCWS) . . . . . . 4.33

4.3.1.4 Source Residual Primary Cooling System

(SRPCS) . . . . . . . . . . . . . . 4.32

4.3.1.5 Source Residual Secondary Cooling

System (SRSC) $\ldots \ldots \ldots \ldots \ldots \ldots \ldots . \ldots . . \ldots \ldots .34$

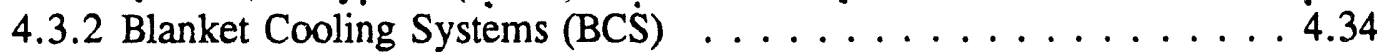

4.3.2.1 Blanket Primary Cooling System (BPCS) . . . . . . . 4.35

4.3.2.1.1 General Description . . . . . . . . . . . . 4.35

4.3.2.1.2 Pumps . . . . . . . . . . . 4.36

4.3.2.1.3 Heat Exchangers . . . . . . . . . . . . 4.36

4.3.2.1.4 Pressurizer and Accumulator . . . . . . . 4.37

4.3.2.1.5 Piping and Valves . . . . . . . . . . 4.38

4.3.2.1.6 Instrumentation . . . . . . . . . . . 4.38

4.3.2.2 Bianket Secondary Cooling System (BSCS) . . . . . 4.40

4.3.2.2.1 General Description . . . . . . . . . . . . 4.40

4.3.2.2.2 Pumps . . . . . . . . . . 4.41

4.3.2.2.3 Heat Exchangers . . . . . . . . . . . 4.41

4.3.2.2.4 Surge Tank . . . . . . . . . . . . 4.41

4.3.2.2.5 Natural Draft Water-to-Air

Heat Exchanger . . . . . . . . . . 4.41

4.3.2.3 Blanket Circulating Water System (SCWS) . . . . . . 4.42

4.3.2.4 Blanket Residual Primary Cooling System

(SRPCS) . . . . . . . . . . . . . . . 4.42

4.3.2.5 Blanket Residual Secondary Cooling

System (BRSCS) . . . . . . . . . . . . . . . . 4.42

4.3.3 Window and Expander Cooling System (WCS) . . . . . . . 4.43

4.3.3.1 Window Primary Cooling System (WPCS) . . . . . . . 4.44

4.3.3.1.1 General Description . . . . . . . . . . . . 4.44

4.3.3.1.2 Pumps . . . . . . . . . . . . . 4.44

4.3.3.1.3 Heat Exchangers . . . . . . . . . . . 4.45

4.3.3.1.4 Pressurizers . . . . . . . . . . . 4.45

4.3.3.1.5 Piping and Valves . . . . . . . . 4.46

4.3.3.1.6 Instrumentation . . . . . . . . . . . 4.46

4.3.3.2 Window Secondary Cooling System (WSCS) . . . . 4.46

4.3.3.3 Window Circulating Water System (WCWS) . . . . 4.48

4.3.4 Source Basin Flood System (SBFS) . . . . . . . . . . . . 4.48

4.3.5 SILC (BNL-APT) Purification System . . . . . . . . . . . . . . 4.49

4.3.5.1 Heavy Water Purification System (HWPS) . . . . . . . 4.49

4.3.5.1.1. General Description . . . . . . . . . . . 4.49

4.3.5.2 Light Water Purification System (LWPS) . . . . . . 4.53

4.3.5.3 $\mathrm{D}_{2} \mathrm{O}$ Upgrade System (DUS) $\ldots \ldots \ldots \ldots \ldots \ldots .4 .55$

4.3.6 Balance of Plant Requirements . . . . . . . . . . . 4.56

Appendices

4A Functions, Systems, and Safety Requirements Document for 
BNL-APT SILC Cooling Systems $\ldots \ldots \ldots \ldots \ldots . \ldots \ldots$

5.0 Waste Stream Management System Design (WBS 5.1.3.1.3.1) . . . . . . . 5.1 Principal Investigator - E-M. Franz

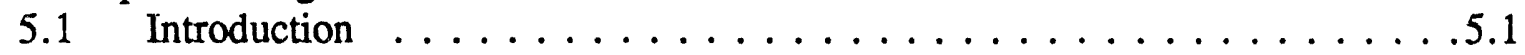

5.1 .1 Volume Estimate of Waste Generated $\ldots \ldots \ldots \ldots \ldots \ldots . \ldots . \ldots$

5.1 .2 Assumptions . . . . . . . . . . . . . . . 5.3

5.2 Waste Management for Tritium Production . . . . . . . . . 5.7

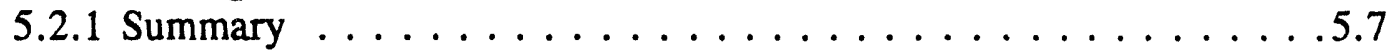

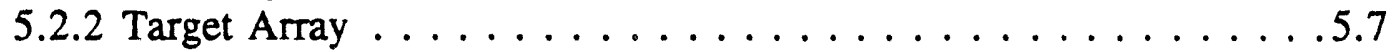

5.2 .3 Blanket Array . . . . . . . . . . . . . . . . .

5.2 .4 Structural Waste . . . . . . . . . . . . . . . . . . 5.9

5.2.5 Waste From Disassembly of Targets and Blankets . . . . . . 5.10

5.2.6 Solid Waste From Water System Purification . . . . . . . 5.10

5.2.7 Job Control Waste From Disassembly Basin . . . . . . . . . . 5.11

5.2 .8 Hazardous Waste . . . . . . . . . . . . . . . . 5.11

5.3 Waste From Tritium Extraction - Purification . . . . . . . . 5.11

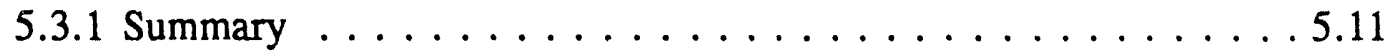

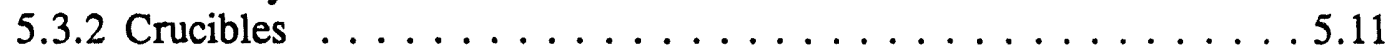

5.3.3 Associated Purification Equipment . . . . . . . . . . 5.13

5.3.4 Job Control Waste and Failed Equipment . . . . . . . . 5.13

5.3 .5 Mixed Waste . . . . . . . . . . . . . . . . . 5.14

5.3 .6 Hazardous Waste . . . . . . . . . . . . . . . 5.14

5.4 Waste Preparation for Transportation . . . . . . . . . . . 5.14

5.4 .1 Disassembly Basin . . . . . . . . . . . . . 5.15

5.4 .2 Waste Treatment Facility . . . . . . . . . . . 5.16

5.4 .3 Heavy Water Management . . . . . . . . . . . . . 5.17

5.5 Items That Need Additional Study $\ldots \ldots \ldots \ldots \ldots \ldots \ldots .17$

Appendices

5.A Definition of Terms . . . . . . . . . . . . . . . . 5.19

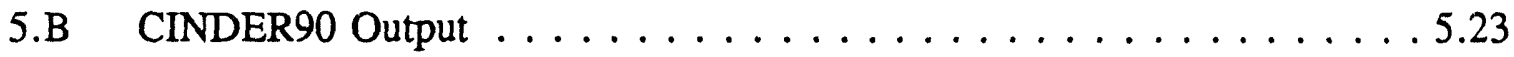

5.C Department of Energy Orders and Code of Federal Regulations

Applicable to Low-Level, Hazardous, and Mixed Waste . . . . . . . . 5.26

5.D Applicable Waste Transportation Orders . . . . . . . . . . . . 5.28

5.E Typical Casks for Transport of Radioactive Materials . . . . . . . . . . . . . . . . . . . . . 5.29

5.F Examples of Volume and Weight Estimates . . . . . . . . 5.30

6.0 Target Window Design (WBS 5.1.3.1.4.1) $\ldots \ldots \ldots \ldots . \ldots \ldots . \ldots \ldots$

Principal Investigator - P. Kroeger

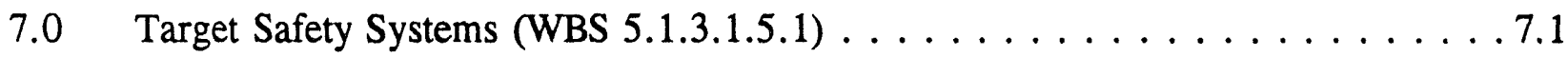

Principal Investigator - R. Youngblood 
7.1 Overview ........................ 7.1

7.1.1 Performance Allocation to Achieve Safety

Objectives . ..................

7.1.2 Functional Requirements $\ldots \ldots \ldots \ldots \ldots \ldots \ldots .2$

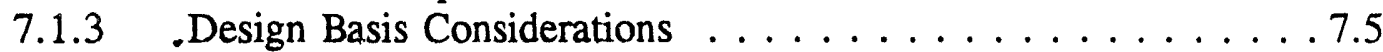

7.2 Safety Functions . . . . . . . . . . . . . . . . 7.6

7.2 .1 The Beam Trip Function $\ldots \ldots \ldots \ldots \ldots \ldots .6 \ldots$

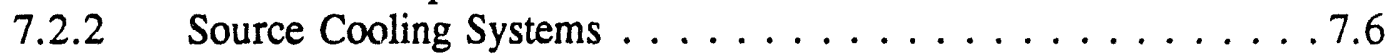

7.2.2.1 General . . . . . . . . . . . . . 7.6

7.2.2.2 Safety Features of the Source Cooling System (SCS) and the Source Basin Flood

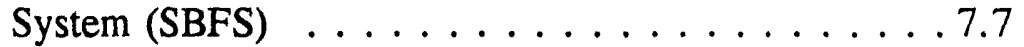

7.2.3 Confinement Safety Function . . . . . . . . . . . . . 7.9

7.3 Event Sequences . . . . . . . . . . . . . . . . . 7.11

7.3.1 Event Sequence Diagrams and Event Trees . . . . . . . . 7.11

7.3.2 Accident Phenomenology . . . . . . . . . . . . 7.14

7.3.3 Key Phenomenological Points . . . . . . . . . . . 7.20

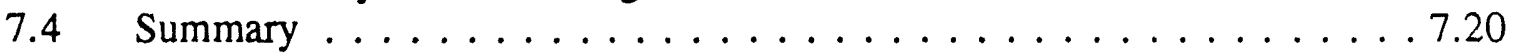

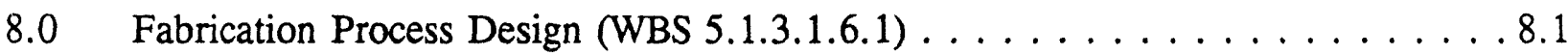
Principal investigator - C. Czajkowski

9.0 Extraction Process Design (WBS 5.1.3.1.7.1) $\ldots \ldots \ldots \ldots . \ldots \ldots . . \ldots \ldots$

Principal Investigator - E-M. Franz

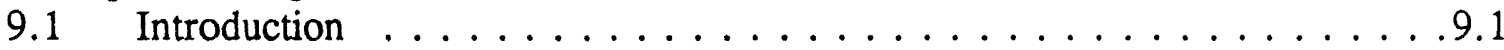

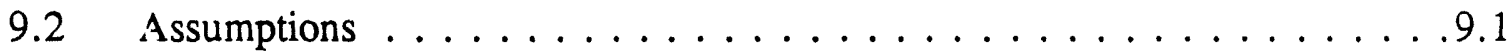

9.3 General Process Description . . . . . . . . . . . . . . . 9.2

9.4 Li-Al Rod Receiving and Spent Melt Handling . . . . . . . . . . 9.3

9.4 .1 Function . . . . . . . . . . . . . . . . . . . . 9.3

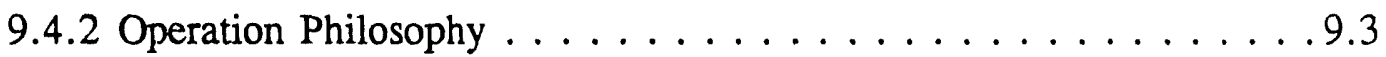

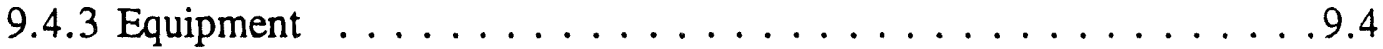

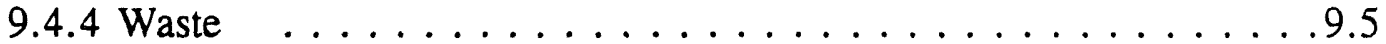

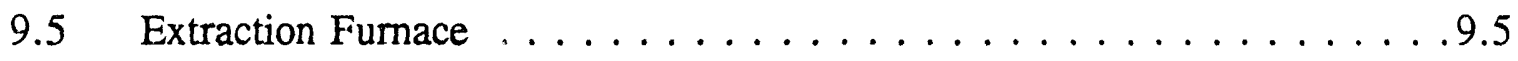

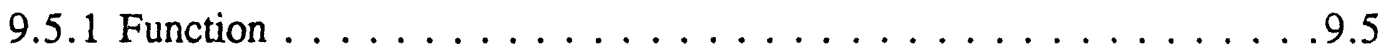

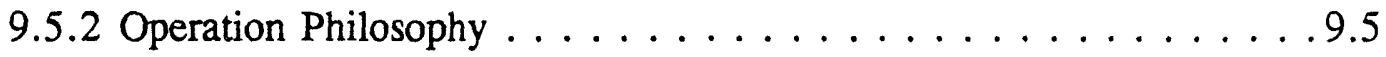

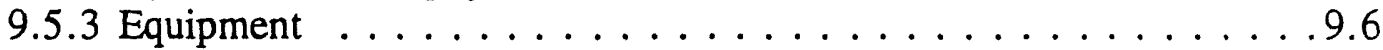

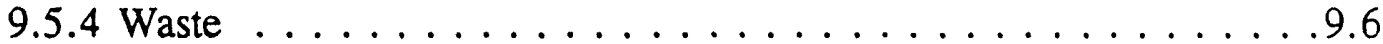

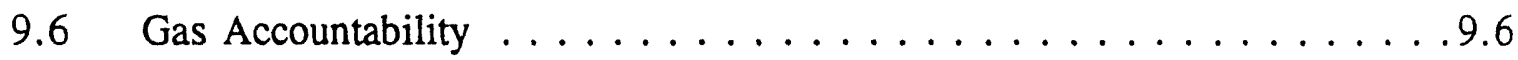

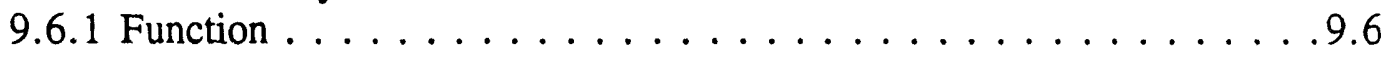

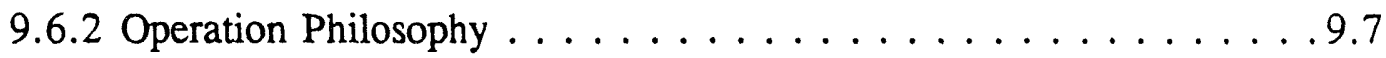

9.6 .3 Equipment $\ldots \ldots \ldots \ldots \ldots \ldots \ldots \ldots . \ldots \ldots . \ldots \ldots . \ldots \ldots$

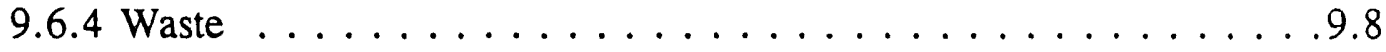

9.7 Purification of Hydrogen Isotopes $\ldots \ldots \ldots \ldots \ldots \ldots \ldots . . . \ldots \ldots$

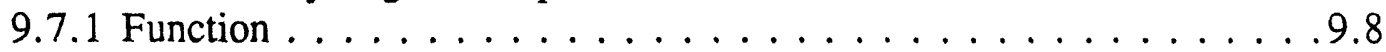




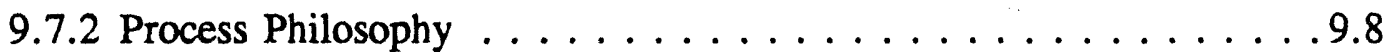

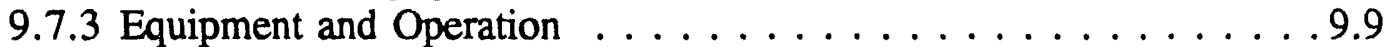

9.7 .4 Waste . . . . . . . . . . . . . . . . . .9.10

9.8 Evacuation and Storage of Hydrogen Isotopes . . . . . . . . . . 9.11

9.8.1 Function . . . . . . . . . . . . . . . . 9.11

9.8.2 Process Philosophy . . . . . . . . . . . . . . $9.11^{-}$

9.8.3 Equipment and Operation . . . . . . . . . . . . 9.11

9.8 .4 Waste . . . . . . . . . . . . . . . . . . . 9.12

9.9 TCAP Hydrogen Isotopes Separation (option 1) $\ldots \ldots \ldots \ldots \ldots .12$

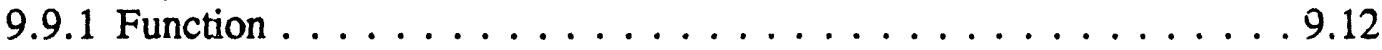

9.9 .2 Process Philosophy $\ldots \ldots \ldots \ldots \ldots \ldots \ldots . \ldots \ldots . \ldots \ldots$

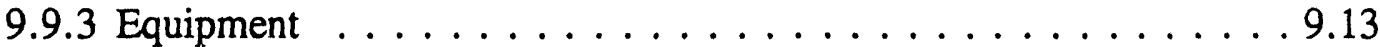

9.9 .4 Waste . . . . . . . . . . . . . . . . . . 9.14

9.10 Cryogenic Distillation System for Hydrogen Isotopes Separation (option 2) 9.14

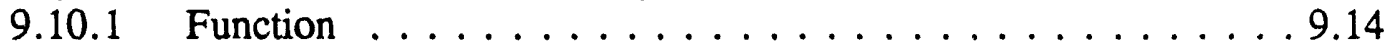

9.10 .2 Operation Philosophy $\ldots \ldots \ldots \ldots \ldots \ldots \ldots .15$

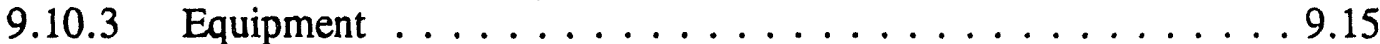

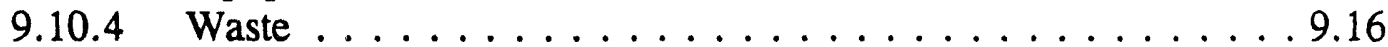

$9.11 \mathrm{Load} /$ Unload Station $\ldots \ldots \ldots \ldots \ldots \ldots \ldots \ldots . \ldots \ldots$

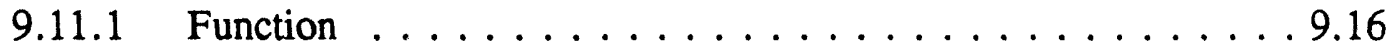

9.11 .2 Operation Philosophy $\ldots \ldots \ldots \ldots \ldots \ldots \ldots .17$

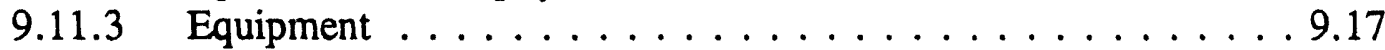

9.12 Glovebox Stripper System . . . . . . . . . . . . . . . . . 9.18

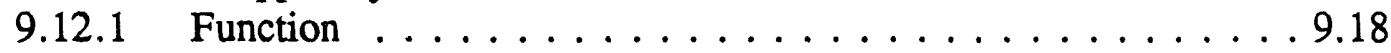

9.12 .2 Operation Philosophy $\ldots \ldots \ldots \ldots \ldots \ldots \ldots \ldots .18$

9.12 .3 Equipment $\ldots \ldots \ldots \ldots \ldots \ldots \ldots \ldots \ldots \ldots . \ldots \ldots$

9.12 .4 Waste . . . . . . . . . . . . . . . . 9.19

9.13 Purge Stripper System . . . . . . . . . . . . . . . . . . . . . . 9.20

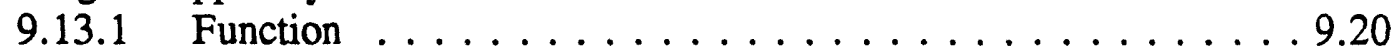

9.13.2 Operation Philosophy $\ldots \ldots \ldots \ldots \ldots \ldots \ldots . \ldots \ldots .20$

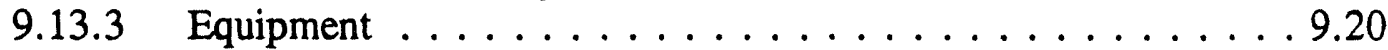

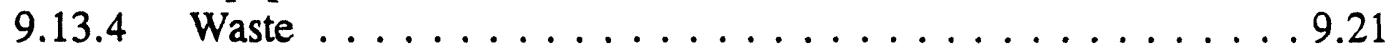

9.14 Process Stripper System . . . . . . . . . . . . . . . . . 9.21

9.14 .1 Function . . . . . . . . . . . . . . 9.21

9.14 .2 Operation Philosophy $\ldots \ldots \ldots \ldots \ldots \ldots \ldots \ldots .21$

9.14 .3 Equipment $\ldots \ldots \ldots \ldots \ldots \ldots \ldots \ldots \ldots \ldots \ldots \ldots \ldots .21$

9.14 .4 Waste $\ldots \ldots \ldots \ldots \ldots \ldots \ldots \ldots \ldots \ldots \ldots .22$

9.15 Zeolite Bed Recovery System . . . . . . . . . . . . . . . . . . 9.22

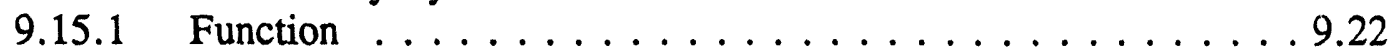

9.15 .2 Operation Philosophy $\ldots \ldots \ldots \ldots \ldots \ldots \ldots \ldots .22$

9.15 .3 Equipment $\ldots \ldots \ldots \ldots \ldots \ldots \ldots \ldots \ldots \ldots \ldots \ldots \ldots .23$

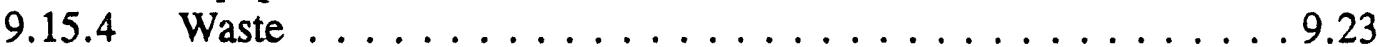

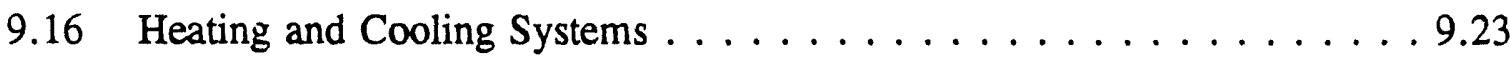

9.16 .1 Function $\ldots \ldots \ldots \ldots \ldots \ldots \ldots \ldots . \ldots \ldots . \ldots \ldots$ 


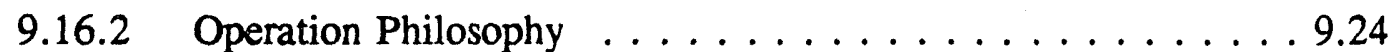

9.16 .3 Equipment $\ldots \ldots \ldots \ldots \ldots \ldots \ldots \ldots \ldots \ldots \ldots .24$

9.16 .4 Waste . . . . . . . . . . . . . . . . .9.24

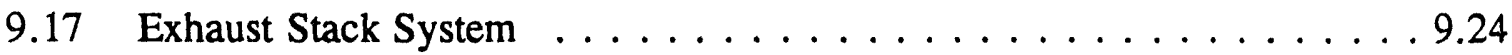

9.17 .1 Function $\ldots \ldots \ldots \ldots \ldots \ldots \ldots \ldots \ldots \ldots \ldots .24$

9.17.2 Operation Philosophy $\ldots \ldots \ldots \ldots \ldots \ldots \ldots \ldots .25$

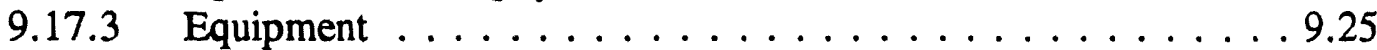

9.18 Glovebox and Hood Design . . . . . . . . . . . . . . . 9.26

9.18.1 Function and Operating Philosophy $\ldots \ldots \ldots \ldots \ldots .26$

9.19 Facility Tritium Inventory . . . . . . . . . . . . . . 9.26

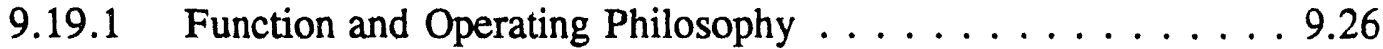

9.20 Atmospheric Release of Tritium . . . . . . . . . . . . . . . . . 9.27

9.21 Items for Further Development . . . . . . . . . . . . . . . . . . 9.27

9.21.1 Closed Crucible for Tritium Extraction _ . . . . . . . 9.27

9.21.2 Diffuser Replacement . . . . . . . . . . . . . . . 9.27

9.21.3 Advanced Thermal Cycling Absorption Process . . . . . . 9.27

9.21.4 Naturally-Cooled Hydride Storage Bed . . . . . . . . . . 9.27

9.21.5 Electrolysis for Tritium Recovery from Tritiated Water . . . 9.28

9.21.6 Non-Oxidative Tritium Strippers . . . . . . . . . . . . 9.28

Appendix 9A Tritium Release Estimate for Accelerator Production

Tritium . . . . . . . . . . . . . . . . 9.41 


\section{LIST OF FIGURES}

FIGURE NO.

PAGE

1

Schematic Diagram for the APT System $\ldots \ldots \ldots \ldots \ldots \ldots \ldots$ iv

$2.1 \quad$ APT Dual Target Beam Transport and Expander . . . . . . . . . . 2.9

2.2 . APT Dual Target Beam Transport and Expander . . . . . . . . . . 2.10

2.3 First Order Optics Cảculations of One Standard Deviation Beam Contour

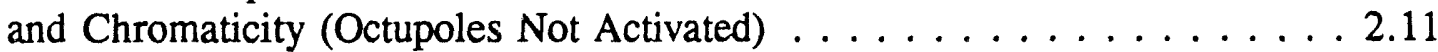

$2.4 \quad \mathrm{X}$ and $\mathrm{Y}$ Beam Profiles on the Target . . . . . . . . . . . 2.12

2.5 Comparison of Gaussian and Modified Gaussian Illuminating the Same Target 2.13

$3.1 \quad$ Components of APT/SILC Target $\ldots \ldots \ldots \ldots \ldots \ldots . \ldots \ldots$

3.2 Assembled APT/SILC Target in Target Chamber . . . . . . . . . . . . 3.19

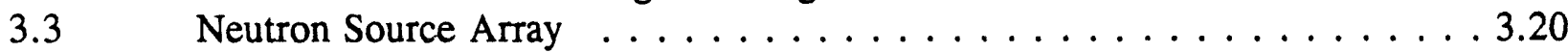

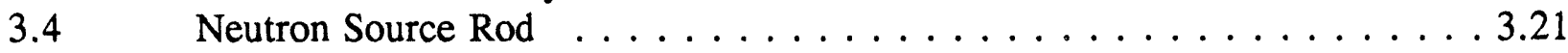

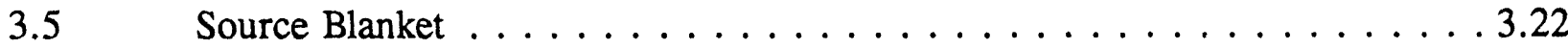

3.6 Beam Window/Expander Tube Assembly . . . . . . . . . . . . 3.23

3.7 Detail of Window and Expander Tube Cooling Channels . . . . . . . . 3.24

$3.8 \quad$ Cooling Loops for Window and Expander Tube . . . . . . . . . . . 3.25

3.9 Target Design: Nuclear Analysis Methodology . . . . . . . . . . . 3.26

3.10 LAHET/MCNP Geometry Model for APT/SILC Target . . . . . . . . . . 3.27

3.11 Region Averaged Fluxes for SILC Target . . . . . . . . . . . . 3.28

3.12 Major Spallation Products in Neutron Source Array After One-Year of Operation . . . . . . . . . . . . . . . . . . . . 3.29

3.13 SILC Target Activity (MCi) Based on CINDER90 Results from LANL . . 3.30

3.14 SILC Target Decay Heat (MW) Based on CINDER90 Results from LANL . 3.31

4.1 SILC APT Source Array Pressure Tube VIPRE-01 Model $\ldots \ldots \ldots . . .4 .6$

4.2 SILC APT Source Array Limiting Pressure Tube Normal Operating

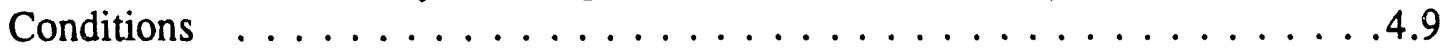

4.3 SILC APT Source Array Limiting Pressure Tube for Limiting AOO Event . 4.10

4.4 Limiting AOO Transient in SILC APT Limiting Pressure Tube . . . . . . 4.11

4.5 SILC APT Source Array Limiting Pressure Tube Residual Heat Removal Operation . . . . . . . . . . . . . . . . . . 4.12

4.6 SILC APT Blanket Array Limiting Pressure Tube - Normal Operating

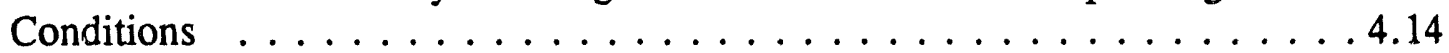

4.7 SILC APT Blanket Array Limiting Pressure Tube - Limiting AOO Event . . 4.15

4.8 SILC APT Blanket Array Limiting Pressure Tube Residual Heat Removal

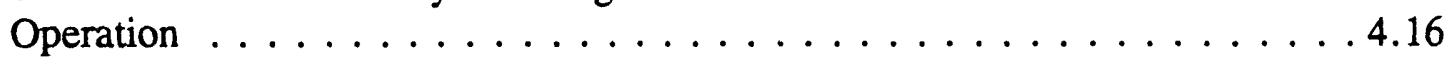

$4.9 \quad$ Beam Expander and Window $\ldots \ldots \ldots \ldots \ldots \ldots \ldots \ldots \ldots \ldots \ldots$

$4.10 \quad$ Beam Expander and Window Junction . . . . . . . . . . . . . . . . . 4.19

4.11 Window Cooling System Flow Diagram . . . . . . . . . . . . . 4.20

4.12 Schematic of Window Cooling System with Plena $\ldots \ldots \ldots \ldots . \ldots .21$

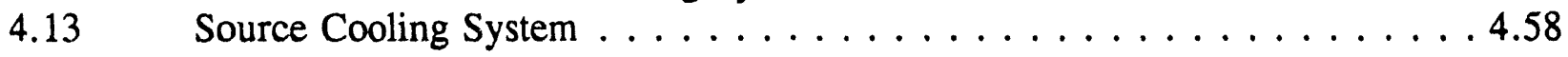




\section{LIST OF FIGURES (continued)}

$4.14 \quad$ Blanket Cooling System $\ldots \ldots \ldots \ldots \ldots . \ldots \ldots . \ldots \ldots$

Source Basin Flooding System-Preconceptual $\ldots \ldots \ldots \ldots \ldots \ldots .64$

7.1 Event Sequences and Design Bases $\ldots \ldots \ldots \ldots \ldots . \ldots \ldots .23$

Blackout Success Sequences . . . . . . . . . . . . . . . . 7.28 


\section{LIST OF TABLES}

TABLE NO.

2.1 Nominal Magnet Specifications $\ldots \ldots \ldots \ldots \ldots \ldots \ldots . \ldots \ldots . \ldots \ldots$

$3.1 \quad$ Parameters for Neutron Source Array $\ldots \ldots \ldots \ldots \ldots . \ldots \ldots . . \ldots \ldots$

3.2 Initial Materials for Neutron Source Array $\ldots \ldots \ldots \ldots \ldots . \ldots \ldots$

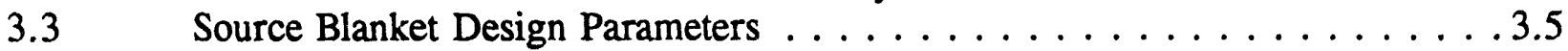

$3.4 \quad$ Back Blanket Design Parameters . . . . . . . . . . . . . . . . 3.6

3.5 Design Parameters for Primary Expander Tube Blanket . . . . . . . . . . . 3.7

3.6 Design Parameters for Secondary Expander Tube Blanket . . . . . . . . . . 3.7

3.7 Relative Tritium Production by Region . . . . . . . . . . . . 3.13

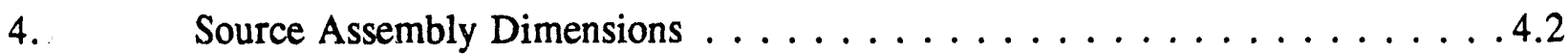

4.2 Source Pressure Tube Power Levels in MW . . . . . . . . . . . . 4.6

4.3 Source Pressure Tube Average Power $(\mathrm{kW}$ per Rod) . . . . . . . . . . 4.7

4.4 Source Pressure Tube Average Rod Heat Flux $\left(\mathrm{kW} / \mathrm{m}^{2}\right) \ldots \ldots \ldots \ldots .7 .7$

4.5 Source Pressure Tube Mass Flow in $\mathrm{kg} / \mathrm{s} \ldots \ldots \ldots . . \ldots \ldots .7$

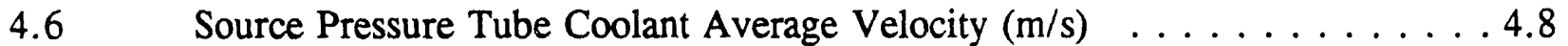

4.7 Source Pressure Tube Coolant Channel Comparison . . . . . . . . . . . . 4.8

4.8 Source Pressure Tube Pressure Drop from Rod Capture Plate to Rod

Channel Exit $(\mathrm{kPa}) \ldots \ldots \ldots \ldots \ldots \ldots \ldots \ldots \ldots . . \ldots \ldots$

4.9 Source Pressure Tube Highest Clad Surface Temperature $\left({ }^{\circ} \mathrm{C}\right) \ldots \ldots \ldots .4 .9$

4.10 Source Pressure Tube Highest Rod Center Line Temperature $\left({ }^{\circ} \mathrm{C}\right) \ldots . . .4 .9$

4.11 SILC Source Primary Cooling System Heat Exchanger . . . . . . . . . . 4.28

$4.12 \quad$ SPCS Preliminary Instrumentation List $\ldots \ldots \ldots \ldots \ldots . . \ldots \ldots$

4.13 Source Requiring Protection Events versus Trip Matrix . . . . . . . . 4.31

$4.14 \quad$ SILC Source Residual Primary Cooling System Heat Exchanger . . . . . . . 4.34

4.15 SILC Blanket Primary Cooling System Heat Exchanger . . . . . . . . . . . 4.37

$4.16 \quad$ BPCS Preliminary Instrumentation List . . . . . . . . . . . . . . . 4.39

4.17 Blanket Events Requiring Protection versus Trip Matrix . . . . . . . . . . . 4.40

4.18 SILC Blanket Residual Primary Cooling System Heat Exchanger . . . . . . 4.43

4.19 SILC Window Primary Cooling System Heat Exchanger . . . . . . . . 4.45

$4.20 \quad$ WPCS Preliminary Instrumentation List . . . . . . . . . . . . . . 4.47

4.21 Window Events Requiring Protection versus Trip Matrix . . . . . . . . 4.48

4.22 BNL-APT Heavy Water Purification System Parameter List . . . . . . . 4.50

4.23 BNL-APT Light Water Purification System Parameter List . . . . . . . . . 4.54

4.24 SILC Cooling System Flow Rates and Coolant Temperatures . . . . . . . . . 4.57

5.1 Estimated Amounts of Waste Generated Annually in the Target, and Blanket . 5.4

5.2 Estimated Amounts of Waste Generated Annually in Tritium Extraction . . . 5.5

5.3 Estimated Total Volume and Weight of Low-Level, Mixed, and Hazardous

Waste Generated Annually in the APT . . . . . . . . . . 5.6

7.1 Target Damage End States for LBLOCA as Function of Source Basin Flood Status; Credit for Heat Removal by Design Basis Natural

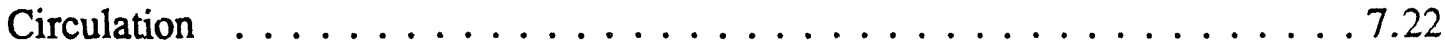




\section{ACKNOWLEDGEMENTS}

Major contributors to various sections are as follows:

SECTION 3.0 - LITHIUM-ALUMINUM TARGET DESIGN:

BNL:

Babcock \& Wilcox:
B. Boyer
G. Bozoki
G. Greene
J. Heiser
O. Lazareth
H. Ludewig
S. Mughabghab
E. Schmidt
N. Tsoupas

R.V. DeMars

Mechanical Design:

D. W. Bell

T. A. Geiger

R. R. Rothermel

S. M. Trepanitis

SECTION 4.0 - HEAT REMOVAL SYSTEM DESIGN AND TARGET WINDOW DESIGN:

BNL:

Babcock \& Wilcox:

B.D. Boyer

\section{Cooling System:}

R.V. DeMars

R.L. Wright

B.E. Bingham

H. Honig

M. Nixon

Thermal-Hydraulics:

T. L. Lotz

L.D. Smith

SECTION 5.0 - WASTE STREAM MANAGEMENT SYSTEM DESIGN:

BNL:

Amparo Corporation:

J. Heiser
E.L. Albenesius
C.B. Goodlett
P. Grand
O.A. Towler

SECTION 7.0 - SAFETY SYSTEMS DESIGN:

BNL:

G. Bozoki

G. Greene

SECTION 9.0 - EXTRACTION PROCESS DESIGN:

Savannah River Technology Center:

L.K. Heung J.H. Owen 


\section{LIST OF ACRONYMS AND ABBREVIATIONS}

AECL Atomic Energy of Canada, Limited

ALARA As Low As Reasonably Achievable (Doses)

AOO Anticipated Operational Occurrence

APT Accelerator Production of Tritium

B\&W Babcock \& Wilcox

BNL Brookhaven National Laboratory

BOP Balance of Plant

CFR Code of Federal Regulations

CHF Critical Heat Flux

CI Curies

CW Continuous Wave

DAT Department of Advanced Technology (BNL)

DBE Design Basis Event

DNB Departure from Nucleate Boiling

DOE Department of Energy

DOT Department of Transportation

ECCS Emergency Core Cooling System

EPA Environmental Protection Agency

EPRI Electric Power Research Institute

ERAB Energy Research Advisory Board

$\mathrm{GeV} \quad$ Giga (billion) Electron Volts

HEPA High Efficiency Particulate Air (Filter)

HIC High Integrity Containers

HVAC Heating, Ventilation and Air Conditioning

JASON DOE Review/Advisory Panel

LAMPF Los Alamos Meson Physics Facility

LANL Los Alamos National Laboratory

LINAC Linear Accelerator

LOCA Loss of Coolant Accident

LWR Light Water (Cooled) Reactor

$\mathrm{MeV} \quad$ Million Electron Volts

MIG Metal-Gas Arc Welding (Metal Inert Gas)

MW Mega Watts 
LIST OF ACRONYMS AND ABBREVIATIONS (Continued)

OSHA Occupational Safety and Health Administration

RAMI Reliability, Availability, Maintainability, and Inspectability

RCRA Resource, Conservation and Recovery Act

SAR Safety Analysis Report

SILC Spallation Induced Lithium Conversion

SNL Sandia National Laboratories

SRL(S) Savannah River Laboratory (Site)

SRTC Savannah River Technology Center

TMI Three Mile Island (Unit 2)

WBS Work Breakdown Structure (Tasks) 


\section{APT OVERVIEW}

The Accelerator Production of Tritium (APT) project, managed by DOE DP-40, involves the preconceptual design of an accelerator system to produce tritium for the nation's stockpile of nuclear weapons. Tritium is an isotope of hydrogen used in nuclear weapons and must be replenished because of radioactive decay (half-life of approximately 12 years). Because the tritium goal quantity amount has significantly decreased over the past several years due to the end of the cold war, an alternative approach to reactors for tritium production based on a linear accelerator can be seriously considered. The tritium goal amount today is $3 / 8$ the 1988 goal. A multi-laboratory team (Los Alamos, Sandia and Brookhaven) collaborating with several industrial partners (Bechtel, Babcock \& Wilcox, Grumman, General Atomics, Maxwell Balboa and Merrick) have developed a preconceptual design for $3 / 8$ goal, and have presented it as a tritium production technology that could be a viable alternative to the reactor concepts proposed for Complex-21. In the context of reduced U.S. weapons stockpile requirements, APT offers significant safety, environmental and production flexibility advantages compared to reactor systems, and can be developed in time to meet the U.S. defense tritium requirements of the 21 st Century. APT has previously been reviewed by the DOE's Energy Research Advisory Board (ERAB) in 1989 and more recently by the JASON panel in 1992. Both reviews wexe positive about the technology, but pointed out the need for a research and development program. As a result of these reviews, DOE decided to sponsor this preconceptual design activity.

The concept uses a high-intensity proton beam (1000 MeV; $200 \mathrm{~mA}$ ) produced by a 1 $\mathrm{km}$ long linear accelerator (similar to the existing LAMPF accelerator at Los Alamos, but more powerful) to strike a heavy metal target (lead or tungsten) to produce neutrons that are moderated before being captured in helium- 3 or lithium- 6 to produce tritium. Figure 1 shows a schematic of the system. Brookhaven is investigating the tritium production target that uses lithium-aluminum technology similar to that used at Savannah River. Target fabrication and tritium extraction technology is therefore based on extensive experience at Savannah River. In the case of the helium-3 target design, helium-3 gas is continuously circulated through the tungsten target region and the blanket region to produce tritium via a $n, p$ (thermal) reaction.

Tritium is produced by the accelerator without the presence of fissionable materialstherefore, no high-level waste is produced and the overall safety impacts are significantly reduced compared to reactor systems. A significant concern for APT is the electricity requirement to power the accelerator-approximately $500 \mathrm{MWe}$ for $3 / 8$ goal design, but this amount of power is available now and in the foreseeable future from the grid at several of the potential tritium production sites. In the more advanced accelerator designs, the potential exists to reduce this power requirement by $(20-40 \%)$. Lower tritium production requirements would also reduce the power demand. 
The LANL, BNL, SNL Laboratory team and the industrial partners believe there are no technical show stoppers to the technology and they also strongly believe the APT system can be built and constructed by 2005 , in time to meet the nation's requirement for tritium for the predicted nuclear weapons stockpile.

\section{Figure 1}

Schematic Diagram of the APT System (not drawn to scale)

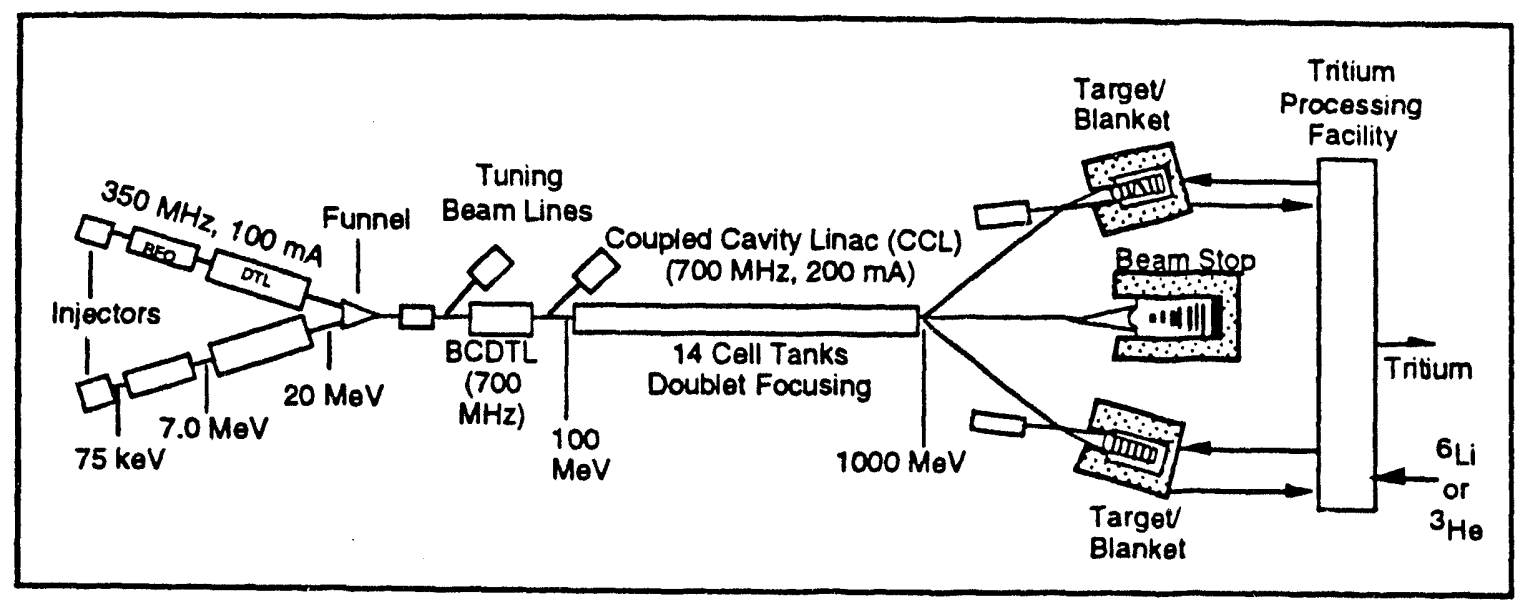




\section{EXECUTIVE SUMMARY}

Because of the reduction in the perceived need for U.S. tritium production, along with recent advances in proton accelerator technology, there now exists the potential to produce the desired amount of tritium using accelerator rather than reactor technology. A major objective of the present DOE-sponsored study of the Accelerator Production of Tritium (APT) is to better quantify the development, capital, and operating costs for this technology, and to assess any potential environmental, safety and health benefits resulting from the use of this alternative technology.

There currently exist two APT target concepts which can be used with the linear accelerator being designed by LANL. The Spallation-Induced Lithium Conversion (SILC) Target Design, based on the lithium-aluminum technology used by Savannah River over the last four decades, is developed primarily by the BNL Team. The LANL Team is focusing primarily on a Helium-3 conversion process.

This report documents the preconceptual design of the BNL/SILC target. As the various aspects of the SILC target design work are tightly coupled, significant efforts of an iterative manner have been made to determine various performance and operational characteristics. A summary of the principal components and processes characterizing the operation of the BNL/SILC target system is presented below.

\section{Beam Expander}

A magneto-optical system has been designed to convey the narrow proton beam exiting the LINAC, condition and expand it to the target dimensions.

The Beam Expander consists of a magnet-free vacuum region of conical shape

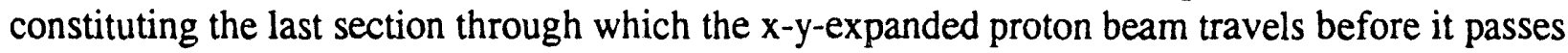
a window to strike the lead target.

\section{Lithium-Aluminum Target}

The lithium-aluminum target consists of the source array (the lead target which acts as the neutron source) and the blanket assemblies which constitute the tritium-producing portions of the target.

Neutrons are generated via spallation/evaporation reactions induced by the proton beam incident on an array of pressure tubes containing aluminum-clad lead rods which are cooled by heavy water. The blanket assemblies surround the source array on its five faces and also consist of pressure tubes containing aluminum-clad lithium-aluminum rods cooled by light water. The blankets are based on the Savannah River technology. Fast neutrons born in the lead pressure 
tubes become thermalized in the bianket and their capture in the lithium leads to the production of tritium.

\section{Target Cooling and Heat Removal}

A heat exchanger system is used in the cooling of the source, blanket and window of the SILC target system. The target cooling and heat removal system contains many redundancies and safety features to provide a high degree of safety and investment protection. Combined with a prompt beam trip at the initiation of accident scenarios, the cooling system can provide protection against almost all conceivable internal accidents.

\section{Fabrication}

Fabrication technology for the lead and lithium-aluminum pins has been identified and evaluated by the Savannah River Technology Center (SRTC), where testing is ongoing.

\section{Extraction}

Tritium extraction is based on the newest technology recommended by Savannah River.

\section{Waste Stream}

Waste-stream management should be largely routine with the exception of lead, where one encounters a mixed-waste problem, i.e., the waste issues involve both chemical and radiological restrictions. The current assumption is for disposal of the lead whenever the aluminum cladding and/or pressure tubes reach the end of their useful lifetimes. This could lead to the activation of around $60 \mathrm{~m}^{3}$ of lead after forty years of operation. However, it is believed

the lead loading could serve for several decades, and some reprocessing options are likely available.

\section{Safety Systems}

The target safety systems include beam trip systems, target after-heat removal systems, and a confinement boundary. 


\subsection{INTRODUCTION}

\section{$1.1 \quad$ HISTORY}

The BNL Spallation Induced Lithium Conversion (SILC) target concept is based on two distinct nuclear processes: 1) the generation of neutrons from proton induced spallation and evaporation reactions in lead, and 2) the production of tritium through neutron capture in lithium-6. The target design has been evolving over a number of years. The initial design effort in 1989 produced a target which satisfied the yearly tritium production goal applicable at that time (100\% goal), and was loosely based on Savannah River Laboratory reactor technology. The target consisted of seven banks of pressure tubes ( $\sim 16$ pressure tubes per bank), with each pressure tube containing a mix of lead rods and lithium-aluminum rods in a ratio of two lead rods to one lithium-aluminum rod. The rods were all clad in aluminum, nominally wire wrapped on a hexagonal pitch, and cooled by light water at low temperatures and pressures. The pressure tubes were assumed to be stainless steel, and the entire target was contained within a vacuum chamber with no window, i.e., the pressure tubes of the front tube bank effectively served as the window. This concept, along with its associated proton accelerator designed by Los Alamos National Laboratory for 1.6 GeV @ $250 \mathrm{~mA}$ continuous wave, "cw", was reviewed by a DOE Energy Research Advisory Board (ERAB) panel in October of 1989, and judged to be a credible candidate for consideration as a tritium production device.

The concept did not receive any additional funding, however, and lay dormant until the tritium production goal was reduced in late 1991 to the range of $1 / 8-3 / 8$ of the 1989 goal amount; at this point DOE expressed renewed interest. (It is the perception of the APT Design Team that the accelerator technology would be more economical at lower production goals, and that the reactor technologies would be more economical a: higher goal quantities.) A scaled down version of the initial design for the production of " $1 / 4 \mathrm{goal}$ " was presented to a DOE convened JASON panel in January 1992, and was subsequently funded through a preconceptual design phase by DOE. In this design, provision was made for an aluminum window separating the target chamber from the accelerator, and the pressure tube material was changed to aluminum.

On the initiation of funding from the DOE in April 1992, the tritium production goal was fixed at 3/8 of the 1989 amount. An initial design satisfying this objective was developed by scaling the target presented to the JASON panel, and presented to DOE at a quarterly review in Oct. 1992. The proton source for the target was based on a LANL designed LINAC operating at $1 \mathrm{GeV}$ and $200 \mathrm{~mA}$ "cw".

While this target design was reasonable, it was not "optimal" in several respects. Chief among these was the fact that the lithium-aluminum (and hence tritium containing rods) were directly in the path of the proton beam and were therefore subject to possible accelerator and cooling system malfunctions which could result in temperature increases that could compromise the integrity of the rods and lead to tritium release into the coolant, etc. In order 
to address this concern the target was reconfigured while still retaining the essential features of the initial design.

The BNL/SILC target that was developed in response to the above concern removed the lithium-aluminum containing rods from the path of the proton beam and resulted in a neutron spallation target, surrounded by a tritium producing blanket configuration. The characteristics of the BNL/SILC target system are described in the following sections. 


\subsection{THE BEAM EXPANDER FOR THE LITHIUM ALUMINUM TARGET}

(WBS 5.1.2.3.3.2)

The purpose of this task is to design a beam-line magneto-optical system which will convey the narrow proton beam exiting the LINAC, condition and expand it in a manner consistent with the goal of uniform illumination over the required area of the target system.

\section{$2.1 \quad$ INTRODUCTION}

The beam line conveying the proton beam from the LINAC to the target (see schematic in Figure 2.1) comprises several sections, each with distinct functions.

(a) The Conditioner line conveys the beam from the exit of the LINAC up to a dipole magnet, $D_{1}$. The four quadrupole magnets, $Q_{(1-4)}$, serve to condition the beam so that any reasonable beam focus condition (emittance) at the LINAC exit can be put into a standard useable format acceptable to the rest of the magneto-optical system.

(b) The Achromatic Bend section, which utilizes two dipoles and four quadrupoles, has three functions. The first dipole, $\mathrm{D}_{1}$, acts as a bending and switching magnet. If unactivated, it will allow the proton beam to proceed straight ahead to a beam dump. Activated, it will bend the beam so that either of the two spallation targets may be accessed. The second dipole, $\mathrm{D}_{2}$, acts solely as a bending magnet, bending the beam even further from the straight ahead direction, so that the dump and each of the two target assemblies are sufficiently distant from one another that the radiation field from one will have minimal (ALARA) impact on the other. The four quadrupoles, $\mathrm{Q}_{(5-8)}$, are configured so that for the particular dipole strength and geometry, the set of six magnets constitute an achromatic system. This will result in target illumination being relatively independent of changes in momentum spread.

(c) The Expander Optics section is composed of six quadrupoles, $\mathrm{Q}_{(9-14)}$, and two octupoles, $\mathrm{O}_{1}$ and $\mathrm{O}_{2}$. Their relative positions, dimensions, and field strengths, are configured according to an algorithm developed at BNL. This configuration has the property of producing a relatively flat beam intensity over a prescribed rectangular area at a given distance from the last of this set of magnets. Quads 13 and 14 are used to provide some additional flexibility; they could be dispensed with.

(d) The Expansion Chamber itself is a magnet-free region conical in shape ending in a metallic "window", defining the end of the vacuum system, and which is some portion of a spherical surface, through which the beam passes enroute to the target. The only function of this section of the beam line is to accommodate the beam under vacuum conditions as it expands to the target dimensions. The outside of the smaller diameter end of the beam expander will have shielding installed against neutrons backstreaming from the target to minimize irradiation of the Expander Optics sections of the beam line. The outside of the larger end of the expander will be where a portion of the SILC target system will be located. 
(e) The Beam Dump Channel extends from the dipole magnet $D_{1}$ to the dump. Its length is approximately equal to the sum of the lengths of the Achromatic Bend, the Expander, and the Expansion Chamber. It will have two main uses, a way of making preliminary beam adjustments and diagnostic measurements, and a safe way of disposing of the beam in certain emergency situations. Quadrupoles $\mathrm{Q}_{(15-20)}$ are used to keep the beam confined as it passes on its way to the Beam Dump. In the event of failure of one or more of these quadrupoles, the defocused beam will strike some area of the walls of the beam pipe. This area will be broad and be symmetric about the beam axis, and extend for a fair length along the beam axis. The way the beam will strike the pipe will be so diffuse that there is no danger of melting, but a significant amount of radiation will be generated, which will trip those monitors in the area designed to detect such "faults", and the LINAC will be tripped off in a few microseconds. There will be residual activation of the beam tunnel walls and of the beam pipe in the area, but there should be no serious lasting damage. It would be advantageous to combine the cul-de-sac with the beam dump as shown in Fig. 2.2, showing an alternate location for the beam dump in relation to the target building.

(f) The Back Leg is a magnetic-field-free backward extension of the expander section ending in a small cul-de-sac designed to catch any back streaming debris from a mechanical failure of the Window, as well as backstreaming neutrons channeling through the Expander beam tube.

\subsection{DESIGN CONSTRAINTS}

(a) The most basic constraint on the system is the overall "emittance" of the beam at the exit of the LINAC. It is a measure of the beam quality, the smaller the better. It is a collection of three quantities, two transverse emittances and one longitudinal emittance. A transverse emittance is the product of the displacement of a particle from the beam axis and the derivative of the displacement with respect to the beam axis, i.e., a measure of the particle direction; two directions perpendicular to the beam axis and each other are used. The longitudinal emittance is the product of the relative uncertainty in the momentum and the length of the beam pulse along the beam axis. These quantities are statistically distributed in a Gaussian-like fashion for typical LINAC beams, and the one-standard-deviation $(1 \sigma)$ contour is usually the value of the quantities used to calculate the emittance. Each of the transverse components of the APT LINAC will have an emittance of $0.04 \mathrm{~cm}$-mrad at the $1 \sigma$ level by design, and this number was assumed in the design of the APT High-Energy Proton Beam Line (see Fig. 2.3).

(b) Using this design value of transverse emittance, the beam transport program "TRANSPORT" was used to calculate, among other quantities, the deviations of the beam from the axis (the "beam envelope") using "first-order optics". The radius of the beam pipe must be greater than the maximum 4 or $5 \sigma$ value of the beam excursion anywhere along the whole beam line in order to minimize beams impacting on the beam pipe. (Aluminum activation is well understood as it has been used extensively in dosimetry.) It was found possible to accommodate the beam according to the above criterion using (BNL standard) beam pipe sizes of $5 \mathrm{~cm}$ radius 
for the Conditioner, Achromatic Bend, and Beam Dump Channel, and $8.25 \mathrm{~cm}$ radius for the Expander Optics section, and, consistent with its function, for the Backleg. However, considering the unusually large beam currents carried by these beam tubes, it may be that larger sized beam tubes than dictated by usual practice will be required in order to keep the radiation induced by fringe-beam activation to allowable limits. Increasing the beam tube dimensions can be accomplished only by also increasing the apertures and other dimensions of magnets and the length of the beam lines, requiring greater capital and operating costs. In the neighborhood of certain elements (see Table 2.1) it is found possible to reduce the beam pipe with benefits to the magnet design (see $2.2 \mathrm{c}$ ).

(c) The apertures of the magnets, dipole, quadruple, and octupole, are determined by the size of the beam envelope. Deciding to use iron-core room-temperature magnets of conservative design for this basic initial design of the APT beam line limits the maximum poletip field strength to (a conservative) $8 \mathrm{kG}$. Above this value of field strength the iron starts to "saturate", i.e., become nonlinear with respect to the current in the coils. The magnets cited were all modelled from existing, working magnets, designed, built, and used in the BNL highenergy physics program. It must be recognized that while this would be safely conservative for a dipole, the highest field intensities in the higher multipolarity magnets will occur in places other than at the pole tips. Minimizing magnet apertures, axial lengths, and field strengths, and the number of magnets required, will directly benefit capital and operating costs and reliability.

(d) In general, it is desirable to limit the size of the vacuum system (length and volume) in order to reduce the size of (underground) beam tunnels and the vacuum pump requirements.

(e) With regard to the expander section, maximizing the expansion angle (while minimizing the length of that section) is beneficial because it allows for more efficient capture of neutrons emitted from the target in the back direction. (The SILC BNL target is configured so that up to half of the neutrons produced by the proton bombardment of the lead and reflected back towards the beam will be captured by an arrangement of ${ }^{6} \mathrm{Li}$-bearing elements surrounding the portion of the Expansion Chamber in the region of the Window Expander Liner.)

(f) The goal of the Expander Optics section is to illuminate the rectangular frontal cross-section area of the target as uniformly as possible. It is believed that the deviations from the average will be of the order of $\pm 7 \%$ using the BNL developed algorithm employing a combination of quadruple and octupole magnets for this purpose.

(g) The two mirror-image Target facilities and the Beam Dump will be separated from each other as much as practical considerations will allow to minimize the radiation field from one interfering with maintenance, repair, fuel reloading, etc. activities in the other, as mentioned in 1(b) above. This can be accomplished by increasing the bending angles of the two dipoles, $D_{1,2}$, or lengthening the beam lines extending from $D_{1}$. These both impact adversely on capital and to a lesser extent the operating costs, so that a compromise has to be effected. Target containment requirements are discussed in Section 2.6. 
Table 2.1

Nominal Magnet Specifications

(For $1.4 \mathrm{~m} \times 1.4 \mathrm{~m}$ Field At Target)

\begin{tabular}{lllccr} 
Section & Mag. & Dist. (m) & Length (m) & Apert. (cm) & Field (kG) \\
\hline \multirow{2}{*}{ Condition. } & $\mathrm{Q}_{1}$ & 3.5 & 0.75 & 10 & -0.8410 \\
& $\mathrm{Q}_{2}$ & 11.25 & 0.75 & 10 & +0.7109 \\
& $\mathrm{Q}_{3}$ & 19.0 & 0.75 & 10 & -0.7125 \\
& $\mathrm{Q}_{4}$ & 26.75 & 0.75 & 10 & -0.7189 \\
Achrom. & $\mathrm{D}_{1}$ & 31.0 & 1.50 & 10 & -9.8738 \\
& $\mathrm{Q}_{5}$ & 36.0 & 0.75 & 10 & -0.5988 \\
& $\mathrm{Q}_{6}$ & 43.75 & 0.75 & 10 & +0.6569 \\
& $\mathrm{Q}_{7}$ & 51.5 & 0.75 & 10 & -0.4573 \\
& $\mathrm{Q}_{8}$ & 59.25 & 0.75 & 10 & +0.497 \\
& $\mathrm{D}_{2}$ & 63.5 & 1.50 & 10 & -9.8738 \\
Expand. & & & & & \\
& $\mathrm{Q}_{9}$ & 68.0 & 0.50 & 16.5 & +6.3824 \\
& $\mathrm{Q}_{10}$ & 69.5 & 0.50 & 16.5 & -7.6349 \\
& $\mathrm{Q}_{11}$ & 72.5 & 1.00 & 16.5 & -7.0259 \\
& $\mathrm{O}_{1}$ & 75.135 & 0.60 & 10.0 & +5.0000 \\
& $\mathrm{Q}_{12}$ & 76.477 & 1.00 & 16.5 & +5.0220 \\
& $\mathrm{O}_{2}$ & 78.077 & 0.60 & 16.0 & +2.7500 \\
& $\mathrm{Q}_{13}$ & 79.138 & 0.50 & 30.0 & 0.0000 \\
& $\mathrm{Q}_{14}$ & 80.138 & 0.50 & 30.0 & +0.9800 \\
Beam & & & & & \\
Dump & $\mathrm{Q}_{15}$ & 34.25 & 0.75 & 10.0 & -0.6408 \\
& $\mathrm{Q}_{16}$ & 43.0 & 0.75 & 10.0 & +0.5417 \\
& $\mathrm{Q}_{17}$ & 50.75 & 0.75 & 10.0 & -0.3485 \\
& $\mathrm{Q}_{18}$ & 58.5 & 0.75 & 10.0 & -0.3833 \\
& $\mathrm{Q}_{19}$ & 65.5 & 0.75 & 10.0 & +0.3485 \\
& $\mathrm{Q}_{20}$ & 74.0 & 0.75 & 10.0 & +0.3833 \\
& & & & & \\
& Length & Of Expansion Chamber & $23 \mathrm{~m}$ & Length Of Beam Line $-103 \mathrm{~m}$ \\
& & & & &
\end{tabular}


Several ways of preventing failures or minimizing their consequences have been developed within the APT design program. (Items 3 (h) and 3 (i) below will be considered in another section of this report but will be mentioned here for completeness.)

(a) Concern has been raised that failure of some or all of the magnets in the optics section will cause a concentration of beam to fall on the target, causing localized overheating. Without commenting on the possible magnitude of such a temperature excursion, or even the likelihood of such an occurrence, it is easily seen that requiring the Expander Optics to be fully functional (e.g., each magnet current in the group being within certain preset limits), as a precondition for any current being supplied to dipole $D_{1}$, may prevent that possibility altogether. Note that this is a passive fail-safe situation; if $D_{1}$ is not energized, for what ever reason, the LINAC beam will be either inhibited or proceed to the Dump.

(b) Aside from the above specific failure mode, there is the more general type of beam line failure in which a particular magnet malfunctions. If it is a dipole, this could possibly result in a more or less focussed beam impacting the wall of the beam tube at some point. If it is a quadrupole, the result could possibly be a less-well-focussed beam impacting the beam tube along some section in a more diffuse manner than the previous case. For either situation, the most immediate consequence would be an excessive production of stray radiation in the vicinity of the beam impact. The standard way this type of occurrence is handled in current accelerator technology is by having radiation detectors distributed along the beam line. Unusual levels of radiation then result in a signal that can be used to put the accelerator complex in a safe mode (inhibit the beam) in less time than it would take serious harm to occur. (The accelerator beam itself can be cut off in microseconds, magnets in milliseconds.)

Of more practical consequence than the preceding is the protection against fault conditions during normal operation:

(c) The Beam Dump Channel affords an initial means of "tuning" the beam without involving the targets. When it is considered satisfactory, the beam, reduced in intensity, can be switched to the appropriate Target. When beam-line diagnostic devices indicate a satisfactory beam distribution on the Target, the beam intensity can be increased to the desired operating level.

(d) The separation of the two Targets from one another and from the Beam dump will allow refueling, repair, etc. on the Target not in use while the other one is under proton bombardment.

(e) The Window is recognized as a vulnerable feature of the APT design concept. Failure would send a shower of debris and perhaps even projectiles streaming down the Expansion Chamber and through the Expander Optics beam tube. It is intended that inertia will carry such material into the Backleg ending in a sturdy cul-de-sac. Fast acting (a few 
milliseconds) gate valves (currently used in modern accelerator installations) would isolate the rest of the upstream beam-line and the LINAC itself from the gaseous or dust component of the failure.

(f) Another function of the Backleg is to allow the evaporation neutrons (average energy $\approx 4.8 \mathrm{MeV}$ ) streaming in the back direction through the Expander Optics beam tube to be safely disposed of in shielding which is part of the cul-de-sac.

There are two safety-related innovative suggestions that have arisen in the APT design community:

(g) The magnetic excitation for some of the magnets in the Expander Optics section could be supplied wholly or in part by permanent-magnet material. Then, it is argued, failure of the current-supplied component of these magnets would result in a beam which would not be dangerously concentrated. Though it might not be satisfactory for production, the beam would at least be in a fail-safe mode. This idea should be examined and compared with the more standard solution in 3(a) above. Aside from the safety question, that some fraction of excitation might be supplied without outside power may have worthwhile economic benefits with respect to operating costs, though surely the initial investment will be substantially higher than for current-driven iron-core magnets.

(h) The concept of a fuse in the neighborhood of the Window, intercepting the same beam that passes through it, has not yet been fully evaluated. One option for the beam fuse would have a standing conduction current passing through, putting the fuse near enough to its melting point so that an unacceptable increase in beam current would be sufficient to cause it to fail. It is necessary however to examine whether such a fuse can be made sensitive enough to be a useful safety device without tripping under normal fluctuations. The LINAC beam will have some nominal (design) value, but it must be assumed that there will, under less than ideal operating conditions, be some fluctuation in the beam from that value. (One of the functions of the operators is to monitor the accelerator and beam line performance continuously, including the beam current output, and to try to make appropriate adjustments.) Some acceptable spread will have to be defined, and the design of the fuse will have to accommodate that acceptable spread, so that even at the lower limit of beam current, beam concentration through a fault will be enough to melt the fuse, while at its upper limit the normal distribution of beam on the target will not melt the fuse. There will probably be a compromise between false trips and sensitivity to beam concentration.

(i) The idea that the Window itself be considered as an expendable part designed to fail before any significant damage accrues to the target has been suggested and will be examined. It is already assumed that the window will, in the course of normal operations, be replaced periodically, and the consequences of its failure (assuming that the fast-acting valves and cul-desac work properly) would not be as serious as if the Target is damaged. 


\subsection{NOMINAL MAGNET SPECIFICATIONS}

A preliminary design to produce a flat field over a $1.4 \mathrm{~m}$ by $1.4 \mathrm{~m}$ area is listed below. It is intended as a proof of principle subject to refinement or even major changes. The magnetic field values are at the pole tips of the respective magnets. Distances are measured from the LINAC exit to the leading edge of the magnet.

The distance from the trailing edge of the last oc $\mathrm{O}_{2}$ to the front of the target is $22.5 \mathrm{~m}$; the total beam path length from LINAC exit to the nont of the target is about $99.5 \mathrm{~m}$. The beam pipes for the Conditioner, Achromatic Bend, and Beam Dump are $10 \mathrm{~cm}$ in diameter. For the Expander Optics they are $16.0 \mathrm{~cm}$ in diameter. These are sizes in use in the BNL HighEnergy Physics accelerator complex. In practice, the size of a beam tunnel is typically large enough to accommodate personnel, say 10 feet in diameter. The beam pipe is also typically off center in the (circular) tunnel to accommodate movement of personnel and equipment on a poured concrete floor that holds the support for magnets, vacuum pipes, diagnostic equipment, radiation alarms, etc.

Plots of the beam intensity at the front of the target in the $\mathrm{x}$ direction averaged over the $\mathrm{y}$ direction and the converse are shown in Figure 2.4. The calculation has a Monte Carlo component to it, which gives rise to the seeming irregularities; these are not physical. The deviation of the extremes of the averaged fields from the mean in either direction is seen to be of the order of $15 \%$ for this particular solution, which is not considered to be as good as can be achieved.

Figure 2.3 shows plots of the deviation of the $1 \sigma$ particle density contour as a function of distance along the beam axis for the vertical and horizontal components of the beam, for the Conditioner, the Achromatic Bend, and for the Expander Section (if the octupoles are not energized) in order to demonstrate that the beam pipe radius exceeds the excursion of the beam from the axis by a comfortable margin everywhere where a uniform beam pipe is supposed to be used, i.e., everywhere except the Expansion Chamber, which will be flared out to accommodate the beam expansion. The plot on the right shows the Expander Optics (less the octupoles) beams leaving out the extreme downstream portion. Note that the vertical scale unit is $10 \mathrm{~cm}$. The plot on the left shows the beam excursion for the Conditioner and Achromatic Bend portion. Note that the vertical scale unit is $1 \mathrm{~cm}$. Also shown in this figure is the degree of chromaticity, in units of $\mathrm{cm}$ times the relative spread in momentum; it starts to increase at the first dipole, reaches a maximum and then declines to zero at the exit of the second dipole, showing that achromaticity has been achieved. The horizontal scale in either case is the distance along the beam axis, $\mathrm{S}$, measured in units of $10 \mathrm{~m}$.

The one-dimensional averaged intensity plots (Figure 2.4) are a convenient and useful way of summarizing the proton current density impacting on the target, but may conceal local over- or under-average proton densities other than what the averaged intensity plots indicate. The calculated density on the target should therefore be plotted in two-dimensional form, i.e., beam intensity as a simultaneous function of both transverse coordinates. An example of this 
is Figure 2.5, which illustrates the improvement in uniformity resulting from application of the field-flattening algorithm to a beam which was originally Gaussian in shape.

\subsection{WHAT REMAINS TQ BE DONE}

This is a report on work still in progress. There are several tasks yet remaining:

(a) There needs to be a study of the intensity distribution of the beam as a function of depth into the target. The calculated values in Figure 2.3 apply strictly speaking only to the front face. The numbers are expected to change somewhat as the depth increases. It would be interesting to know if there are significant departures from the field flattening achieved on the front face for the uncollided component of the proton flux, corresponding to the depth-of-field in a (light) optical system.

(b) Another requirement is the evaluation of the effect of small changes or errors in magnet settings on the quality of the beam, ("sensitivity" analysis). This would reveal what the tolerances of the components of the magneto-optical system should be, the accuracy and precision with which adjustments need to be made, and the differences likely to be observed between the actual optical system and the theoretically calculated one.

(c) The behavior of the magneto-optical system for large perturbations, such as a large change in operating point(s) or the complete loss of a magnet or group of magnets, has obvious relevance to safety, both of personnel and equipment, and so should be studied.

(d) The design involves optimization of the optical components relative to one another by applying a computer program to an arrangement of magnets proposed on the basis of some semi-quantitative algorithm and previous experience. This tends to be a local rather than a global optimization. It is quite possible that another arrangement of magnets would be significantly better, or that between two arrangements that seem approximately equal in merit in basic properties, one might be significantly better when considered as part of the whole accelerator-beam line-target complex. Therefore, some effort should be made to considering these possibilities.

(e) In the above discussions in several places there are indications of the need for further inquiry, in particular the question of whether a practical beam-tripped fuse can be designed, or whether there is some merit in focussing magnets being at least partially excited by incorporating permanent-magnetic material into the yoke or pole structure.

(f) It is also appropriate to discuss the economics of construction and operation of the High-Energy Transport and Expansion Beam Line.

(g) A more complete calculation of the beam envelope at various points along the beam line after the octupoles. 


\section{Figure 2.1 APT DUAL TARGET
Beam Transport and Expander}

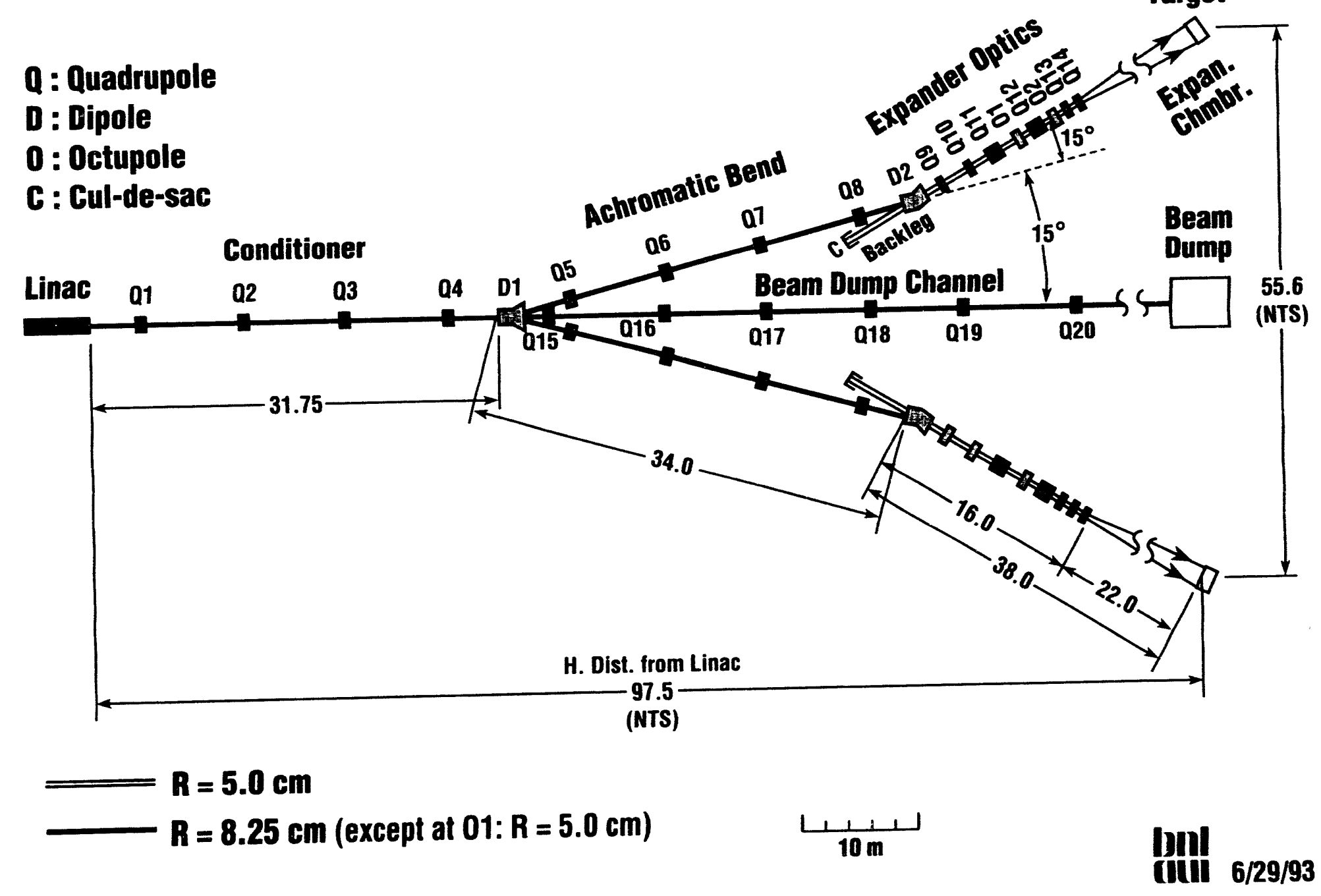




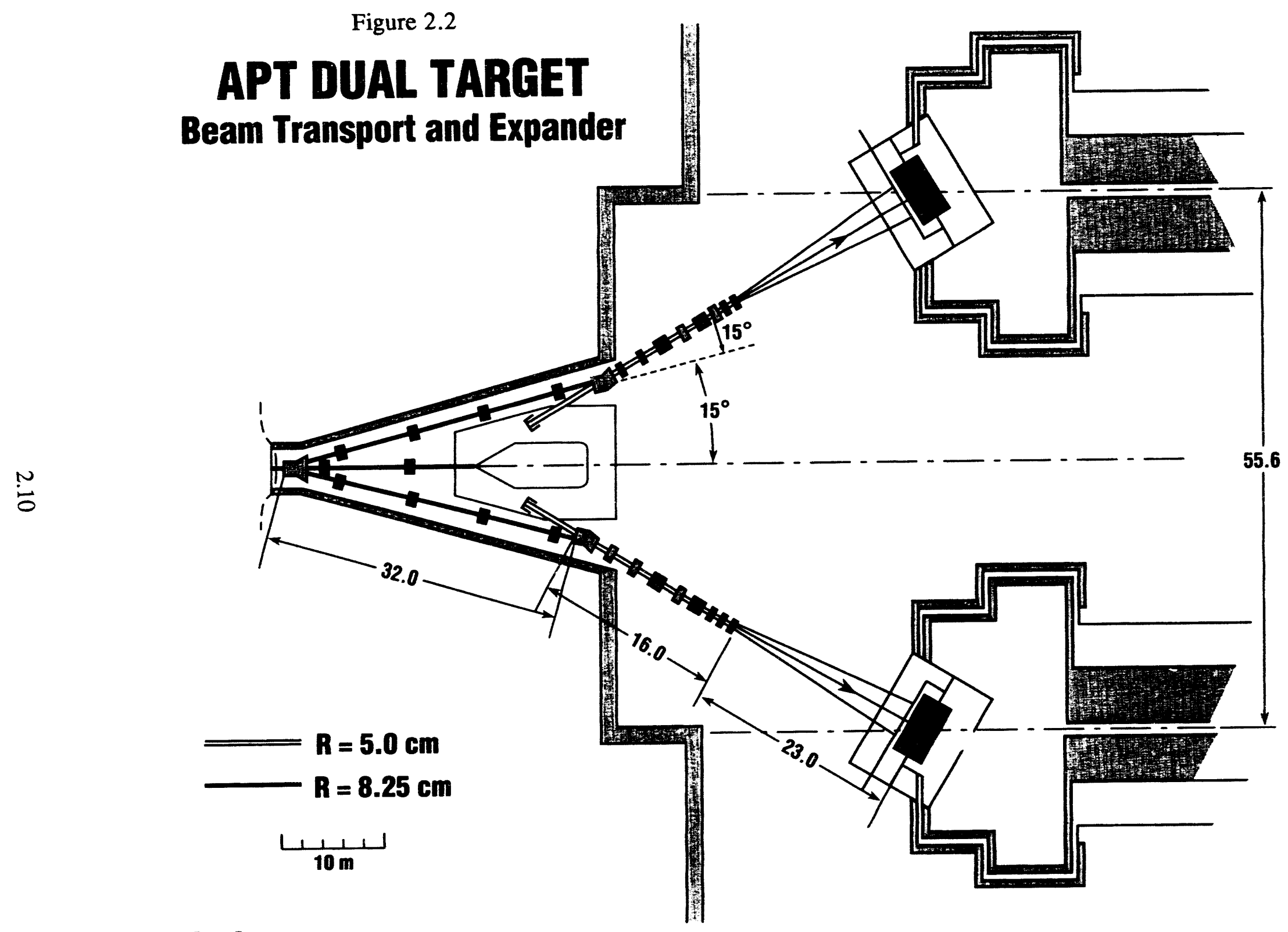

IJII

III $6 / 29 / 93$ 

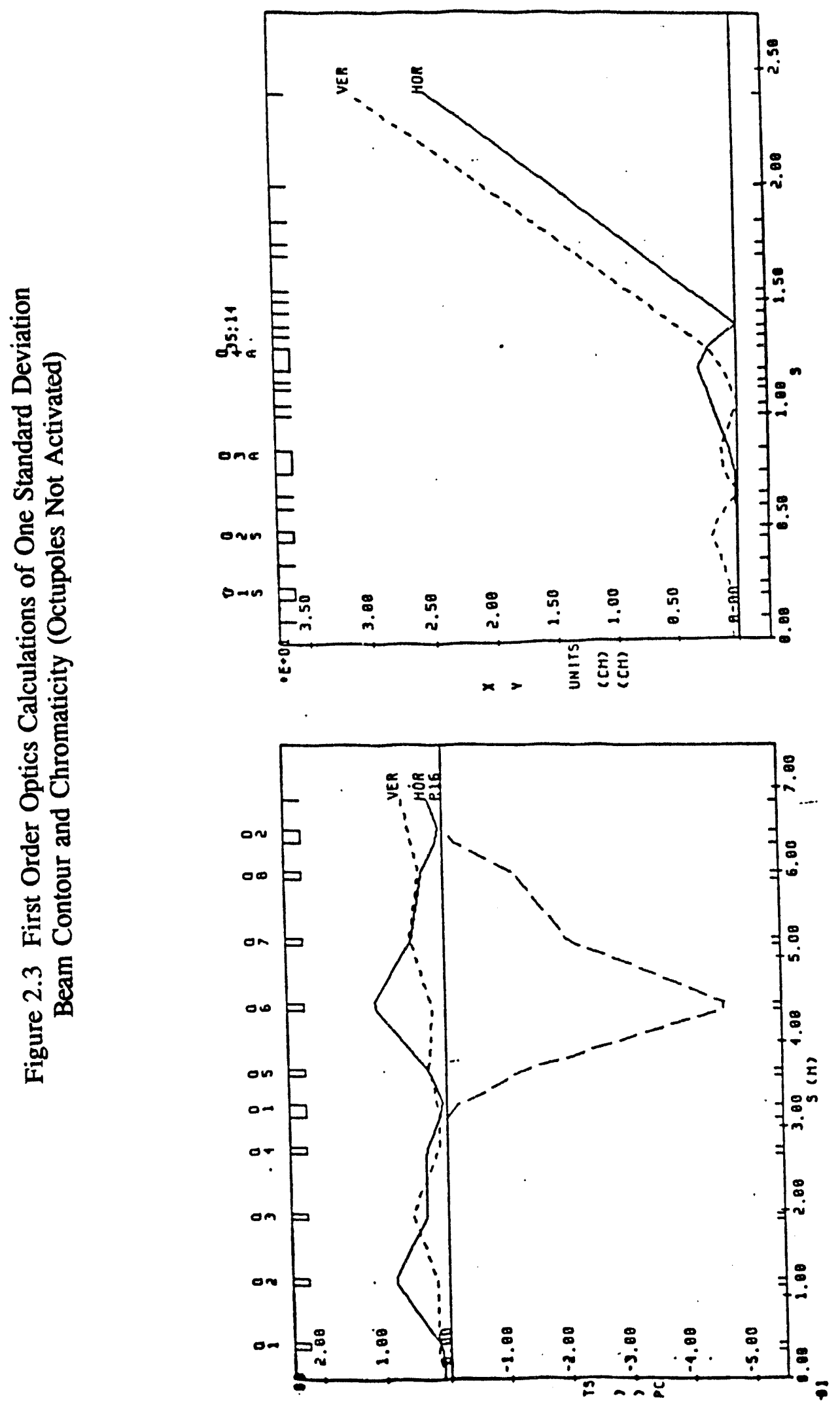

2.11 


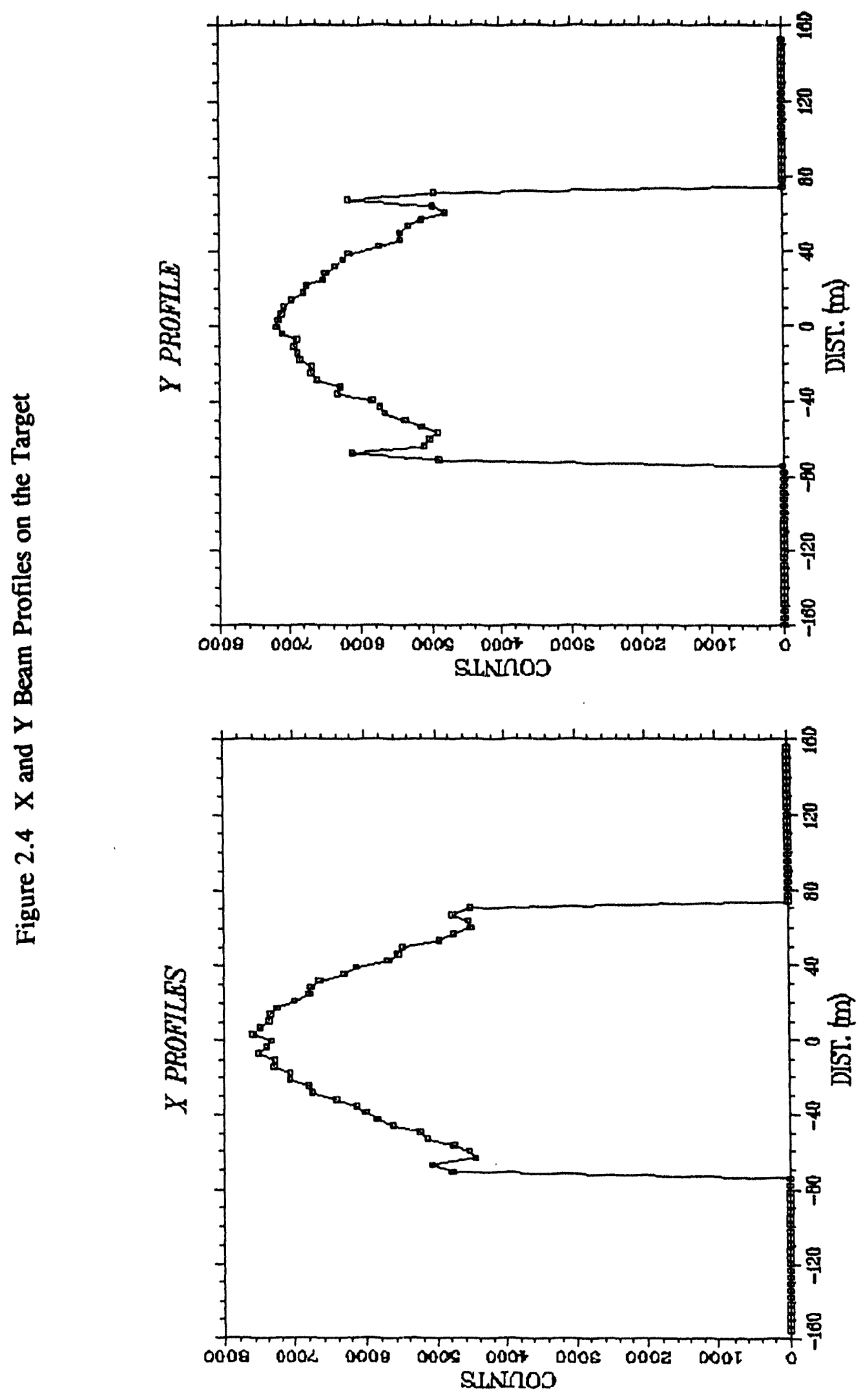

2.12 


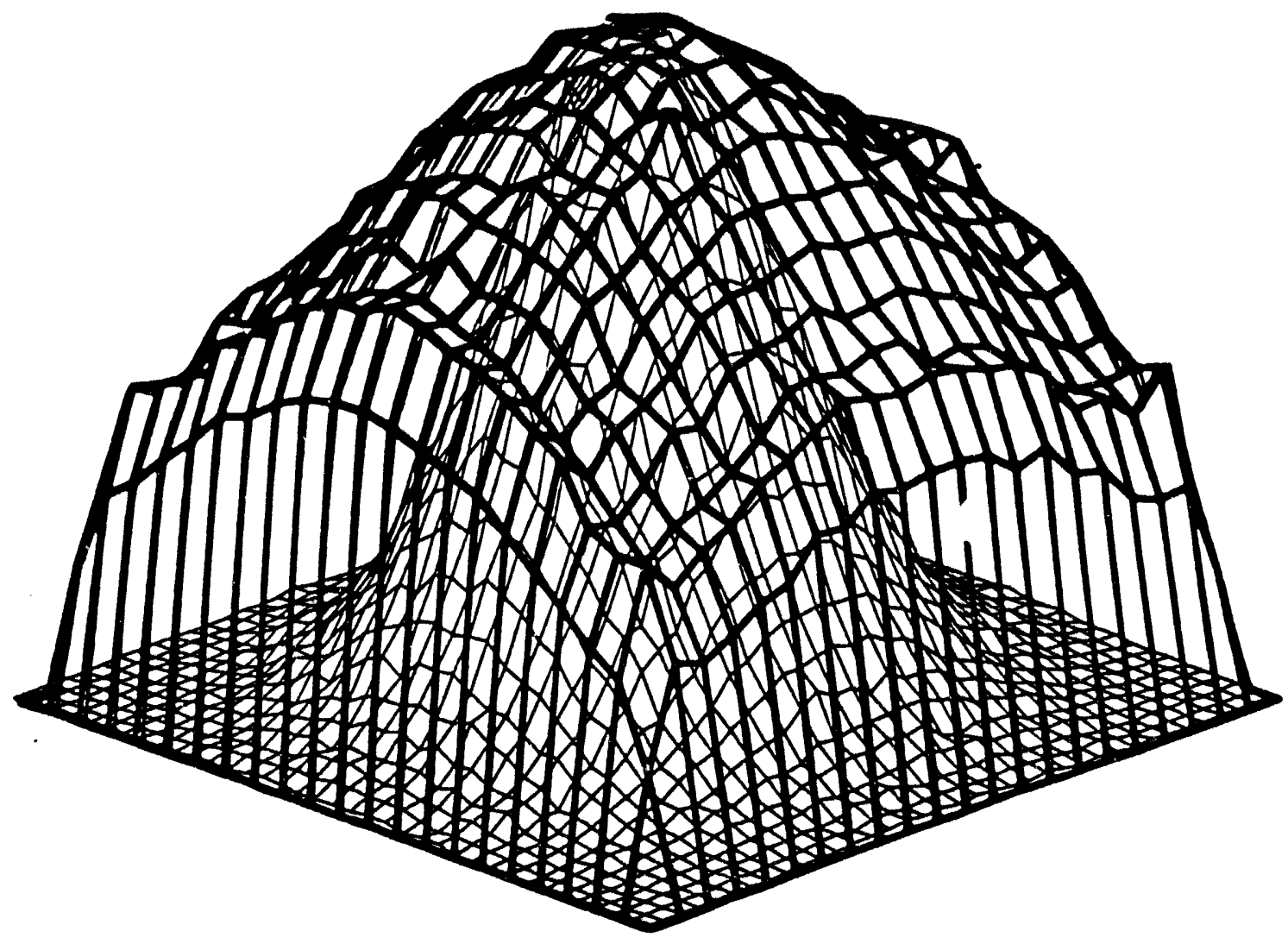

Figure 2.5 Comparison of Gaussian and Modified Gaussian Illuminating the Same Target 


\subsection{LITHIUM-ALUMINUM TARGET DESIGN (WBS 5.1.3.1.1.2)}

\section{$3.1 \quad$ INTRODUCTION}

This chapter describes the work performed for the preconceptual design of the lithiumaluminum target under WBS 5.1.3.1.1.2. The activities consisted of the mechanical design of the target (performed primarily by Babcock \& Wilcox as subcontractor), and the nuclear design performed by BNL.

The SILC target consists of the following elements:

Target Chamber - The target chamber contains the target during operation and "shutdown" cooling prior to removal for tritium extraction, and target component refurbishment/ disposition. The chamber also contains the connections to the target cooling systems, shielding, and structural interfaces to the target components.

Source - The neutron generating portion of the target. The neutrons are generated via spallation reactions induced by the incident proton beam in an array of pressure tubes containing lead rods, clad in aluminum, and cooled by heavy water.

Blankets - The tritium producing portions of the target. In the SILC design, there are four separate blanket assemblies; the Source Blanket, Back Blanket, Primary Expander Tube Blanket, and the Secondary Expander Tube Blanket. All blankets are based on the lithium-aluminum technology used at the Savannah River Site, and consist of pressure tubes containing aluminum-clad lithium-aluminum rods, cooled by light water.

Source Flood Basin - When the Beam Window/Expander Tube Assembly is inserted in the Target Chamber, the Chamber is partitioned into two sections: the Source side and the Expander tube side. In the unlikely event that the Source Array should experience a pipe break, the Source side of the chamber is provided with a flood system that will completely cover the Source Array, guaranteeing that air will not be drawn in through the break and block coolant flow. During this scenario, the Source side of the Target Chamber becomes the Source Flood Basin.

Beam Window/Expander Tube - The proton beam that ultimately impinges on the Source Array of the SILC Target is transported to the Target Chamber in a vacuum. The Beam Window/Expander Tube Assembly is the terminus of the vacuum boundary. Protons enter the open end of the Expander Tube and exit through the Beam Window.

These target components are shown in exploded view in Figure 3.1. Because of the numerous interfaces between components, the Beam Window/Expander Tube Assembly is considered part of the SILC target design, although it plays no direct part in the generation of 
neutrons or tritium. The relationship of the Beam Window/Expander Tube is also shown in Figure 3.1.

The above elements are configured as inseparable assemblies consisting of individually fabricated components joined to form an integral unit not normally capable of being disassembled for repair. This design approach minimizes material otherwise present in flanges, transfer tubes, etc., and contributes to overall system reliability by reducing seal connections.

Fig. 3.2 shows the as-installed configuration of all the assemblies in the target chamber.

\subsection{DESIGN DESCRIPTION}

\subsubsection{Source Array}

The Source Array of the SILC target consists of aluminum-clad lead rods with integrally extruded helical ribs to maintain uniform rod spacing when the rods are grouped into bundles. The three equally spaced ribs are integrally extruded with the clad material. Each rod is retained at the inlet end of the pressure tube by swaging of the inlet end fitting to a perforated capture plate. The other end of the rod is unrestrained, which allows the rods to expand freely in operation. Figure 3.3 shows details of the source rod configuration. These bundles are housed in aluminum pressure tubes of varying size which maintain the rod bundle arrangement and serve as a pressure boundary for the flow of heavy water $\left(\mathrm{D}_{2} \mathrm{O}\right)$ coolant.

The pressure tubes containing the rod bundles are arranged vertically in rows and joined top and bottom by coolant cross headers. The cross headers are in turn connected to two inlet and two outlet pipes. These pipes connect to the two loops of the cooling system. Coolant enters the pressure tubes in the array from the bottom and flows upward through the heated rod bundle, exiting at the top. Flow to the individual pressure tubes is controlled by an orifice at the inlet of each tube.

Figure 3.4 shows the general arrangement of the Source Array including general envelope dimensions (in millimeters) and the orientation of the assembly relative to the proton beam.

In order to enhance the neutronic and thermal-hydraulic performance of the Source Array, the number of source rods and their basic diameter (diameter over the cladding) varies from row to row. As shown in Table 3.1 and Figures 3.4 and 3.10, the pressure tube and rod diameters increase with increasing distance into the target. This variation is based on a number of considerations, and represents a compromise between neutronic and thermal-hydraulic objectives. 
Table 3.1 Parameters for Neutron Source Array

\begin{tabular}{|c|c|c|c|c|c|c|}
\hline ROW & $\begin{array}{c}\text { No. } \\
\text { PRESSURE } \\
\text { TUBES }\end{array}$ & $\begin{array}{c}\text { PRESSURE } \\
\text { TUBE } \\
\text { O.D. } \\
(\mathrm{MM})\end{array}$ & $\begin{array}{c}\text { No. } \\
\text { RODS/TUBE }\end{array}$ & $\begin{array}{c}\text { BASIC ROD } \\
\text { DIA.(MM) }\end{array}$ & $\begin{array}{c}\text { CORE DIA. } \\
\text { (MM) }\end{array}$ & $\begin{array}{c}\text { ROD } \\
\text { PITCH } \\
(\mathrm{MM})\end{array}$ \\
\hline 1 & 7 & 150.0 & 121 & 10.75 & 9.75 & 12 \\
\hline 2 & 6 & 219.5 & 265 & 10.75 & 9.75 & 12 \\
\hline 3 & 7 & 299.8 & 511 & 11.25 & 10.25 & 12 \\
\hline 4 & 6 & 299.8 & 511 & 11.50 & 10.50 & 12 \\
\hline 5 & 7 & 299.8 & 511 & 11.50 & 10.50 & 12 \\
\hline
\end{tabular}

The neutron source receives the bulk of the protons from the accelerator and produces neutrons, primarily via spallation and evaporation reactions in the lead rods. The desire to minimize proton energy and current while maximizing tritium yield resulted in the selection of source, structural, and coolant materials with very low capture cross sections (i.e., natural lead, almost pure aluminum, heavy water). In addition, neutron thermalization in the source region should be minimized, and neutron production maximized so as to provide the greatest number of neutrons to the tritium production zones. Consequently, the size and composition of this region, as well as the lead-to-coolant ratio, represent a compromise, minimizing the volume and coolant fraction to keep the spectrum hard and parasitic capture down, while simultaneously having sufficient lead to produce the maximum number of neutrons, and an energy deposition (power density) which can be accommodated without compromising the integrity of the lead rods. The pressure-tube and rod dimensions shown in Table 3.1 reflect a first-order attempt to optimize neutron production and leakage into the tritium production blankets, while insuring adequate cooling of the Source Array and thermal-hydraulic characteristics (e.g., coolant flow velocity, pressure drops, etc.). Other considerations which influenced the selection of materials was favorable and extensive experience with the selected materials in proton beams, and minimization of activation and decay heat. Initial material selections for various components of the SILC Source Array are given in Table 3.2. Material selections are based on required mechanical properties, minimization of adverse neutronic performance, and survivability in the anticipated proton and neutron fluxes. 
Table 3.2 Initial Materials for Neutron Source Array

\begin{tabular}{||l|l|}
\hline SOURCE ARRAY COMPONENT & \multicolumn{1}{|c|}{ MATERIAL SPECIFICATION } \\
\hline \hline Rod cladding & 1100 Aluminum per ASTM B241 \\
\hline Rod core & Lead per ASTM B29 \\
\hline Rod end fittings & $\begin{array}{l}6061-\mathrm{T} 6 \text { Wrought Aluminum or A356 Cast } \\
\text { Aluminum }\end{array}$ \\
\hline Pressure tube & $6061-\mathrm{T} 6$ Extruded Aluminum \\
\hline Pressure tube end fittings & $6061-\mathrm{T} 6$ Wrought Aluminum \\
\hline Headers and piping & $\begin{array}{l}\text { 6061-T6 Wrought Aluminum or A356 Cast } \\
\text { Aluminum }\end{array}$ \\
\hline
\end{tabular}

\subsubsection{Overview of Blanket Assemblies}

The SILC target design, in addition to the Source Array, includes four Blanket Assemblies: the Source Blanket, Back Blanket, Primary Expander Tube Blanket, and the Secondary Expander Tube Blanket. All four blankets are configured as inseparable assemblies. Refer to Fig. 3.1 for the relationship of the blanket assemblies to the other SILC Target components.

The blanket design for the SILC target is based on well-proven lithium-aluminum technology used at the Savannah River Site. Similar to the Source Array, the blanket arrays consist of aluminum clad rods arranged in bundles. Whereas the core material in the Source Array rods is elemental lead, the blanket rods have a solid core of lithium-aluminum alloy $(\sim 3$ weight percent lithium max.) with ${ }^{6} \mathrm{Li}$ enrichments in the range of 50-90 atom percent considered. These baseline parameters are governed by considerations of manufacturing, tritium retention, and tritium extraction.

Blanket rod bundles are housed in aluminum pressure tubes similar to the Source Array tubes. The pressure tubes maintain the rod bundle arrangement and serve as a pressure boundary for the flow of light water $\left(\mathrm{H}_{2} \mathrm{O}\right)$ coolant. The coolant used in these pressure tubes is low temperature/low pressure light water so as to minimize the heavy water inventory (and tritium production in the coolant), and thermalize the neutron spectrum more efficiently to maximize the $\mathrm{Li}-6(\mathrm{n}, \alpha) \mathrm{T}$ reaction, i.e.

$$
{ }_{3}^{6} \mathrm{Li}+{ }_{0}^{1} \mathrm{n}-\cdots>{ }_{1}^{3} \mathrm{H}(=\mathrm{T})+{ }_{2}^{4} \mathrm{He}(=\alpha)
$$


Blanket rods are externally similar to the source rods described above, with integrally extruded helical ribs to maintain uniform rod spacing in the bundle and single end rod capture to allow for differential thermal expansion. Manifolds are located at the top and bottom of the pressure tube assemblies. Coolant enters at the bottom and flows generally upward through the array. Other material selection for the blanket was governed by the same considerations noted above.

It is important to note that in this current target configuration it is virtually impossible for the proton beam to strike lithium-aluminum containing rods (with the possible exception of a portion of the back blanket in case of a catastrophic melt/slump of the neutron source region). This means that tritium, other than that in the heavy water coolant of the neutron source region, shoule not be part of the "source term" for worst-case accident scenarios (or will be at most $-15 \%$ of that in the original JASON design).

\subsubsection{Source Blanket}

The Source Blanket Array consists of lithium-aluminum rod bundles inserted into pressure tubes fabricated into a " $\mathrm{C}$ " shape. This configuration maximizes the absorption of neutrons streaming from the Source Array in the lithium-aluminum rods, and also supports the natural circulation cooling mode in the event of a loss of pump accident or other event where forced-flow cooling is not available to the blanket. Refer to Fig. 3.5 for general envelope information and construction details of the Source Blanket Array.

The following table presents basic Source Blanket design parameters.

Table 3.3 Source Blanket Design Parameters

\begin{tabular}{|l|c|}
\hline Number of C-Tubes & 32 \\
\hline C-Tube Dia. (mm) & 299.8 \\
\hline No. short rods/ C-Tube & 1022 \\
\hline No. long rods/ C-Tube & 511 \\
\hline Blanket Rod Diameter (mm) & 10.6 \\
\hline
\end{tabular}

\subsubsection{Back Blanket}

The Back Blanket Array is the only blanket assembly of the four to be configured with straight pressure tubes rather than C-tubes. This blanket assembly fits into the Source Array described above. Refer to Fig. 3.1 for the relationship of the Back Blanket Array to the Source Array. In this position, it serves to absorb neutrons streaming from the back of the Source Array to increase tritium production. 
The following table presents basic Back Blanket design parameters.

Table 3.4 Back Blanket Design Parameters

\begin{tabular}{|l|l|}
\hline Number of Pressure Tubes & 15 \\
\hline Pressure Tube Dia. (mm) & 299.8 \\
\hline No. rods/tube & 511 \\
\hline Blanket Rod Diameter (mm) & 10.6 \\
\hline
\end{tabular}

\subsubsection{Expander Tube Blankets}

As noted above, the goal of minimizing the proton accelerator energy and current while maximizing tritium production requires maximum utilization of neutrons in $\mathrm{Li}-6(\mathrm{n}, \alpha) \mathrm{T}$ reactions. This implies that leakage of neutrons from the system as well as parasitic capture be minimized. In principle, leakage from the top, bottom, sides and back of the target can be reduced by increasing the thickness of the source and back blankets described above. Utilization of the neutrons leaking from the front face of the target, however, is not so straightforward. This problem is exacerbated by the fact that the relatively low energy of the proton beam results in the peak of the neutron production from the lead being relatively close to the front face of the target. Since the bulk of the neutrons are produced via evaporation, which is essentially an isotropic process, unless some mitigating measures are taken, an unacceptably large number of the neutrons produced in the neutron source region would be unproductively lost due to leakage out of the front of the target.

In order to "solve" this problem without the introduction of a reflector containing lithium-aluminum on the front face of the target with its attendant problems of "source term", experience in a proton beam, etc., the use of lithium-aluminum blankets on the beam expander chamber was incorporated in the design (cf. Figs. 3.1 and 3.2).

The Primary Expander Tube Blanket is similar in configuration to the Source Blanket Array, with the design parameters of Table 3.5 .

The Secondary Expander Tube Blanket is similar in configuration to the Source Blanket Array and the Primary Expander Tube Blanket. The overall envelope of the Secondary Expander Tube Blanket is reduced relative to the Primary Expander Tube Blanket to more closely conform to the taper of the Expander Tube. Table 3.6 presents basic Secondary Expander Tube Blanket design parameters. 
Table 3.5 Design Parameters for Primary Expander Tube Blanket

\begin{tabular}{|l|l|}
\hline Number of C-Tubes & 32 \\
\hline C-Tube Dia. (mm) & 299.8 \\
\hline No. short rods/ C-Tube & 1022 \\
\hline No. long rods/ C-Tube & 511 \\
\hline Blanket Rod Diameter $(\mathrm{mm})$ & 10.6 \\
\hline
\end{tabular}

Table 3.6 Design Parameters for Secondary Expander Tube Blanket

\begin{tabular}{||l|l|}
\hline Number of C-Tubes & 48 \\
\hline C-Tube Dia. (mm) & 299.8 \\
\hline No. short rods/ C-Tube & 1022 \\
\hline No. long rods/ C-Tube & 511 \\
\hline Blanket Rod Diameter (mm) & 10.6 \\
\hline
\end{tabular}

\subsubsection{Beam Window/Expander Tube (Ref. WBS 5.1.3.1.4.1)}

The Beam Window/Expander Tube Assembly terminates the vacuum boundary required for beam transport to the SILC Target. The assembly is an inseparable assembly comprised of three functional subassemblies; the Beam Window, the Expander Tube, and the Partition. Refer to Fig. 3.1 for the relationship of the Beam Window/Expander Tube to the other components in the Target Chamber. Refer to Fig. 3.6 for details of the Beam Window/Expander Tube.

The Beam Window/Expander Tube will be constructed largely of 6061-T6 aluminum. Integral cooling jackets are provided on the Expander Tube, Beam Window, and Partition portions of the assembly. These cooling jackets are configured to provide radial and axial stiffness to the Expander Tube required to prevent buckling due to external pressure loads. To provide cooling to the Beam Window in the event of loss of coolant accident or other design basis event, the porting of coolant through the assembly is divided into two channels. One channel provides coolant to the Expander Tube and Partition as well as one-half of the Beam Window. The other channel is dedicated to the Beam Window. Refer to Fig. 3.7 for details of the Expander Tube and Beam Window cooling jackets. Refer to Fig. 3.8 for a schematic representation of the coolant porting. 


\subsection{MECHANICAL DESIGN ANALYSES}

Mechanical design analysis for the SILC Target components consistent with the preconceptual level of design includes hand calculations, spreadsheet iteration, and finite element analysis. Analytical efforts focused on areas that require proof-of-concept due to lack of proven design basis, unusual or uncertain loading conditions, or low anticipated design margins. Calculations and analyses were performed largely to support the development of layout drawings and accordingly are informal. Calculations to accommodate dynamic effects due to handling, seismic spectra, etc. were not performed at this stage of design.

The SILC Target is comprised of six major assemblies (refer to Figure 3.1). For purposes of mechanical analysis, the four blanket assemblies are treated as a group, and the Beam Window/Expander Tube and Neutron Source Assembly are treated individually. The following describes the design features investigated analytically in each of the three areas.

\subsubsection{Blanket Assemblies}

Analysis of the blanket assemblies includes sizing calculations for pressure tube wall thickness, rod end fitting integrity, and manifold configurations. These analyses served largely to initiate layout work and provide reference points for the evolving preconceptual design. Detailed mechanical analysis was not performed due to significant evolution of the blanket designs driven by concerns of handling, separation, and neutronics. As the blankets approach a baseline configuration during the next phase of design, in-depth analysis will be performed.

\subsubsection{Neutron Source Assembly}

Analysis of the Neutron Source Assembly includes sizing calculations for pressure tube walls, rod capture plates, and axial compensation bellows. Finite element analysis was performed to establish stress intensity and distribution for the inlet and outlet piping and cross headers shown in Figure 3.1. Hand calculations established envelope requirements for thermal expansion of the source rods within the pressure cans and excursion requirements for the axial compensation bellows. Material number densities for the Neutron Source Assembly and its installation envelope were determined as input to neutronics calculations.

\subsubsection{Beam Window/Expander Tube}

Mechanical analysis of the Beam Window/Expander Tube was directed to three major features of the assembly: the Beam Window and the adjoining flange, the integral partition, and the Expander Tube cross section. Finite element modeling was performed on the window/flange region to determine the effects of beam induced heating and coolant pressure. Stress and deflection maps were generated for several loading cases. Analysis for the integral partition was performed solely to establish bounding load spectra and evaluate several configuration alternatives. Sizing calculations of the Expander Tube cross section were performed to assure adequate margin for radial buckling due to vacuum induced external pressure loads. 


\subsection{NUCLEAR DESIGN ANALYSES}

The nuclear analysis of the APT/SILC target is based on the use of sophisticated computer codes to model the expected behaviour of a complex system. The calculational models must simulate the interaction of the incident proton beam with the target constituents, predict the particles and nuclei that are produced, and then follow the particles through subsequent transport and interactions until they are absorbed or leak from the system. To complicate matters further, these predictions must also take into account the build-up, burn-out, and decay of nuclei with time, and the impact of these processes on the time-dependent behaviour of the system as a whole. To date, calculational methods that satisfy all of the above stated requirements in a convenient integrated fashion do not exist. The analyses for the target have therefore decoupled the problem into a detailed simulation of the system at essentially $t=0.0$, and a more simplified treatment of time-dependent behaviour.

The major outputs required from the nuclear analyses of the target are:

- Flux levels, space and energy-dependent spectra, and reaction rates to define materials and geometry so as to maximize Tritium production.

- Nuclear heating, both prompt and decay, for setting cooling requirements, determining material performance, and evaluating accident scenarios/consequences.

- Isotopic inventories as a function of time to estimate source terms, identify potential materials compatibility problems, and estimate system performance and define operations.

The nuclear design methodology that was selected to perform these tasks will be described below. In addition, some of the activities performed to validate the design predictions and quantify some of the uncertainties/sensitivities will be discussed.

\subsubsection{Nuclear Design Methodology}

The methodology employed for the nuclear evaluation of the APT/SILC target is summarized in Figure 3.9. The basic tool is the LANL developed LAHET Code System (LCS) which consists of two major modules: 1) LAHET, a modified version of the HETC intranuclear cascade code for evaluations above $20 \mathrm{MeV}$, and 2) HMCNP, a modified version of the wellknown MCNP transport code for calculations from $20 \mathrm{MeV}$ down to thermal energies. A number of additional codes are also provided with the LCS to perform linking between modules and post-process the results.

The fact that both LAHET and HMCNP are Monte Carlo codes is of particular significance to the design of the APT target. Both codes employ a combinatorial surface/ cell specification of the problem geometry which permits modelling of the target configuration (cf. Fig. 3.1) with minimal approximations. In addition HMCNP employs nuclear data from the 
ENDF/B-V files in essentially unapproximated point-wise form which avoids the complications associated with collapsing the data to a group structure, and a priori knowledge of the spaceenergy dependent spectra in the system. In addition, HMCNP utilizes the $S(\alpha, \beta)$ formalism for scattering off the bound water molecules throughout the target. The major disadvantage of Monte Carlo is the statistical nature of the results; this is inherent to the method, and creates difficulties when localized information is desired. In principle, however, the accuracy of the predictions is limited only by the accuracy of the nuclear data, the detail to which the actual geometry is modelled (which as noted above does not have to conform to the regular meshes required by most deterministic methods), and the number of particle histories considered. This last point is not trivial, however, and the statistical uncertainties acceptable for typical design calculations place considerable demands on computer resources in terms of running time and storage.

The above discussion is reflected in Fig. 3.9 which shows that the only inputs required for the LCS analyses are the target geometry and materials, the minimally processed ENDF/B nuclear data, and the starting distribution of protons which is assumed to be a pencil beam, uniform over the beam footprint, and constant in energy at $1.0 \mathrm{GeV}$. A typical LCS geometry model for the APT/SILC target of Fig. 3.1, is shown in Figure 3.10. Note that the essential features that are expected to have an impact on the nuclear design calculations are preserved. Indeed, the major approximations are the homogenization of the internals of the pressure tubes, and headers and inlet/outlet piping. The approximation introduced by homogenizing the pressure tube internals was evaluated for an earlier design vis a vis tritium production and found to be negligible, but will be reevaluated for the present system in the future. Coupling between the LAHET and HMCNP calculations is via a file that is written by LAHET which contains the space-energy-angle coordinates of neutrons which have slowed down below $20 \mathrm{MeV}$. These neutrons are subsequently transported by HMCNP until they are captured or leak from the system. Reaction rates and leakages are obtained from this calculation, and yearly tritium production is estimated assuming that the $\mathrm{Li}-6(\mathrm{n}, \alpha) \mathrm{T}$ reaction rate remains constant.

Note that the above analysis is essentially static in nature, i.e., the impact of spallation product build-up/decay is not accounted for in either the LAHET or HMCNP analyses. Adjunct calculations are performed by LANL with the CINDER90 code to account for time-dependent effects. These calculations are based on energy-dependent fluxes and net spallation product yields from HMCNP and LAHET, respectively. These data are usually for large volumes, and therefore represent averages over the selected zones. For the SILC target, initial CINDER90 calculations were performed for eight distinct zones/materials, e.g., homogenized neutron source pressure tube internals, homogenized source blanket pressure tube internals, etc. In these calculations, the neutron flux level and spectra are assumed to remain constant over the irradiation period.

Outputs from CINDER90 for an input irradiation/decay cycle include the mass, activity, and decay heat for the various nuclides in the system. Totals, and percentage contributions are also given. Finally, the variation in the macroscopic absorption cross section $\left(\Sigma_{2}\right)$ with time is provided along with gamma spectra. The variation in $\Sigma_{a}$ with time provides 
an indication of how parasitic capture may change as a result of irradiation and provides a quantitative measure of how target performance may be affected. However, it should be reiterated that these results do not account for flux spectra and level changes due to the changing isotopic composition of the target; this would require repeating the entire LCS analysis with the new compositions explicitly included.

\subsubsection{Validation of Methodology}

The ability of the LAHET, MCNP, and CINDER90 codes to accurately simulate the nuclear performance of the SILC target system are critical to the demonstration of the viability of the APT concept.

Extensive validation of the LAHET code for the prediction of neutron yields, differential data, isotopic production, and heating have been performed by both LANL and BNL for a range of incident proton energies, and a variety of materials. Some of the results of these comparisons to experimental data are given in References 1-4.

The MCNP code has been used extensively for radiation transport and criticality calculations in nuclear reactor and other applications. It is also used by the Cross-Section Evaluation Working Group (CSEWG), which serves in an advisory capacity to the National Nuclear Data Center at BNL, to evaluate the accuracy of nuclear data in the Evaluated Nuclear Data Files (ENDF/B) because of its ability to do highly accurate simulations of nuclear experimental configurations. Some of the results of benchmark calculations for MCNP are given in References 5-7.

The CINDER90 code is a modern variant of the CINDER code which has been used for decades in the nuclear industry for evaluating time-dependent isotopics. The nuclear data libraries and solution algorithms in CINDER90 have been significantly modified for use in the APT program. While it is a state-of-the-art code it is still evolving, and is not yet available for use outside LANL; therefore, all CINDER90 calculations for the SILC target were performed by LANL based on input provided by BNL. BNL has undertaken an effort to provide an independent confirmation of the reasonableness of the CINDER90 results based on a modified version of the ORIGEN2 code. ORIGEN2 is an industry standard code for performing timedependent calculations for reactors. It is essentially a "point reactor model," and is restricted to a one-group representation of the nuclear data; different reactor types are accommodated by different sets of nuclear data which account for the specific spatial and energy characteristics. While this effort is ongoing, selected results of some early comparisons between CINDER90 and the BNL ORIGEN2 are given in Reference 8.

As noted above, LAHET, MCNP, and CINDER90 are state-of-the-art codes which are well suited for, and have demonstrated applicability and accuracy for the nuclear design of the APT targets as evidenced by cross code comparisons, and comparisons to experimental results. Differences do exist, however, in part due to uncertainties and inconsistencies in experimental results. Therefore, a series of experiments in the areas which exhibit the greatest experimental- 
to-calculational differences, and which are most significant for defining expected target performance and safety are also being performed as part of the current APT activities. The objective of these additional experiments is to reduce the uncertainties in the experimental data so as to improve the current estimates of uncertainties/biases in the calculational methodologies, and better focus efforts to improve the confidence in the model predictions.

\subsubsection{Selected Results of Nuclear Design Calculations}

As has been noted earlier, the design of the APT/SILC target is an iterative process involving input from a number of other BNL and B\&W design activities (e.g., mechanical, cooling system, materials, safety, etc.). For a number of reasons, some of which have been mentioned above, a consistent, integrated design which satisfies all performance requirements does not exist at this time. In addition, significant potential improvements in performance (e.g., reduced waste stream) which have been identified during the design process have not yet been incorporated. It is expected that this situation will be rectified in the next few months (FY94).

As a result of the above caveat, the details of the results presented here are subject to change during the next few months. However, the philosophy followed throughout the nuclear design effort has been to limit the degree of variation about a "nominal" configuration, and get concurrence, to the degree possible, from the mechanical and coolant design teams prior to considering modified configurations. Therefore, while preliminary and subject to change, the results presented here should reasonably reflect the expected performance of the final preconceptual design of the APT/SILC target.

\section{Tritium Production}

In order to avoid classification issues, the performance of the SILC target with respect to tritium production will be discussed only in relative terms. It should be noted, however, that the present static estimates of tritium production for the baseline design range from being low by $\sim 5 \%$ to a margin of $\sim 2 \%$ relative to the " $3 / 8$ goal, " depending on what parameters are chosen in the nuclear design models. The uncertainty in these predictions is estimated to be in the 20-30\% range based on comparisons to available experiments for simple geometries. As the design efforts at both BNL and LANL continue, and new experimental data become available for both simple geometries and more prototypic configurations, the uncertainty should be reduced and the approach for the treatment of calculational/experimental disagreements developed (e.g., methods improvements, biases, etc).(Preliminary interpretation of recent experimental result suggests the $20-30 \%$ uncertainty will soon be reduced.)

The tritium production by blanket module is given below: 
Table 3.7 Relative Tritium Production by Region

\begin{tabular}{|l|c|}
\hline REGION & $\begin{array}{c}\text { Percent of Total } \\
\text { T-Production }\end{array}$ \\
\hline \hline Source Blanket & 24.3 \\
\hline Back Blanket & 22.7 \\
\hline Primary Expander Blanket & 42.8 \\
\hline Secondary Expander Blanket & 8.0 \\
\hline "Extra" Primary Expander Blanket & 1.6 \\
\hline "Extra" Secondary Expander Blanket & 0.6 \\
\hline
\end{tabular}

The "Extra" expander blanket regions shown in Table 3.7 represent additional regions of homogenized pressure tubes in the expander region beyond the two explicit rows of pressure tubes shown for the nominal configuration in Figures 3.1, 3.2 and 3.10.

Two issues arise in connection with tritium production in the APT/SILC target:

- How much tritium is produced per unit volume of target, or more precisely per pressure tube? This issue relates both to waste stream and extraction efficiency, e.g., are you required to process large quantities of material to extract relatively small amounts of tritium, and does the tritium extraction efficiency in these situations decrease to such a degree that relatively significant quantities remain in the target, but at low concentration?

- Does the tritium production, given the selected lithium loading in the $\mathrm{Li}-\mathrm{Al}$ (3.0 w/o) and the enrichment of $\mathrm{Li}-6$ (in the range of 50-90 a/o), satisfy the SRS requirements of GVR $<130$, and sufficient $\mathrm{Li}$ remaining to ensure tritium retention for the postulated one-year irradiation cycle.

In order to address these points, the trium production by pressure tube has been examined for all the blanket regions. Initial results of this examination indicate that the one-year operating cycle can be sustained without violating the GVR/tritium retention requirements. In addition, it appears that reductions in the amount of lithium-aluminum in the blanket modules can be achieved without significantly compromising production, while reducing the waste stream. Studies of this type will be used to optimize the APT target, and over-all system. 


\section{Eluxes and Spectra}

Typical energy dependent spectra $(E<20 \mathrm{MeV})$ averaged over the neutron source, and source blanket pressure tubes are shown in Figure 3.11. The results are presented as flux per unit lethargy per source proton and were obtained in the CINDER90 62-group structure. At $200 \mathrm{~mA}$, these fluxes translate into total fluxes of $\sim 10^{15}$ and $\sim 10^{13} \mathrm{n} / \mathrm{cm}^{2}-\mathrm{sec}$ in the neutron source and blanket respectively.

\section{Nuclide Production}

The major spallation products produced in the neutron source region after one year of operation (not accounting for the $75 \%$ capacity factor) are shown in Figure 3.12. These results are based on the latest version of CINDER90 with updated nuclear data libraries, but do not account for the changes to the SILC target resulting from the B\&W design activities. The lead, aluminum, and heavy water, and any nuclide appearing at less than 10 grams are not shown. The major new elements that are produced are thallium $(\mathrm{Tl})$, mercury $(\mathrm{Hg})$, platinum $(\mathrm{Pt})$, osmium (Os) and silicon ( $\mathrm{Si})$. Of these, thallium and mercury are the major potential contributors to the source term in an accident (however, see the discussion in Section 7.0 on the potential for release of these elements, and ways of preventing release). In addition, production of elements such as $\mathrm{Ta}, \mathrm{Hf}$, and $\mathrm{W}$ are of potential concern due to their large capture cross sections and the potential for increased parasitic capture in the neutron source during operation resulting in reduced tritium production. The CINDER90 results for the neutron source region show that the one-group $\Sigma_{a}$ increases from $\sim 5.5 \times 10^{-4}$ to $\sim 8.5 \times 10^{-4}$ after one year. Recall that these results are based on a constant flux/spectra assumption throughout the entire irradiation. While the impact of this assumption will have to be evaluated, the magnitude of $\Sigma_{\mathrm{a}}$ is still small, and therefore should not result in a significant increase in parasitic capture in the neutron source.

\section{Activity and Decay Heat vs. Time}

The activity and decay heat vs. time for a one-year irradiation/six-month decay cycle are shown in Figures 3.13 and 3.14, respectively, for the neutron source region, and the target total with the tritium product removed. These results are based on the latest version of CINDER90 with updated nuclear data libraries, but do not account for the changes to the SILC target resulting from the $\mathrm{B} \& \mathrm{~W}$ design activities.

\subsection{DESIGN OPTIONS/OPTIMIZATION}

The target/blanket configuration described in the previous sections reflects a number of evolutionary improvements of the initial ERAB/JASON designs which improved the performance and safety of the system. However, it still represents only a "snapshot" in time of the design process and does not reflect an optimized system; nor does it fully incorjoraie feedback from the safety and ES\&H activities, or the mechanical and coolant system design activities. 
In addition to developing an integrated, optimized design for the current target/blanket configuration incorporating input from the other design activities, a number of design options are already under consideration to improve the SILC target. These are primarily in the areas of simplifying the geometry to improve target handling, manufacturing, RAMI, etc., and examining other materials in order to improve safety and performance by offering higher temperature capabilities and temperature margins, and minimize source term/dose. Modifications to the nominal materials may also improve tritium production.

\section{Geometry}

As noted in Section 1.0, the original BNL SILC target consisted of a pressure tube array where each pressure tube contained a mixture of lead and lithium-aluminum bearing rods. While there were drawbacks associated with this approach, it was more neutronically efficient in producing tritium (had lower parasitic capture) than the current design where the lead and lithium-aluminum bearing pressure tubes are separated. Some preliminary evaluations suggest that placing a mixture of lead and lithium-aluminum bearing rods in selected blanket pressure tubes (accompanied by a reduction in the size of the neutron source array) offers improved tritium production relative to the current baseline design. This approach should be acceptable as long as the proton beam cannot strike these pressure tubes, and decay heat does not become a problem. Preliminary indications from B\&W are that this approach should not cause difficulties in assembly/disassembly, and by effectively moving the neutron "multiplier" portion of the source array (i.e., the lead outside the beam footprint) may improve the thermal-hydraulic characteristics of the source module.

The current pressure tube design for the target and lattice blanket modules offers a number of advantages (including isolation of potential failures and flexibility in tailoring coolant parameters), coupled with the disadvantage of considerable complexity in the coolant supply system layout with attendant safety and operational implications. A more reactor-like pressure vessel configuration is an obvious alternate option.

In addition, heat transfer from rod bundles has inherent limitations when other considerations drive the design toward compact dimensions and hence high power densities. Therefore, the literature on neutron spallation sources has been reviewed, and alternative target configurations are being screened for possible candidates for further study. In particular, a number of studies have considered particle beds for their targets with encouraging results. Since BNL has extensive experience in the use of particle beds in high power/compact applications such as nuclear rocket engines, this design option needs to be evaluated for the SILC target neutron source. (A compact/high power density neutron spallation target based on the particle bed approach is currently being evaluated by BNL for a pulsed neutron experimental facility).

\section{Materials}

The bases for the materials selected for the nominal target and blanket modules has been discussed earlier. Briefly, the major criteria were: 1) favorable operating experience in 
similar applications (i.e., radiation and temperature environments); 2) low neutron capture cross sections to minimize parasitic neutron losses and maximize tritium production; and 3) for the lithium-aluminum, Savannah River Laboratory (SRL) experience in fabrication, operation, and tritium extraction.

As the target design proceeds, and requirements/"desirable attributes" dictated by mechanical, safety, waste stream and other considerations are identified, other materials than those currently employed may offer sufficient benefits to be included in the next phase of the design effort. The primary characteristics that are sought in the alternate materials are: 1) higher melting temperatures, 2) greater strength at elevated temperatures (including potential accident scenarios), 3) improved material compatibility, and 4) reduced source term/dose. Some materials that are currently under consideration as a result of these considerations are lithiumaluminate as a possible replacement for the lithium-aluminum; tungsten and lead-oxide as possible replacements for the lead; and Inconel, stainless steel, Zircalloy, and various aluminum grades as possible replacements for the essentially pure aluminum currently employed for structural components. In addition, increased loading of lithium, or enrichment of Lithium-6 within the current SRL envelope may increase the tritium production sufficiently to warrant modifications.

It should be noted that advantages/penalties associated with various materials, and geometric configurations may be strongly interrelated. 


\section{REFERENCES}

1. R. E. Prael, "LAHET Benchmark Calculations of Differential Neutron Production Cross Sections for $113 \mathrm{MeV}$ and $256 \mathrm{MeV}$ Protons", LA-UR-89-3347, Los Alamos National Laboratory (September, 1989)

2. R. E. Prael, "LAHET Benchmark Calculations of Neutron Yields from StoppingLength Targets for $113 \mathrm{MeV}$ and $256 \mathrm{MeV}$ Protons", LA-UR-90-1620, Los Alamos National Laboratory (May, 1990)

3. G. J. Russell, "APT Santa Fe Design Review", March 1-4, 1993.

4. M. Todosow, "APT Santa Fe Design Review", March 1-4, 1993.

5. S. Sitaraman," MCNP: Light Water Reactor Critical Benchmarks", NEDO-32028, General Electric Nuclear Energy, March, 1992.

6. D. Whalen, et al, "MCNP: Neutron Benchmark Problems", LA-12212, Los Alamos National Laboratory, November, 1991.

7. J. C. Wagner, et al, "MCNP: Criticality Safety Benchmark Problems", LA-12415, Los Alamos National Laboratory, October, 1992.

8. E. Schmidt, et al., "Preliminary Comparisons Between CINDER90 and ORIGEN2 for the APT/SILC Target", BNL Memorandum, May, 1993. 
Figure 3.1 Components of APT/SILC Target

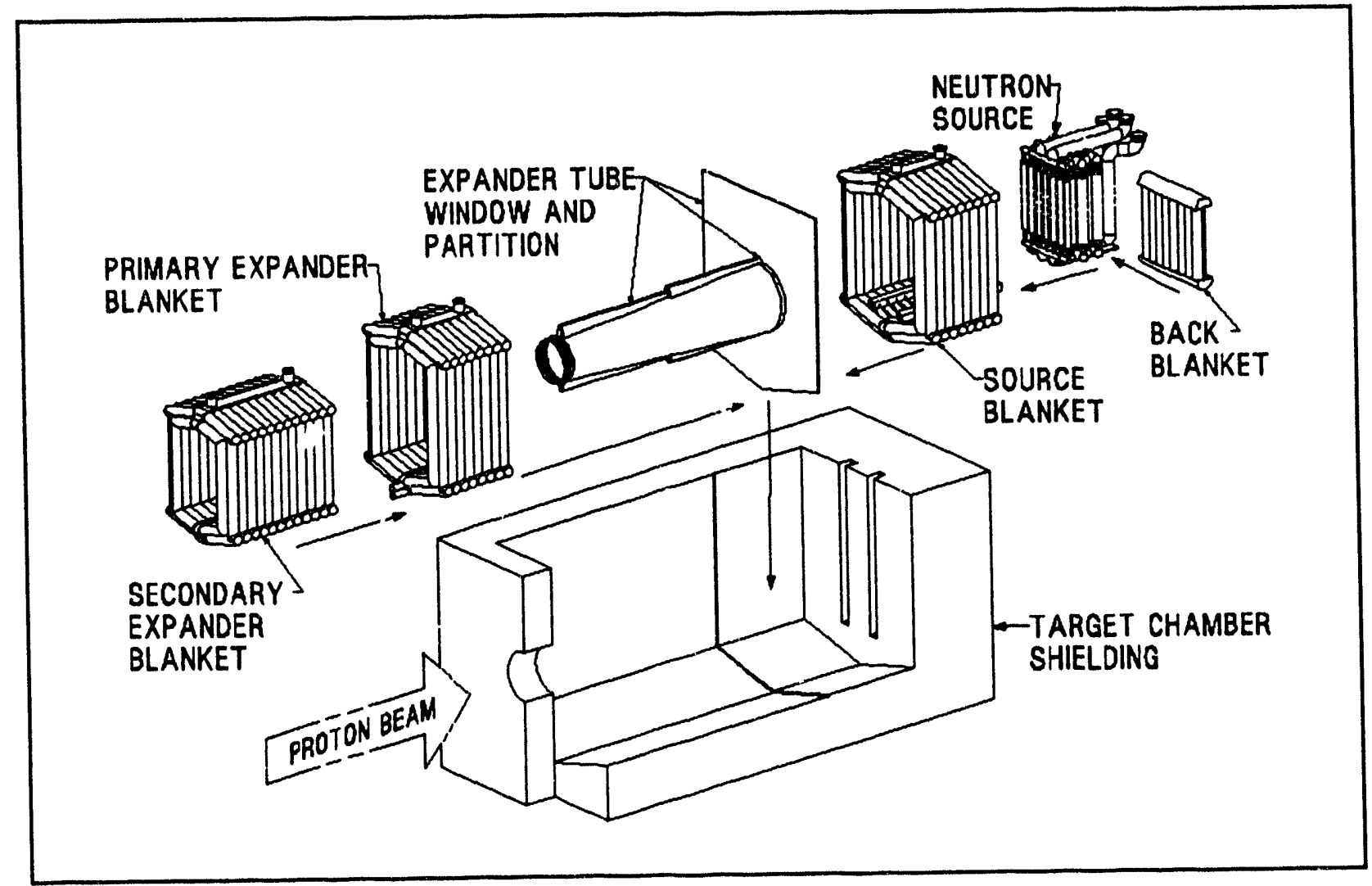


Figure 3.2 Assembled APT/SILC Target in Target Chamber

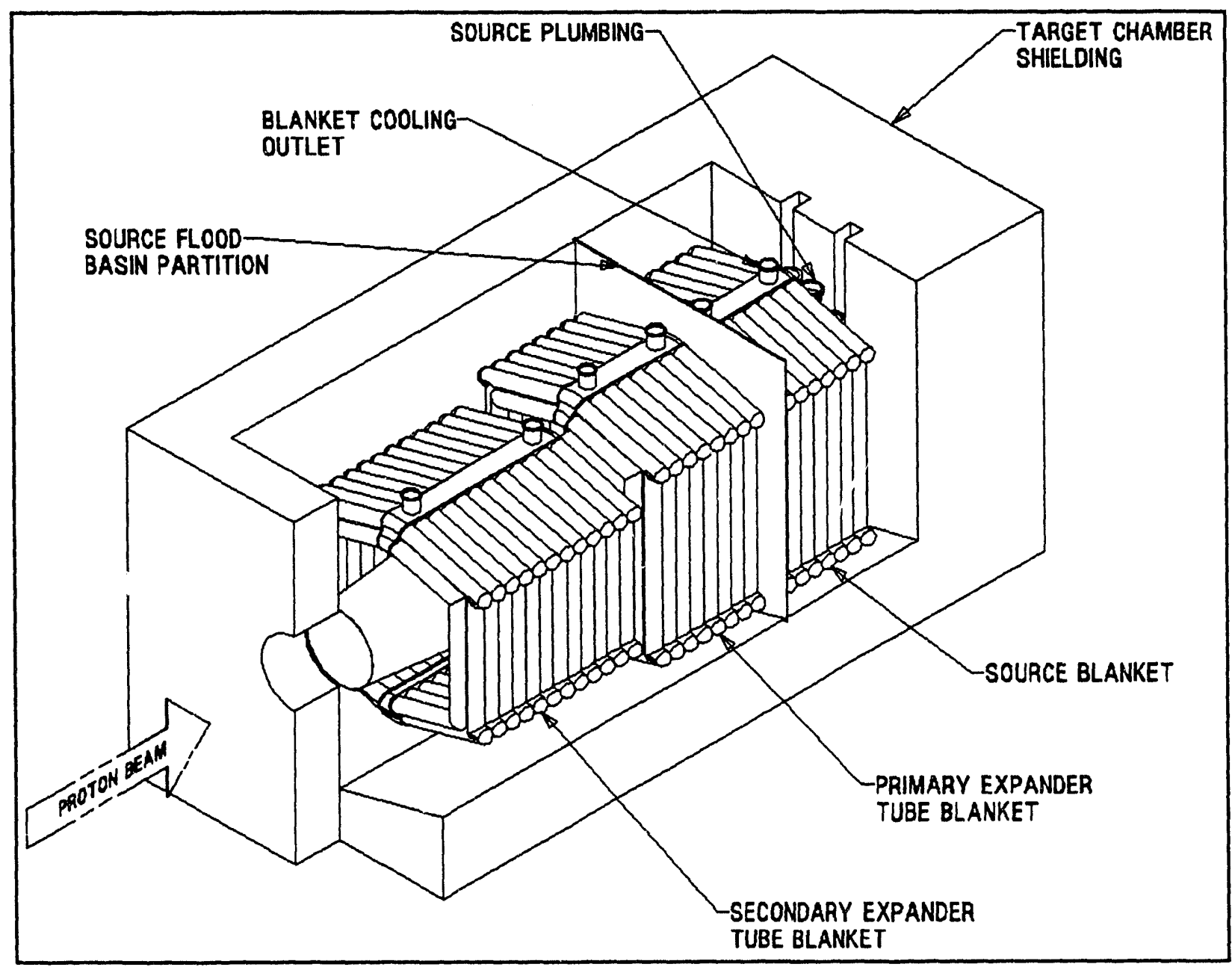


Figure 3.3 Neutron Source Rod

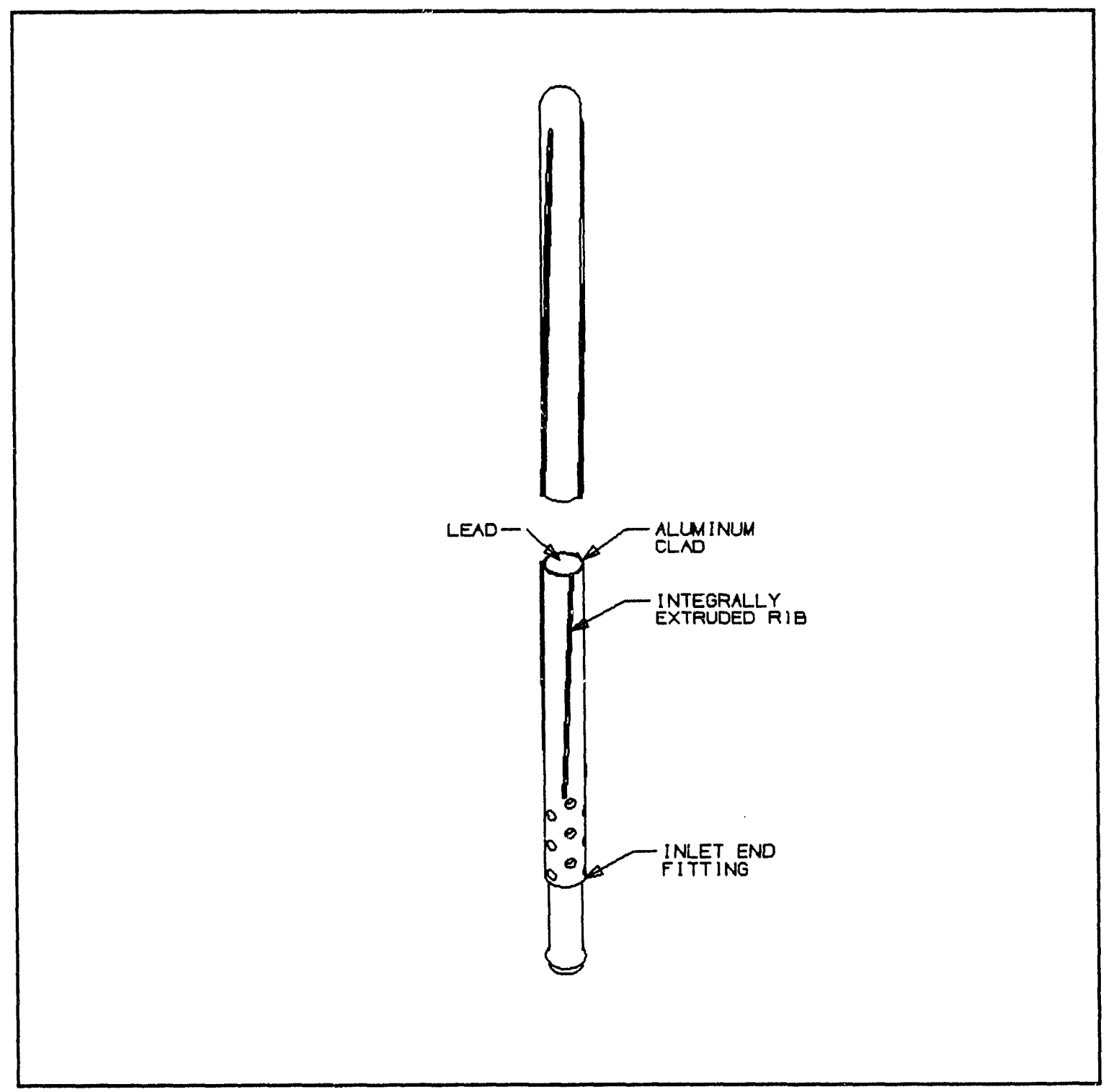


Figure 3.4 Neutron Source Array

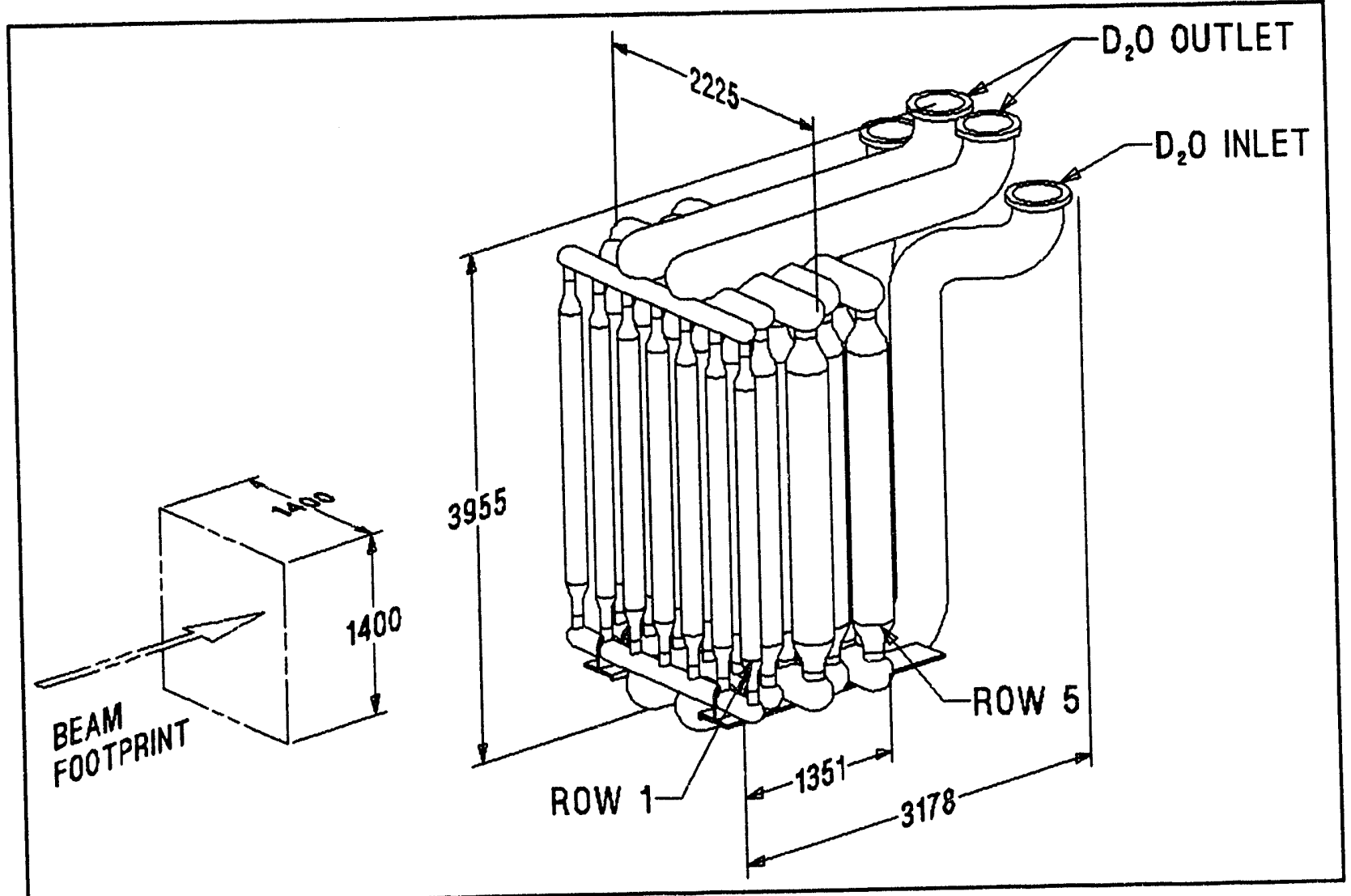


Figure 3.5 Source Blanket

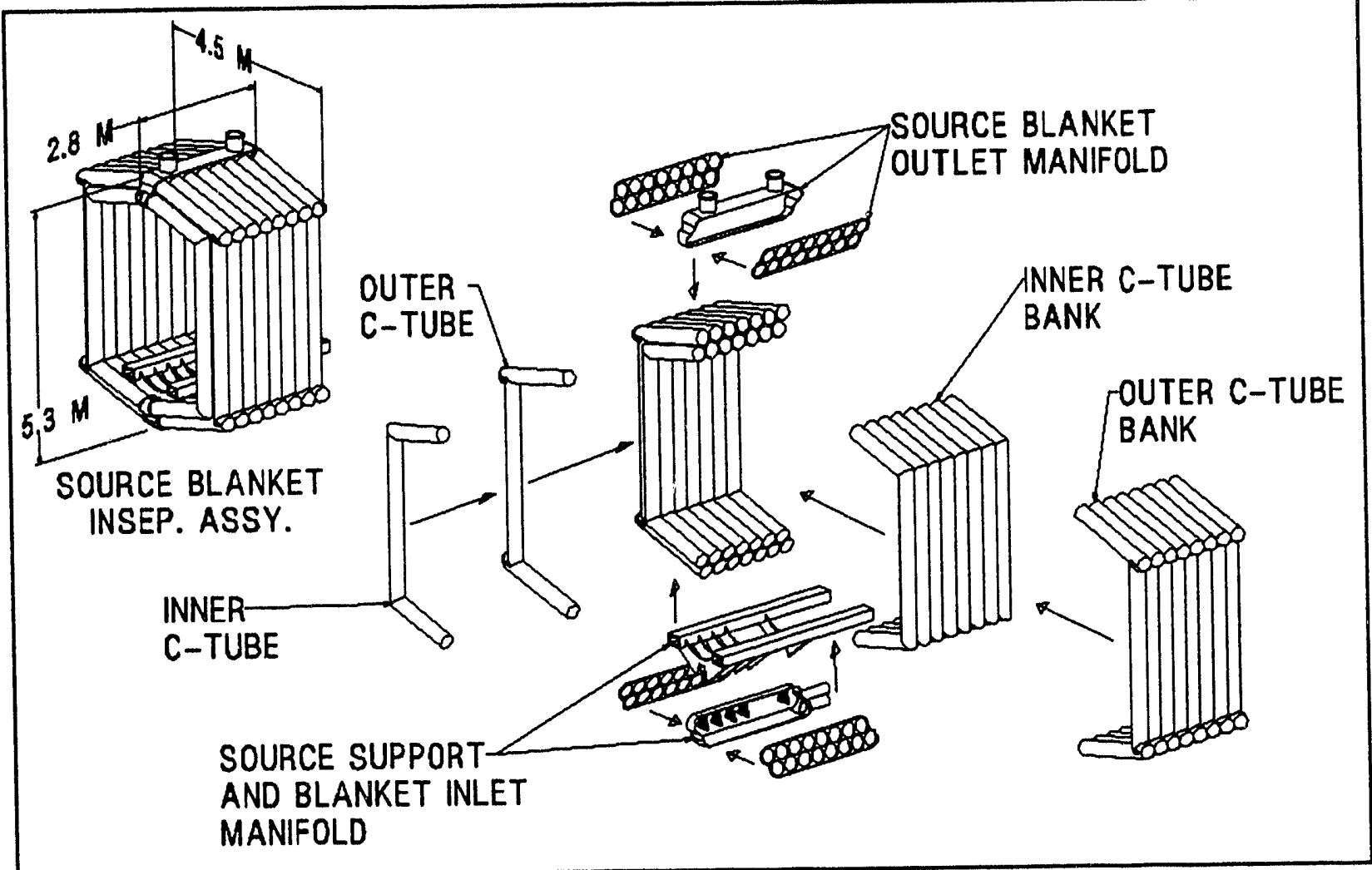


Figure 3.6 Beam Window/Expander Tube Assembly

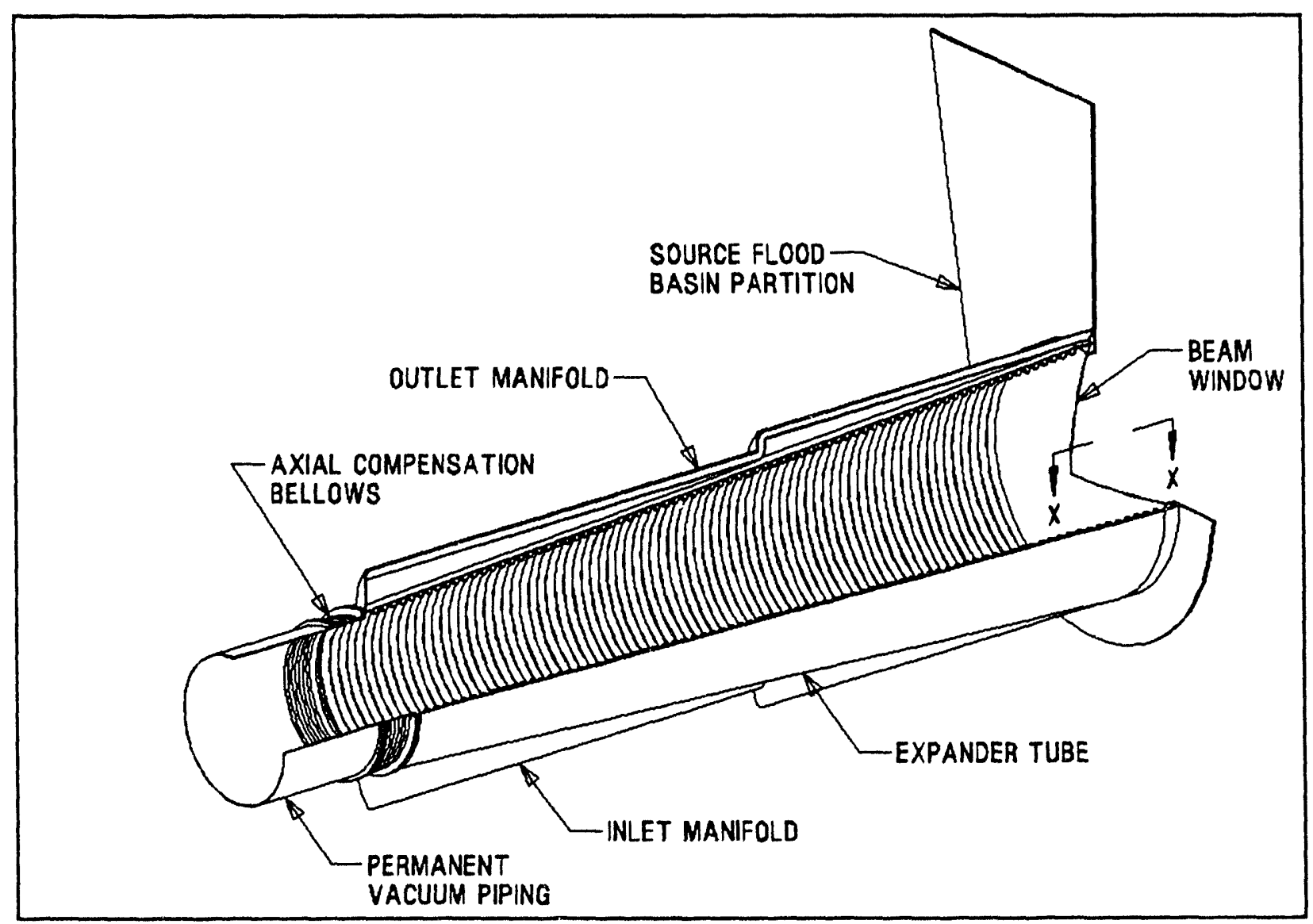


Figure 3.7 Detail of Window and Expander Tube Cooling Channels

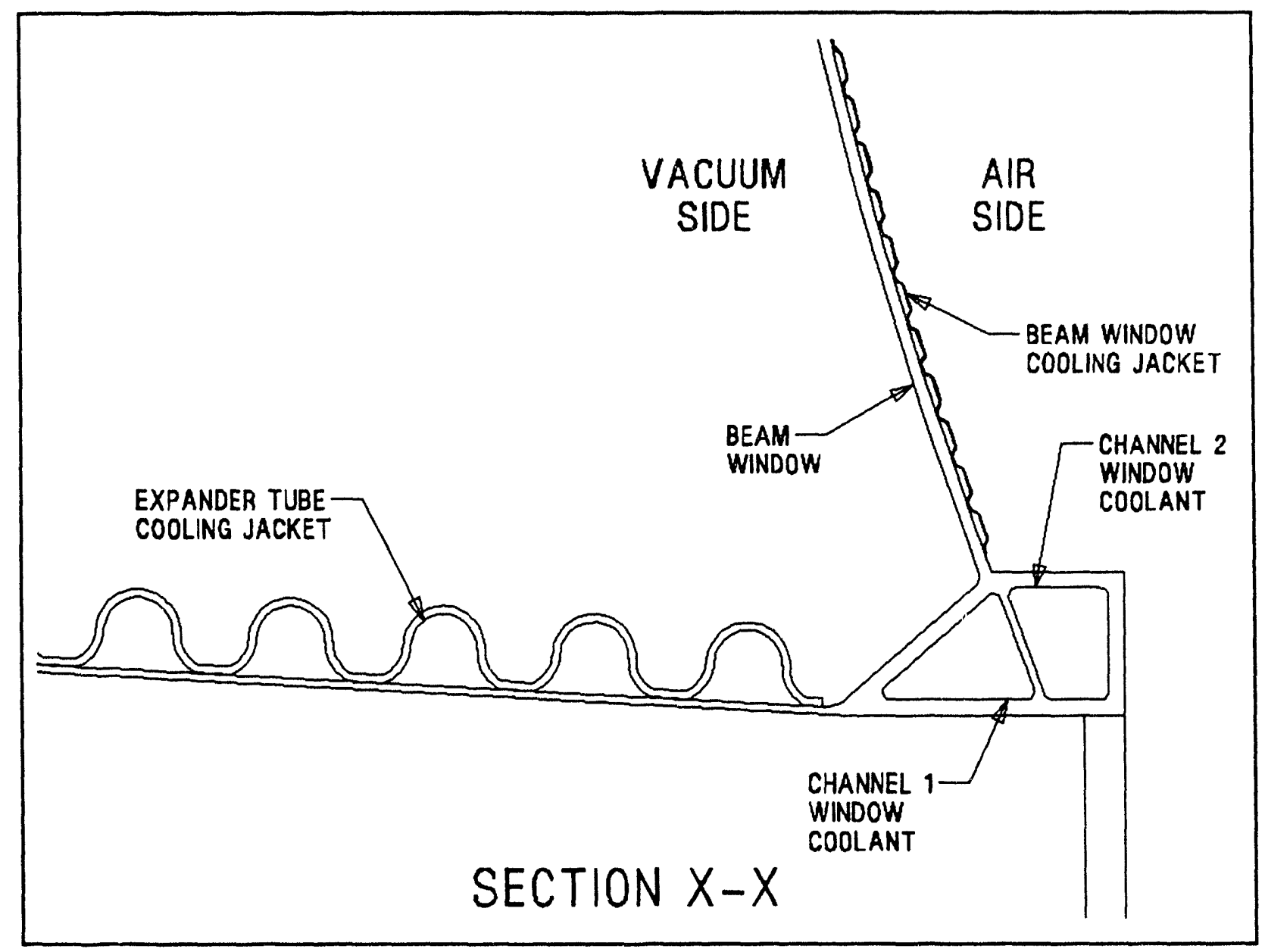


Figure 3.8 Cooling Loops for Window and Expander Tube

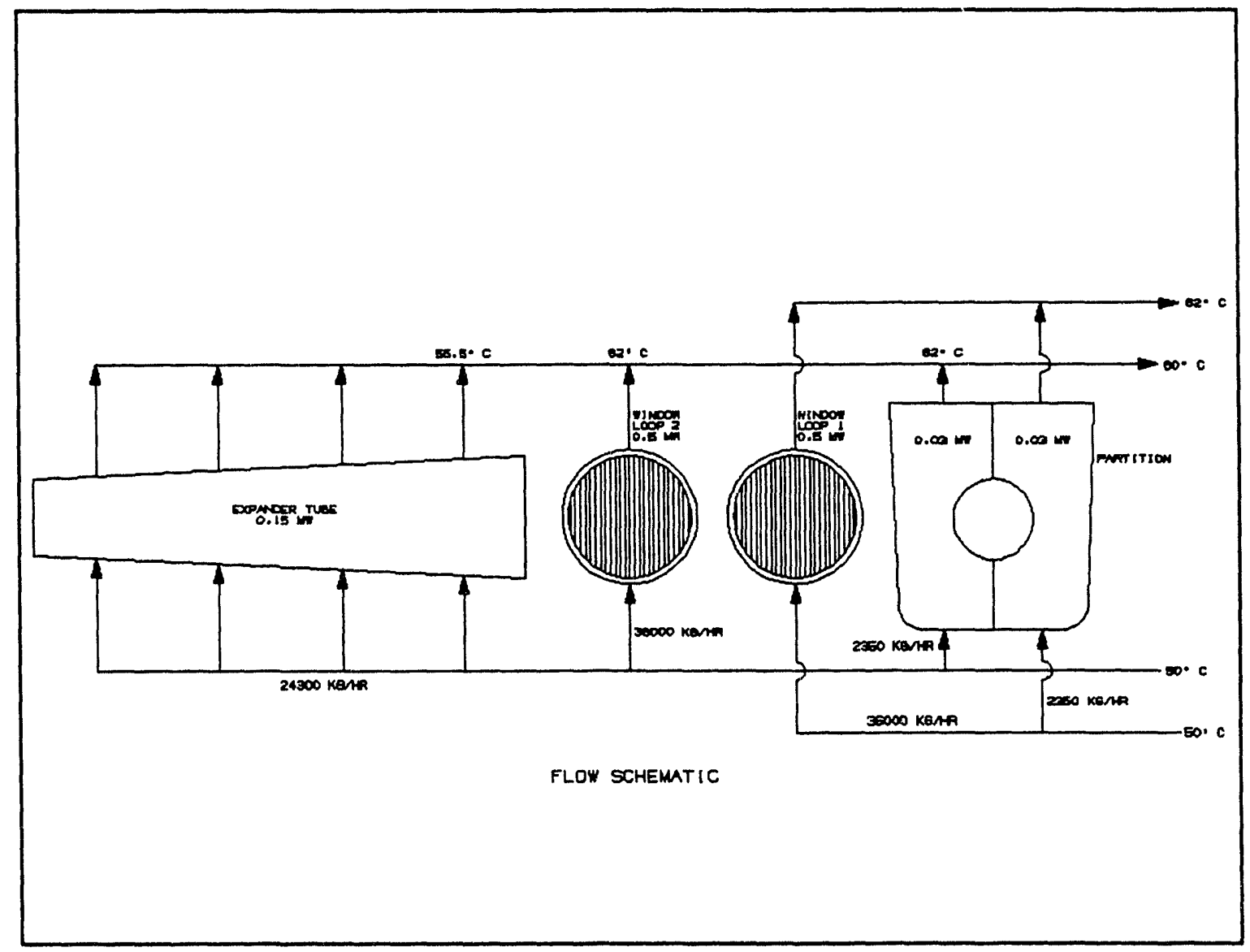




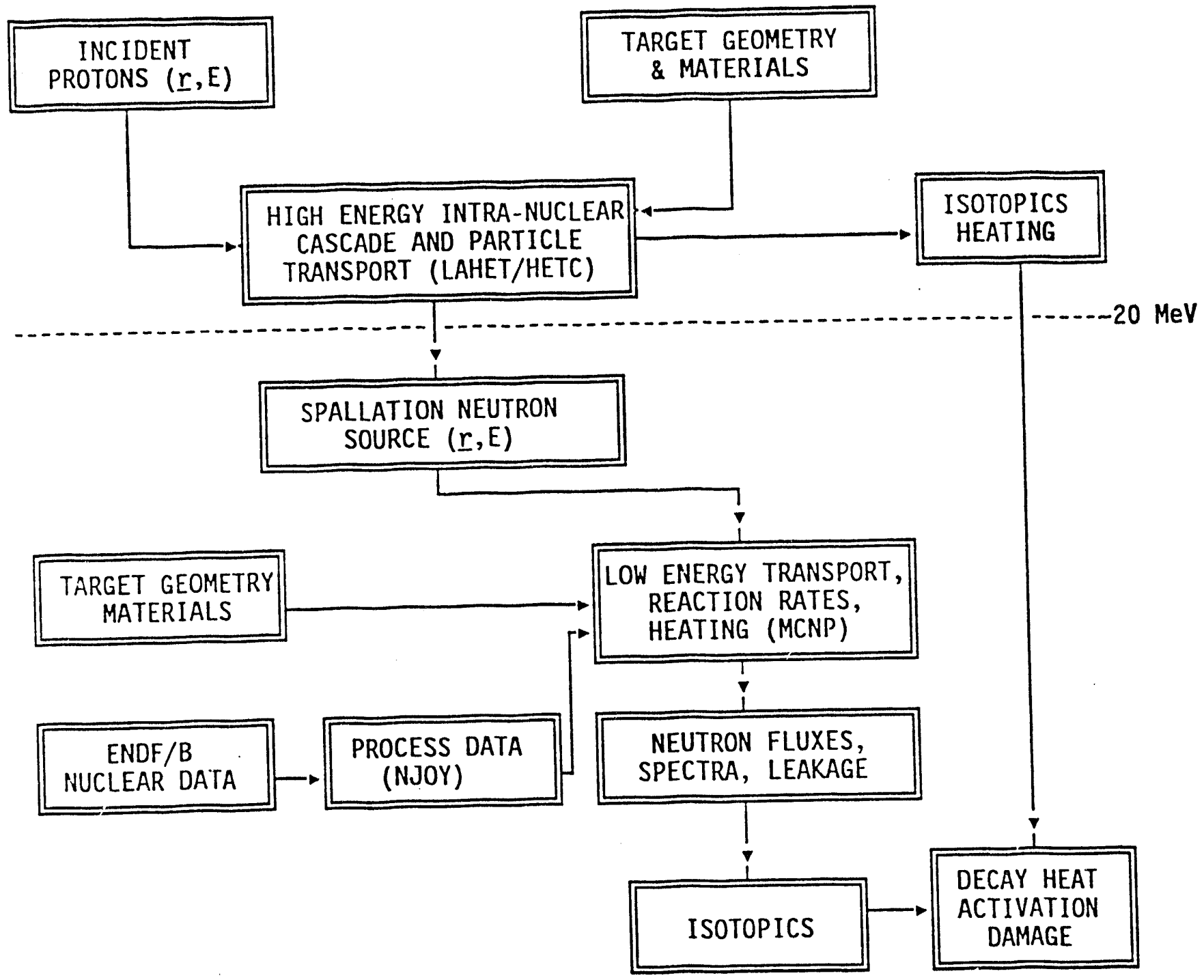

Figure 3.9 Target Design: Nuclear Analysis Methodology 


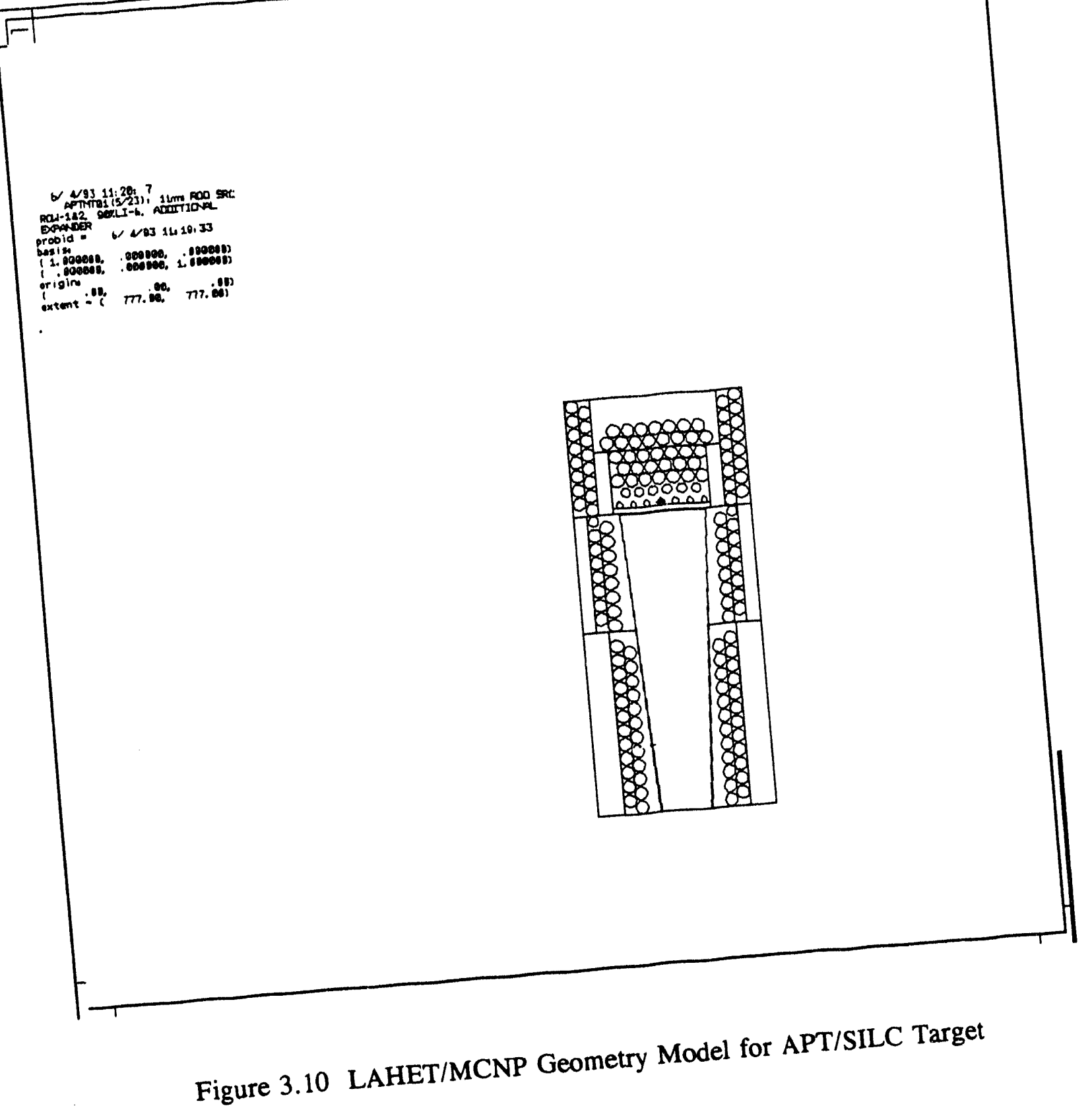




\section{Flux/Lethargy/Proton}

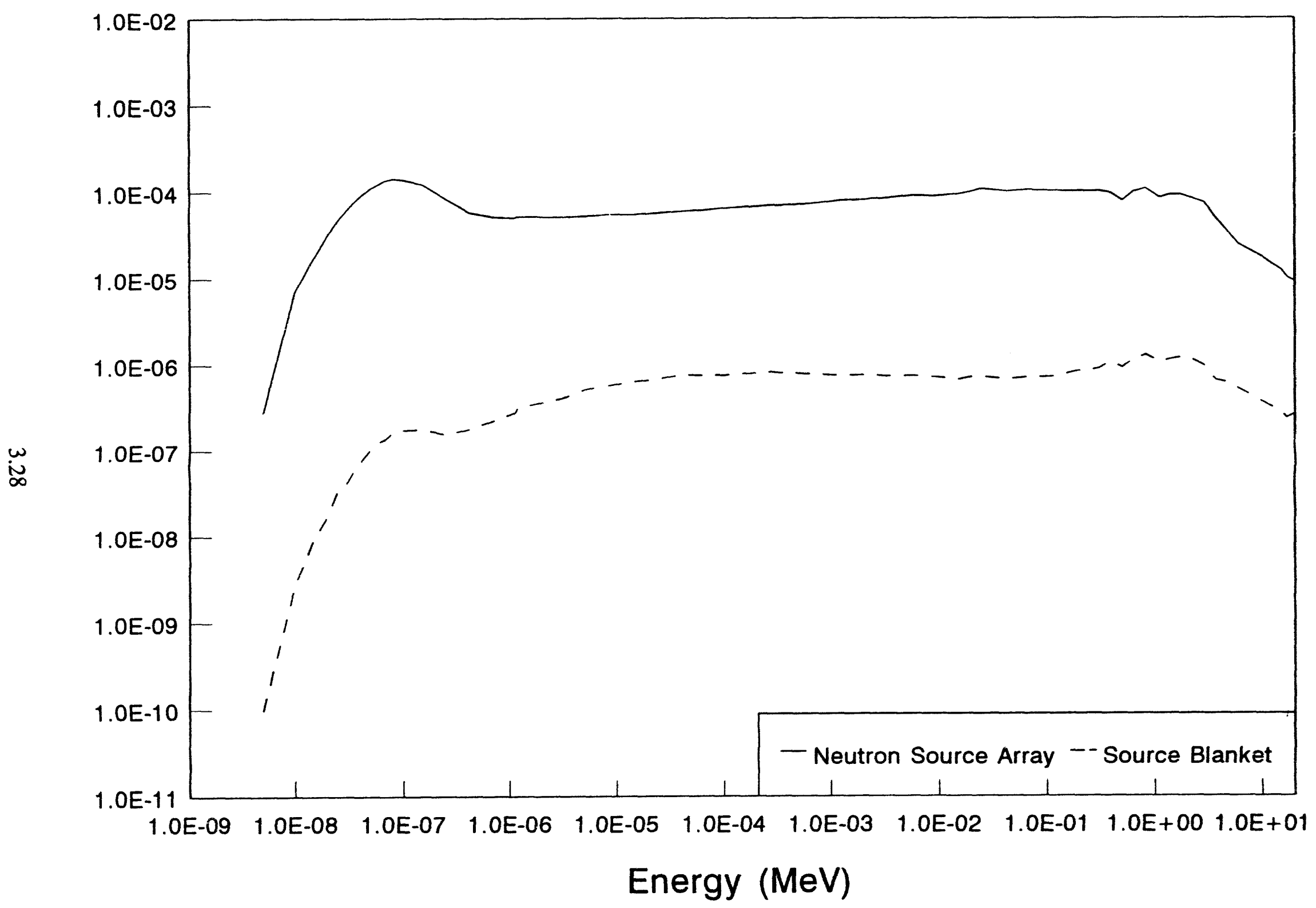

Figure 3.11 Region Averaged Fluxes for SILC Target 


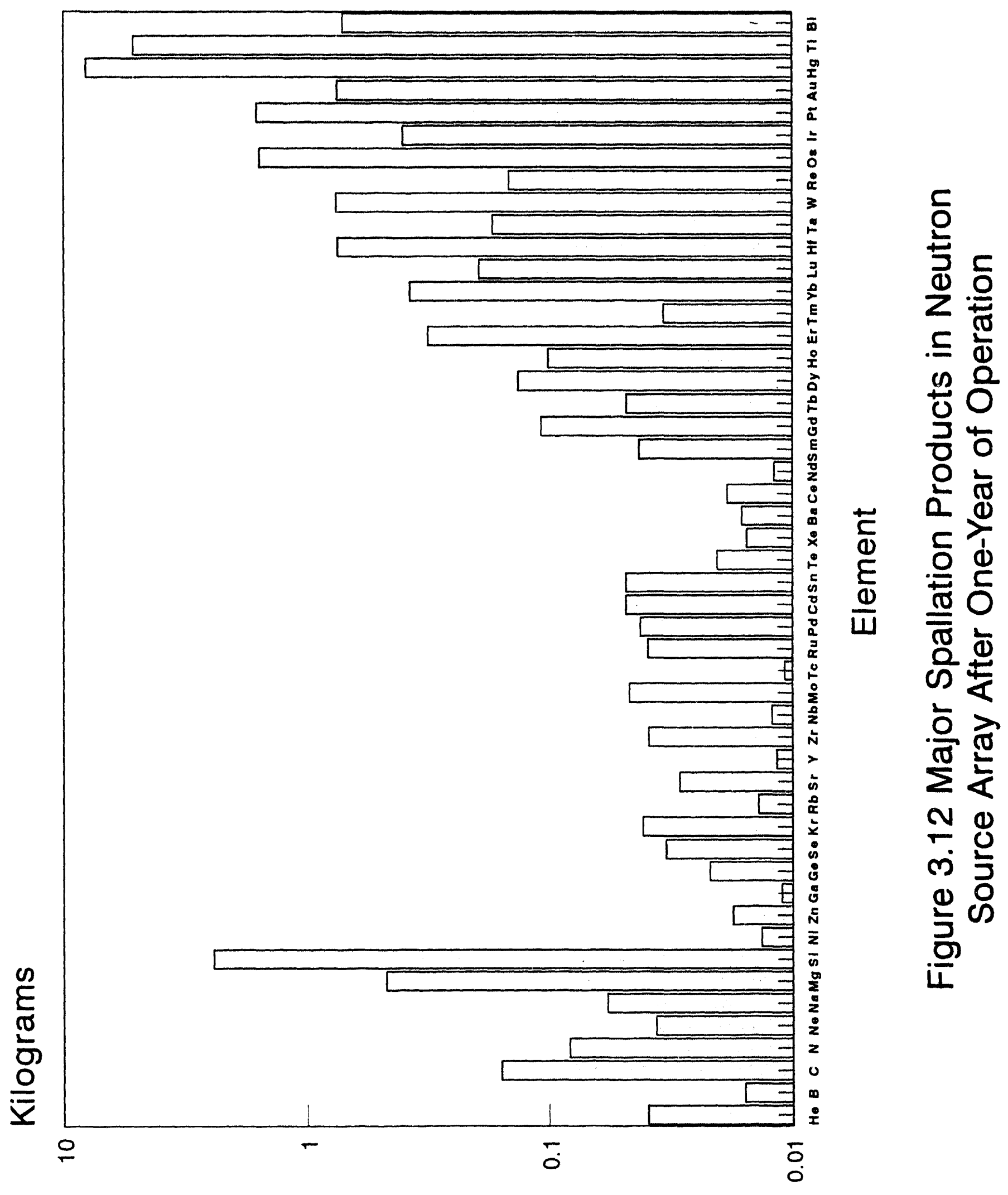




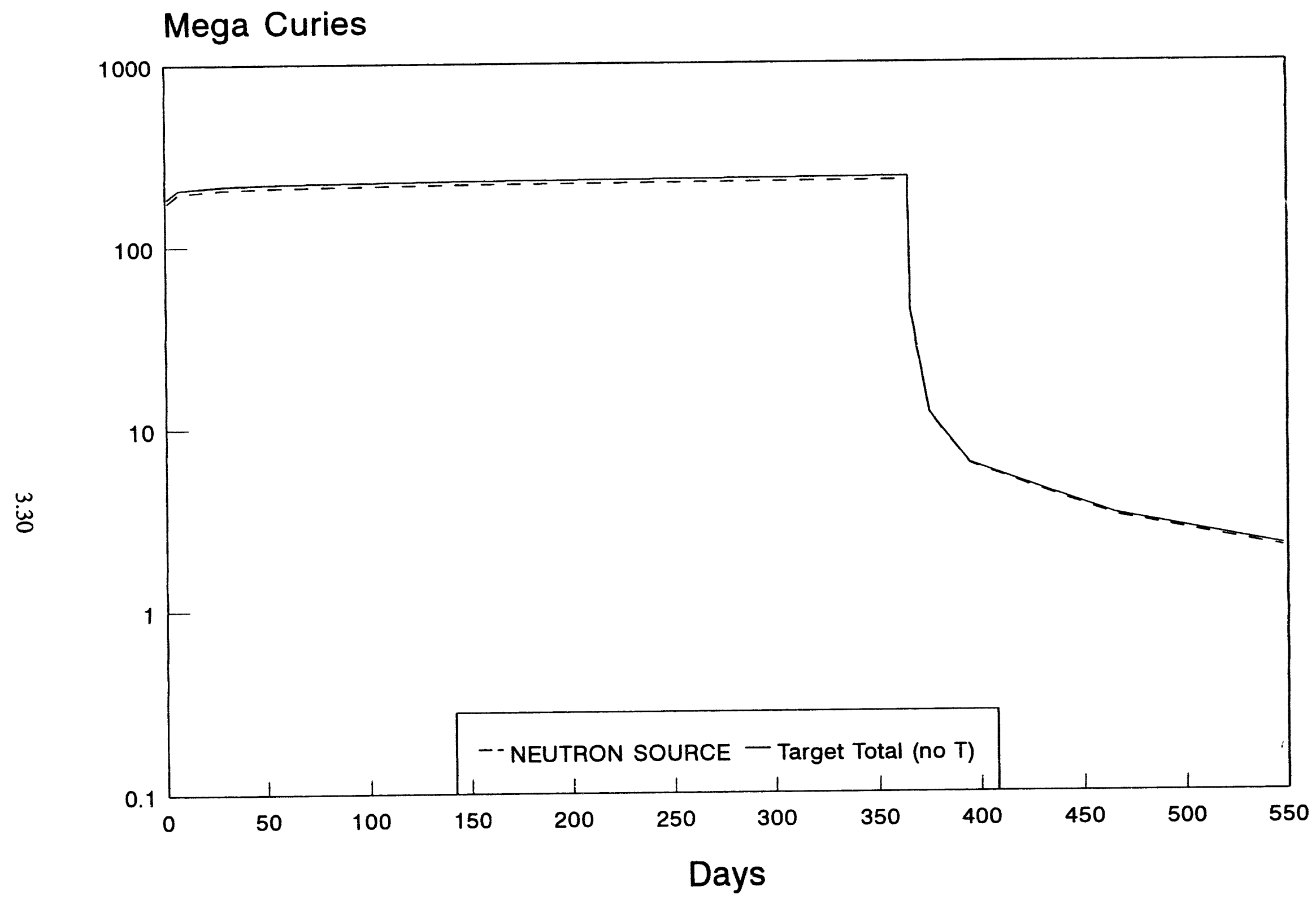

Figure 3.13 SILC Target Activity (MCi) Based on CINDER90 Results from LANL 


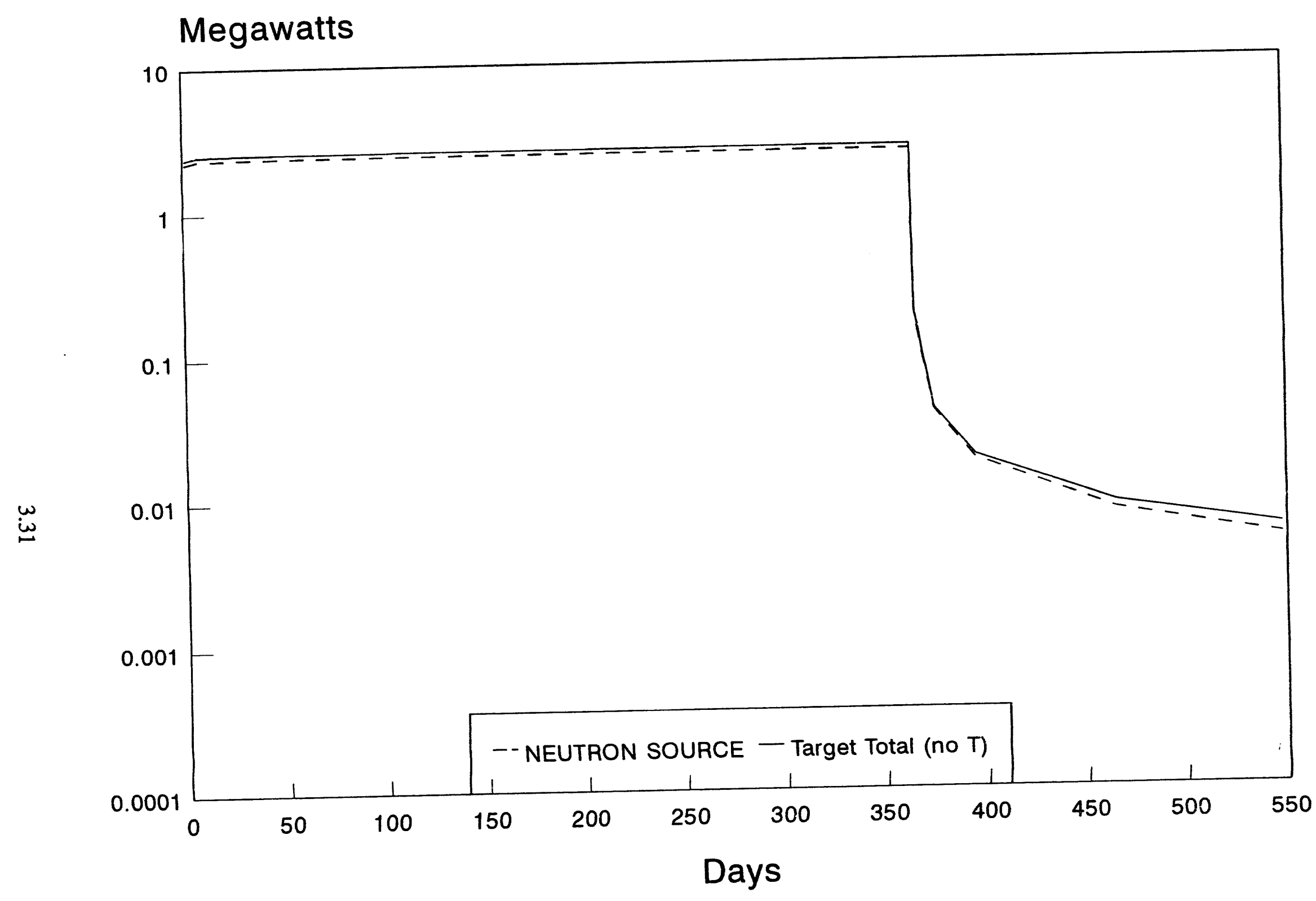

Figure 3.14 SILC Target Decay Heat (MW) Based on CINDER90 Results from LANL 


\subsection{TARGET COOLING AND HEAT REMOVAL SYSTEM DESIGN}

(WBS 5.1.3.1.2.1 and WBS 5.1.3.1.4.1)

\section{$4.1 \quad$ INTRODUCTION}

The heat rejection from the source, blanket and window sections of the target requires cooling of the components and removal of the energy, via a heat exchanger system, to the environment. With the entry of our industrial contractor (Babcock \& Wilcox) into the project, the system design has undergone significant changes, increasing system reliability and enhancing investment protection.

The mechanical design of the target is covered in detail in Section 3, LithiumAluminum Target Design. The features, important for an understanding of the component cooling system, will be repeated here also.

This section describes the design of the APT Target Cooling and Heat Removal System based on its status as of early June , 1993. The design is still pre-conceptual, and several details have not been finalized at this time. In particular, the heat generation data are based on nuclear design data, obtained with a $1.7 \mathrm{~m}$ by $1.7 \mathrm{~m}$ beam footprint. Our current goal is to reduce the beam footprint to $1.4 \mathrm{~m}$ by $1.4 \mathrm{~m}$. Engineering estimates have been made to obtain the appropriate redistribution of energy within the source. The revised design description, due in September, will be based on a completely consistent set of nuclear, mechanical and thermal design data. It is anticipated, that the resulting changes in the cooling and heat removal system will not be major.

The target cooling and heat removal system, in its current design, contains many redundancies and safety features, to provide a high degree of safety and investment protection. In a future extension of the cooling system requirements document (Appendix 4A) the temporal and spatial beam power fluctuations, which can be accommodated by the target cooling system, will be specified. Combined with a prompt beam trip at the initiation of accident scenarios, the cooling system can provide protection against almost all conceivable internal accidents. In particular, one aim of this design is to make scenarios with significant melting of lead incredible events, of probabilities much below $10^{-7}$ per year.

\subsection{COMPONENT COOLING SYSTEM DESIGN}

\subsubsection{Source Assembly Cooling}

\subsubsection{Source Assembly Description}

The source array currently consists of 33 assemblies arranged in five rows. Each assembly consists of an aluminum pressure tube that is filled with lead $(\mathrm{Pb})$ rods having aluminum cladding. A detailed mechanical design description of the source array is provided in Section 3. The most important assembly dimensions are summarized in Table 4.1. The current 
design has a $1.40 \mathrm{~m}$ square proton beam foot print which dictates the heated length of each pressure tube. The source rods in each pressure tube are $1.90 \mathrm{~m}$ long.

The source assemblies are cooled with $\mathrm{D}_{2} \mathrm{O}$. To protect against boiling in case of a loss of coolant accident, the coolant temperature exiting the assemblies is limited to $105^{\circ} \mathrm{C}$ during normal operation. To achieve a uniform coolant exit temperature distribution from all assemblies, each pressure tube is orificed, adjusting the coolant flow rate to its thermal load.

Table 4.1: Source Assembly Dimensions

\begin{tabular}{||c|c|c|c|c|c|c||}
\hline Row & $\begin{array}{c}\text { No. of } \\
\text { Assemblies }\end{array}$ & $\begin{array}{c}\text { Assembly } \\
\text { Outer } \\
\text { Diameter } \\
(\mathrm{mm})\end{array}$ & $\begin{array}{c}\text { Rods per } \\
\text { Assembly }\end{array}$ & $\begin{array}{c}\text { Basic Rod } \\
\text { Diameter } \\
(\mathrm{mm})\end{array}$ & $\begin{array}{c}\text { Lead Core } \\
\text { Diameter } \\
(\mathrm{mm})\end{array}$ & $\begin{array}{c}\text { Rod } \\
\text { Pitch } \\
(\mathrm{mm})\end{array}$ \\
\hline 1 & 7 & 150.0 & 121 & 10.75 & 9.75 & 12 \\
\hline 2 & 6 & 219.5 & 265 & 10.75 & 9.75 & 12 \\
\hline 3 & 7 & 299.8 & 511 & 11.25 & 10.25 & 12 \\
\hline 4 & 6 & 299.8 & 511 & 11.50 & 10.50 & 12 \\
\hline 5 & 7 & 299.8 & 511 & 11.50 & 10.50 & 12 \\
\hline
\end{tabular}

This arrangement makes the most efficient use of the required coolant flow and minimizes the size of the required heat removal equipment. The normal operation system parameters are:

1) Total Heat Load

2) Coolant Temperatures:

Inlet at plenum header

$163 \mathrm{MW}$

Outlet at plenum header

$60{ }^{\circ} \mathrm{C}$

$105^{\circ} \mathrm{C}$

3) Total Coolant Flow

$867 \mathrm{~kg} / \mathrm{s}$

4) Coolant Pressure in hot leg at the row 5 outlet header $9.65 \mathrm{bar}$

The source array cooling requirements for normal operation and Anticipated Operational Occurrences (AOO's) are evolving and currently have been set at:

1) Maximum aluminum cladding temperature:

$250{ }^{\circ} \mathrm{C}$

2) Lead temperatures will be less than melting lead melting temperature:

$327^{\circ} \mathrm{C}$

3) Minimum Critical Heat Flux Ratio (CHFR) value:

2.0 


\subsubsection{Calculation Methodology}

The thermal-hydraulic analysis of the SILC APT Source array was performed using the three computer codes VIPRE-01, FSPLIT, and RELAP5. The VIPRE-01 code was developed by EPRI for the U.S. commercial nuclear reactor industry to perform detailed coolant flow and Critical Heat Flux (CHF) analysis for nuclear fuel bundles. VIPRE-01 was used to calculate the local Critical Heat Flux Ratio (CHFR), coolant velocities, coolant temperatures, coolant pressure drop, rod surface temperatures, and rod internal temperatures in each pressure tube for the region from the rod capture plate to the end of the rod length. VIPRE-01 was also used to perform transient analysis for limiting Anticipated Operational Occurrences (AOO). FSPLIT is a steady state flow network code developed by B\&W. FSPLIT calculates pressure drops and flow fractions for flow paths connected in parallel. FSPLIT was used to determine the required inlet orifice loss coefficients (i.e. orifice sizes) for each pressure tube such that each pressure tube has an exit temperature of $105^{\circ} \mathrm{C}$. RELAP5 is a thermal hydraulic systems code to be used to perform transient analysis which has system feed back considerations, such as Loss of Cooling (LOCA) events and Design Basis Events (DBE's). Thus, the basic flow of the analysis is: 1) use VIPRE-01 to set individual pressure tube coolant flow, rod dimensions, and pressure drops such that the system requirements are satisfied. 2) The VIPRE-01 results are used as input to the FSPLIT code to determine the pressure tube orifice pressure drop/size requirements. 3) Use VIPRE-01 and RELAP5 to perform AOO and DBE transient analysis. This basic path is repeated until all the design criteria and system design preferences have been satisfied.

The analysis of any system should consider the impact of design uncertainties. The major design uncertainties considered for the SILC APT design are as follows:

1) Rod heat flux peaking due to rib/wire wrap coolant flow anomalies.

2) Rod heat flux peaking due to power generation peaking distributions.

3) Manufacturing tolerance variations (tolerance stacking).

4) Non-uniform proton beam power distribution.

5) Coolant flow distribution anomalies.

6) Computer code/correlation uncertainties.

Uncertainties have been addressed in the current analysis with the use of the following assumptions.

1) The minimum design CHFR has been set to 2.0 in order to account for uncertainties for radial power peaking within a pressure tube, CHF correlation uncertainties, and rib/wire wrap uncertainties. The CFHR is taken as the minimum value of four commonly accepted correlations (Bowring, EPRI, MacBeth 12 Coefficient, AECL Tables). The design CHFR can be lowered in the future by A) modeling radial power peaking within a pressure tube explicitly and B) collecting CHF data for the SILC APT design condition.s. 
2) In evaluating the CHFR and the lead core center line temperature, the coolant flow rate is reduced by $5 \%$ for the "hottest" pressure tube of each row of the source array. This assumption is used to account for manufacturing tolerance uncertainties and coolant flow distribution anomalies.

3) A peak axial power peaking factor of 1.15 was used to account for proton beam power distribution uncertainties. The anticipated proton beam power distribution has an uncertainty of $7 \%$. To be conservative, this uncertainty was doubled and applied as the maximum axial power peaking factor for the analysis. This creates higher local power peaking to increase the local heat flux for CHFR calculations. The 7\% uncertainty was doubled to add conservatism and to show that the current design still provides large thermal margins even with very conservative modeling assumptions. All rods are assumed to have the same axial power distribution.

4) Assume all of the heat generation within a pressure tube occurs in the lead core of each rod. This assumption increases the rod heat flux and the rod center line temperatures. Experience has shown that this is a conservative assumption for CHFR analysis.

The CHF is characterized by a rapid rise of a rod's skin temperature due to the formation of a vapor layer which significantly reduces the local heat transfer coefficient. The rise of the rod skin temperature typically occurs extremely rapidly and will ultimately lead to the failure of the rod. The Departure from Nucleate Boiling (DNB) and CHF are equivalent for low quality flows but are different for high quality flows. For current application the flow quality is low, thus, the CHFR design limit can also be termed a DNBR limit. The definition of the critical heat flux ratio is

$$
\text { CHFR }=\frac{\text { critical heat flux }}{\text { actual local heat flux }}
$$

Traditionally, a CHFR design limit is set to account for correlation/modeling uncertainties. Then the system is modeled as accurately as possible, including local axial power peaking variations, to calculate local CHFR values. Thermal margin for CHF is then determined by comparing the smallest local CHFR value to the CHFR design limit. If the modeling method is perfect; i.e. the CHF correlation predicted CHF conditions exactly with no deviations, the heat transfer coefficient correlation predicted rod temperatures exactly, etc., then the CHFR design limit would be 1.0. A typical CHFR design limit for the commercial nuclear reactor industry falls in the 1.25 to 1.30 range. The uncertainties for the commercial nuclear industry are fairly well defined; however, to account for the SILC APT design uncertainties a CHFR design limit of 2.0 will be used. This means that the SILC APT system will be modeled as described in the preceding paragraphs and a minimum CHFR value for each event will be determined. The minimum CHFR value calculated must be above 2.0 for the design to be acceptable. If the 
minimum calculated value is below 2.0 , the design would require changes to add thermal margin. Thus, for example, if the minimum CHFR value from the analysis of a loss of pump event was 4.0, the local heat flux would have to increase by a factor of 2 to reach the CHFR design limit. Likewise, if the minimum CHFR value from the analysis had been 1.0 , the system would require the local heat flux be reduced by a factor of 2 in order to meet the CHFR design limit criteria.

The VIPRE-01 model is one sixth of a pressure tube as shown in Figure 4.1. Each individual lead rod in a sixty degree sector is modeled explicitly. A coolant channel is defined by the coolant flow area in the triangle defined by a line joining the center of three adjacent lead rods. The channels at the edge of the bundle that are defined by the outer most lead rods and the inside surface of the pressure tube have a larger flow area. Thus, these channels will have more coolant flow than the interior coolant channels. The VIPRE-01 model captures this effect. Axially, the VIPRE-01 model begins just below the rod capture plate and ends at the end of the lead rods (See Figure 4.1). The VIPRE-01 analysis performed to date assumes that each lead rod generates the same amount of power. Rod to rod radial power peaking effects may be explicitly modeled in the future when this information is available. Rod axial power peaking effects have been explicitly modeled. All rods are assumed to have the same axial power distribution.

The VIPRE-01 analysis performed to data for the current SILC APT design source array includes: 1) normal operating conditions, 2) residual heat removal conditions, and 3) an AOO transient which models a ramp flow reduction to $50 \%$ of normal in 5 seconds with a beam shut down 3 seconds after the ramp flow reduction was initiated. This AOO event is considered to be the limiting AOO event.

\subsubsection{Analysis Results}

The normal operating conditions for the SILC APT source array were calculated using the methodology described in Section 4.2.1.2. A summary of the results for each pressure tube is provided in Tables 4.2 through Table 4.10. The pressure drops provided in Table 4.8 includes the rod capture plate, fiction losses, expansion losses at the rod channel exit, and elevation losses. This does not include the orifice plate pressure drop. The system pressure drop is from the source array main inlet pipe hook up to the main exit pipe hook up is 5.52 bar. The pressure drop for the SILC APT source array can be reduced significantly by reducing the length of the rods from $1.9 \mathrm{~m}$ to $1.6 \mathrm{~m}$ and using a single wire wrap for spacers rather than a rod with three ribs.

The use of a single wire wrap increases the channel flow areas and the reduction in the length of the rods reduces the friction pressure drop. Figure 4.2 provides a summary of the limiting pressure tube of the source array, the coolant pressures are at the inlet and exit headers. 
Figure 4.1 SILC APT Source Array Pressure Tube Channel VIPRE-01 Model
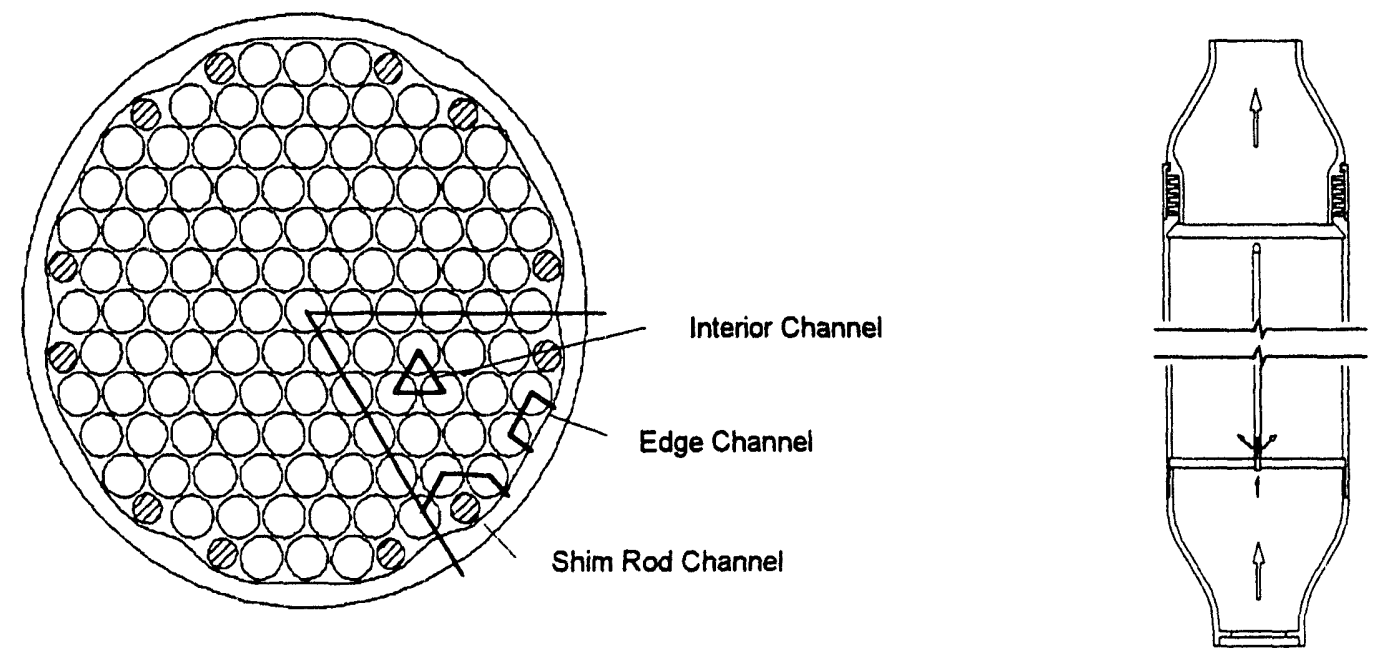

Table 4.2 Source Pressure Tube Power Levels in MW (Total Power $=163.1 \mathrm{MW}$ )

Tube Row

Row 1

Row 2

Row 3

Row 4

Row 5

P. Tube 1

0.1496

5.7860

4.7130

10.5400

0.5514

5.0890

10.9200

8.7610

1.9760

0.3676

P. Tube 3

5.0430

10.6100

10.9500

4.8860

1.2100

P. Tube 4

4.9430

10.4700

11.1300

5.2230

1.7460

P. Tube 5

5.0120

5.7540

10.7800

5.1770

1.7770

0.1534

8.6380

4.9010

1.7000

P. Tube 7

0.5054

1.2100

0.3676 
Table 4.3 Source Pressure Tube Average Power ( $\mathrm{kW}$ per Rod)

Tube Row

$\begin{array}{rrrrr}\text { Row 1 } & \text { Row 2 } & \text { Row 3 } & \text { Row 4 } & \text { Row 5 } \\ & & & & \\ 1.2360 & 21.8400 & 1.0790 & 3.8670 & 0.7194 \\ 38.9500 & 39.7700 & 17.1400 & 9.5610 & 2.3680 \\ 42.0500 & 41.1900 & 21.4300 & 10.2200 & 3.4170 \\ 41.6700 & 40.0500 & 21.7900 & 10.1300 & 3.4770 \\ 40.8500 & 39.5200 & 21.1000 & 9.5910 & 3.3270 \\ 41.4200 & 21.7100 & 16.9000 & 3.9860 & 2.3680 \\ 1.2680 & & 0.9891 & & 0.7194\end{array}$

Table 4.4 Source Pressure Tube Average Rod Heat Flux $\left(\mathrm{kW} / \mathrm{m}^{2}\right)$

Tube Row

Row 1 Row 2

Row 3

Row 4

Row 5

P. Tube 1

26.13

461.7

840.9

P. Tube 2

823.60

889.20

881.20

P. Tube 4

871.0

846.8

863.80

835.6

21.80

346.40

433.00

440.30

426.30

875.80

P. Tube 6

26.80

459.1

341.60

19.98

$\begin{array}{rr}76.42 & 14.22 \\ 189.00 & 46.80 \\ 202.00 & 67.54 \\ 200.20 & 68.72 \\ 189.60 & 65.76 \\ 78.79 & 46.80 \\ & 14.22\end{array}$

Table 4.5 Source Pressure Tube Mass Flow in $\mathrm{kg} / \mathrm{s}$ (Total Flow $=867.2 \mathrm{~kg} / \mathrm{s}$ )

Tube Row

$\begin{array}{rr}\text { Row } 1 & \text { Row } 2 \\ & \\ 0.795 & 30.770 \\ 25.060 & 56.040 \\ 27.060 & 58.050 \\ 26.810 & 56.430 \\ 26.280 & 55.690 \\ 26.650 & 30.600 \\ 0.816 & \end{array}$

Row 3

Row 4

Row 5

P. Tube 1

P. Tube 2

P. Tube 3

P. Tube 4

P. Tube 5

P. Tube 6

P. Tube 7

0.816

$\begin{array}{rr}2.932 & 10.510 \\ 46.590 & 25.980 \\ 58.230 & 27.770 \\ 59.210 & 27.530 \\ 57.340 & 26.060 \\ 45.940 & 10.830 \\ 2.688 & \end{array}$

1.955

6.434

9.285

9.448

9.041

6.434

1.955 
Table 4.6 Source Pressure Tube Coolant Average Velocity $(\mathrm{m} / \mathrm{s})$

$\begin{array}{llllll}\text { Tube Row } & \text { Row 1 } & \text { Row 2 } & \text { Row 3 } & \text { Row 4 } & \text { Row 5 } \\ & & & & & \\ \text { P. Tube 1 } & 0.1793 & 3.2650 & 0.2071 & 0.8685 & 0.1616 \\ \text { P. Tube 2 } & 5.6510 & 5.9470 & 3.2910 & 2.1480 & 0.5319 \\ \text { P. Tube 3 } & 6.1020 & 6.1600 & 4.1130 & 2.2960 & 0.7675 \\ \text { P. Tube 4 } & 6.0470 & 5.9880 & 4.1820 & 2.2760 & 0.7810 \\ \text { P. Tube 5 } & 5.9270 & 5.9100 & 4.0500 & 2.1540 & 0.7473 \\ \text { P. Tube 6 } & 6.0100 & 3.2470 & 3.2450 & 0.8954 & 0.5319 \\ \text { P. Tube 7 } & 0.1839 & & 0.1898 & & 0.1616\end{array}$

Table 4.7 Source Pressure Tube Coolant Channel Comparison Fraction of Coolant Flow Area $\quad$ Fraction of Coolant Flow

$\begin{array}{lllllll}\text { Channel Type } & \text { Interior } & \text { Edge } & \text { Shim Rod } & \text { Interior } & \text { Edge } & \text { Shim Rod } \\ & & & & & & \\ \text { Row 1 P. Tube: } & 0.6712 & 0.0953 & 0.2335 & 0.6390 & 0.1079 & 0.2531 \\ \text { Row 2 P. Tube: } & 0.7897 & 0.1121 & 0.0983 & 0.7668 & 0.1295 & 0.1037 \\ \text { Row 3 P. Tube: } & 0.8243 & 0.0596 & 0.162 & 0.7921 & 0.0691 & 0.1388 \\ \text { Row 4 P. Tube: } & 0.8907 & 0.0606 & 0.1297 & 0.7511 & 0.0638 & 0.1851 \\ \text { Row 5 P. Tube: } & 0.8097 & 0.0606 & 0.1297 & 0.7561 & 0.0638 & 0.1801\end{array}$

Table 4.8 Source Pressure Tube Pressure Drop from Rod Capture Plate to Rod Channel Exit (kPa)

$\begin{array}{lrrrrr}\text { Tube Row } & \text { Row 1 } & \text { Row 2 } & \text { Row 3 } & \text { Row 4 } & \text { Row 5 } \\ & & & & & \\ \text { P. Tube 1 } & 20.88 & 145.10 & 20.94 & 35.60 & 21.11 \\ \text { P. Tube 2 } & 357.20 & 406.00 & 172.20 & 96.85 & 26.73 \\ \text { P. Tube 3 } & 409.60 & 432.40 & 250.90 & 107.00 & 32.58 \\ \text { P. Tube 4 } & 403.00 & 411.10 & 258.20 & 105.60 & 32.96 \\ \text { P. Tube 5 } & 388.90 & 401.50 & 244.30 & 97.30 & 32.01 \\ \text { P. Tube 6 } & 398.60 & 143.70 & 168.30 & 36.46 & 26.73 \\ \text { P. Tube 7 } & 20.91 & & 20.81 & & 21.11\end{array}$


Table 4.9 Source Pressure Tube Highest Clad Surface Temperature $\left({ }^{\circ} \mathrm{C}\right)$

$\begin{array}{llllll}\text { Tube Row } & \text { Row 1 } & \text { Row 2 } & \text { Row 3 } & \text { Row 4 } & \text { Row 5 } \\ & & & & & \\ \text { P. Tube 1 } & 152.60 & 126.70 & 137.80 & 120.20 & 127.60 \\ \text { P. Tube 2 } & 132.00 & 128.90 & 123.10 & 121.70 & 119.50 \\ \text { P. Tube 3 } & 132.30 & 129.00 & 123.70 & 121.90 & 120.10 \\ \text { P. Tube 4 } & 132.20 & 128.90 & 123.70 & 121.80 & 120.10 \\ \text { P. Tube 5 } & 132.10 & 128.90 & 123.60 & 121.70 & 120.00 \\ \text { P. Tube 6 } & 132.20 & 126.70 & 123.10 & 120.30 & 119.50 \\ \text { P. Tube 7 } & 153.60 & & 135.50 & & 127.60\end{array}$

Table 4.10 Source Pressure Tube Highest Rod Center Line Temperature $\left({ }^{\circ} \mathrm{C}\right)$

$\begin{array}{llllll}\text { Tube Row } & \text { Row 1 } & \text { Row 2 } & \text { Row 3 } & \text { Row 4 } & \text { Row 5 } \\ & & & & & \\ \text { P. Tube 1 } & 154.80 & 165.10 & 139.70 & 127.00 & 128.90 \\ \text { P. Tube 2 } & 200.30 & 198.70 & 153.20 & 138.50 & 123.70 \\ \text { P. Tube 3 } & 206.10 & 201.30 & 161.20 & 139.80 & 126.00 \\ \text { P. Tube 4 } & 205.30 & 199.20 & 161.90 & 139.60 & 126.20 \\ & & & & & \\ \text { P. Tube 5 } & 203.80 & 198.20 & 160.60 & 138.60 & 125.90 \\ \text { P. Tube 6 } & 204.90 & 164.80 & 152.70 & 127.30 & 123.70 \\ \text { P. Tube 7 } & 155.90 & & 137.30 & & 128.90\end{array}$

Figure 4.2 SILC APT Source Array Limiting Pressure Tube Parameters for Normal Operating Conditions

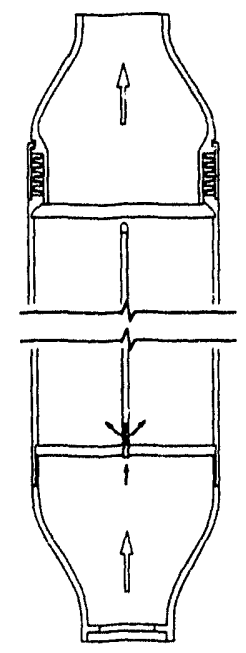

$\begin{array}{ll}\text { Coolant Exit Temp. } & 105.0{ }^{\circ} \mathrm{C} \\ \text { Coolant Exit Pressure } & 10.06 \mathrm{bar} \\ \text { Pressure Tube Power } & 5.09 \mathrm{MW} \\ \text { Minimum CHF Ratio } & 3.90 \mathrm{~m} \\ \text { Max. Coolant Velocity } & 6.74 \mathrm{~m} / \mathrm{s} \\ \text { Mass Flow } & 27.1 \mathrm{~kg} / \mathrm{s} \\ \text { Max. Clad Temp. } & 132{ }^{\circ} \mathrm{C} \\ \text { Max. Pb C.L. Temp. } & 206{ }^{\circ} \mathrm{C} \\ \text { Max . Rod Heat Flux } & 1023 \mathrm{~kW} / \mathrm{m}^{2} \\ \text { Coolant Inlet Temp. } & 60{ }^{\circ} \mathrm{C} \\ \text { Coolant Inlet Pressure } & 14.3 \mathrm{bar}\end{array}$


The limiting AOO event is considered to be a loss of one cooling loop which causes the coolant flow to be reduced to $50 \%$ of the normal operating flow rate. This transient was simulated using the VIPRE-01 code with the following conditions:

1) Coolant flow is reduced by $50 \%$ in 5 seconds.

2) Proton Beam is turned off 3 seconds after the loss of a coolant loop.

The transient should be considered conservative since the pump coast down is anticipated to be not 5 seconds, as assumed here, but 45 seconds or more, as specified in the requirements document for the heat removal system. Furthermore, the beam trip time is anticipated to be less than 1.0 second rather than 3.0 seconds. Figure 4.3 presents the CHFR and rod temperature results for the transient. Thus, the APT SILC source array appears to have sufficient design margins.

Figure 4.3 SILC APT Source Array Limiting Pressure Tube for Limiting AOO Event (Worst Value for Each Variable)

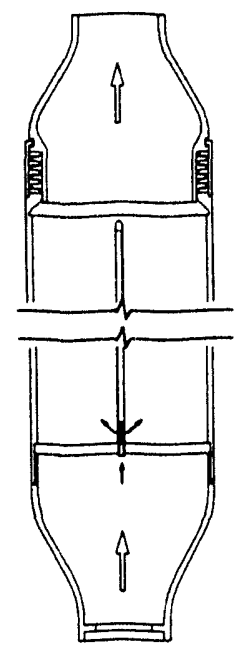

Max. Coolant Exit Temp.

Minimum CHF Ratio

Max. Clad Temp.

Max. Pb C.L. Temp.

Coolant Inlet Temp.

$60{ }^{\circ} \mathrm{C}$ 


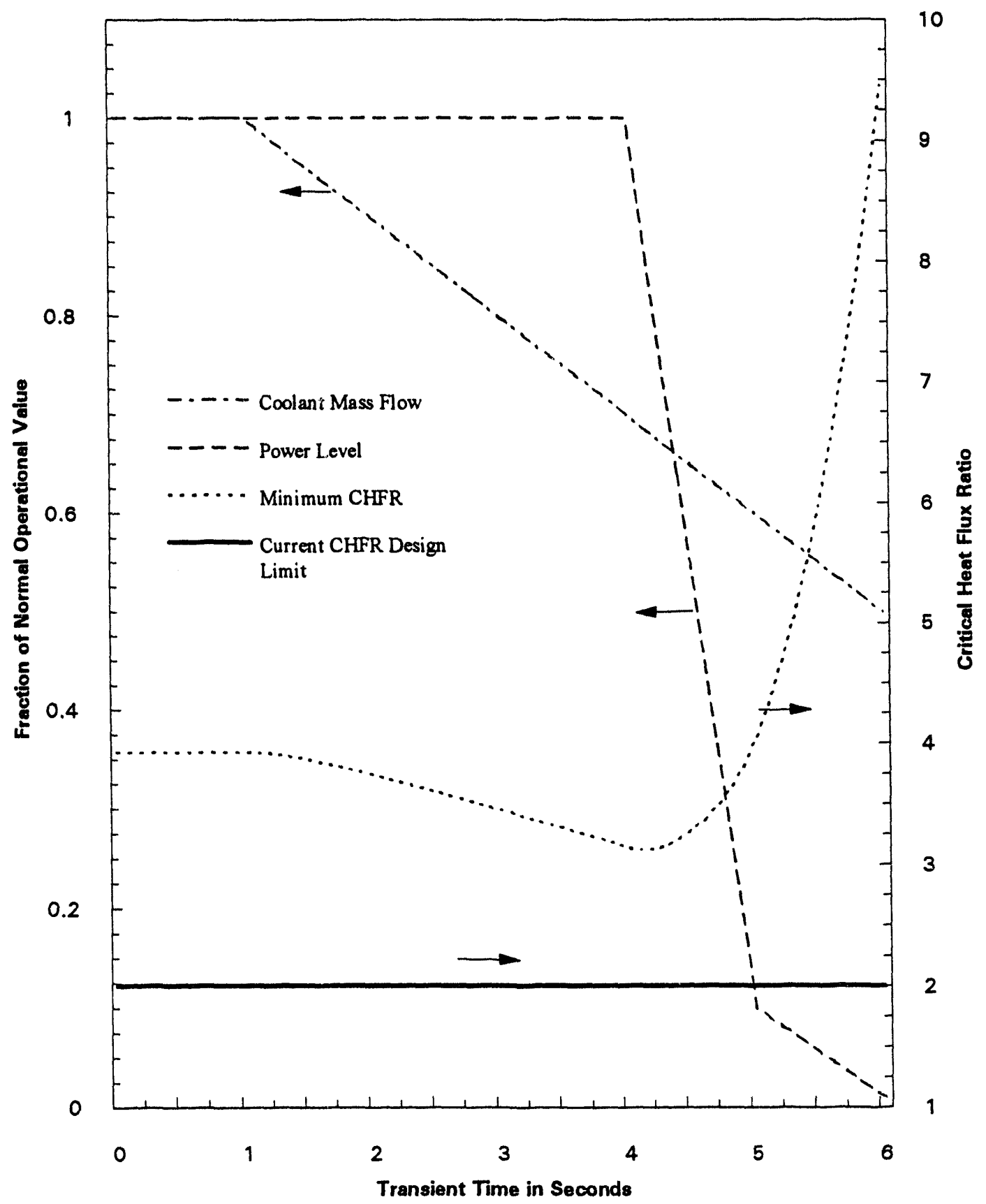

Figure 4.4 Limiting AOO Transient in SILC APT Limiting Pressure Tube 
The residual heat removal system parameters are:

1) Total Heat Load

$1.63 \mathrm{MW}$

2) Coolant Temperatures:

Inlet at plenum header

$57.2^{\circ} \mathrm{C}$

Outlet at plenum header

$82.2^{\circ} \mathrm{C}$

3) Total Coolant Flow

$9.59 \mathrm{~kg} / \mathrm{s}$

4) Coolant Pressure at the row 5 outlet header

$9.65 \mathrm{bar}$

The residual heat removal system conditions for the SILC APT source array were calculated using the methodology described in Section 4.2.1.2. A summary of the results for the limiting pressure tube is provided in Figure 4.5, the coolant pressures are at the inlet and exit headers. Note that these evaluations are based on use of the residual heat removal system, with forced flow. The corresponding evaluations for the residual heat removal system under natural circulation conditions have not been completed at this time. Natural circulation would be required for loss of pumping situations.

Figure 4.5 SILC APT Source Array Limiting Pressure Tube Residual Heat Removal Operation

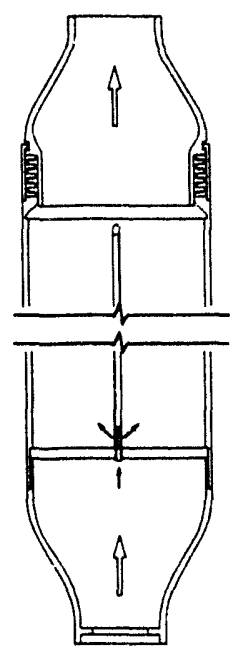

Coolant Exit Temp.

Coolant Exit Pressure

Pressure Tube Power

Minimum CHF Ratio

Max. Coolant Velocity

Mass Flow

Max. Clad Temp.

Max. Pb C.L. Temp.

Max. Rod Heat Flux

Coolant Inlet Temp.

Coolant Inlet Pressure
$82{ }^{\circ} \mathrm{C}$

$9.8 \mathrm{bar}$

$50.4 \mathrm{~kW}$

9.80

$0.153 \mathrm{~m} / \mathrm{s}$

$0.598 \mathrm{~kg} / \mathrm{s}$

$132{ }^{\circ} \mathrm{C}$

$206^{\circ} \mathrm{C}$

$10.1 \mathrm{~kW} / \mathrm{m}^{2}$

$57{ }^{\circ} \mathrm{C}$

$10.0 \mathrm{bar}$ 


\subsubsection{Blanket Assembly Cooling}

\subsubsection{Blanket Assembly Description}

The current blanket design includes a large number of assemblies which enclose the source array and the proton beam expander region. Each assembly consists of an aluminum pressure tube that is filled with lithium-aluminum $(\mathrm{Li}-\mathrm{Al})$ rods having aluminum cladding. A detailed mechanical design description of the blanket assemblies design and arrangement is provided in Section 3. The blanket pressure tubes are the same size as the row 5 source pressure tubes and the $\mathrm{Li}-\mathrm{Al}$ rod dimensions are the same as the row 1 source pressure tube rods (see Table 4.1 for source assembly and $\mathrm{Pb}$ rod dimensions). The blanket tubes are cooled with $\mathrm{H}_{2} \mathrm{O}$. Each blanket pressure tube is orificed such that the coolant exit temperature will not exceed 99 ${ }^{\circ} \mathrm{C}$, to avoid boiling during depressurization transients. This arrangement makes the most efficient use of the required coolant flow. The normal operation system parameters are:

1) Total Heat Load

2) Coolant Temperatures: Inlet at plenum header

Outlet at plenum header

3) Total Coolant Flow

4) Coolant Pressure in the outlet header
$26 \mathrm{MW}$

$82.20^{\circ} \mathrm{C}$

$98.89^{\circ} \mathrm{C}$

$372.4 \mathrm{~kg} / \mathrm{s}$

$9.65 \mathrm{bar}$

The source array cooling requirements for normal operation and Anticipated Operational Occurrences (AOO's) are:
1) Highest permissible $\mathrm{Li}-\mathrm{Al}$ rod average temperature:
$130^{\circ} \mathrm{C}$
2) Minimum CHFR value:

\subsubsection{Calculation Methodology}

The thermal-hydraulic analysis of the SILC APT Blanket array is the same as presented in Section 4.2.1.2 with the exception that a 1.25 peak pressure tube power peaking factor was also applied. The $\mathrm{Li}-\mathrm{Al}$ rod axial power peaking distribution is assumed to have a larger peak than the source assembly. The VIPRE- 01 model is one sixth of a blanket pressure tube as shown in Figure 4.1. Each individual Li-Al rod in a sixty degree sector is modeled explicitly. A coolant channel is defined by the coolant flow area in the triangle defined by a line joining the center of three adjacent $\mathrm{Li}$ - $\mathrm{Al}$ rods. The channels at the edge of the bundle that are defined by the outer most $\mathrm{Li}-\mathrm{Al}$ rods and the inside surface of the blanket pressure tube have a larger flow area. Thus, these channels will have more coolant flow than the interior coolant channels. The VIPRE-01 model captures this effect. Axially, the VIPRE-01 model begins just below the rod capture plate and ends at the end of the Li-Al rods (See Figure 4.1). The VIPRE-01 analysis performed to date assumes that each $\mathrm{Li}-\mathrm{Al}$ rod generates the same amount of power. Power peaking effects may be explicitly modeled in the future when this information is available. 
The VIPRE-01 analysis performed to data for the current SILC APT design blanket array includes: 1) normal operating conditions, 2) residual heat removal conditions, and 3) an AOO transient which models a ramp flow reduction to $50 \%$ of normal in 5 seconds with a beam shut down 3 seconds after the ramp flow reduction was initiated.

\subsubsection{Analysis Results}

The normal operating conditions for the SILC APT blanket array were calculated using the methodology described in Section 4.2.1.2. A summary of the results for the limiting $\mathrm{Li}-\mathrm{Al}$ Blanket pressure tube is provided in Figure 4.6.

Figure 4.6 SILC APT Blanket Array Limiting Pressure Tube Normal Operating Conditions

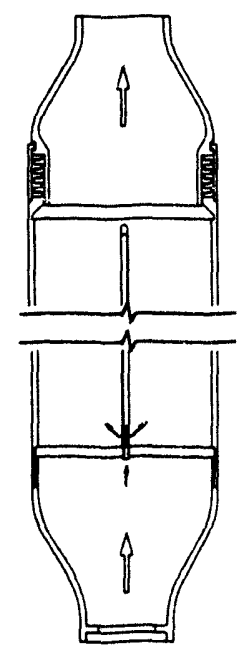

Coolant Exit Temp.

Coolant Exit Pressure

Pressure Tube Power

Minimum CHF Ratio

Max. Coolant Velocity

Mass Flow

Max. Clad Temp.

Max. Li-Al C.L. Temp

Max . Rod Heat Flux

Coolant Inlet Temp.

Coolant Inlet Pressure
$99{ }^{\circ} \mathrm{C}$

$10.1 \mathrm{bar}$

$358.3 \mathrm{~kW}$

3.9

$0.281 \mathrm{~m} / \mathrm{s}$

$5.11 \mathrm{~kg} / \mathrm{s}$

$111^{\circ} \mathrm{C}$

$114{ }^{\circ} \mathrm{C}$

13.76

$\mathrm{kW} / \mathrm{m}^{2}$

$82{ }^{\circ} \mathrm{C}$

10.2 bar

The limiting AOO event is considered to be a loss of one cooling loop which causes the coolant flow to be reduced to $50 \%$ of the normal operating flow rate. This transient was simulated using the VIPRE-01 code with the following conditions:

1) Coolant flow is reduced by $50 \%$ in 5 seconds.

2) Proton Beam is turned off 3 seconds after the loss of a coolant loop.

The transient should be considered conservative since the pump coast down is anticipated to be not 5 seconds, as assumed here, but 45 seconds or more, as specified in the requirements document for the heat removal system. Furthermore, the beam trip time is anticipated to be less 
than 1.0 second rather than 3.0 seconds. A summary of the results for the limiting Li-Al Blanket pressure is provided in Figure 4.7. The APT SILC blanket array appears to have sufficient design margins.

Figure 4.7 SILC APT Blanket Array Limiting Pressure Tube - Limiting AOO Event (Worst Value for Each Variable)

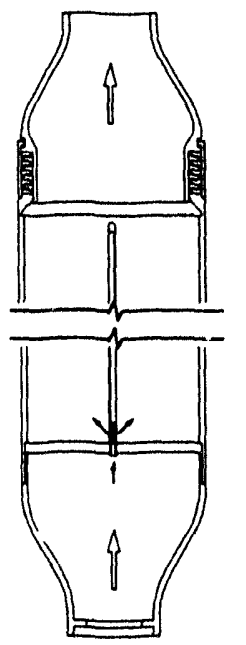

Max. Coolant Exit Temp. $\quad 116^{\circ} \mathrm{C}$

Minimum CHF Ratio $\quad 2.4$

Max. Clad Temp.

$127{ }^{\circ} \mathrm{C}$

Max. Li-Al C.L. Temp. $\quad 129^{\circ} \mathrm{C}$

Coolant Inlet Temp.

$82{ }^{\circ} \mathrm{C}$ 
The residual heat removal system param cers are:

1) Total Heat Load

2) Coolant Temperatures:

Inlet at plenum header

Outlet at plenum header

3) Total Coolant Flow

4) Coolant Pressure at the outlet pipe
$200 \mathrm{~kW}$

$71.1^{\circ} \mathrm{C}$

$76.7^{\circ} \mathrm{C}$

$9.59 \mathrm{~kg} / \mathrm{s}$

$9.65 \mathrm{bar}$

The residual heat removal system conditions for the SILC APT blanket array were calculated using the methodology described in Section 4.2.2.2. A summary of the results for the limiting blanket pressure tube is provided in Figure 4.5, the coolant pressures are at the inlet and exit headers.

Figure 4.8 SILC APT Blanket Array Limiting Pressure Tube Residual Heat Removal Operation

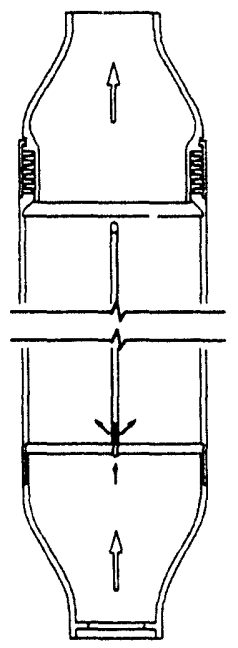

Coolant Exit Temp.

Coolant Exit Pressure

Pressure Tube Power

Minimum $\mathrm{CH}^{2}$ Ratio

Max. Coolant Velocity

Mass Flow

Max. Clad Temp.

Max. Li-Al C.L. Temp.

Max. Rod Heat Flux

Coolant Inlet Temp.

Coolant Inlet Pressure $77^{\circ} \mathrm{C}$

$9.72 \mathrm{bar}$

$2.76 \mathrm{~kW}$

$>10$

0.843

$\mathrm{cm} / \mathrm{s}$

$0.154 \mathrm{~g} / \mathrm{s}$

$77.5^{\circ} \mathrm{C}$

$78.1^{\circ} \mathrm{C}$

91.82

$\mathrm{W} / \mathrm{m}^{2}$

$71{ }^{\circ} \mathrm{C}$

$9.91 \mathrm{bar}$ 


\subsubsection{Target Window and Beam Expander Cooling}

\subsubsection{Cooling System Loop Description}

The cooling system for the window and the beam expander are shown schematically in Figures 4.9 to 4.12. The target window, expander, and partition are liquid-cooled using H2O. Figures 4.10 and 4.11 show the flow arrangement. The window has two independent flow loops. One is dedicated to one half of the window, the other cools the other half plus the expander and partition. Physically, window coolant channels 1 and 2 alternate in a 1-2-1-2 fashion. The total heat load is approximately 1.2 MW, divided as:

\begin{tabular}{ll} 
Window & $1.00 \mathrm{MW}$ \\
Expander Tube & $0.15 \mathrm{MW}$ \\
Partition & $\underline{0.06 \mathrm{MW}}$ \\
\multicolumn{1}{c}{ TOTAL } & $1.21 \mathrm{MW}$
\end{tabular}

Flow rates are designed to yield a $62{ }^{\circ} \mathrm{C}$ coolant temperature at the exit of each window "half" and at the exit of the expander/partition loop with $50^{\circ} \mathrm{C}$ at the inlets. The following sections provide additional detail about the window and expander cooling conceptual design.

\subsubsection{Window Cooling}

\subsection{Thermal Requirements}

Since the window material is aluminum, the stiffness decreases quickly above $121^{\circ} \mathrm{C}$. Allowing ample design margin for normal operation, the driving limitation is:

$$
\begin{array}{ll}
\mathrm{T}_{\text {max,alum }} \leq 105^{\circ} \mathrm{C} & \text { (Normal Operation) } \\
\mathrm{T}_{\text {max,alum }} \leq 110^{\circ} \mathrm{C} \quad \text { (AOO events) } \\
\mathrm{T}_{\text {max,alum }} \leq 121{ }^{\circ} \mathrm{C} \quad \text { (DBE events) }
\end{array}
$$

Another limitation applied for AOO's and DBE's is that the Critical Heat Flux Ratio (CHFR) should not drop below 1.3 (3.0 for normal operation). This CHFR value is used as the current CHFR design limit. Use of the CHFR design limit is the same as outlined in section 4.2.1.2 for the source assembly design.

A safety assessment considered for pre-conceptual design is a partially blocked flow channel with the following design requirements:

CHFR $\geq 1.3$ (AOO: partially-blocked channel)

$$
\mathrm{T}_{\text {mex, dum }} \leq 121^{\circ} \mathrm{C}
$$

The hert load on the $1400 \mathrm{~mm} \times 1400 \mathrm{~mm}$ beam footprint is $1 \mathrm{MW}$. 


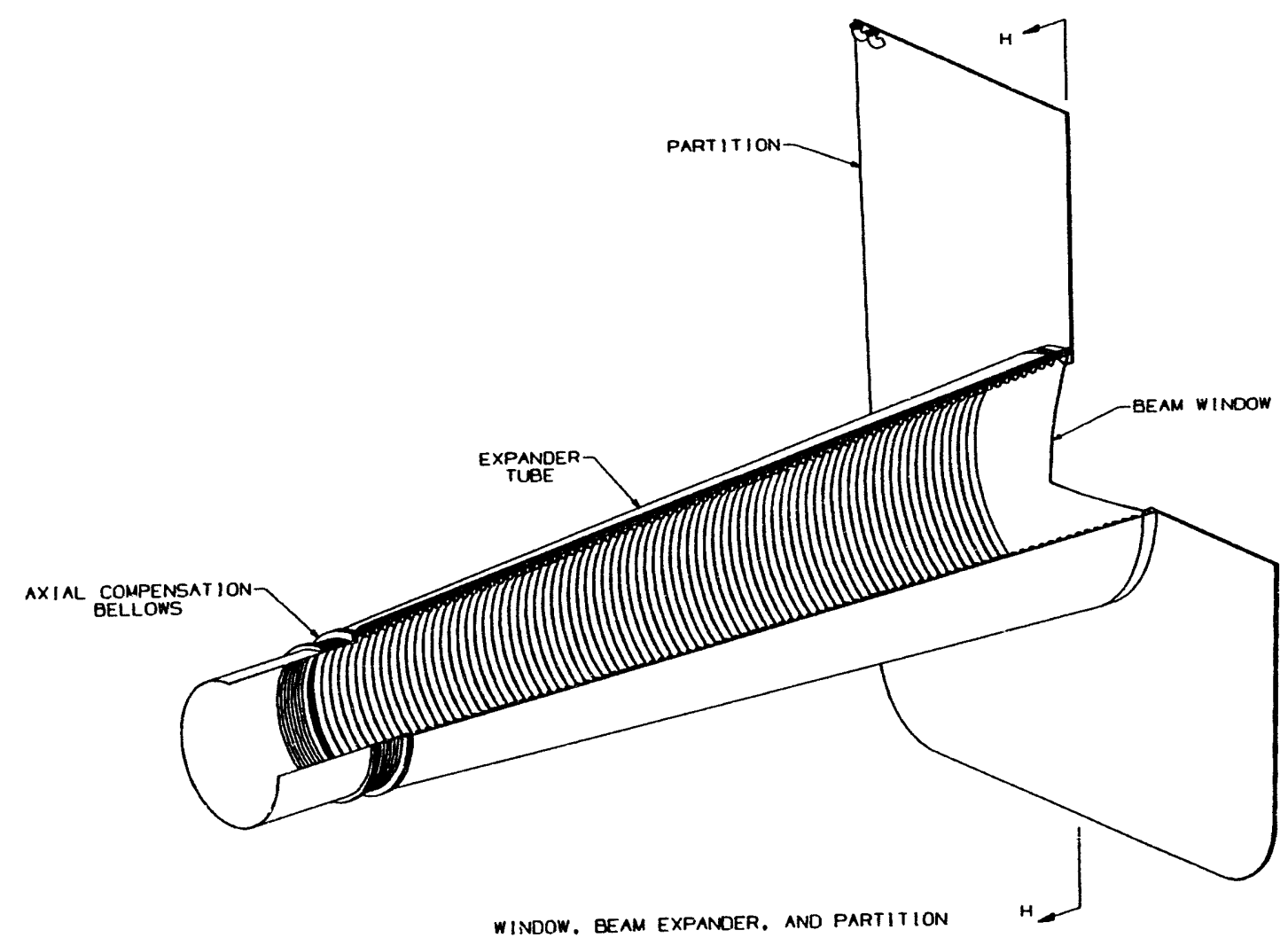

Figure 4.9: Beam Expander and Window 

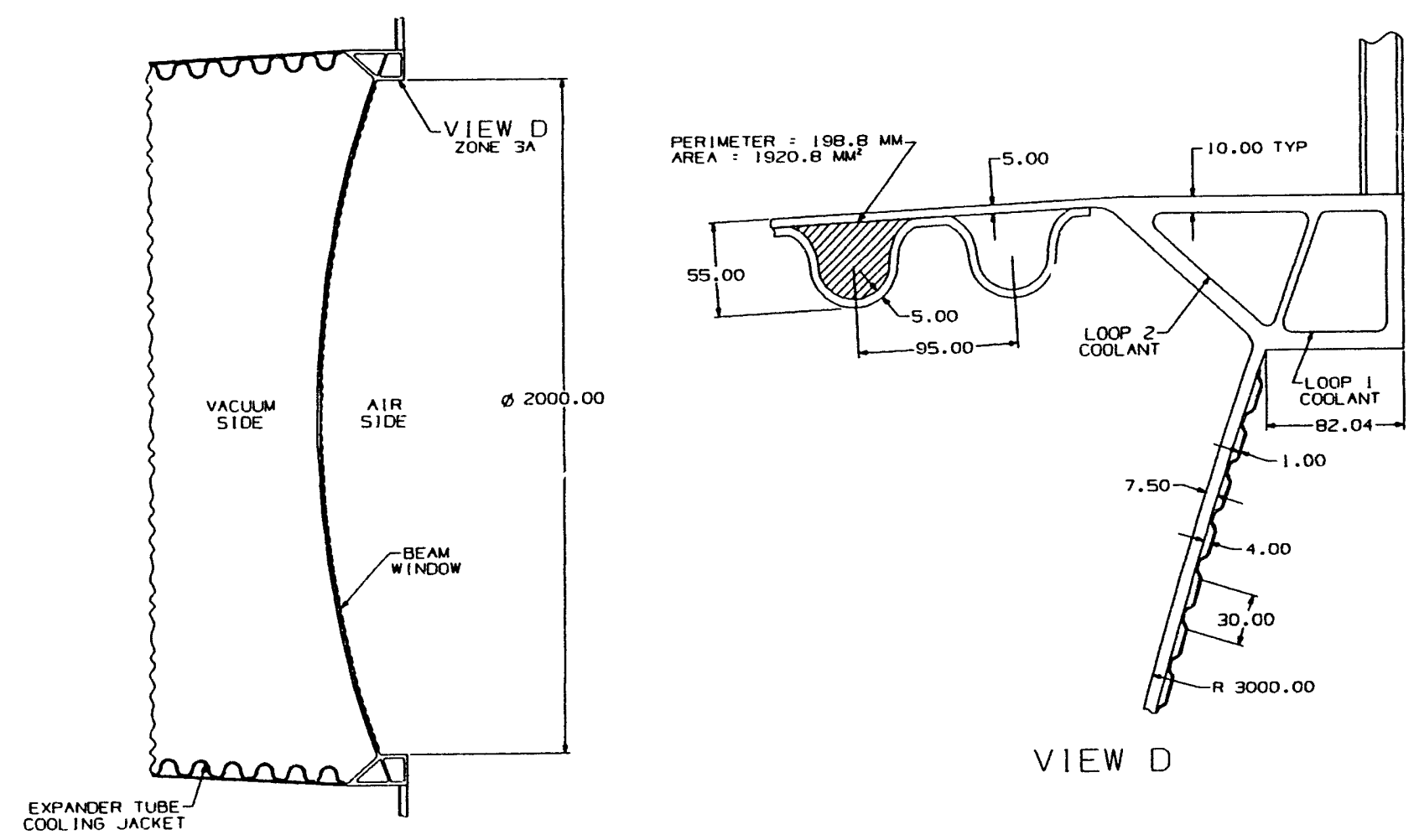

VIEW D

Figure 4.10: Beam Expander and Window Junction 
$\stackrel{+}{0}$

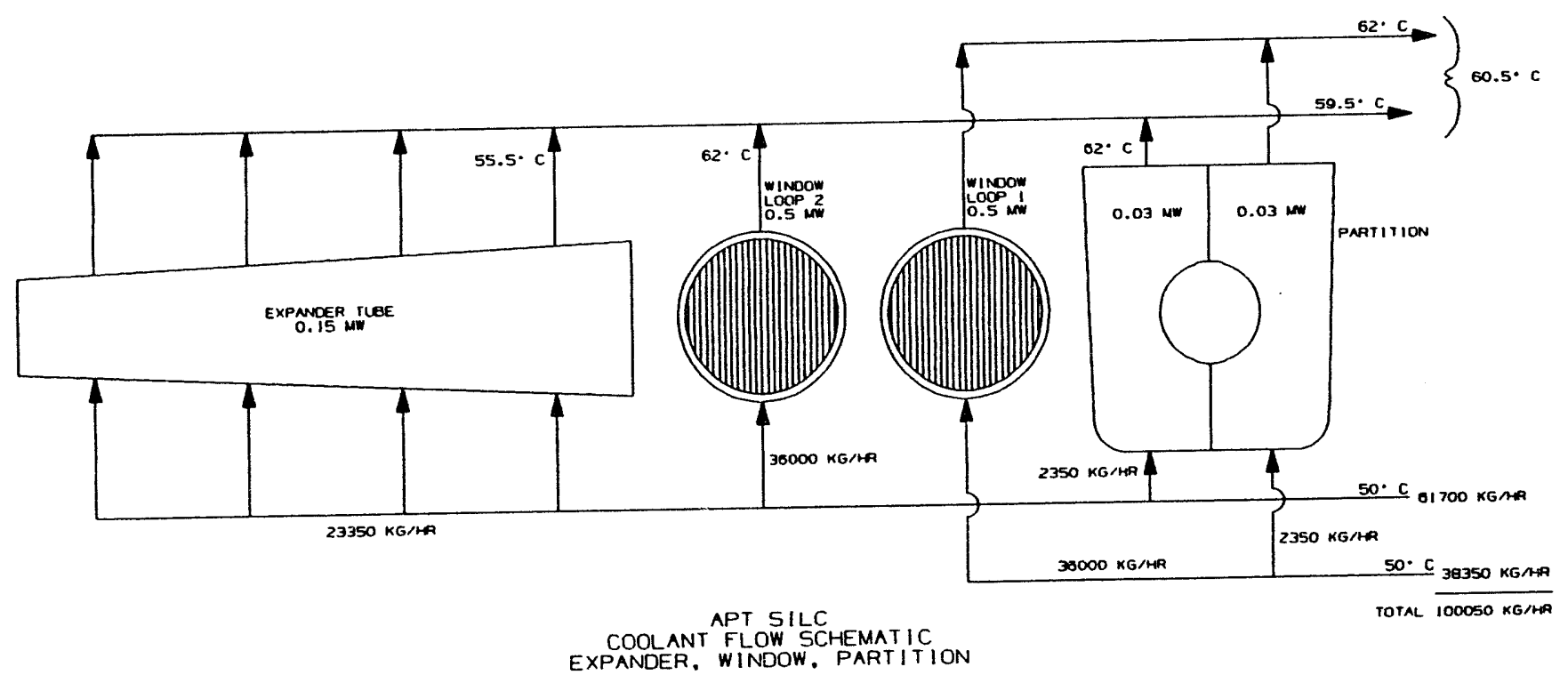

Figure 4.11: Window Cooling System Flow Diagram 

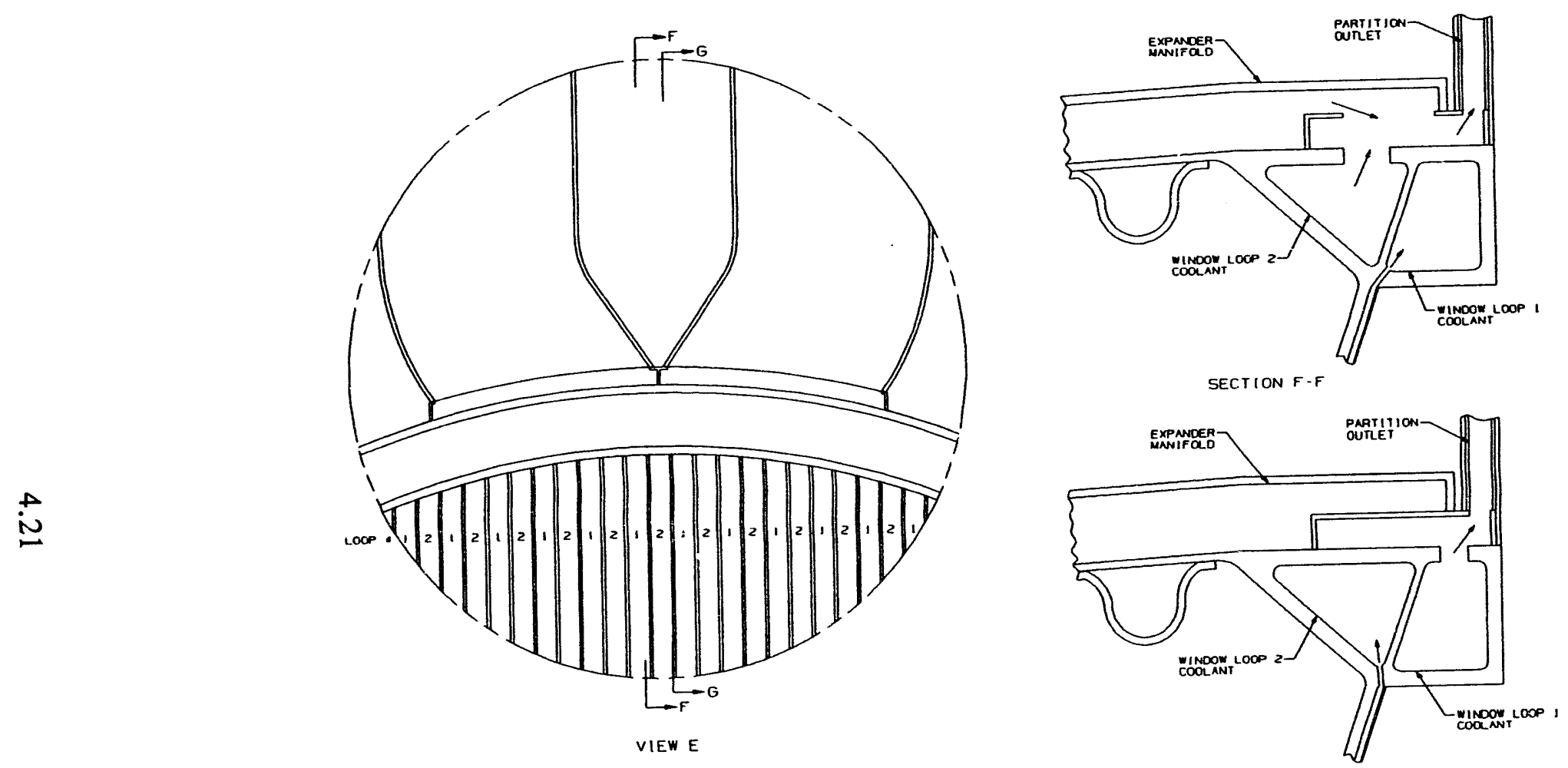

SECTION G-G

WINOOW FLANGE AREA

Figure 4.12: Schematic of Wirdow Cooling System with Plena 


\subsection{Configuration}

Figures 4.10 and 4.12 show the window cooling configuration. Flow ciannels are formed by attaching a thin aluminum corrugated sheet to a thicker (approximately $7.5 \mathrm{~mm}$ ) plate. Coolant is supplied to and exits from the window via a plenum which also forms a flange with the expander tube.

There are two completely independent cooling loops to remove the window heat. The channels on the window itself alternate supply source between loop 1 and loop 2 . The plenum distributes flow to the set of channel "1's" and channel "2's" through orifices (shown in Figure 4.12). The orifices are sized to direct the vast majority of flow through those channels cooling the beam footprint.

\subsection{Predicted Operating Parameters}

Normal Operation (best estimate):

$\begin{array}{ll}\text { Heat Load } & 1 \mathrm{MW} \\ \text { Inlet Temperature } & 50^{\circ} \mathrm{C} \\ \text { Exit Temperature } & 62^{\circ} \mathrm{C} \\ \text { Exit Pressure } & 2.41 \mathrm{bar} \\ \text { Total Flow } & 72,000 \mathrm{~kg} / \mathrm{hr} \\ \text { Max. Wall Temperature } & 100{ }^{\circ} \mathrm{C} \\ \text { Channel Velocity } & 4.3 \mathrm{~m} / \mathrm{s} \\ \text { Pressure Drop } & 0.99 \mathrm{bar} \\ \text { CHFR } & >10\end{array}$

Safety Assessment (Partially Blocked Charnel)

Preliminary analysis using VIPRE found that a channel can be blocked to restrict flow to 40 percent of design flow level and still stay within wall temperature criteria. The heat flux is sufficiently low to maintain ample CHFR margin. Hence, wall temperature is the limiting criteria. The values listed below are best estimate. Future thermal design work will concentrate on VIPRE model refinements.

For 20 percent blockage of one channel:

Max. Wall Temperature $108^{\circ} \mathrm{C}$

CHFR (DP-1306 Correlation) $>10$

For 40 percent blockage of one channel:

Max. Wall Temperature $\quad 120^{\circ} \mathrm{C}$

CHFR (DP-1306) 9.6 


\subsection{Analysis Methodology}

The primary analysis tool utilized was VIPRE-01. This is a thermal-hydraulics code widely used by utilities to perform reload safety and licensing analyses and to evaluate thermal margins. Boundary conditions for VIPRE input were determined using hand calculations with the aid of MathCad.

The VIPRE analysis modeled the three middle channels as separate walls. Heat conduction in both the lateral and axial directions was switched on. For the safety assessment analysis, the middle channel flow was manually reduced to achieve the desired flow reduction.

Correlations for heat transfer were as follows:

single-phase: Dittus-Boelter

sub-cooled boiling: Chen

Bulk boiling: Chen

CHF DP-1306

Correlations for predicting void formation and their affect for sub-cooled boiling, bulk boiling, and friction factors were based on EPRI correlations.

\subsection{Future Thermal Design Needs}

Future work should refine the VIPRE model to include orificing effects for all window channels. Additionally, transient analysis should be performed to examine pump coast down events (AOO and DBE). Although, no problems are anticipated due to the long pump coast down times (i.e. 45 seconds).

\subsubsection{Expander Cooling}

\subsection{Thermal Requirements}

The same temperature and CHFR limitations apply to the expander as the window, i.e,

$$
\begin{aligned}
& \mathrm{T}_{\max } \leq 105^{\circ} \mathrm{C} \text { (Normal operation) } \\
& \mathrm{T}_{\max } \leq 110^{\circ} \mathrm{C} \text { (AOO events) } \\
& \mathrm{T}_{\max } \leq 121{ }^{\circ} \mathrm{C} \text { (DBE events) } \\
& \text { CHFR }>3.0 \text { (Normal operation) } \\
& \text { CHFR }>1.3 \text { (AOO and DBE events) }
\end{aligned}
$$

\subsection{Configuration}

The expander is cooled by H20 pumped through the corrugations shown in Figures 4.9, 10 and 12. Flow direction is from bottom to top. Orificing along the inlet manifold will direct 
the majority of flow toward the window end. The total flow is feed by one loop, shared with half of the window and the partition.

\subsection{Operating Parameters}

$\begin{array}{ll}\text { Heat Load: } & 0.15 \mathrm{MW} \\ \text { Peak/Avg Axial Power: } & 3.2 \\ \text { Avg. Heat Flux: } & 1500 \mathrm{~W} / \mathrm{m}^{2} \\ \text { Inlet Temperature: } & 50{ }^{\circ} \mathrm{C} \\ \text { Exit Temperature (avg): } & 55.5^{\circ} \mathrm{C} \\ \text { Flow Rate: } & 23,350 \mathrm{~kg} / \mathrm{hr} \\ \text { Max. Temperature: } & 83^{\circ} \mathrm{C} \\ \text { Max. Velocity: } & 0.07 \mathrm{~m} / \mathrm{s}\end{array}$

\subsection{Methodology}

The analysis was performed using hand calculations with the aid of MathCad. The average heat load was distributed assuming the same profile of power distribution as the blankets.

\subsection{Future Thermal Design Effort}

Future effort should focus on determining an orificing scheme for distribution of flow and reducing channel flow area in order to reduce the total flow required. The latter would require a re-evaluation of the expander structural analysis. The primary window cooling system heat exchanger will also need to be resized due to the lower exit temperature and higher flow rates recommended herein.

\subsubsection{Partition Cooling}

As seen in Figure 4.11, cooling flow is bled from each loop into opposing halves of the partition bottom. The coolant passes vertically through the partition via tubes sandwiched between the partition skin. The thermal requirements are assumed to be the same as those for the expander (section 4.2.3.3.1). Due to a lack of neutronic heating information, the heat load is based on the average volumetric heat generation of the expander $(0.286 \mathrm{~W} / \mathrm{cc})$.

A scoping thermal analysis was performed using MathCAD. Results indicate that the cooling concept is feasible. Skin (aluminum 6061-T6) temperature had a normal operating design margin of $28^{\circ} \mathrm{C}$. Although CHF was not computed, the partition cooling design will probably be driven by metal temperature due to the low heat flux level.

$\begin{array}{ll}\text { Heat Load: } & 0.066 \mathrm{MW} \\ \text { Inlet Temperature: } & 50^{\circ} \mathrm{C} \\ \text { Exit Temperature: } & 62^{\circ} \mathrm{C} \\ \text { Exit Pressure: } & 2.41 \mathrm{bar}\end{array}$


Total Flow: $\quad 4700 \mathrm{~kg} / \mathrm{hr}$

Max. Wall Temperature: $100{ }^{\circ} \mathrm{C}$

Channel Velocity: $\quad 0.5 \mathrm{~m} / \mathrm{s}$

Pressure Drop: $\quad 2 \mathrm{kPa}$ (frictional)

It is recommended that, as more heat load information is made available, the analysis should be repeated for normal operation, AOO, and DBE conditions. 


\subsection{HEAT REMOVAL SYSTEM DESIGN}

The heat removal systems for the spallation induced lithium conversion target consist of four sets of systems broadly defined by: the source cooling systems, the blanket cooling systems, the window cooling systems, and the source basin flood system. Flow diagrams for these systems are presented as Figures 4.13 to $4.16^{1}$. The functions, system and safety requirements for the individual systems are provided in B\&W Document 12-3002053-00, which is attached here as Appendix 4A. A brief description of each system and its major components vill follow in the same order as they are in the requirements document.

\subsubsection{Source Cooling Systems (SCS)}

The source cooling systems are made up of those systems that remove and transport the lead source generated energy to the ultimate heat sink, (refer to Figure 4.13). It is composed of the following five systems: the source primary cooling system (SPCS), the source secondary cooling system (SSCS), the source circulating water system (SCWS), the source residual primary cooling system (SRPCS) and the source residual secondary cooling system (SRSCS). All of the systems contain two loop. The main cooling systems contain two 50\% loops for normal operation where both trains are required to function. The loss of any one loop in the normally operating cooling systems will result in an accelerator trip. All of the residual heat removal systems use two $100 \%$ loops and this includes the passive cooling capability included in the source primary and the source secondary cooling systems through a natural draft water-to-air heat exchanger, thus each of the diverse residual heat removal trains has a redundant train.

\subsubsection{Source Primary Cooling System (SPCS)}

\subsection{General Description}

The source primary cooling system (SPCS) provides forced circulation of the source coolant, $\mathrm{D}_{2} \mathrm{O}$, to remove the energy generated within the source assembly array and deliver this energy to the source secondary cooling system under all conditions when $\mathrm{AC}$ power is available except for the case when the system is depressurized. The SPCS contains $49 \mathrm{~m}^{3}\left(1730 \mathrm{ft}^{3}\right)$ of $\mathrm{D}_{2} \mathrm{O}$. When the system is depressurized the beam must be shut down and the cooling transferred to either the passive system or the source residual primary cooling system, the active backup system. The passive cooling function is provided through the natural circulation of the source primary cooling system at the decay heat level. Again the energy is transported to the SSCS which is also naturally circulating, through to the natural draft water-to-air haat exchanger.

All component parts in contact with the source coolant are fabricated from highly corrosion resistant materials designed to ensure a 40 -year minimum life for the SPCS when

\footnotetext{
${ }^{1}$ Since most figures in this section are extensively referenced throughout the section, they have all been placed at the end of the section, for more convenient access.
} 
operated at the temperature, pressure, and water chemistry conditions expected in the SPCS.

The SPCS consists of two loops with each loop connected in parallel to the source inlet headers at the top and buttom of each row of source assemblies, (refer to Figure 4.13). Each loop removes approximately $50 \%$ of source generated energy, about $82 \mathrm{MWth}$, and contains one pump, one heat exchanger, connecting piping, one pressurizer or one accumulator, and the associated instrumentation to meet the required single failure and redundancy criteria. The loops are independent outside the source region, source and source headers, for decay heat and stored sensible stored energy removal. This independence allows either loop of the system to be used to cool the source down for all normal shutdowns and abnormal shutdown events including the large break LOCA. The independence provides the capability for one SPCS to remove the energy deposited at rates up to $50 \%$ power, but at this time loss of either loop would result in an accelerator trip.

The source coolant pumps are vertical canned motor units designed to circulate about $410 \mathrm{l} / \mathrm{s}(6500 \mathrm{gpm})$ each. These pumps are expected to have an internally mounted inertial unit to extend the flow coastdown of the system to at least 45 seconds, allowing the system to coastdown to natural circulation in the event of a loss-of-offsite power or a station blackout. The two SPCS heat exchangers are horizontal, two-pass, straight tube and shell design with the source coolant, $\mathrm{D}_{2} \mathrm{O}$, on the tube side. The pressurizer is gas charged, and the surge line serves as a return line for one loop of the source residual primary cooling system (SRPCS). The function of the pressurizer is to maintain the SPCS and the SRPCS in a subcooled state providing the required NPSH for the circulating pumps. The accumulator and pressurizer provide makeup in the event of a SPCS loss-of-coolant accident (LOCA). Two code safety valves will be used on the pressurizer. The pressurizer is designed to allow its operation in a manner that will not inject any of the charge gas into the system in the event of a LOCA or leak. The accumulator contains a parallel redundant set of check and stop valves in the surge line. It is also gas charged and designed for operation such that the gas will not be injected into the source primary cooling system should a LOCA or leak occur. The surge line for the accumulator downstream of the check valves serves as the return line for the second loop of the SRPCS.

\subsection{Pumps}

Forced flow, $410 \mathrm{l} / \mathrm{s}(6500 \mathrm{gpm})$, through each of the SPCS loops is provided by a canned motor, vertical, single-stage, single-suction, mixed flow pump (refer to Figure 4.17 for a sketch of the pump). The bottom suction nozzle delivers the $\mathrm{D}_{2} \mathrm{O}$ to the eye of the impeller, and the impeller discharges the $\mathrm{D}_{2} \mathrm{O}$ radially into the diffuser that delivers it to the tangential outlet nozzle. The pump nozzles are butt welded to the SPCS hot leg piping. An internal inertial unit is provided, sized to provide a 45 second coastdown when power is lost to both SPCS pumps. The bearings are water lubricated and cooled. A heat exchanger may be needed to remove a portion of the energy deposited inside the motor and inertial assembly. The pumps were scaled from previous vendor quotes and are considered to be adequate for this preconceptual design stage. 


\subsection{Heat Exchangers}

The SPCS heat exchangers were sized using the Heat Transfer Research, Inc. heat exchanger software. The general characteristics are provided in Figure 4.18 and Table 4.11. The two SPCS heat exchangers are horizontal, two-pass, straight tube and shell design with the source coolant, $\mathrm{D}_{2} \mathrm{O}$, on the tube side. Entrance and exit annuli are provided on the shell side to distribute the coolant flow evenly to the heat exchanger and to eliminate high velocity fluid impingement cross flow on the outside of the heat exchanger tubes. Margin was added to the heat transfer surface to allow for surface fouling, tube plugging and conceptual design uncertainties. It is further expected as the conceptual design evolves the heat load may change slightly. Optimization studies incorporating the source circulating water system (SCWS) and the SSCS also will generate minor changes in the surface requirements. However, it is believed that the heat exchangers are adequately sized for the pre-conceptual study.

Table 4.11 SILC Source Primary Cooling System Heat Exchanger

Data

Fluid

Total Flow Rate, $\mathrm{kg} / \mathrm{s}$

Inlet Temperature, ${ }^{\circ} \mathrm{C}$

Outlet Temperature, ${ }^{\circ} \mathrm{C}$

Heat Exchanger Pressure Drop, MPa

Film Resistance, $\mathrm{m}^{2}-\mathrm{C} / \mathrm{w}$

Fouling Resistance, $\mathrm{m}^{2}-\mathrm{C} / \mathrm{w}$

Overall Heat Transfer Coefficient, $w / \mathrm{m}^{2}-\mathrm{C}$

- Required

- Clean

- Estimated for Actual Conditions

Tube

- Number

- Diameter, mm

- Thickness, mm

- Length, mm

- Total Area (OD), $\mathrm{m}^{2}$
Shellside

$\mathrm{H}_{2} \mathrm{O}$

501

38

77

0.091

9.825E-5

5.841E-5
Tubeside

$\mathrm{D}_{2} \mathrm{O}$

433

105

60

0.127

6.632E-5

$1.770 \mathrm{E}-5$
2635

3768

2892

3912

12.7

1.245

8077

1261

\subsection{Pressurizer and Accumulator}

The SPCS contains one pressurizer that is helium charged to maintain the SPCS in a subcooled state. Helium fills the space above the $\mathrm{D}_{2} \mathrm{O}$ and is at the pressure, about $1.5 \mathrm{MPa}$ (217 psia), required to maintain the source outlet header at $0.97 \mathrm{MPa}(140 \mathrm{psia})$ when the SPCS 
system pumps are operating at their design conditions (refer to Figure 4.19). The pressure was selected based on the heat fluxes, their uncertainty, and the required margins to critical heat flux for the pins in the source assemblies. The pressurizer contains a power actuated relief valve, two code safety valves, and a relief isolation valve. The pressurizer controls are based on the maintenance of a constant gas inventory. The only reason for makeup is losses of gas due to solubility in the water or losses due to leakage such as through a valve. The gas inventory maintained in the pressurizer is not sufficient to inject gas into the system should the system depressurize as it would with a LOCA. The pressurizer is $7.3 \mathrm{~m}(24 \mathrm{ft})$ tall and $1.7 \mathrm{~m}(66$ inches) in diameter with 2:1 elliptical heads. At the expected operating temperatures, the pressurizer contains, $14.81 \mathrm{~m}^{3}\left(513 \mathrm{ft}^{3}\right)$ of $\mathrm{D}_{2} \mathrm{O}$ and $0.99 \mathrm{~m}^{3}\left(35 \mathrm{ft}^{3}\right)$ helium cover gas resulting in a normal water level of $0.61 \mathrm{~m}(2 \mathrm{ft})$ down from the top.

The accumulator is the same dimensions as the pressurizer but will be operated at a gas pressure $0.10 \mathrm{MPa}$ (15 psi) below that in the pressurizer, thus the gas volume is about $1.08 \mathrm{~m}^{3}$ $\left(38 \mathrm{ft}^{3}\right)$. The accumulator operates with the same gas inventory as the pressurizer (They have the same total volume) to prevent injection of gas into the source primary cooling system should the system be depressurized as in the event of a LOCA.

The instrumentation included for the pressurizer and accumulator include $\mathrm{D}_{2} \mathrm{O}$ level, cover gas pressure, and cover gas temperature, to allow an evaluation of the gas inventory.

\subsection{Piping and Valves}

The SPCS piping is seamless $250 \mathrm{~mm}$ (10 inch) Schedule 40 nominal, 316 stainless steel piping (refer to Figure 4.20). The maximum allowable design velocity is $15.2 \mathrm{~m} / \mathrm{s}(50$ $\mathrm{ft} / \mathrm{sec})$, however, the maximum velocity in the $250 \mathrm{~mm}$ (10 inch) hot leg pipe is about $7.9 \mathrm{~m} / \mathrm{s}$ $(26 \mathrm{ft} / \mathrm{sec})$ at the design operating temperature of $105^{\circ} \mathrm{C}\left(221^{\circ} \mathrm{F}\right)$.

\subsection{Instrumentation}

At this pre-conceptual design stage, the information needed for operation and protection has not been adequately investigated, and the parameters needed may change as the operational and safety analyses are completed. Table 4.12 is a list of those parameters that are expected to be measured. Table 4.13 is a list of those parameters that are expected to be used in the protection system for the various types of transients identified. Although it may be desirable to include parameters from the source secondary and the source circulating water systems to provide anticipatory signals for protection, they are not expected to be necessary at this time. 


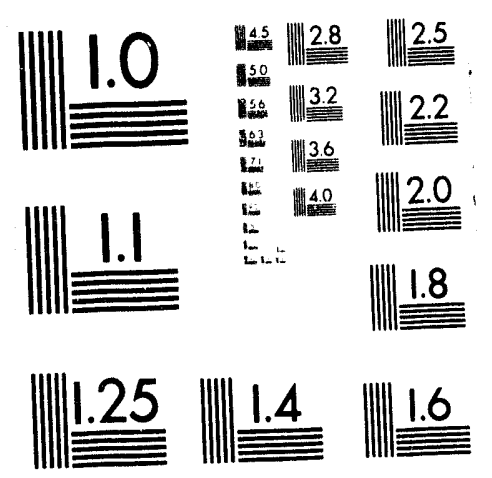



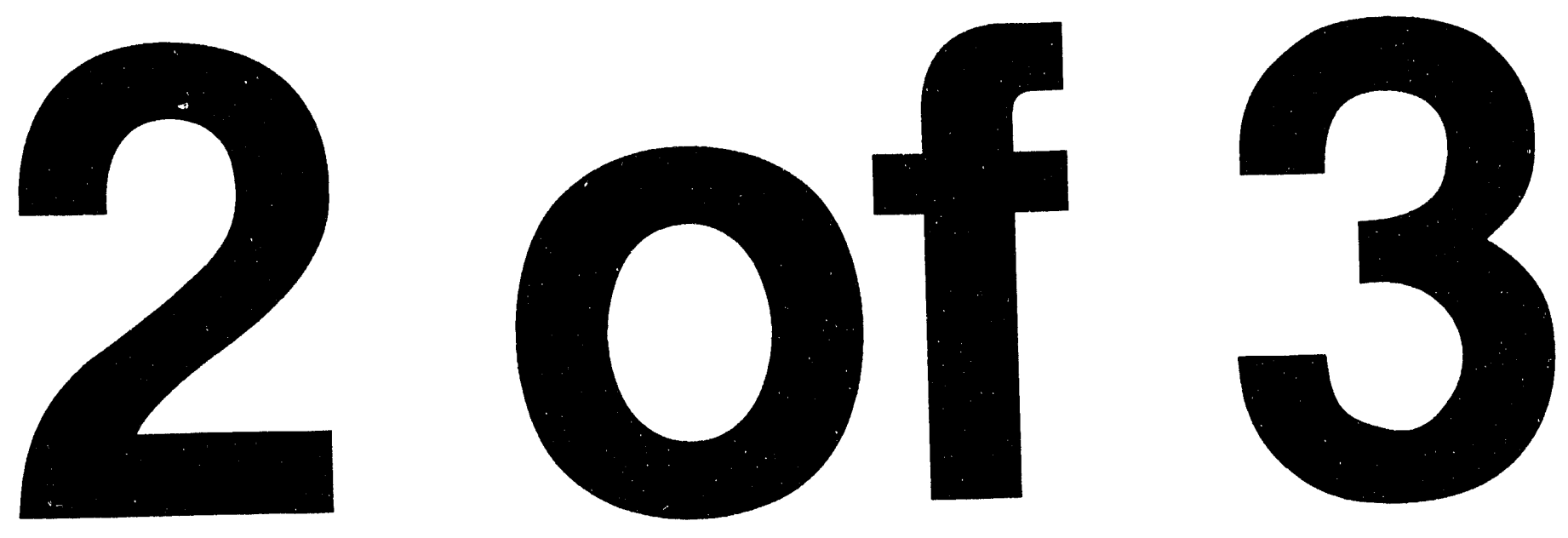
Table 4.12 SPCS Preliminary Instrumentation List

1) Inlet header pressure

2) Outlet header pressure

3) . Pump inlet pressure

4) Pump outlet pressure

5) Inlet header temperature

6) Source rod bundle outlet temperature (each bundle)

7) Outlet header temperature

8) Source primary heat exchanger primary inlet temperature

9) Source primary heat exchanger outlet primary temperature

10) Source flow rate

11) Pump power monitors

12) Pressurizer liquid level

13) Pressurizer gas temperature

14) Pressurizer gas pressure

15) Accumulator gas pressure

16) Accumulator gas temperature

17) Accumulator liquid level

18) Loop radiation monitor

19) Water in source side of basin 
Table 4.13 Source Requiring Protection Events versus Trip Matrix

\begin{tabular}{|c|c|c|c|c|c|c|}
\hline & \multicolumn{6}{|c|}{ MEASUREMENT } \\
\hline Events/Trips & PRESS & PUMP & FLOW & TEMP & SBLVL & PLVL \\
\hline 1) Large Break LOCA Inside Basin & PRI,SEC & & & & $\overline{\mathrm{FB}}$ & \\
\hline 2) Small Break LOCA Inside Basin & Sec & & & & $\mathrm{FB}$ & PRा \\
\hline 3) Large Break LOCA Outside Basin & PRI,SEC & & & & & \\
\hline 4) Smanl Break LOCA Outside Basin & SEC & & & & & PRI \\
\hline 5) LOFA, One Pump, Coastdown/Locked & & PRI & $\overline{\text { SEC }}$ & & & \\
\hline 6) LOFA, All SPCS Pumps Coastdown & & PRI & SEC & & & \\
\hline 7) Loss of Heat Sink & & & & PRI,SEC & & \\
\hline 8) Source Rod Bundle Blockage & & & & PRI & & \\
\hline 9) Loss of Offsite Power & & PRI & SEC & & & \\
\hline 10) Station Blackout & & PRI & SEC & & & \\
\hline
\end{tabular}

NOTES

1) SPCS PUMP TRIP WTTH SPCS LOCA.

2) SRPCS START ON HIGH SPCS TEMPERATURE.

3) DIESELS START ON LOSS OF OFFSITE POWER

\subsubsection{Source Secondary Cooling System (SSCS)}

\subsection{General Description}

The source secondary cooling system (SSCS) provides forced circulation of light water, $\mathrm{H}_{2} \mathrm{O}$, to remove the energy generated within the source assembly array from the SPCS heat exchanger and deliver this energy to the source circulating water system under all conditions when AC power is available. A passive cooling function is also provided through the source primary cooling system at the decay heat level. The energy is transported through natural circulation to the atmosphere by a natural draft water-to-air heat exchanger.

All component parts are designed to ensure a 40-year minimum life for the SSCS when operated at the temperature, pressure, and water chemistry conditions expected in the SSCS.

The SSCS consists of two independent loops, each serving one source primary cooling system heat exchanger and discharging the energy to the source circulating water system through the source secondary cooling system heat exchanger. Each loop removes approximately $50 \%$ of source generated energy and contains the necessary pump, heat exchanger, a natural draft waterto-air heat exchanger, connecting piping, a surge tank, and the associated instrumentation. The natural draft water-to-air heat exchanger is designed and arranged to promote natural circulation cooling of the source through the source primary cooling system and the source secondary cooling system. Either loop is designed to remove $100 \%$ of the decay heat and sensible stored energy, based on natural circulation and the normal pump coastdown for all events including the design basis events. 


\subsection{Pumps}

The source secondary cooling system pumps are normal centrifugal pumps designed to withstand the primary cooling system design pressure and are considered to be a part of the source secondary cooling system boundary thus they are safety related class 2 components.

\subsection{Heat Exchangers}

The source secondary cooling system heat exchangers have not been optimized, however, the following cooling water conditions can be met and are a reasonable compromise at this stage in the design.

Cold leg Temperature, ${ }^{\circ} \mathrm{C}(\mathrm{F})$

$38(100)$

Hot Leg Temperature, ${ }^{\circ} \mathrm{C}(\mathrm{F})$

$77(171)$

Secondary Coolant Loop Flow Rate, $\mathrm{kgm} / \mathrm{s}(\mathrm{lbm} / \mathrm{s})$

501(1106)

The cooling water is based on the source circulating water system conditions of:

Cold Leg Temperature, ${ }^{\circ} \mathrm{C}(\mathrm{F})$

29(84)

Hot Leg Temperature, ${ }^{\circ} \mathrm{C}(\mathrm{F})$

$49(120)$

\subsection{Natural Draft Water-to-Air Heat Exchanger}

A natural draft water-to-air heat exchanger is used in the source secondary system loop to remove the source assembly decay heat passively. Each heat exchanger is sized to remove $100 \%$ of the decay heat at 200 seconds with the source outlet temperature of $82^{\circ} \mathrm{C}\left(180^{\circ} \mathrm{F}\right)$, about $1.0 \mathrm{MWt}$. With both loops operational, the peak temperature will be much less. The water-toair heat exchangers are elevated above the primary and secondary heat exchangers. The piping to and from the water-to-air heat exchangers is arranged such that it contains no loop seals, and it promotes flow in the positive direction during normal forced operation of the source secondary system as it is parallel to the hot leg piping in the secondary loop.

\subsection{Surge Tank}

Each loop contains a surge tank that is designed such that a leak in the source primary heat exchanger will not cause a discharge to the environment. The design pressure of the source secondary cooling system is higher than that of the source primary cooling system. This allows the source primary cooling system relief valves relieve at a lower pressure than the set point for the source secondary cooling system relief valves. This assures that the source primary coolant will not be released to the environment if a source primary cooling system heat exchanger tube should fail. 


\subsubsection{Source Circulating Water System (SCWS)}

The source circulating water system provides the cooling to the source secondary cooling system heat exchangers. The source secondary cooling system has not been optimized, however, the following circulation water conditions were selected as reasonable and can be met:

Cold Leg Temperature, ${ }^{\circ} \mathrm{C}(\mathrm{F})$

Hot Leg Temperature, ${ }^{\circ} \mathrm{C}(\mathrm{F}) \quad \cdot \quad 49(120)$

Circulating Water Loop Flow Rate, $\mathrm{kg} / \mathrm{s}(\mathrm{lb} / \mathrm{s}) \quad$ 976(2152)

These conditions are based on using a cooling tower with a design wet bulb temperature of $25{ }^{\circ} \mathrm{C}(77 \mathrm{~F})$.

\subsubsection{Source Residual Primary Cooling System (SRPCS)}

The primary function of the source residual primary cooling system (SRPCS) is to remove energy from the lead source assemblies when the beam is shut down and to cool the source down for replacement when the source primary cooling system is not available for cooling either with normal operation or natural circulation. The SRPCS contains two loops each capable of providing $100 \%$, approximately $1 \mathrm{MWt}$, of the cooling of the lead source following an accident. Each loop contains $0.77 \mathrm{~m}^{3}\left(27 \mathrm{ft}^{3}\right)$ of $\mathrm{D}_{2} \mathrm{O}$. The loops are designed to be operable when the SPCS is depressurized. They are capable of cooling the lead source following a LOCA, thus the pump and heat exchanger are located low relative to the SPCS. Isolation valves are provided to isolate a loop should a break occur in that loop. These isolation valves are required to prevent the draining of the SPCS and the source array by siphoning of the water from them.

The hot leg of each loop is connected to the source outlet header, (refer to Figure 4.13). The pipe goes up where it exits the source basin, then to the pump which is located low to assure adequate NPSH when the system is depressurized and the source primary cooling system is partially drained to allow for maintenance of source primary cooling system comf onents. Each loop uses one canned motor (Figure 4.17), a $\mathrm{D}_{2} \mathrm{O}$ to $\mathrm{H}_{2} \mathrm{O}$ shell and tube heat exchanger (Figure 4.18 \& Table 4.14), isolation valves, and instrumentation with the redundancy required for a safety related system. The canned motor, vertical, bottom suction, side discharge, single stage, mixed-flow pump is designed to circulate about $9.51 / \mathrm{s}(150 \mathrm{gpm})$ each. Outside of the isolation valves, the system is safety class 2 . Inside the valves and including the valves the system is designed to safety class 1 . The pumps and valves can be operated with offsite power or onsite emergency power. 
Table 4.14 SILC Source Residual Primary Cooling System Heat

Data

Shellside

Tubeside

Fluid

Total Flow Rate, $\mathrm{kg} / \mathrm{s}$

$\mathrm{H}_{2} \mathrm{O}$

Inlet Temperature, ${ }^{\circ} \mathrm{C}$

14.34

49

Outlet Temperature, ${ }^{\circ} \mathrm{C}$

66

14.35

82

66

Heat Exchanger Pressure Drop, MPa

0.0282

0.0994

Film Resistance, $\mathrm{m}^{2}-{ }^{\circ} \mathrm{C} / \mathrm{w}$

$1.618 \mathrm{E}-4$

6.664E-5

Fouling Resistance, $\mathrm{m}^{2}-{ }^{\circ} \mathrm{C} / \mathrm{w}$

$5.841 \mathrm{E}-5$

$1.770 \mathrm{E}-5$

Overall Heat Transfer Coefficient, $w / \mathrm{m}^{2}-^{\circ} \mathrm{C}$

- Required

2220

- Clean

- Estimated Under Actual Conditions

2431

Tube

- Number

124

- Diameter, mm

12.7

- Thiclness, mm

- Length, mm

5578

- Total Area (OD), $\mathrm{m}^{2}$

27.69

\subsubsection{Source Residual Secondary Cooling System (SRSCS)}

The source residual secondary cooling system uses two trains. One train serves each source residual primary heat exchanger. The system is designed to remove about $1 \mathrm{MWt}$ from the SRPCS heat exchangers when the source primary hot leg temperatures are about $82^{\circ} \mathrm{C}\left(180^{\circ} \mathrm{F}\right)$ and return the water to the source at about $66^{\circ} \mathrm{C}\left(150^{\circ} \mathrm{F}\right)$. Each train contains an air blast waterto-air heat exchanger, a surg- tank, a pump, and the required instrumentation. The air blast water-to-air heat exchanger is designed to remove $1 \mathrm{MWt}$ from the SRPCS heat exchanger when the air temperature is $38^{\circ} \mathrm{C}\left(100^{\circ} \mathrm{F}\right)$. The hot leg temperature is expected to be $66^{\circ} \mathrm{C}\left(150^{\circ} \mathrm{F}\right)$ and the cold leg is expected to be $49^{\circ} \mathrm{C}\left(120^{\circ} \mathrm{F}\right)$. The pumps, fans, and isolation valves can be operated using either offsite power or onsite emergency power.

\subsubsection{Blanket Cooling Systems (BCS)}

The blanket cooling systems consist of those systems that remove and transport the blanket assembly generated energy to the ultimate heat sink, (refer to Figure 4.14). It is composed of the following five systems: the blanket primary cooling system (BPCS), the blanket secondary cooling system (BSCS), the blanket circulating water system (BCWS), the blanket residual primary cooling system (BRPCS), and the blanket residual secondary cooling system 
(BRSCS). All of the systems contain two loops. The main cooling systems contain two $50 \%$ loops for normal operation where both loops are required to function. The loss of any one loop in the BPCS, BSCS or BCWS will result in an accelerator trip. All of the residual decay heat loops include two $100 \%$ loops and this includes the passive cooling capability included in the blanket primary and the blanket secondary cooling systems through to the natural draft water-toair heat exchanger. Thus the decay heat removal trains are redundant. The function, system and safety requirements are provided for these systems in the requirements document, Appendix 4A, and the ability to meet these are described below.

\subsubsection{Blanket Primary Cooling System (BPCS)}

\subsection{General Description}

The blanket primary cooling system (BPCS) provides forced circulation of the blanket coolant, $\mathrm{H}_{2} \mathrm{O}$, to remove the energy generated within the blanket assembly array and deliver this energy to the blanket secondary cooling system under all conditions when AC power is available except for the case when the system is depressurized. The BPCS contains $17.7 \mathrm{~m}^{3}\left(625 \mathrm{ft}^{3}\right)$ of $\mathrm{H}_{2} \mathrm{O}$. When the system is depressurized the beam must be shut down and the cooling transferred to either the passive system or the blanket residual primary cooling system. The blanket passive cooling function is provided through the natural circulation of the blanket primary and secondary cooling system at the decay heat level. Again the energy is transported to the BSCS which is also naturally circulating through to the natural draft water-to-air heat exchanger.

All component parts in contact with the blanket coolant are fabricated from highly corrosion resistant materials designed to ensure a 40-year minimum life for the BPCS when operated at the temperature, pressure, and water chemistry conditions expected in the BPCS.

The BPCS consists of two loops witil each loop connected in parallel to the blanket inlet headers at the top and bottom of each row of blanket assemblies, (refer to Figure 4.14). Each loop removes approximately $50 \%$ of source generated energy, about $13 \mathrm{MWt}$. Each loop contains one pump, one heat exchanger, connecting piping, one pressurizer or one accumulator, and the associated instrumentation to meet the required single failure and redundancy criteria.

The blanket coolant pumps are vertical units designed to circulate about $284 \mathrm{l} / \mathrm{s}$ (4500 gpm) each. These pumps are expected to have a flywheel unit attached to the motor shaft to extend the flow coastdown of the system to at least 45 seconds, allowing the system to coastdown to natural circulation in the event of a station blackout. The two BPCS heat exchangers are horizontal, two-pass, straight tube and shell design with the blanket coolant, $\mathrm{H}_{2} \mathrm{O}$, on the tube side.

The pressurizer is gas charged and the surge line serves as a return line for one loop of the blanket residual primary cooling system (BRPCS). The function of the pressurizer is to maintain the BPCS and the BRPCS in a subcooled state providing the required NPSH for the circulating pumps and to provide makeup in the event of a BPCS loss-of-coolant accident 
(LOCA). Two code safety valves will be used on the pressurizer. The pressurizer is designed to allow its operation in a manner that will not inject any of the charge gas into the system in the event of a LOCA. One accumulator is provided to supply additional makeup in the event of a LOCA. The accumulator contains a parallel redundant set of check and stop valves in the surge line. It is also gas charged and designed for operation such that the gas will not be injected into the blanket primary cooling system should a LOCA occur. The surge line for the accumulator down stream of the check valves serves as the return line for the second loop of the BRPCS.

\subsection{Pumps}

Forced flow, $2841 / \mathrm{s}(4500 \mathrm{gpm})$, through each of the BPCS loops is provided by a vertical, single-stage, single-suction, mixed flow pump (refer to Figure 4.17 for a sketch of the pump). The bottom suction nozzle delivers the $\mathrm{H}_{2} \mathrm{O}$ to the eye of the impeller, and the impeller discharges the $\mathrm{H}_{2} \mathrm{O}$ radially to the diffuser that delivers it to the tangential outlet nozzle. The pump nozzles are butt welded to the BPCS hot leg piping. An inertial unit is attached to the motor, sized to provide a 45 second coast down when power is lost to both BPCS pumps. The pump bearings are water lubricated and cooled. A heat exchanger may be needed to remove much of the energy deposited in the motor and inertial assembly bearings. The pumps were scaled from previous vendor quotes and are considered to be adequate for this pre-conceptual design stage.

\subsection{Heat Exchangers}

The BPCS heat exchangers were sized using the Heat Transfer Research, Inc. heat exchanger software. The general characteristics are provided in Figure 4.18 and Table 4.15. The two SPCS heat exchangers are horizontal, two-pass, straight tube and shell design with the blanket coolant, $\mathrm{H}_{2} \mathrm{O}$, on the tube side. Entrance and exit annuli are provided on the shell side to distribute the coolant flow evenly to the heat exchanger and to eliminate high velocity fluid impingement on the outside of the tubes. Margin was added to the heat transfer surface to allow for surface fouling, tube plugging and conceptual design uncertainties. It is further expected as the conceptual design evolves, the heat load may change slightly and the optimization studies to incorporate the blanket circulating water system (BCWS) and the BSCS will make minor changes in the heat transfer surface, however, are believed to be adequately sized for the pre-conceptual study. 
Table 4.15 SILC Blanket Primary Cooling System Heat Exchanger

Data

Fluid

Total Flow Rate, $\mathrm{kg} / \mathrm{s}$

Inlet Temperature, ${ }^{\circ} \mathrm{C}$

Outlet Temperature, ${ }^{\circ} \mathrm{C}$

Heat Exchanger Pressure Drop, MPa

Film Resistance, $\mathrm{m}^{2}-{ }^{\circ} \mathrm{C} / \mathrm{w}$

Fouling Resistance, $\mathrm{m}^{2}-{ }^{\circ} \mathrm{C} / \mathrm{w}$

Overall Heat Transfer Coefficient, $w / \mathrm{m}^{2}-^{\circ} \mathrm{C}$

- Required

- Clean

- Estimated Under Actual Conditions

Tube

- Number

- Diameter, mm

- Thickness, mm

- Length, mm

- Total Area (OD), $\mathrm{m}^{2}$
Shellside

$\mathrm{H}_{2} \mathrm{O}$

80 .

38

77

0.0109

$1.878 \mathrm{E}-4$

$5.841 \mathrm{E}-5$

2190

3027

2434

1254

12.7

3810

190.6
Tubeside

$\mathrm{H}_{2} \mathrm{O}$

186

99

82

0.1216

4.62E-5

$1.770 \mathrm{E}-5$

\subsection{Pressurizer and Accumulator}

The BPCS contains one pressurizer that is helium charged to maintain the BPCS in a subcooled state. Helium fills the space above the $\mathrm{H}_{2} \mathrm{O}$ and is at the pressure, approximately 1.03 $\mathrm{MPa}$ (150 psia), required to maintain the source outlet header at $0.97 \mathrm{MPA}$ (140 psia) when the BPCS system pumps are operating at their expected conditions (refer to Figure 4.19). The pressure was selected based on the pin heat fluxes in the lithium-aluminum assemblies, their uncertainty, and the required margin to the critical heat flux. The pressurizer contains a power actuated relief valve, two code safety valves, and a relief isolation valve. The pressurizer controls are based on the maintenance of a constant gas inventory. The only reason for cover gas makeup is losses due to solubility in water or losses due to leakage such as through a valve. The gas inventory maintained is not sufficient to inject gas into the system should the system depressurize, as it would with a LOCA. The pressurizer is $6.1 \mathrm{~m} \mathrm{(20} \mathrm{ft)} \mathrm{tall} \mathrm{and} 0.91 \mathrm{~m} \mathrm{(36}$ inches) in diameter with $2: 1$ elliptical heads. At the design operating temperatures, the pressurizer contains, $3.09 \mathrm{~m}^{3}\left(109 \mathrm{ft}^{3}\right)$ of $\mathrm{H}_{2} \mathrm{O}$ and $326 \mathrm{l}\left(11.5 \mathrm{ft}^{3}\right)$ helium cover gas resulting in a normal water level of $0.64 \mathrm{~m}(2.1 \mathrm{ft})$ down from the top.

The accumulator is the same dimensions as the pressurizer but will be operated at a gas pressure $0.10 \mathrm{MPa}$ (15 psi) below that in the pressurizer, thus the gas volume will increase to about $3681\left(13 \mathrm{ft}^{3}\right)$. The accumulator operates with the same gas inventory as the pressurizer 
(They have the same total volume) to prevent injection of gas into the blanket primary coolant system should the system depressurize.

The instrumentation included for the pressurizer and accumulator include water level, cover gas pressure and cover gas temperature, to allow an evaluation of the gas inventory.

\subsection{Piping and Valves.}

The BPCS piping is seamless $150 \mathrm{~mm}$ ( 6 inch) Schedule 40 nominal, 316 stainless steel piping (refer to Figure 4.20). The maximum allowable design velocity limit is $15.2 \mathrm{~m} / \mathrm{s}$ (50 $\mathrm{ft} / \mathrm{sec})$, therefore the $150 \mathrm{~mm}$ (6 inch) pipe which yields a velocity in the hot leg of approximately $10.4 \mathrm{~m} / \mathrm{s}(34 \mathrm{ft} / \mathrm{sec})$ has sufficient margin.

\subsection{Instrumentation}

At this pre-conceptual design stage, the information needed for operation and protection has not been adequately investigated, and the parameters needed may change as the operational and safety analyses are completed. Table 4.16 is a list of those parameters that are expected to be measured in the BPCS. Table 4.17 is a list of those parameters that are expected to be used in the protection system for the various types of transients, AOOs and DBEs that require the accelerator to be tripped. Although it may be desirable to include parameters from the blanket secondary and blanket circulating water systems to provide anticipatory signals, they are not expected to be necessary. An outlet temperature from each blanket assembly is included for information purposes only, because it is expected that the blanket bundles would cool by top flooding should a blockage occur in the inlet of an assembly. 
Table 4.16 BPCS Preliminary Instrumentation List

1) Inlet header pressure

2) Outlet header pressure

3) Pump inlet pressure • .

4) Pump outlet pressure

5) Inlet header temperature

6) Blanket rod bundle outlet temperature (each bundle)

7) Outlet header temperature

8) Blanket primary heat exchanger primary inlet temperature

9) Blanket primary heat exchanger outlet primary temperature

10) Blanket flow rate

11) Pump power monitors

12) Pressurizer liquid level

13) Pressurizer gas temperature

14) Pressurizer gas pressure

15) Accumulator gas pressure

16) Accumulator gas temperature

17) Accumulator liquid level

18) Loop radiation monitor

19) Water in source side of basin (Same monitor as indicated for source) 
Table 4.17 Blanket Events Requiring Protection versus Trip Matrix

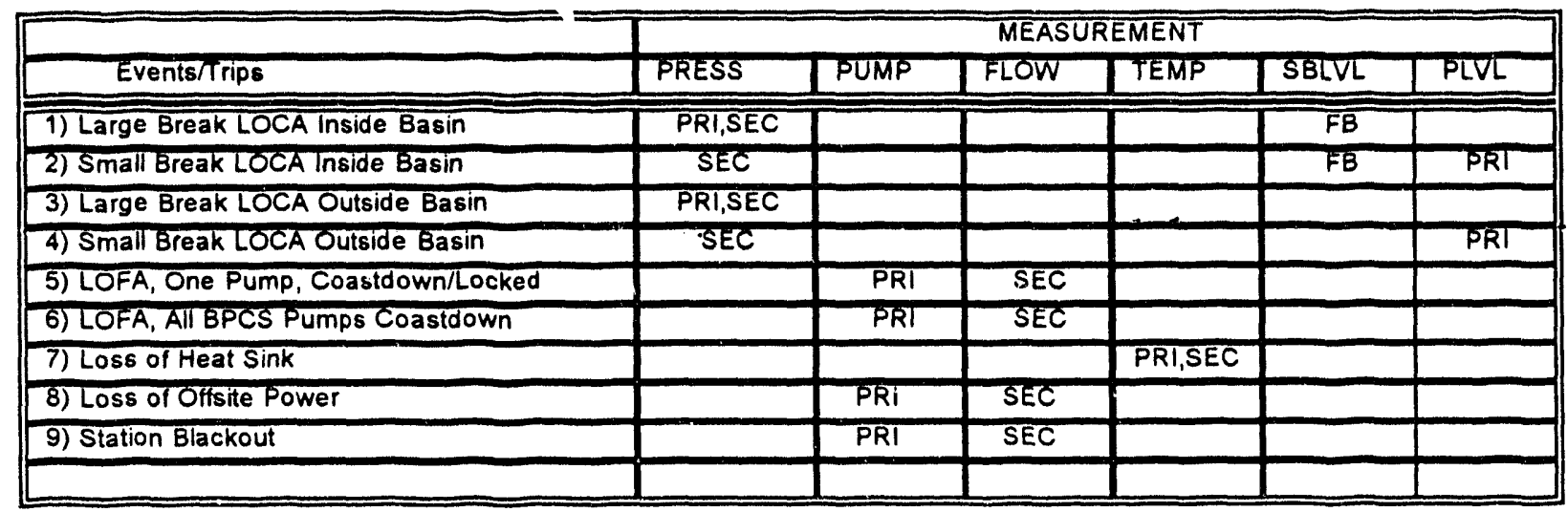

NOTES

1) BPCS PUMP TRIP WITH BPCS LOCA.

2) BRPCS START ON HIGH BPCS TEMPERATURE.

3) DIESELS START ON LOSS OF OFFSITE POWER.

\subsubsection{Blanket Secondary Cooling System (BSCS)}

\subsection{General Description}

The blanket secondary cooling system (BSCS) provides forced circulation of light water, $\mathrm{H}_{2} \mathrm{O}$, to remove the energy generated within the blanket assembly array from the BPCS heat exchanger and deliver this energy to the blanket circulating water system (BCWS) under all conditions when AC power is available. The passive cooling function is provided through the blanket primary cooling system at the decay heat level. The energy is transported through natural circulation to the atmosphere by a natural draft water-to-air heat exchanger. All component parts are designed to ensure a 40-year minimum life for the BSCS when operated at the temperature, pressure, and water chemistry conditions expected in the BSCS.

The BSCS uses two independent loops each serving one blanket primary cooling system heat exchanger and discharging the energy to the blanket circulating water system through one secondary heat exchanger. Each loop removes approximately $50 \%$ of blanket generated energy, and contains one pump, one main heat exchanger, one natural draft water-to-air heat exchanger, connecting piping, one surge tank, and the associated instrumentation. The natural draft waterto-air heat exchanger is designed and arranged to promote natural circulation cooling of the blanket through the blanket primary cooling system. Either loop is designed to remove $100 \%$ of the decay heat and sensible stored energy, based on natural circulation and the normal pump coastdown for all events including the design basis events. 


\subsection{Pumps}

The blanket secondary cooling system pumps are normal centrifugal pumps designed to withstand the blanket primary cooling system design pressure as a part of the pressure boundary. As a part of the pressure boundary they are a safety class 2 component.

\subsection{Heat Exchangers}

The blanket secondary cooling system heat exchangers have not been optimized, however, the following cooling water conditions are reasonable and can be met:

Cold leg Temperature, ${ }^{\circ} \mathrm{C}(\mathrm{F})$

Hot Leg Temperature, ${ }^{\circ} \mathrm{C}(\mathrm{F})$

Secondary Coolant Loop Flow Rate, $\mathrm{kgm} / \mathrm{s}(\mathrm{lbm} / \mathrm{s})$
$38(100)$

$77(170)$

80(176.4)

The cooling water is based on the blanket circulating water system conditions of:

Cold Leg Temperature, ${ }^{\circ} \mathrm{C}(\mathrm{F})$

Hot Leg Temperature, ${ }^{\circ} \mathrm{C}(\mathrm{F})$
29(84)

$49(120)$

\subsection{Surge Tank}

Each blanket secondary coo'ing system loop contains a surge tank that is designed such that a leak in the blanket primary cooling system heat exchanger will not cause a discharge of blanket primary cooling system coolant to the environment. The design pressure of the blanket secondary cooling system is higher than that of the blanket primary cooling system. This allows the blanket primary cooling system relief valves to relieve water before the set point for the blanket secondary valves. This assures that the blanket primary cooling system coolant will not be released to the environment if a blanket primary heat exchanger tube should fail.

\subsection{Natural Draft Water-to-Air Heat Exchanger}

A natural draft water-to-air heat exchanger is used in the blanket secondary cooling system loop to remove the blanket assembly decay heat passively. Each heat exchanger is sized to remove $100 \%$ of the decay heat at 200 seconds with the blanket outlet temperature of $82^{\circ} \mathrm{C}$ $\left(180^{\circ} \mathrm{F}\right)$, about $200 \mathrm{KWt}$. With both loops operational, the peak temperature will be much less. The water-to-air heat exchangers are elevared above the blanket primary and secondary cooling systems heat exchangers. The piping to and from the water-to-air heat exchangers is arranged such that it contains no loop seals, and it promotes flow in the positive direction during normal forced operation of the source secondary cooling system as it is parallel to the hot leg piping in the BSCS loop. 


\subsubsection{Blanket Circulating Water System (SCWS)}

The blanket circulating water system provides the cooling to the blanket secondary cooling system heat exchangers. The blanket secondary cooling system has not been optimized, the following circulation water conditions were selected as reasonable and can be met:

Cold Leg Temperature, ${ }^{\circ} \mathrm{C}(\mathrm{F})$

Hot Leg Temperature, ${ }^{\circ} \mathrm{C}(\mathrm{F})$

Circulating Water Loop Flow Rate, $\mathrm{kgm} / \mathrm{s}(\mathrm{lbm} / \mathrm{s})$
29(84)

$49(120)$

$156(344)$

These conditions are based on using a cooling tower with a design wet bulb temperature of $25{ }^{\circ} \mathrm{C}(77 \mathrm{~F})$.

\subsubsection{Blanket Residual Primary Cooling System (SRPCS)}

The primary function of the blanket residual primary cooling system (BRPCS) is to remove energy from the lithium-aluminum assemblies when the beam is shut down, to cool the system down for replacement or repairing when the blanket primary system is not available for cooling either normal operation or natural circulation. The BRPCS contains $0.71 \mathrm{~m}^{3}\left(25 \mathrm{ft}^{3}\right)$ of $\mathrm{H}_{2} \mathrm{O}$. The BRPCS contains two loops each capable of providing $100 \%$ of the cooling of the lithium-aluminum target assemblies following an accident, about $200 \mathrm{KWt}$. The loop is designed to be operable when the BPCS is depressurized, as it is capable of cooling the lithium-aluminum assemblies following a LOCA.

The hot leg of each loop is connected to the lithium-aluminum outlet header, (refer to Figure 4.14). The hot leg goes up to where it exits the source basin, then from the basin nozzle to the pump (Figure 4.17). The pump is located low to assure adequate NPSH is available when the system is depressurized and the blanket primary cooling system partially drained to allow for maintenance of blanket primary cooling system components. Each loop uses one single stage pump designed to circulate about $5.4 \mathrm{l} / \mathrm{s}(85 \mathrm{gpm})$ each. The heat exchanger, (refer to Figure 4.18 and Table 4.18), operates to cool the blanket water at $82^{\circ} \mathrm{C}\left(180^{\circ} \mathrm{F}\right)$ in the hot leg to $66^{\circ} \mathrm{C}$ $\left(150^{\circ} \mathrm{F}\right)$ in the cold leg in a single pass through the shell and tube heat exchanger.

\subsubsection{Blanket Residual Secondary Cooling System (BRSCS)}

The blanket residual secondary cooling system uses two trains. One train serves each blanket residual primary heat exchanger. The system is designed to remove about $200 \mathrm{KWt}$ from the BRPCS heat exchangers when the blanket primary hot leg temperatures are about $82^{\circ} \mathrm{C}$ $\left(180^{\circ} \mathrm{F}\right)$ and return the water to the blanket at about $66^{\circ} \mathrm{C}\left(150^{\circ} \mathrm{F}\right)$. Each train contains an air blast water-to-air heat exchanger, a surge tank, a pump, and the required instrumentation. The air blast water-to-air heat exchanger is designed to remove $200 \mathrm{KWt}$ from the BRPCS heat exchanger when the air temperature is $38^{\circ} \mathrm{C}\left(100^{\circ} \mathrm{F}\right)$. The hot leg temperature is expected to be $66^{\circ} \mathrm{C}\left(150^{\circ} \mathrm{F}\right)$ and the cold leg is expected to be $49^{\circ} \mathrm{C}\left(120^{\circ} \mathrm{F}\right)$ in the BRSCS. The pumps, fans, and isolation valves can be operated using either offsite power or onsite emergency power. 
Table 4.18 SILC Blanket Residual Primary Cooling System Heat Exchanger

Data

Fluid

Total Flow Rate, $\mathrm{kg} / \mathrm{s}$

Inlet Temperature, ${ }^{\circ} \mathrm{C}$

Outlet Temperature, ${ }^{\circ} \mathrm{C}$

Heat Exchanger Pressure Drop, MPa

Film Resistance, $\mathrm{m}^{2}-{ }^{\circ} \mathrm{C} / \mathrm{w}$

Fouling Resistance, $\mathrm{m}^{2}-{ }^{\circ} \mathrm{C} / \mathrm{w}$

Overall Heat Transfer Coefficient, $w / \mathrm{m}^{2}{ }^{\circ} \mathrm{C}$

- Required

- Clean

Tube

- Estimated for Actual Conditions

- Number

- Diameter, mm

- Thickness, mm

- Length, mm

- Total Area (OD), $\mathrm{m}^{2}$
Shellside

$\mathrm{H}_{2} \mathrm{O}$

1.689

49

66

0.0120

$3.276 \mathrm{E}-4$

5.841E-5
Tubeside

$\mathrm{H}_{2} \mathrm{O}$

1.688

82

66

0.0348

$1.027 \mathrm{E}-4$

$1.770 \mathrm{E}-5$
1485

1846

1608

28

12.7

4420

5.02

\subsubsection{Window and Expander Cooling Systems $(W C S)^{2}$}

The window cooling systems are made up of those systems that remove and transport the accelerator window assembly generated energy to the ultimate heat sink, (refer to Figure 4.15). It is composed of the following three systems: window primary cooling system (WPCS), the window secondary cooling system (WSCS) and the window circulating water system (WCWS). All of the systems contain two loops. Each loop provides 50\% of the window cooling and one of the loops provides additional cooling for the expander tube assembly. Both systems are required to function, i.e., the loss of either loop in the cooling trains to the environment will result in an accelerator trip. Since the residual decay heat is very low, (see Figure 4.21), the passive cooling capability provided by the window primary and the window secondary cooling systems to their surroundings was considered to be adequate for residual decay heat cooling. The ability of these systems to meet the functions and safety requirements are outlined in the following subsections.

\footnotetext{
${ }^{2}$ The cooling flow rates and temperatures, given here, differ slightly from those of Section 4.2 .3 , since recent revisions included there have not yet been incorporated here.
} 


\subsubsection{Window Primary Cooling System (WPCS)}

\subsection{General Description}

The window primary cooling system (WPCS) provides forced circulation of the window coolant, $\mathrm{H}_{2} \mathrm{O}$, to remove the energy generated within the window and expander tube assembly and deliver this energy to the window secondary cooling system under all conditions when AC power is available except for the case when either loop of the system is depressurized. The WPCS contains $0.66 \mathrm{~m}^{3}\left(23 \mathrm{ft}^{3}\right)$ of $\mathrm{H}_{2} \mathrm{O}$. When a loop is depressurized the beam must be shut down. The passive cooling function, about $24 \mathrm{KWt}$, is provided through the natural circulation of the window primary cooling system at the decay heat level. Again, some of the energy is transported to the WSCS which is also naturally circulating and to the building environment. All component parts in contact with the window coolant are fabricated from highly corrosion resistant materials designed to ensure a 40-year minimum life for the WPCS when operated at the temperature, pressure, and water chemistry conditions expected in the WPCS.

The WPCS consists of two independent loops with each loop connected in parallel to the window and expansion tube assembly at the top and bottom of these assemblies, (refer to Figure 4.15). Each loop removes approximately $50 \%$ of window generated energy, about 0.5 $\mathrm{MWt}$, and contains one pump, one heat exchanger, one pressurizer, connecting piping, and the associated instrumentation to meet the required single failure and redundancy criteria. The pumps are expected to have a flywheel associated with the motor to extend the flow coastdown of the system to at least 45 seconds, allowing the system to coastdown to natural circulation in the event of a loss of offsite power or a station blackout. The two WPCS heat exchangers are horizontal, one-pass, straight tube and shell design with the window coolant on the tube side. The pressurizers are gas charged. The function of the pressurizer is to maintain each WPCS loop in a subcooled state providing the required NPSH for the circulating pump and to provide makeup in the event of a WPCS loss-of-coolant accident (LOCA). Two code safety valves will be used on the pressurizer. The pressurizer is designed to allow its operation in a manner that will not inject any of the charge gas into the system in the event of a LOCA. The two loops are independent thus they do not share a common coolant, and each loop cools every other channel in the window. Even though the window may exceed the normal design limit if the accelerator is not tripped, the window is not expected to fail if one of the two cooling loops fails.

\subsection{Pumps}

Forced flow through each of the WPCS loops is provided by a single-stage, singlesuction, centrifugal flow pump (refer to Figure 4.17 for a sketch of the pump). The suction nozzle delivers the $\mathrm{H}_{2} \mathrm{O}$ to the eye of the impeller, and the impeller radially the $\mathrm{H}_{2} \mathrm{O}$ radially to the diffuser that delivers it to the tangential outlet nozzle. Thie pump nozzles are butt welded to the WPCS hot leg piping. An inertial unit is provided, sized to provide a 45 second coast down when power is lost to a WPCS pumps. The pumps were scaled from previous vendor quotes and are considered to be adequate for this pre-conceptual design stage. 


\subsection{Heat Exchangers}

The WPCS heat exchangers were sized using the Heat Transfer Research, Inc. heat exchanger software. The general characteristics are provided in Figure 4.18 and Table 4.19. The two WPCS heat exchangers are horizontal, single-pass, straight tube and shell design with the window coolant on the tube side. Margin was added to the heat transfer surface to allow for surface fouling, tube plugging, and conceptual design uncertainties. It is further expected, as the conceptual design evolves, the heat load may change slightly. Optimization studies incorporating the window circulating water system (WCWS) and the WSCS also will generate minor changes. However, it is believed that the heat exchangers are adequately sized for the pre-conceptual design study.

Table 4.19 SILC Window Primary Cooling System Heat Exchanger

Data

Fluid

Total Flow Rate, $\mathrm{kg} / \mathrm{s}$

Inlet Temperature, ${ }^{\circ} \mathrm{C}$

Outlet Temperature, ${ }^{\circ} \mathrm{C}$

Heat Exchanger Pressure Drop, MPa

Film Resistance, $\mathrm{m}^{2}-{ }^{\circ} \mathrm{C} / \mathrm{w}$

Fouling Resistance, $\mathrm{m}^{2}-{ }^{\circ} \mathrm{C} / \mathrm{w}$

Overall Heat Transfer Coefficient, $w / \mathrm{m}^{2}-{ }^{\circ} \mathrm{C}$

- Required

- Clean

Tube

- Estimated for Actual Conditions

- Number

- Diameter, mm

- Thickness, mm

- Length, mm

- Total Area (OD), $\mathrm{m}^{2}$
Shellside

$\mathrm{H}_{2} \mathrm{O}$

9.768

38

50

0.0336

$1.51 \mathrm{E}-4$

$5.841 \mathrm{E}-5$
Tubeside

$\mathrm{H}_{2} \mathrm{O}$

6.323

80

61

0.0559

7.32E-5

$1.770 \mathrm{E}-5$

2224

3044

2445

66

12.7

1.245

3261

8.64

\subsection{Pressurizers}

The WPCS contains two pressurizers, one for each loop, that are helium charged to maintain the WPCS loops in a subcooled state, Helium fills the space above the $\mathrm{H}_{2} \mathrm{O}$ and is at the pressure, about $0.32 \mathrm{MPa}$ (47 psia), required to maintain the window outlet header at 0.28 MPa (40 psia) when the SILC system is operating at the design conditions (refer to Figure 4.19). The pressure was selected based on the window coolant channel heat fluxes, their uncertainty, 
and the margin required to the critical heat fluxes in the coolant channel. Each pressurizer contains a power actuated relief valve, two code safety valves, and a relief isolation valve. The pressurizer controls are based on the maintenance of a constant gas inventory. The gas inventory is not sufficient to inject gas into the system should the system depressurize as it may with a LOCA if the gas inventory were not controlled at a constant value. The pressurizer is $4.9 \mathrm{~m}$ (16 $\mathrm{ft}$ ) tall and $0.14 \mathrm{~m}$ (5.5 inches) in diameter with 2:1 elliptical heads. At the design operating temperatures, the pressurizer contains about $28 \mathrm{l}\left(1 \mathrm{ft}^{3}\right)$ of $\mathrm{H}_{2} \mathrm{O}$ and $171\left(0.6 \mathrm{ft}^{3}\right)$ helium cover gas, resulting in a normal water level of $3.4 \mathrm{~m}(11 \mathrm{ft})$.

The second pressurizer may be somewhat larger to accommodate the impact of the added water inventory required for the expansion tube assembly cooling. Cooling for the expansion tube assembly is not split between the two independent cooling loops.

The instrumentation included for the pressurizers include water level, cover gas pressure and cover gas temperature, to allow evaluation of the gas inventory.

\subsection{Piping and Valves}

The WPCS piping is seamless $50 \mathrm{~mm}$ ( 2 inch) Schedule 40 nominal, 316 stainless steel piping (refer to Figure 4.20). The maximum allowable design velocity is $15.2 \mathrm{~m} / \mathrm{s}(50 \mathrm{ft} / \mathrm{sec}$ ). However, the velocity in the $50 \mathrm{~mm}(2 \mathrm{inch})$ pipe is about $3.0 \mathrm{~m} / \mathrm{s}(10 \mathrm{ft} / \mathrm{sec})$, thus allowing sufficient margin.

\subsection{Instrumentation}

At this pre-conceptual design stage the information needed for operation and protection has not been adequately investigated, and the parameters needed may change as the operational and safety analyses are completed. Table 4.20 is a list of those parameters that are expected to be measured. Table 4.21 is a list of those parameters that are expected to be used in the protection system for the various types of transients. Although it may be desirable to include parameters from the window secondary cooling system and the window circulating system to provide anticipatory signals, they are not expected to be necessary.

\subsubsection{Window Secondary Cooling System (WSCS)}

The window secondary cooling system have not been optimized, the following cooling water conditions can be met and are a reasonable compromise at the pre-conceptual stage in the design.

Cold leg Temperature, ${ }^{\circ} \mathrm{C}(\mathrm{F})$

Hot Leg Temperature, ${ }^{\circ} \mathrm{C}(\mathrm{F})$

Secondary Coolant Flow Rate, $\mathrm{kg} / \mathrm{s}(\mathrm{lb} / \mathrm{s})$
$38(100)$

$50(122)$

9.8(21.6) 
The cooling water is based on the window circulating water system conditions of:

Cold Leg Temperature, ${ }^{\circ} \mathrm{C}(\mathrm{F})$

Hot Leg Temperature, ${ }^{\circ} \mathrm{C}(\mathrm{F})$
29(84)

$49(120)$

Table 4.20 WPCS Preliminary Instrumentation List

1) Inlet header pressure

2) Outlet header pressure

3) Pump inlet pressure

4) Pump outlet pressure

5) Inlet header temperature

7) Outlet header temperature

8) Window primary heat exchanger primary inlet temperature

9) Window primary heat exchanger primary outlet temperature

10) Loop flow rates

11) Pump power monitors

12) Pressurizer liquid level

13) Pressurizer gas temperature

14) Pressurizer gas pressure

18) Loop radiation monitor

19) Water in source side of basin (Same monitor as indicated for source) 
Table 4.21 Window Events Requiring Protection versus Trip Matrix

\begin{tabular}{||l|l|l|l|l|l|l|}
\hline \multicolumn{1}{|c|}{ Events/Trips } & MEASUREMENT & \\
\hline \hline 1) Large Break LOCA Inside Basin & PRESS & PUMP & FLOW & TEMP & SBLVL & PLVL \\
\hline 2) Small Break LOCA Inside Basin & PRI,SEC & & & & FB & \\
\hline 3) Large Break LOCA Outside Basin & SEC & & & & FB & PRI \\
\hline 4) Small Break LOCA Outside Basin & PRI,SEC & & & & & \\
\hline 5) LOFA, One PUmp, Coastdown/Locked & SEC & & & & & PRI \\
\hline 6) LOFA, All WPCS Pumps Coastdown & & PRI & SEC & & & \\
\hline 7) Loss of Heat Sink & & PRI & SEC & & & \\
\hline 8) Loss of Offitite Power & & & & PRI,SEC & & \\
\hline 9) Station Blackout & & PRI & SEC & & & \\
\hline
\end{tabular}

NOTES

1) WPCS PUMP TRIP WITH WPCS LOCA.

2) DIESELS START ON LOSS OF OFFSITE POWER.

\subsubsection{Window Circulating Water System (WCWS)}

The window circulating water system provides the cooling to the window secondary cooling system heat exchangers. The window circulating water system has not been optimized, however, the following circulation water conditions were selected as reasonable and can be met:

Cold Leg Temperature, ${ }^{\circ} \mathrm{C}(\mathrm{F})$

Hot Leg Temperature, ${ }^{\circ} \mathrm{C}(\mathrm{F})$

Circulating Water Flow Rate, $\mathrm{kgm} / \mathrm{s}(\mathrm{lbm} / \mathrm{s})$
29(84)

$49(120)$

$6(13.2)$

These conditions are based on using a cooling iower with a design wet bulb temperature of $25^{\circ} \mathrm{C}(77 \mathrm{~F})$.

\subsubsection{Source Basin Flood System (SBFS)}

The source basin flood system is designed to support the cooling of the source and blanket in the event of a LOCA in either the source or blanket primary coolant systems inside the source side of the basin. A line diagram is provided in Figure 4.16. The system was recently added to provide assurances that a break in any primary cooling system inside the source side of the basin would not result in loss of cooling for that cooling system. The system as shown, is sized to flood the source side of the basin in about 90 seconds following a signal for a basin source side LOCA when both trains of the source basin flood system are open. The storage tank contains $77 \mathrm{~m}^{3}\left(2720 \mathrm{ft}^{3}\right)$ of water. For redundancy, a third pipe train may be added between the tank and the basin. The storage tank contains enough water to cover all of the headers in the source, blanket and window primary cooling systems by one foot. The purpose is to cover any break that could result in the loss of passive or active cooling in any of the systems. The flooding to cover the headers allows the continued cooling of the source or blanket 
array through the passive or residual heat removal systems. The integrity of the source or blanket assembly will be maintained.

In order to accommodate cleanup of the basin, a drain pump is provided that can return the water to the storage tank. This would allow the unit to be returned to power once the leak/break is repaired. In conjunction with this forced return, a heat exchanger has been included that has the capability to remove about $1 \mathrm{MWt}$, which more than adequate for removal of the decay heat. The use of this pump and heat exchanger could serve as a back up to all of the decay heat removal systems, however, by today's standard, this third level system heat exchanger would not be required. The valves associated with each train are considered to be passive by today's standards as each valve has an associated source of energy for opening should that be required. Each train of the system may use a different motive source: for example, DC battery, pneumatic or hydraulic. A $0.15 \mathrm{~m}$ (6 inch) loop seal is used in the vent line that returns the displaced air to the tank in the event that the system is used. This seal is easily blown by the dumping head and the resulting gas flow. Its main purpose is to prevent gasses that are activated in the vicinity of the target from being transported to the tank during normal power operation.

The system components are considered to be safety related, however, none of the components are a pressure retaining part of any primary cooling system boundary. Thus, they are considered to be safety class 2 . The system boundary does provide a confinement type area inside the containment system.

\subsubsection{SILC (BNL-APT) Purification Systems}

The SILC purification systems contains three systems: the heavy water purification system, the light water purification system and the $\mathrm{D}_{2} \mathrm{O}$ upgrade system. A schematic diagram for the SILC purification systems is provided in Figure 4.22. The requirements for these systems are attached as Appendix 4B.

\subsubsection{Heavy Water Purification System (HWPS)}

\subsection{General Description}

\subsection{Summary}

The Heavy Water Purification System (HWPS) maintains the required water quality in the Source Primary Cooling System (SPCS) by removing soluble, particulate and gaseous chemical and radioactive impurities and maintaining $\mathrm{pD}$ within design limits. In addition, the HWPS can add oxygen to stabilize nitrate and prevent ammonia formation.

The HWPS takes its input from the SPCS cold leg. The SPCS provides flow to the HWPS Degasifier Tank from which the coolant is processed through an initial cartridge filter, two mixed bed ion exchangers, a final cartridge filter and returned to the SPCS. Nitric acid and 
oxygen are added for $\mathrm{pD}$ control and nitrate stabilization when needed. Systems parameters are given in Table 4.22 .

Table 4.22 BNL-APT Heavy Water Purification System Parameter List

\begin{tabular}{|c|c|c|}
\hline $\begin{array}{l}\text { Flow Rate, } 1 / \mathrm{S}(\mathrm{GPM}) \\
\text { Temperature, Max, }{ }^{\circ} \mathrm{C}\left({ }^{\circ} \mathrm{F}\right)\end{array}$ & $\begin{array}{r}1.9 \\
49\end{array}$ & $\begin{array}{r}(30) \\
(120)\end{array}$ \\
\hline \multicolumn{3}{|l|}{ Degasifier Tank } \\
\hline Capacity, 1 (gal) & 7600 & $(2000)$ \\
\hline Normal Operation, 1 (gal) & 2300 & $(600)$ \\
\hline \multicolumn{3}{|l|}{ Heavy Water Holdup Tanks } \\
\hline Capacity, Each 1 (gal) & 76000 & $(20000)$ \\
\hline \multicolumn{3}{|l|}{ Ion Exchangers } \\
\hline Diameter, cm (in) & 76 & (30) \\
\hline Bed Volume, $1\left(\mathrm{ft}^{3}\right)$ & 566 & $(20)$ \\
\hline \multicolumn{3}{|l|}{ Filters } \\
\hline \multicolumn{3}{|l|}{ Rating (micrometers) } \\
\hline Absolute & 2 & \\
\hline $99 \%$ & 0.8 & \\
\hline \multicolumn{3}{|l|}{ Vessel Clearance Envelope } \\
\hline Height cm (in) & 305 & (120) \\
\hline Width $\mathrm{cm}$ (in) & 50 & (20) \\
\hline \multicolumn{3}{|l|}{ Annual Waste Production (estimated) } \\
\hline $\operatorname{Resin} 1\left(\mathrm{ft}^{3}\right)$ & 4530 & $(160)$ \\
\hline Filters $1\left(\mathrm{ft}^{3}\right)$ & 805 & (30) \\
\hline
\end{tabular}




\subsection{Detailed System Description}

\section{(a) Feed and Return}

Pressure from the SPCS cold leg feeds the letdown flow to the HWPS Degasifier. Feed flow is coordinated with the return flow to maintain SPCS inventory. The Degasifier Tank provides a surge volume to decouple the volume control function from short term variations in process flow rates. Feed and return lines have redundant control valves providing assurance that single failure will not cause a shutdown of the HWPS. Redundant Feed Pumps are also provided. A small continuous bleed flow is provided to prevent stagnation in the Source Residual Primary Coolant System (SRPCS) when not in use.

The system is designed to provide for transfer of batches of processed coolant to the $\mathrm{D}_{2} \mathrm{O}$ Upgrade System (DUS) for light water removal (upgrade). Removal of coolant from the HWP system is coordinated with addition of makeup from DUS so as to maintain the volume of the HWPS. Makeup is transferred to the Degasifier Tank from the DUS Product Tank which stores heavy water purified by the DUS.

Two Heavy Water Holdup Tanks provide secure storage for the entire required plant inventory of heavy water before startup and are used to hold heavy water drained during Source replacement. They are housed in cubicles designed to retain the entire tank volume.

\section{(b) Process Description}

Heavy water coolant from the SPCS is sprayed into the Degasifier Tank to remove excess dissolved gases to prevent their evolution if the SPCS should depressurize. This tank also serves as a feed tank for the HWPS. The tank is helium blanketed to exclude oxygen and nitrogen. (Nitrogen is converted to nitric acid by radiation exposure and lowers the pD below the operating range.) The vent passes through a chilled water cooled condenser which minimizes the loss of heavy water vapor and tritium. The remaining heavy water is recovered by dryers in the gaseous waste system.

The coolant is pumped from the Degasifier Tank through the Letdown Cooler which cools it to $49^{\circ} \mathrm{C}\left(120^{\circ} \mathrm{F}\right)$ for compatibility with the ion exchange resin. The cooler is placed after the Degasifier to increase the effectiveness of degasification which is more efficient at higher temperatures. From the Letdown Cooler, the coolant flows through one of two redundant prefilters. The use of redundant filters permits filter changeout during operation without shutdown of the HWPS. The nuclear grade cartridge filters are designed for remote changeout. The filter elements are a pleated glass fiber paper. A $152.4 \mathrm{~mm}$ (6 inches) diameter x $762 \mathrm{~mm}$ (30 inches) long element has a filtration area of about $5.11 \mathrm{~m}^{2}\left(55 \mathrm{ft}^{2}\right)$ and is available with absolute ratings of 1.0 micrometer and larger. 
After filtration, the coolant is processed through a pair of mixed bed ion exchangers. The design provides for series operation of the ion exchange beds so that the resin in the first bed of the pair can be fully utilized to minimize resin waste volume. The beds in each pair are interconnected so that when the first bed saturates, inlet is switched to the second bed, the resin in the saturated bed is replaced, and it then becomes the new second bed.

Following the practice at SRS, a resin mix of one exchange equivalent cation resin to two equivalents of anion resin will be used for normal operation (to maximize bed life). Bed life is expected to be about three months for the first bed in series. Saturation with nitrate is the limiting factor.

To minimize $\mathrm{D}_{2} \mathrm{O}$ loss and tritium release, canned pumps and bellows or diaphragm sealed valves are to be used. No open vents or drains are permitted.

Spent resins are sluiced to a spent resin tank for $D_{2} O$ recovery. Fresh resin is deuterated in the deuteration subsystem by displacement of the light water in the resin with $\mathrm{D}_{2} \mathrm{O}$. The deuterated resin is then added to the empty ion exchange column.

From the ion exchangers, the reactor coolant is filtered to prevent resin fines carryover. Due to the lower anticipated loading on the After Filter, redundancy is not provided. to the SPCS.

Nitric acid, added for $\mathrm{pD}$ control, is introduced by metering pump to the return flow

Oxygen addition is required to stabilize the nitrate radical and prevent formation of ammonia which could attack aluminum. The addition is usually required with a fresh source to replenish the oxygen consumed in oxide film formation. This is injected as a gas into the return line to the SPCS.

\section{(c) Instrumentation and Control}

All instrumentation and controls required for normal operation are operated from a central control room.

Flow controls and alarm interlocks are provided to maintain the inventory of the SPCS and the level in the Degasifier Tank within setpoint limits by automatically adding water from the Heavy Water Holdup Tanks to makeup system losses. Safety control of the SPCS inventory is provided by the SPCS which can initiate isolation of the HWPS if normal control malfunctions.

Transfer of heavy water to or from other purification facilities is done under administrative control. 


\subsubsection{Light Water Purification System (LWPS)}

\subsection{General Description}

\subsection{Summary}

The Light Water Purification System (LWPS) maintains the required water quality in the Window Primary Cooling System (WPCS), Blanket Primary Cooling System (BPCS) and Blanket Residual Primary Cooling System (BRPCS) by removing soluble, particulate and gaseous chemical and radioactive impurities and maintaining $\mathrm{pH}$ within design limits. In addition, the LWPS can add oxygen to stabilize nitrate and prevent ammonia formation.

The LWPS takes its input from the cooling systems cold legs. The cooling systems provide flow to the LWPS Degasifier Tank from which the coolant is processed through an initial cartridge filter, two mixed bed ion exchangers, a final cartridge filter and returned to the respective cooling system. Nitric acid and oxygen are added for $\mathrm{pH}$ control and nitrate stabilization when needed.

System parameters are given in Table 4.23.

\subsection{Detailed System Description}

(a) Feed and Return

Pressure from the cold legs of the WPCS and BPCS feeds the letdown flow to the HWPS Degasifier. Feed flow is coordinated with the return flow to maintain inventory in each cooling system. The Degasifier Tank provides a surge volume to decouple the volume control function from short term variations in process flow rates. Feed and return lines have redundant control valves providing assurance that single failure will not cause a shutdown of the LWPS. Redundant Feed Pumps are also provided. A small continuous bleed flow is provided to prevent stagnation in the Blanket Residual Primary Coolant System (BRPCS) when not in use.

\section{(b) Process Description}

Incoming coolant is sprayed into the Degasifier Tank to remove excess dissolved gases to prevent their evolution if the WPCS or BPCS should depressurize. The tank also serves as a feed tank for the LWPS. This tank is helium blanketed to exclude oxygen and nitrogen. (Nitrogen is converted to nitric acid by radiation exposure and lowers the $\mathrm{pH}$ below the operating range.) The coolant is pumped from the Degasifier Tank through the Letdown Cooler which cools it to $49^{\circ} \mathrm{C}\left(120^{\circ} \mathrm{F}\right)$ for compatibility with the icn exchange resin. The cooler is placed after the Degasifier to increase the effectiveness of degasification which is more efficient at higher temperatures. From the Letdown Cooler, the coolant flows through one of two redundant prefilters. The use of redundant filters permits filter changeout during operation without 
Table 4.23 BNL-APT Light Water Purification System Parameter List

\begin{tabular}{|c|c|c|}
\hline $\begin{array}{l}\text { Flow Rate, } 1 / \mathrm{S}(\mathrm{GPM}) \\
\qquad \text { Temperature, } \operatorname{Max},{ }^{\circ} \mathrm{C}\left({ }^{\circ} \mathrm{F}\right)\end{array}$ & $\begin{array}{r}1.9 \\
49\end{array}$ & $\begin{array}{r}(30) \\
(120)\end{array}$ \\
\hline \multicolumn{3}{|l|}{ Degasifier Tank } \\
\hline Capacity, 1 (gal) & 7600 & $(200 C)$ \\
\hline Normal, 1 (gal) & 2300 & (600) \\
\hline \multicolumn{3}{|l|}{ Ion Exchangers } \\
\hline Diameter, $\mathrm{cm}$ (in) & 76 & (30) \\
\hline Bed Volume, $1\left(\mathrm{ft}^{3}\right)$ & 566 & (20) \\
\hline \multicolumn{3}{|l|}{ Filters } \\
\hline Rating (micrometers) & & \\
\hline Absolute & 2 & \\
\hline $99 \%$ & 0.8 & \\
\hline \multicolumn{3}{|l|}{ Vessel Clearance Envelope } \\
\hline Height $\mathrm{cm}$ (in) & 305 & (120) \\
\hline Width $\mathrm{cm}$ (in) & 50 & (20) \\
\hline \multicolumn{3}{|l|}{ Annual Waste Production (estimated) } \\
\hline $\operatorname{Resin} 1\left(\mathrm{ft}^{3}\right)$ & 4530 & $(160)$ \\
\hline Filters $1\left(\mathrm{ft}^{3}\right)$ & 805 & (30) \\
\hline
\end{tabular}

shutdown of the LWPS. The nuclear grade cartridge filters are designed for remote changeout. The filter elements are a pleated glass fiber paper. A $152.4 \mathrm{~mm}$ (6 inches) diameter $\times 762 \mathrm{~mm}$ (30 inches) long element has a filtration area of about $5.11 \mathrm{~m}^{2}\left(55 \mathrm{ft}^{2}\right)$ and is available with absolute ratings of 1.0 micrometer and larger. Turbidity not removed by the filters can be removed by replacement of the coolant with fresh makeup, if required. With good chemistry control, this should be infrequent.

After filtration, the coolant is processed through a pair of mixed bed ion exchangers. The design provides for series operation of the ion exchange beds so that the resin in the first bed of the pair can be fully utilized to minimize resin waste volume. The beds in each pair are interconnected so that when the first bed saturates, inlet is switched to the second bed, the resin in the saturated bed is replaced, and it then becomes the new second bed. 
Following the practice at SRS, a resin mix of one exchange equivalent cation resin to two equivalents of anion resin will be used for normal operation (to maximize bed life). Bed life is expected to be about three months for the first bed in series. Saturation with nitrate is the limiting factor.

Spent resins are sluiced to a spent resin tank for disposal.

From the ion exchangers, the coolant is filtered to prevent resin fines carry-over. Due to the lower anticipated loading on the After Filter, redundancy is not provided.

Nitric acid, added for $\mathrm{pH}$ control, is introduced by metering pump to the return flow to the cooling systems.

Oxygen addition is required to stabilize the nitrate radical and prevent formation of ammonia which could attack aluminum. The addition is usually required with a fresh blanket to replenish the oxygen consumed in oxide film formation. This is injected as a gas into the return line to the cooling systems.

\section{(c) Instrumentation and Control}

All instrumentation and controls required for normal operation are operated from a central control room.

Flow controls and alarm interlocks are provided to maintain the inventory of the cooling systems and the level in the Degasifier Tank within setpoint limits by automatically adding makeup water to makeup system losses. Safety control of the inventory of each cooling system is provided by the controls for the respective cooling system which can initiate isolation of the LWOS if normal control malfunctions.

\subsubsection{3 $\underline{D}_{2} \mathrm{O}$ Upgrade System (DUS)}

\subsection{General Description}

$\mathrm{D}_{2} \mathrm{O}$ isotopic purification system will provide the capability to upgrade approximately $0.061 / \mathrm{sec}(1 \mathrm{gpm})$ of feed from $99.5 \% \mathrm{D}_{2} \mathrm{O}$ to $99.7 \% \mathrm{D}_{2} \mathrm{O}$ by fractional distillation. Overheads concentration will be approximately $0.1 \% \mathrm{D}_{2} \mathrm{O}$. Two fractional distillation columns operating under vacuum in tandem with specially selected packing will be used. The columns will be fed by a $0.30 \mathrm{l} / \mathrm{sec}(5 \mathrm{gpm})$ capacity feed evaporator which can also be used to remove particulates from the coolant which are too fine to be removed by the filters or demineralizers. The columns will be operated at an extremely high reflux ratio and a large number of transfer units will be required to accomplish the required isotopic separation. Vacuum will be maintained by a pair of $\mathrm{D}_{2} \mathrm{O}$ sealed mechanical vacuum pumps equipped with coolant vapor traps and dryers to minimize $\mathrm{D}_{2} \mathrm{O}$ losses. Upgraded $\mathrm{D}_{2} \mathrm{O}$ is returned to the source cooling system as makeup to maintain the required inventory and water quality. 


\subsubsection{Balance of Plant Requirements}

While the balance of plant design is the responsibility of Bechtel, BNL and B\&W have interfaced with the designers, conveying our cooling requirements and ascertaining that our design can be accommodated within the plant.

All coolant flow rates and temperatures have been summarized in Table 4.24. The source, the blanket and the window, each are cooled by a primary and a secondary cooling system, with final heat rejection to cooling towers in the respective circulating water system. There are two parallel loops for each cooling system. Total flow rates are given, as well as flow rates per loop.

By current interface definition, the secondary cooling system and the cooling water system for each component are considered to be part of the balance of plant. 
Table 4.24 SILC Cooling System Flow Rates and Coolant Temperatures

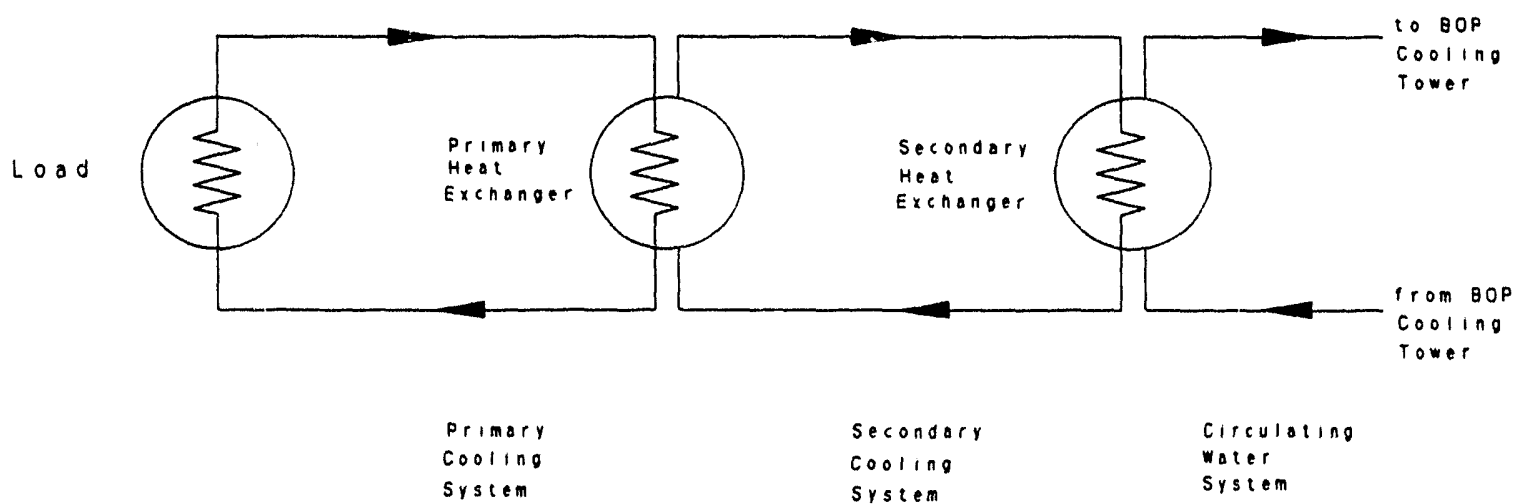

$\begin{array}{lll}\text { Primary } & \text { Secondary } & \text { Ciralating } \\ \text { Cooling } & \text { Cooling } & \text { Water } \\ \text { System } & \text { System } & \text { System }\end{array}$

Source Cooling System $\left(\mathrm{D}_{2} \mathrm{O}\right.$, Total Heat Load $163 \mathrm{MW}, 81.5 \mathrm{MW}$ per loop)

Coolant Flow (kg/s) per loop total

Hot Leg Temperatures $\left({ }^{\circ} \mathrm{C}\right)$

Cold Leg Temperatures $\left({ }^{\circ} \mathrm{C}\right)$
433

867

105

60
501

1002

77

38
976

1952

49

29

Blanket Cooling System $\left(\mathrm{H}_{2} \mathrm{O}\right.$, Total Heat Load $26 \mathrm{MW}, 13 \mathrm{MW}$ per loop)

Coolant Flow $(\mathrm{kg} / \mathrm{s})$ per loop total

Hot Leg Temperatures $\left({ }^{\circ} \mathrm{C}\right)$

Cold Leg Temperatures $\left({ }^{\circ} \mathrm{C}\right)$
186

372

99

82
80

160

49

29

Window Cooling System $\left(\mathrm{H}_{2} \mathrm{O}\right.$, Total Heat Load 1.3 MW, 0.65 MW per loop)

Coolant Flow (kg/s) per loop

Hot Leg Temperatures $\left({ }^{\circ} \mathrm{C}\right)$ Cold Leg Temperatures $\left({ }^{\circ} \mathrm{C}\right)$
6.3

12.6

9.8

19.6

6

12

80

61

50

38

29 


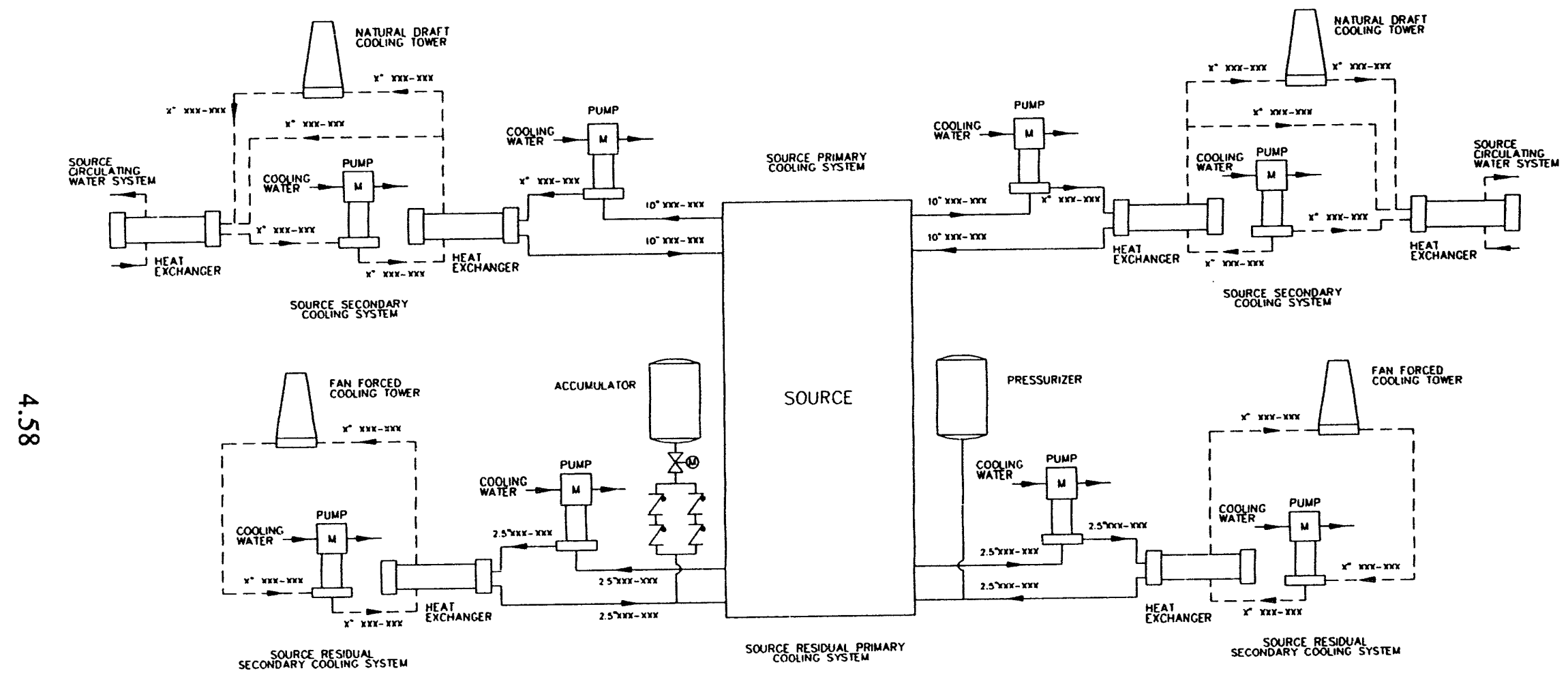

Figure 4.13 Source Cooling Systems - Pre-Conceptual 


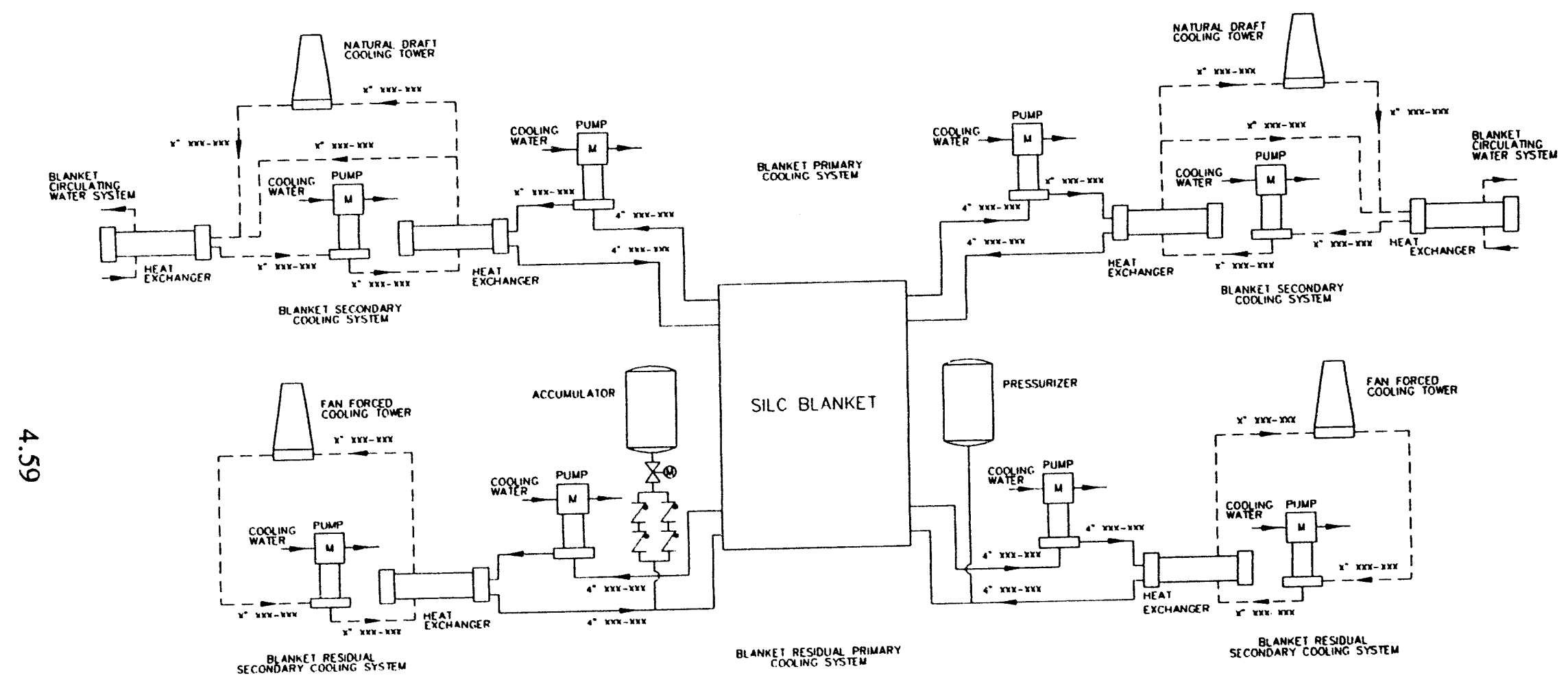

Figure 4.14 Blanket Cooling Systems - Pre-Conceptual 


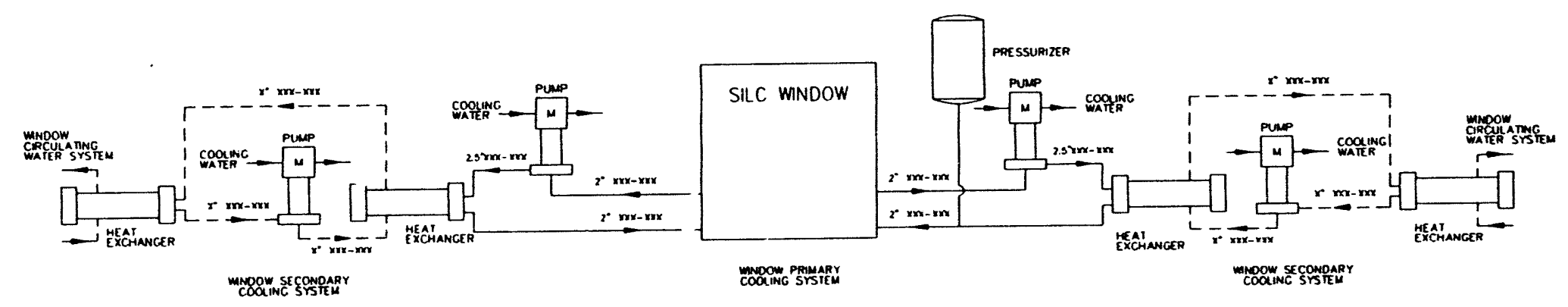

Figure 4.15 Window Cooling Systems - Pre-Conceptual 


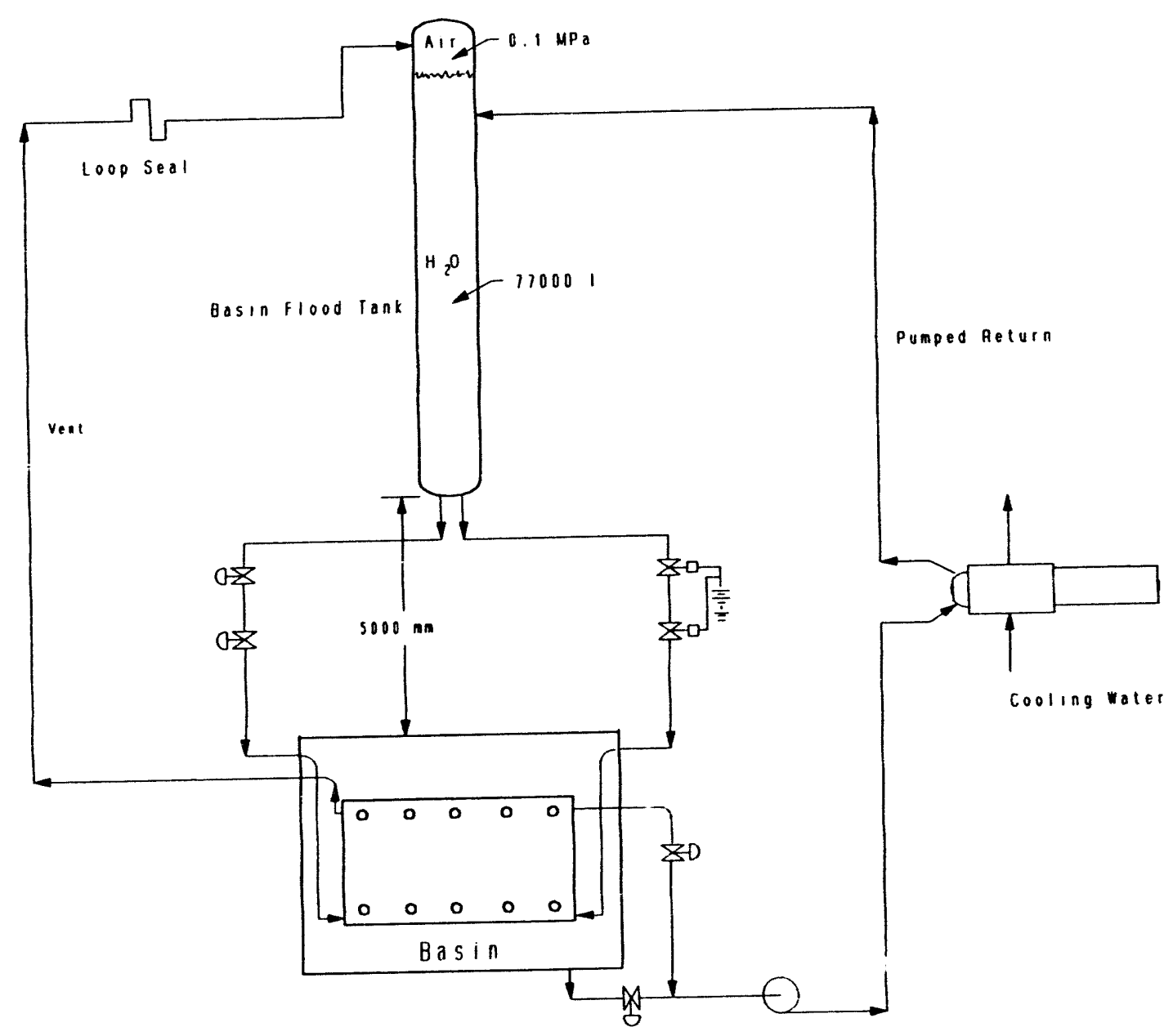

Figure 4.16 Source Basin Flood System - Pre-Conceptual 


\begin{tabular}{|l|c|c|c|c|c|c|}
\hline \multicolumn{1}{|c|}{ PUMP APPLICATION } & $\begin{array}{c}A \\
(\mathrm{~mm})\end{array}$ & $\begin{array}{c}B \\
(\mathrm{~mm})\end{array}$ & $\begin{array}{c}\mathrm{C} \\
(\mathrm{mm})\end{array}$ & $\begin{array}{c}D \\
(\mathrm{~mm})\end{array}$ & $\begin{array}{c}E \\
(\mathrm{~mm})\end{array}$ & $\begin{array}{c}F \\
(\mathrm{~mm})\end{array}$ \\
\hline $\begin{array}{l}\text { SOURCE PRIMARY } \\
\text { COOLANT SYSTEM }\end{array}$ & 2740 & 1070 & 760 & 460 & 273 & 273 \\
\hline $\begin{array}{l}\text { BLANKET PRIMARY } \\
\text { COOLANT SYSTEM }\end{array}$ & 1860 & 730 & 520 & 305 & 168 & 168 \\
\hline $\begin{array}{l}\text { WINDOW PRIMARY } \\
\text { COOLANT SYSTEM }\end{array}$ & 940 & 430 & 366 & 244 & 60 & 60 \\
\hline $\begin{array}{l}\text { SOURCE RESIDUAL PRIMARY } \\
\text { HEAT REMOVAL SYSTEM }\end{array}$ & 880 & 430 & 335 & 213 & 73 & 73 \\
\hline $\begin{array}{l}\text { BLANKET RESIDUAL PRIMARY } \\
\text { HEAT REMOVAL SYSTEM }\end{array}$ & 880 & 430 & 335 & 213 & 73 & 73 \\
\hline
\end{tabular}

Figure 4.17 SILC Cooling System - Pumps 


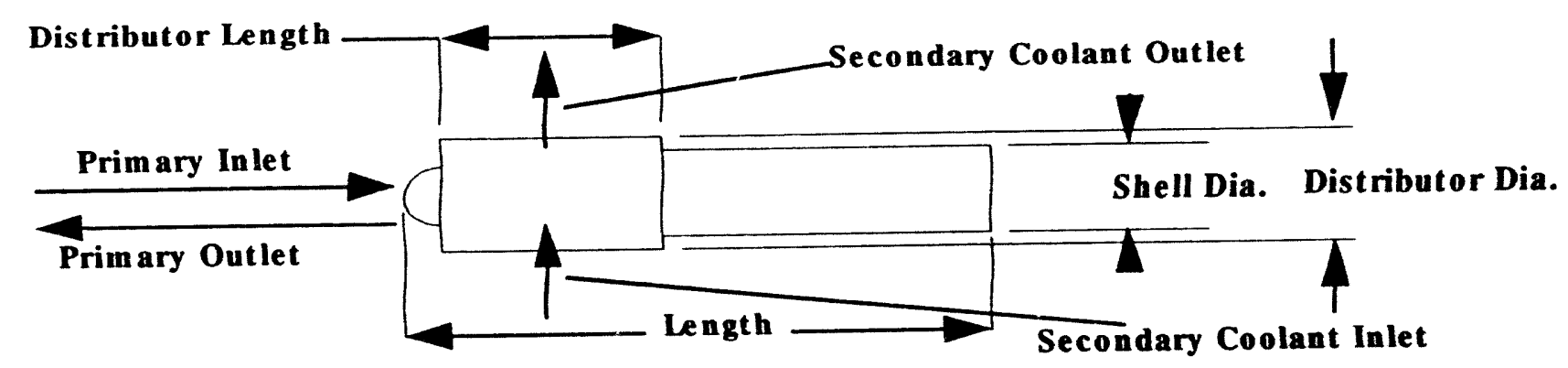

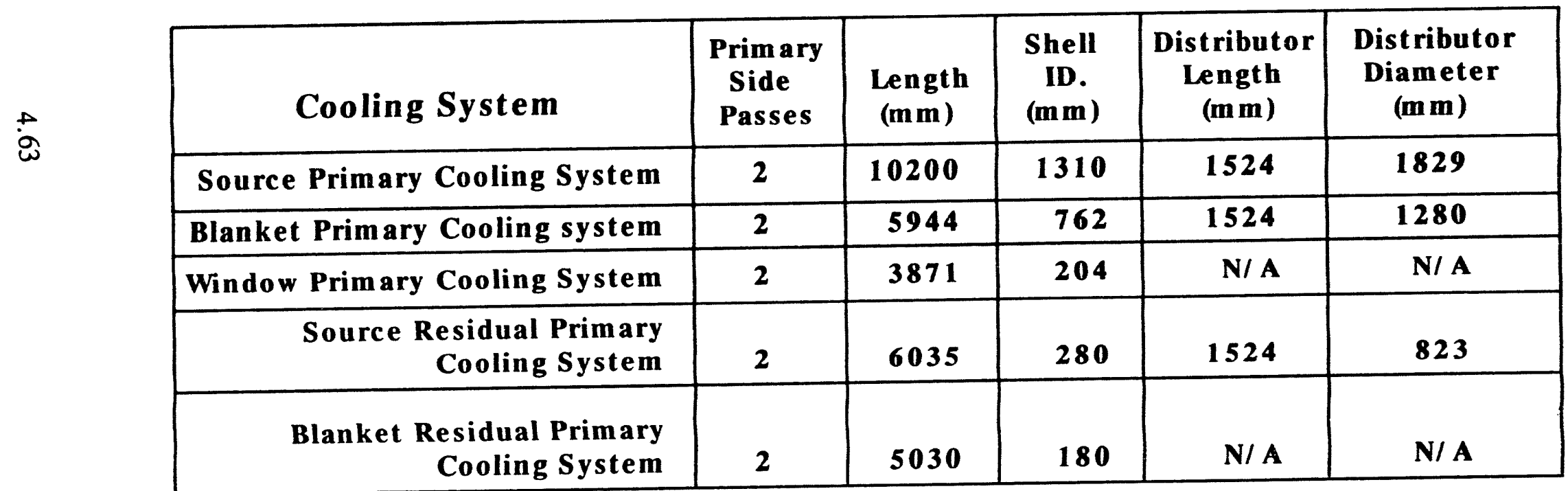

Figure 4.18 SILC Cooling System - Heat Exchangers 


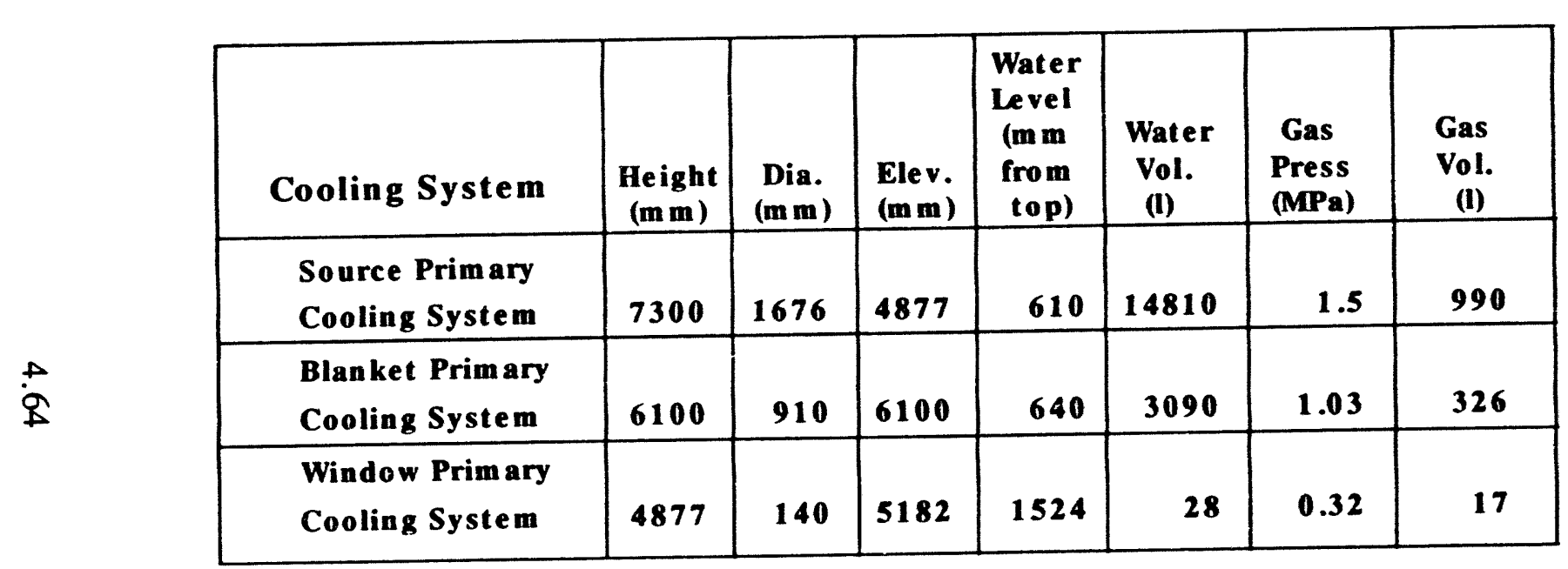

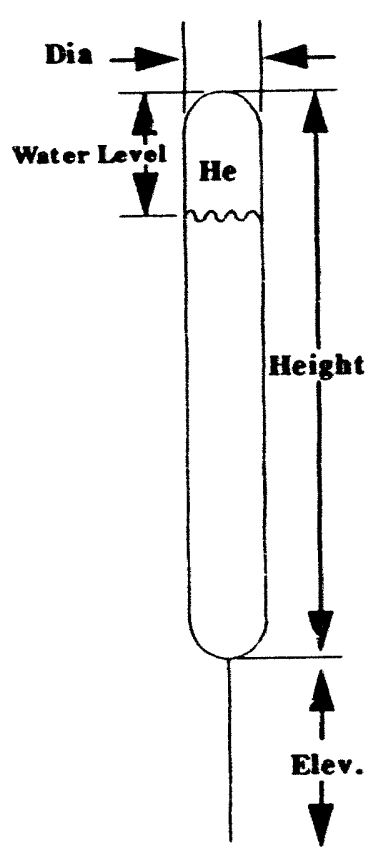

Figure 4.19 SILC Cooling System - Pressurizers 


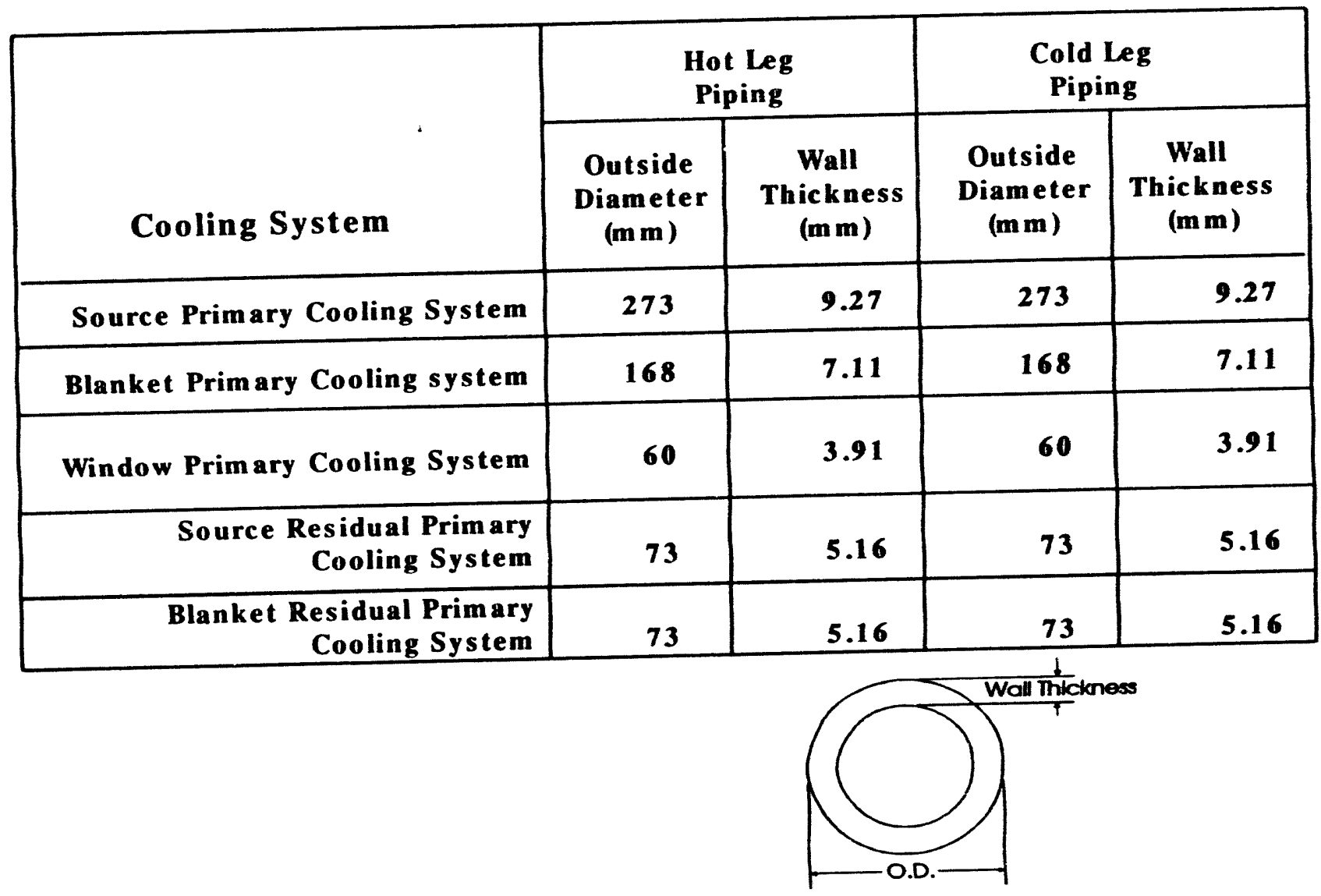

Figure 4.20 SILC Cooling System - Primary Piping 


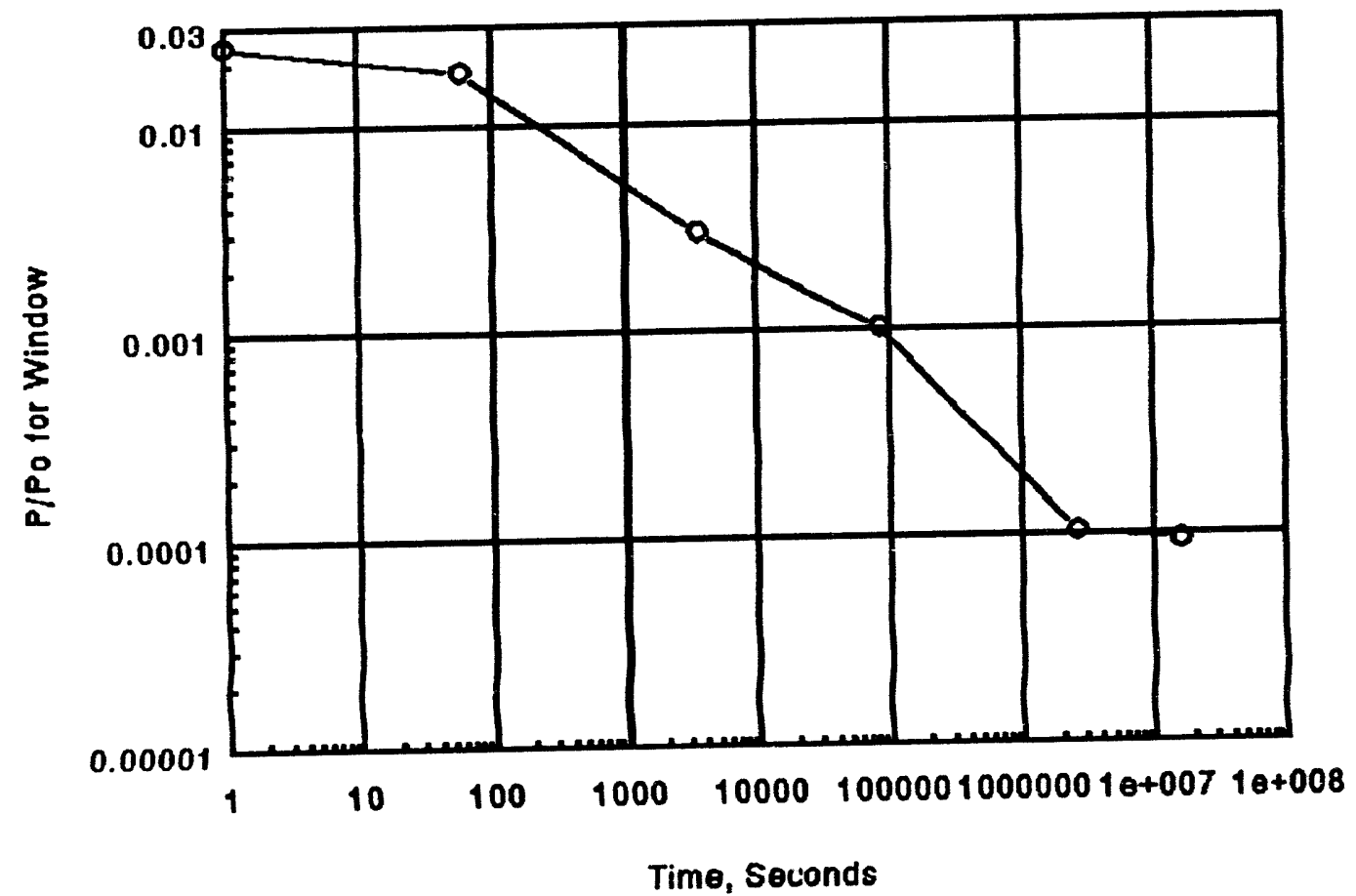

Figure 4.21 Window Decay Heat 


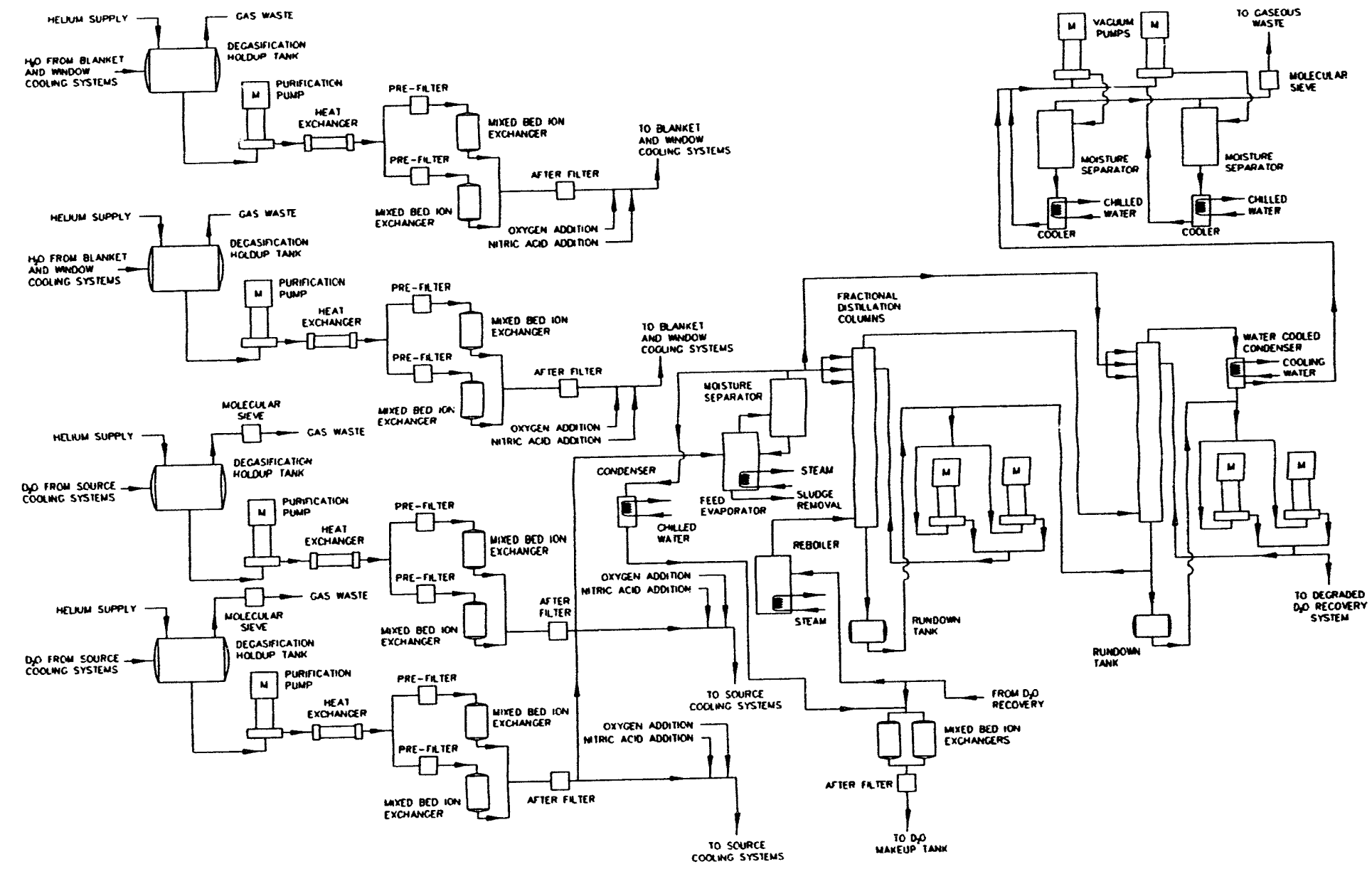

Figure 4.22 SILC Purification Systems - Pre-Conceptual 
Appendix 4A

Functions, Systems \& Safety Requirements Document for BNL-APT SILC Cooling Systems 
TITLE:

PREPARED BY:

REVIEWED BY:
Functions, System \& Safety Requirements Document for BNL-APT SILC Cooling Systems

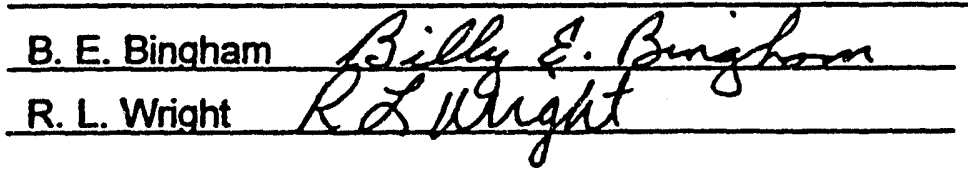

DATE: June 23, 1993

DATE: June 23,1993

REMARKS:

The spallation induced lithium conversion (SILC) systems are divided between four sets of systems:

1. Source Cooling Systems (SCS)

- Source Primary Cooling System (SPCS)

- Source Secondary Cooling System (SSCS)

- Source Circulating Water System (SCWS)

- Source Residual Primary Cooling System (SRPCS)

- Source Residual Secondary Cooling System (SRSCS)

2. Blanket Cooling Systems (BCS)

- Blanket Primary Cooling System (BPCS)

- Blanket Secondary Cooling System (BSCS)

- Blanket Circulating Water System (BCWS)

- Blanket Residual Primary Couling System (BRPCS)

- Blanket Residual Secondary Cooling System (BRSCS)

3. Window Cooling Systems (WCS)

- Window Primary Cooling System (WPCS)

- Window Secondary Cooling System (WSCS)

- Window Circulating Water System (WCWS)

4. Source Basin Flood System (SBFS)

The function and interface system and safety requirements were developed to the stage needed for the pre-conceptual design for the SILC system design. These are presented in a format that is consistent with the DOE document NE-F 1-2T, "Preparation of Plant and System Description Documents," dated January 1989.

\section{DISTRIBUTION:}

ASE Document Control 


\section{ADVANCED SYSTEMS ENGINEERING RECORD OF REVISION}

Revision No.

00

01

$$
\text { 1.3.1.2.15 }
$$

1.3.1.2.6

1.2.1.2.18

1.1.4.2.4

1.1.2.2.3

1.2.2.2.2

1.1.4.2.10

1.1.5.2.5

1.2.4.2.6

1.2.5.2.5

02

\section{Description}

Original Issue.

Corrected the indicated flow rates

Corrected footnotes 15 and 18 to indicate window

Corrected the footnotes 5 and 11 to indicate blanket

Normal operation flow through natural draft water-to-air heat exchanger

Positive flow through

Natural draft heat exchanger during normal power operation

Updated the required temperatures to allow dry built air temperature to go to $100^{\circ} \mathrm{F}$

Corrected heat exchanger outlet and inlet temperatures 


\begin{tabular}{l|l} 
ADVANCED SYSTEMS ENGINEERING & ASE-013-0 \\
\cline { 2 - 2 } TABLE OF CONTENTS & $12-3002053-02$ \\
\hline
\end{tabular}

TABLE OF CONTENTS

Section Description Page

1.0 Spallation Induced Lithium Conversion (SILC) Cooling Systems $\quad 4$

1.1 Source Cooling Systems (SCS) 4

$1.2 \quad$ Blanket Cooling Systeins (BCS) 15

1.3 Window Cooling Systems (WCS) 26

1.4 Source Basin Flood System (SBFS) 32

\section{List of Figures}

Figure 1 APT-SILC: Target Decay Heat Megawatts 11

Figure 2 Decay Heat Deposition in LiAl Blanket 22

$\begin{array}{lll}\text { Figure } 3 & \text { Window Decay Heat }\end{array}$ 
The spallation induced lithium conversion cooling systems are divided between four sets of systems broadly defined by: the source cooling systems, the blanket cooling systems, the window cooling systems, and the source basin flood system, refer to Drawing 02-3100895, Sheets 1 through 6 . The functions and requirements for the individual system will follow in the same order.

\section{Source Cooling Systems (SCS)}

The source cooling systems are made up of those systems that remove and transport the lead source generated energy to the ultimate heat sink, Refer to Drawing 02-3100895, Sheet 3 . It is composed of the following five systems: source primary cooling system (SPCS), the source secondary cooling system (SSCS), the source circulating water system (SCWS), the source residual primary cooling system (SRPCS) and the source residual secondary cooling system (SRSCS). All of the systems contain two luops. The main cooling systems contain two $50 \%$ loops for normal operation. All of the residual decay heat loops include two $100 \%$ loops and this includes the passive cooling capability included in the source primary and the source secondary cooling systems. The functions, system and safety requirements are provided for these systems in the following subsections.

1.1.1 Source Primary Cooling System (SPCS)

1.1.1.1 Functions

The functions of the source primary cooling system (SPCS) are:

1.1.1.1.1 To provide pumped/forced circulation of $\mathrm{D}_{2} \mathrm{O}$ coolant for source lead assembly heat removal and transfer of the energy from the source lead assemblies and SPCS pumps to the source secondary cooling system under all plant conditions whenever sufficient AC power and SPCS pressure are available to run the SPCS pumps.

1.1.1.1.2 To provide natural circulation of the coolant through the source lead assemblies to remove residual heat and sensible stored energy and transfer the energy to the secondary system during a station blackout.

1.1.1.1.3 To maintain subcooled conditions in the SPCS coolant during all plant conditions whenever sufficient $D_{2} \mathrm{O}$ and helium can be maintained in the SPCS pressurizer.

1.1.1.1.4 To provide over pressure control for the lead source and the source residual primary system.

1.1.1.1.6 To provide lead source assembly flooding following a loss-of-coolant accident (LOCA) in the source basin.

1.1.1.2 Requirements 


\section{ADVANCED SYSTEMS ENGINEERING TECENICAI DOCUMENT}

1.1.1.2.1 The system shall use $\mathrm{D}_{2} \mathrm{O}$ as the coolant.

1.1.1.2.2 Two source primary cooling system loops, each with $50 \%$ capacity, shall be used with one pump in each loop so that the $T / H$ safety criteria shall not be violated for a locked rotor event or a LOCA.

1.1.1.2.3 For a LOCA, the expansion of the gas in the pressurizer or the accumulator shall not inject gas into the source primary cooling system when the system depressurizes. (This is intended to prevent the injection of gas into the source primary cooling system following a LOCA or a leak in the source primary cooling system boundary. Inert gases could block the natural circulation cooling.)

1.1.1.2.4 Arrange the piping so there are no loop seals. (When the system is using natural circulation cooling, any collection of gases in the loop will block the natural circulation since loop seals in pipes require only a small volume of gas to effectively block natural circulation in pipes.) The heat exchanger in the top of the loop shall be designed and arranged such that it can accommodate a volume of gases before a seal will develop.

1.1.1.2.5 Arrange components and their nozzles for the promotion of natural circulation in the forward direction. (Assume the centerline of the heat exchanger inlet nozzle must be no higher than the centerline of the heat exchanger and must be $1.83 \mathrm{~m}$ ( 6 feet) or more above the source outlet until the safety analyses are completed that may provide corrected values.)

1.1.1.2.6 The lowest point in the piping outside the source basin area must be no lower than the inlet or outlet penetrations to the basin whichever is lower. (This is to prevent the siphoning of water from the system in the event of a LOCA at the lowest point.)

1.1.1.2.7 $1.22 \mathrm{~m}$ (4 feet) clearance shall be allowed around all components and piping welds for inspection and maintenance. Space shall be allowed for isolation valves. Provisions shall be included to allow heat exchanger removal. (The studies required to decide whether or not to include isolation valves in the SPCS loops have not been completed, thus the requirement to allow space for isolation valves should be retained. $1.22 \mathrm{~m}$ ( 4 feet) of clearance is required for access for inspection and maintenance, and additional space should be provided for laydown within all cells. The production reactors and commercial reactors have found it necessary to replace heat exchangers/steam generators, thus a removal requirement was included.)

1.1.1.2.8 Provide a minimum of four pipe diameters of straight pipe at the suction of the pumps. (Most pump manufacturers recommend 3 to 5 diameters of straight pipe at the pump suction, four is the mid-point of their recommendation.)

1.1.1.2.9 The top of the heat exchanger shall be located such that the loop flow will not be blocked in an unbroken loop when the lowest horizontal pipe is at atmospheric pressure in the broken or leaking loop when the blowdown is complete. 


\section{ADVANCED SYSTEMS ENGINEERING TECHNICAL DOCUMENT}

ASE- 013-0

(Assume the top of the heat exchanger can be no higher than $3.66 \mathrm{~m}$ (12 feet) above the source basin outlet or inlet penetrations until the safety analyses are completed at which time they may be corrected. The pressure of the water in the raised piping must remain above the saturation pressure, otherwise it will boil forming a void that may block natural circulation or cause the pump to cavitate.)

1.1.1.2.10 The SPCS circulation pumps shall have flywheels to provide extended codstdown (use 45 seconds until system analyses are completed at which time they may change). The SPCS circulation pumps can be located in either the hot or cold legs. The location should be based on the ability to meet pump NPSH requirements and the ability to eliminate loop seals.

1.1.1.2.11 The source primary cooling system shall use one pressurizer and one heavy water accumulator to provide makeup should the pressurizer surge line fail. Both surge lines shall be connected to the source inlet header.

1.1.1.2.12 The accumulator gas pressure shall be set no more than 1.034 bar (15 psi) below the operating pressure of the SPCS pressurizer,

1.1.1.2.13 The accumulator discharge line shall use parallel redundant check valve trains to eliminate/minimize the probability that a single valve failure will render the accumulator inoperative.

1.1.1.2.14 The lead source assembly pressure boundary exposed to the cavity, and the incavity piping shall be designed to take the maximum cavity pressure as an external load.

1.1.1.2.15 The SPCS shall be designated a safety related system and designed, fabricated, erected and tested in accordance with the appropriate codes and standards. The system and components shall be designed and fabricated to the ASME B\&PV Code Section III (APT-RD 0001 requirement G.11.1). As the design is further developed, appropriate design classification shall be applied to the systems and components with due consideration being given to the application and overall safety aspects of the plant. B\&W document 12-3002062 provides guidance in selecting the classifications.

1.1.1.2.16 Operational Requirements:

- Power Level, MWt 163

- Rod Bundle Inlet Plenum Temperature, C(F) 60(140)

- Rod Bundle Outlet Plenum Temperature, C(F) 105(221)

- Rod Bundle Outlet Plenum Pressure, bar(psia) 9.65(140)

- Maximum Piping Coolant Velocity, m/s(ft/s) 15.24(50)

- Source Coolant Flow Rate, $\mathrm{kg} / \mathrm{s}(\mathrm{lbm} / \mathrm{s}) \quad$ 868(1914)

- Accumulator Operating Gas Pressure, $\mathrm{Pa}(\mathrm{psia})$ TBD

- Maximum Allowable Accumulator Temperature, $C(F) \quad$ TBD

- Accumulator Water Volume, $\mathrm{m}^{3}\left(\mathrm{ft}^{3}\right) \quad$ TBD 


\section{ADVANCED SYSTEMS ENGINEERING TECHNICAL DOCUNENT}

ASE-013-0

\subsection{Analysis/Evaluation Criteria}

Category

Event Frequency Range

Criteria

AOOs

1 to $10^{-2}$

DBEs

$10^{-2}$ to $10^{-4}$

CHF/OFI with high confidence ${ }^{1}$

BDBEs

$10^{-4}$ to $\mathrm{TBD}^{3}$

$\mathrm{CHF}^{2}$

RR

Less than $\mathrm{TBD}^{5}$

\section{Source Cladding $250 \mathrm{C}^{4}$}

Containment of inventory

\subsubsection{Interface Requirements}

1.1.1.3.1 The SPCS shall interface with the heavy water purification and chemical treatment system for the purification and detritiation of the coolant and to provide for inventory control via letdown and makeup.

1.1.1.3.2 Any interfacing systems shall use isolation valves with a means for leak detection provided that will automatically close the isolation valves should a leak occur in the interfacing system pressure boundary.

1.1.1.3.3 The pressurizer and the accumulator surge lines shall serve as the return lines for the SRPCS going to the lead source assembly inlet plenum with one surge line serving each train of the SRPCS.

1 The criterion will be based on the critical heat flux (CHF) or the onset of a flow instability between assemblies (OFI). Since orificing may be used in the lead source assemblies at their inlets to distribute the flow such that many of the assemblies will operate with nearly the same margin to CHF/OFI, the confidence will need to be greater than it was for commercial reactors but probably less than was anticipated for the NPR. For the interim period a 99/99 confidence of not exceeding the design critical heat flux ratio (CHFR) equivalent to the $1.3 \mathrm{CHFR}$ for commercial reactors is recommended.

2 If commercial conservative analysis practice is used, then the CHFR $\geq 1$ or the avoidance of a flow instability is recommended. If a best estimate statistical approach is used the equivalent of the commercial $C H F R=1.3$ or an equivalent margin to the onset of flow instability is recommended.

3 Refer to APT RD A.1.2 and SEN-35-91.

4 The $250 \mathrm{C}$ limit for the source was based on the structural integrity of the aluminum clad used to protect the lead and must be reconsidered when the clad material is selected.

$5 \quad$ Refer to APT RD A.1.2 and SEN-35-91. 
1.1.2 Source Secondary Cooling System (SSCS)

\subsubsection{Functions}

The functions of the source secondary cooling system (SSCS) are:

1.1.2.1.1 To provide pumped/forced circulation of coolant for removal of energy from the SPCS and SSCS pumps to the source circulating water system under all plant conditions whenever sufficient AC power and SSCS pressure are available to run the SSCS pumps.

1.1.2.1.2 To provide natural circulation of the coolant through the source primary heat exchanger to remove residual heat and sensible stored energy and transfer the energy to the environment during a station blackout.

1.1.2.1.3 To maintain subcooled conditions in the SSCS coolant during all plant conditions whenever sufficient $\mathrm{H}_{2} \mathrm{O}$ and cover gas can be maintained in the SSCS pressurizer/surge tank.

\subsubsection{Requirements}

1.1.2.2.1 The source secondary cooling system shall use two $50 \%$ loops for normal power operation, one serving each source primary cooling loop. The secondary loops shall be independent to avoid the loss of both loops with a single failure.

1.1.2.2.2 The secondary system shall be designed to a higher pressure than the source primary cooling system so that the primary cooling system pressure relief valves will relieve at a lower pressure. (This should prevent the loss of primary coolant system heavy water to the buildings/containment in the event of a heatup accident following a heat exchanger tube leak. The primary system shall operate at a higher pressure on the primary side of the primary heat exchanger than on the secondary cooling system side in the heat exchanger so that leakage will be into the secondary cooling system to prevent the dilution of the $\mathrm{D}_{2} \mathrm{O}$ should a tube leak occur.

1.1.2.2.3 A $100 \%$ residual heat removal natural draft water-to-air heat exchanger shall be used in both of the secondary system loops to remove the residual heat assuming a station blackout using natural circulation in all loops. The loop shall be arranged to provide positive flow through the water-to-air heat exchanger during normal operation. (The large primary piping in the source primary cooling loops and the large primary heat exchangers allow the primary systern to be cooled effectively by using a natural draft heat exchanger in the secondary cooling loop.)

1.1.2.2.4 The secondary heat exchanger(s) shall be located such that the thermal center of the source primary and secondary heat exchangers are separated by a minimum of $3.66 \mathrm{~m}$ (12 feet) vertically. The water-to-air heat exchangers should be located to provide about $6.1 \mathrm{~m}$ (20 feet) or more separation vertically in the 


\section{ADVANCED SYSTEMS ENGINEERING TECHNICAL DOCUMENT}

ASE-013-0

thermal centers of the source primary cooling system heat exchanger to waterto-air heat exchanger serving that loop. (This allows the water in the secondary system to act as a buffer to store energy, thus reducing the required size of the water-to-air heat exchangers.)

1.1.2.2.5 The SSCS circulation pumps can be located in either the hot or cold legs. The location should be based on the ability to meet pump NPSH requirements and the ability to eliminate loop seals.

1.1.2.2.6 The SSCS shall be designated a safety related system and designed, fabricated, erected and tested in accordance with the appropriate codes and standards. The system and components shall be designed and fabricated to the ASME B\&PV Code Section III (APT-RD 0001 requirement G.11.1). As the design is further developed, appropriate design classification shall be applied to the systems and components with due consideration being given to the application and overall safety aspects of the plant. B\&W document 12-3002062 provides guidance in selecting the classifications.

1.1.2.2.7 Operational Requirements

$\begin{array}{llr}0 & \text { Source Residual Decay Heat,MWt } & \text { Figure } 1^{6} \\ 0 & \text { Primary Heat Exchanger Inlet Temperature, C(F) } & 38(100) \\ 0 & \text { Heat Exchanger Outlet Temperature, C(F) } & 77(170) \\ 0 & \text { Water Flow Rate, } \mathrm{kg} / \mathrm{s}(\mathrm{lbm} / \mathrm{s}) & 502(1106)\end{array}$

$6 \quad$ Suggest that the water-to-air heat exchangers be sized for decay heat at 200 seconds until the safety analyses are available when a better value may become available. 


\section{ADVANCED SYSTEMS ENGINEERING TECHNICAL DOCUMENT}

\subsubsection{Source Circulating Water System (SCWS)}

\subsubsection{Functions}

The function of the source circulating water system (SCWS) are:

1.1.3.1.1 To remove energy from the SSCS during normal operation when offsite power is available, and transfer the energy to the ultimate heat sink.

\subsubsection{Requirements}

1.1.3.2.1 The SCWS shall be designed to operate during normal operation when offsite power is available, and transport the energy transferred from the SSCS and generated by the SCWS pumps to the environment.

1.1.3.2.2 The location of the pumps shall be based on the ability to meet pump NPSH requirements.

1.1.3.2.4 Operational Requirements:

- SSCS Heat Exchanger Inlet Temperature, $C(F)$

- SSCS Heat Exchanger Outlet Temperature, $C(F)$

- Design Wet Bulb Temperature, $C(F)$ 


\section{ADVANCED SYSTEMS ENGINEERING TECHNICAI DOCUMENT

FIGURE 1

APTISILC: TARGET

DECAY HEAT MEGAWATTS

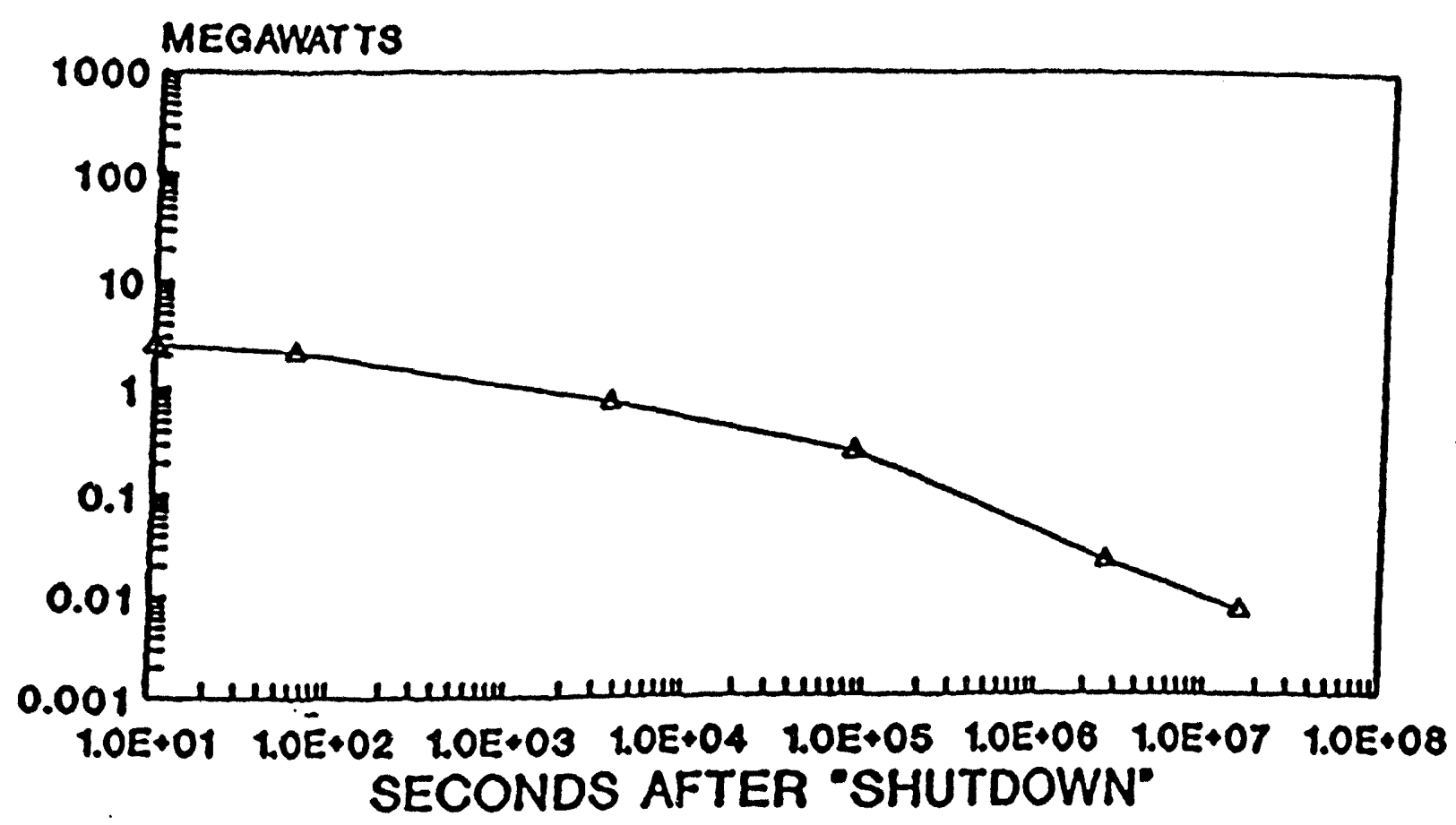




\section{ADVANCED SYSTEMS ENGINEERING TECHNICAL DOCUMENT}

1.1 .4

1.1.4.1

Source Residual Primary Cooling System (SRPCS)

The functions of the source residual primary cooling system (SRPCS) are:

1.1.4.1.1 To provide pumped/forced circulation of $D_{2} \mathrm{O}$ coolant for heat removal from the lead source assembly at the decay heat rate.

1.1.4.1.2 To transfer the decay heat and the sensible stored energy from the lead source assemblies and SRPCS pumps to the source residual secondary cooling system under all plant conditions whenever offsite AC power is not available/sufficient to run the SPCS, SSCS or SCWS pumps or the SPCS, SSCS or SCWS pumps are shutdown for any reason.

\subsubsection{Requirements}

1.1.4.2.1 Two loops, each with 100 percent capacity, shall be used.

1.1.4.2.2 The piping in the source basin and cavity shall be designed to take the maximum cavity pressure from the outside.

1.1.4.2.3 The pump head shall be designed such that air will not be drawn into the loop due to the source assembly pressure drop when both SRPCS trains are operating following a LOCA.

1.1.4.2.4 The point in the SRPCS piping lower than the source basin inlet or outlet penetrations should have a means of detecting a leak that can be used to isolate the failure should one occur while the valves are open. The loop shall be maintained low to assure its operability with the SPCS drained to allow component repair.

1.1.4.2.5 $\quad 1.22 \mathrm{~m}$ (4 feet) clearance shall be allowed around all components and piping welds for inspection and maintenance. Space shall be allowed for isolation valves. Provisions shall be included to allow heat exchanger removal.

1.1.4.2.6 A minimum of four pipe diameters of straight pipe at the suction of the pumps must be provided.

1.1.4.2.7 The location of the pump shall be based on the ability to meet NPSH pump requirements.

1.1.4.2.8 The SRPCS shall be designated a safety related system and designed, fabricated, erected and tested in accordance with the appropriate codes and standards. The system and components shall be designed and fabricated to the ASME B\&PV Code Section III (APT-RD 0001 requirement G.11.1). As the design is further developed, appropriate design classification shall be applied to the systems and components with due consideration being given to the 


\section{ADVANCED SYSTEMS ENGINEERING TECHNICAL DOCUMENT}

ASE-013-0

application and overall safety aspects of the plant. B\&W document 12-3002062 provides guidance in selecting the classifications.

1.1.4.2.9 Pressure protection shall be provided for any segments that can be isolated from the SPCS.

1.1.4.2.10 Performance Requirements:

- Residual Heat, MWt

- Rod Bundle Inlet Plenum Temperature, $C(F)$

Figure $1^{7}$

- Rod Bundle Outlet Plenum Temperature, $C(F)$

$82.2(180)$

Flow Rate, $\mathrm{kg} / \mathrm{s}(\mathrm{lbm} / \mathrm{s})$

TBD(TBD)

1.1.4.3 Interface Requirements

1.1.4.3.1 An emergency power system shall be provided to operate the system when normal $A C$ power is not available.

1.1.4.3.2 Any interfacing systems shall use isolation valves with a means for leak detection provided that will automatically close the isolation valves should a leak occur in the interfacing system pressure boundary.

1.1.4.3.3 The pressurizer and the accumulator surge line in the SPCS shall serve as the return lines for the SRPCS going to the lead source assembly inlet plenum with one surge line serving each train of the SRPCS.

1.1.4.3.4 The SRPCS shall interface with the heavy water purification and chemical treatment system for the purification and detritiation of the coolant and to provide for inventory control via letdown and makeup for any segments that can be isolated from the SPCS.

7 Suggest that the components for the active residual system be sized for decay heat at 200 seconds until analyses are available to support a better value. 


\section{ADVANCED SYSTEMS ENGINEERING TECHNICAL DOCUMENT}

1.1.5 Source Residual Secondary Cooling System (SRSCS)

1.1.5.1 Functions

The functions of the source residual secondary cooling system (SRSCS) are:

1.1.5.1.1 To provide pumped/forced circulation of $\mathrm{H}_{2} \mathrm{O}$ coolant for heat removal from the source residual primary heat exchanger.

1.1.5.1.2 Tc transfer the energy from the lead source assemblies and the SRPCS and SRSCS pumps to the environment under all plant conditions whenever offsite/sufficient AC power is not available to run the SPCS, SSCS or SCWS pumps or the SPCS, SSCS or SCWS pumps are shutdown for any reason.

\subsubsection{Requirements}

1.1.5.2.1 Design the secondary system to a higher pressure than the source residual primary cooling system so that the source residual primary cooling system relief valves will relieve at a lower pressure to prevent the loss of primary coolant to the buildings in the event of an accident following a heat exchanger tube leak. The source residual primary cooling system shall operate at a higher pressure in the heat exchanger than the secondary so that any leakage will be into the secondary to prevent the dilution of the $\mathrm{D}_{2} \mathrm{O}$ should a tube leak occur.

1.1.5.2.2 A forced draft water-to-air heat exchanger shall be used as the ultimate heat sink.

1.1.5.2.3 The location of the pump shall be based on the ability to meet pump NPSH requirements.

1.1.5.2.4 The SRSCS shall be designated a safety related system and designed, fabricated, erected and tested in accordance with the appropriate codes and standards. The system and components shall be designed and fabricated to the ASME B\&PV Code Section III (APT-RD 0001 requirement G.11.1). As the design is further developed, appropriate design classification shall be applied to the systems and components with due consideration being given to the application and overall safety aspects of the plant. B\&W document 12-3002062 provides guidance in selecting the classifications.

\subsection{Performance Requirements:}

- SRPCS Heat Exchanger Inlet Temperature, C(F)

- SRPCS Heat Exchanger Outlet Temperature, $C(F)$

- Water Flow Rate, $\mathrm{kg} / \mathrm{s}(\mathrm{lbm} / \mathrm{s})$

$\operatorname{TBD}(\mathrm{TBD})$ 


\subsubsection{Interface Requirements}

1.1.5.3.1 An emergency power system shall be provided to operate the system when normal AC power is not available.

Blanket Cooling Systems (BCS)

The blanket cooling systems are made up of those systems that remove and transport the blanket assembly generated energy to the ultimate heat sink, refer to Drawing 02-3100895 Sheet 4 . It is composed of the following five systems: blanket primary cooling system (BPCS), the blanket secondary cooling system (BSCS), the blanket circulating water system (BCWS), the blanket residual primary cooling system (BRPCS) and the blanket residual secondary cooling system (BRSCS). All of the systems contain two loops. The main cooling systems contain two $50 \%$ loops for normal operation. All of the residual decay heat loops include two $100 \%$ loops and this includes the passive cooling capability included in the blanket primary and the blanket secondary cooling systems. The functions, system and safety requirements are provided for these systems in the following subsections.

\subsubsection{Blanket Primary Cooling System (BPCS)}

\subsubsection{Functions}

The functions of the blanket primary cooling system (BPCS) are:

1.2.1.1. To transfer the energy generated in the light water coolant, lithium-aluminum blankets and the BPCS pumps to the blanket secondary cooling system.

1.2.1.1.2 To provide natural circulation of the coolant through the blanket to remove the blanket decay heat and the sensible stored energy in the blanket assemblies, and transfer the energy to the secondary system during a station blackout.

1.2.1.1.3 To maintain subcooled conditions in the BPCS coolant during all plant conditions whenever sufficient $\mathrm{H}_{2} \mathrm{O}$ and helium can be maintained in the BPCS pressurizer.

1.2.1.1.4 To provide over pressure control for the blanket primary cooling system and the blanket residual heat removal system.

1.2.1.1.5 To provide blanket fiooding following a loss-of-coolant accident (LOCA).

1.2.1.2 Requirements

1.2.1.2.1 The BPCS shall use $\mathrm{H}_{2} \mathrm{O}$ as the coolant.

1.2.1.2.2 Two blanket primary cooling system loops, each with $50 \%$ capacity, shall be used with one pump in each loop as the safety $T / H$ criteria shall not be violated for a locked rotor event or a LOCA. 


\section{ADVANCED SYSTEMS ENGINEERING TECENICAL DOCUMENT}

ASE-013-0

1.2.1.2.3 For a LOCA, the expansion of the gas in the pressurizer or the accumulator shall not inject gas into the blanket primary cooling system when the blanket cooling system depressurizes.

1.2.1.2.4 Arrange the piping so there are no loop seals to promote natural circulation and to allow any water in the system to drain to the blanket cooling channels to cool the lithium-aluminum pins.

1.2.1.2.5 Arrange piping and components to promote natural circulation in the cooling system in the forward direction (assume the centerline of the heat exchanger inlet nozzle must be no higher than the centerline of the heat exchanger and must be $1.83 \mathrm{~m}$ ( 6 feet) or more above the cavity penetrations until the system \& safety analyses are completed and better numbers are available).

1.2.1.2.6 The lowest point in the piping outside of the cavity must be no lower than the cavity inlet or outlet penetrations.

1.2.1.2.7 $1.22 \mathrm{~m}$ (4 feet) clearance shall be allowed around all components and piping welds for inspection and maintenance. Space shall be provided for isolation valves. Provisions shall be included to allow heat exchanger removal.

1.2.1.2.8 Provide a minimum of four pipe diameters of straight pipe at the suction of the pumps.

1.2.1.2.9 The top of the heat exchanger shall be located such that the loop flow will not be blocked when the lowest horizontal pipe is at atmospheric pressure (assume the top of the heat exchanger can be no more than $3.66 \mathrm{~m}$ (12 feet) above the nozzles on the cavity until the safety analyses are completed providing better values).

1.2.1.2.10 The pumps sinall have flywheels to provide extended coastdown (use 45 seconds until safety analyses are completed and better numbers are available).

1.2.1.2.11 The blankot primary cooling system shall use one pressurizer and one accumulator. (The accumulator requirement may be dropped once the LOCA analyses are complete.)

1.2.1.2.12 The system shall be designed to provide adequate pressure to assure that parallel redundant check valves in the accumulator surge line will be operable or the system shall use redundant parallel DC operated valves set to open on LOCA trip.

1.2.1.2.13 The coolant paths in the lithium-aluminum blanket assemblies shall have no loop seals and shall be arranged to support positive flow (normal flow direction) in all assemblies. Where parallel horizontal channels are used in a series arrangement with vertical channels, a margin to two-phase flow shall be maintained for all accidents up-to and including the design basis events. 


\section{ADVANCED SYSTEMS ENGINEERING TECHNICAL DOCUMENT}

1.1.2.2.14 The location of the pumps shall be based on the ability to meet pump NPSH requirements and the ability to eliminate loop seals.

1.2.1.2.15 The source basin containing the lead source target assemblies shall be designed to withstand any external pressure imposed by a blanket assembly pressure boundary failure.

1.2.1.2.16 The energy deposited in the lithium-aluminum blanket, the moderator, the aluminum supports, and the piping shall be removed by the blanket primary cooling system.

1.2.1.2.17 The BPCS shall be designated a safety related system and designed, fabricated, erected and tested in accordance with the appropriate codes and standards. The system and components shall be designed and fabricated to the ASME B\&PV Code Section III (APT-RD 0001 requirement G.11.1). As the design is further developed, appropriate design classification shall be applied to the systems and components with due consideration being given to the application and overall safety aspects of the plant. B\&W document 12-3002062 provides guidance in selecting the classifications.

1.2.1.2.18 Performance Parameters:

- Power Level, MWt

- Pressure at Blanket outlet, bar(psia)

$9.65(140)$

Blanket Cold Leg Temperature, C(F)

$82(180)$

- Blanket Hot Leg Temperature, $C(F)$

$98.9(210)$

Blanket Flow Rate, $\mathrm{kg} / \mathrm{s}$ (lbs/s)

$372(821)$

Maximum Piping Coolant Velocity, $\mathrm{m} / \mathrm{s}(\mathrm{ft} / \mathrm{s})$

$15.24(50)$

Accumulator Operating Gas Pressure, bar(psia)

$8.14(118)$

Maximum Allowable Accumulator Temperature, $C(F)$

$60(140)$

Accumulator Water Volume, $\mathrm{m}^{3}\left(\mathrm{ft}^{3}\right)$

$4.25(150)$ 
1.2.1.2.18 Analysis/Evalıation Criteria

Category

Event Frequency Range

Criteria

AOOs

1 to $10^{-2}$

DBEs

$10^{-2}$ to $10^{-4}$

$130 \mathrm{C} \mathrm{CHF/OFI} \mathrm{with}$

high confidence ${ }^{8}$

BDBEs

$10^{-4}$ to $\mathrm{TBD}^{10}$

$\mathrm{CHF}^{9}$

RR

Less than $T_{B D}{ }^{12}$

Blanket Cladding $250 \mathrm{C}^{11}$

Containment of inventory

\subsubsection{Interface Requirements}

1.2.1.3.1

1.2.1.3.2

Any interfacing systems shall use isolation valves with a means for leak detection provided that will automatically close the isolation valves should a leak occur in the interfacing system pressure boundary.

The pressurizer and the accumulator surge lines shall serve as the return lines for the BRPCS going to the blanket assembly inlet plena with one surge line serving each train of the BRPCS.

8 The criterion will be based on the critical heat flux (CHF) or the onset of a flow instability between assemblies (OFI). Since orificing may be used in the blanket assemblies at their inlets to distribute the flow such that many of the assemblies will operate with nearly the same margin to CHF/OFI, the confidence will need to be greater than it was for commercial reactors but probably less than was anticipated for the NPR. For the interim period a 99/99 confidence of not exceeding the design critical heat flux ratio (CHFR) equivalent to the 1.3 CHFR for commercial reactors is recommended. The 130 C limit was chosen on NPR to limit the loss of tritium through the cladding to less than $10 \%$.

9 If commercial conservative analysis practice is used, then the CHFR $\geq 1$ or the avoidance of a flow instability is recommended. If a best estimate statistical approach is used the equivalent of the commercial CHFR $=1.3$ or an equivalent margin to the onset of flow instability is recommended.

10 Refer to APT RD A.1.2 and SEN-35-91.

11 The $250 \mathrm{C}$ limit for the blanket assembly was based on the structural integrity of the aluminum clad used to protect the lithium-aluminum and must be reconsidered when the clad material is selected.

12 Refer to APT RD A.1.2 and SEN-35-91. 


\section{ADVANCED SYSTEMS ENGINEERING TECHNICAL DOCUMENT}

ASE-013-0

\subsubsection{Blanket Secondary Cooling System (BSCS)}

\subsubsection{Functions}

The functions of the blanket secondary cooling system (BSCS) are:

1.2.2.1.1 To transfer the energy transferred in from the blanket primary cooling system and generated in the BSCS pumps to the blanket circulating water system whenever adequate $A C$ power and BSCS pressure are available to run the BSCS pumps.

1.2.2.1.2 To provide natural circulation of the coolant through the blanket primary heat exchanger to remove the blanket decay heat and sensible stored energy in the blanket assemblies, and transfer the energy to the environment using a passive water-to-air natural heat exchanger during a station blackout whenever sufficient water is available in the BSCS to allow natural circulation.

1.2.2.1.3 To maintain subcooled conditions in the BSCS coolant during all plant conditions whenever sufficient $\mathrm{H}_{2} \mathrm{O}$ and pressurizer/surge tank cover gas can be maintained in the BSCS pressurizer.

\subsubsection{Requirements}

1.2.2.2.1 The blanket secondary cooling system shall use two $50 \%$ loops for normal power operation, one serving each blanket primary cooling system loop. The secondary loops shall be independent to avoid the loss of both loops with a single failure like a LOCA in a secondary system loop boundary to retain the capability to remove residual heat following a LOCA in a primary loop passively.

1.2.2.2.2 A natural draft water-to-air heat exchangers shall be used in the secondary system of each loop for decay heat removal. The water-to-air heat exchanger in each secondary loop shall be designed to reject $100 \%$ of the residual heat generated in the blanket primary cooling system. The loops shall be arranged to provide positive flow through the water-to-air heat exchanger during normal power operation.

1.2.2.2.3 Design the secondary system to a higher pressure than the primary system so that the primary system relief valves will relieve at a lower pressure to prevent the loss of primary coolant to the buildings in the event of an accident following a heat exchanger tube leak.

1.2.2.2.4 The secondary heat exchanger shall be located such that the thermal center of the primary and secondary heat exchangers are separated by a minimum of 3.66 $\mathrm{m}$ (12 feet). The water-to-air heat exchangers should be located to provide about $6.1 \mathrm{~m}$ (20 feet) or more in the thermal centers of the primary to water-to-air heat exchangers. 


\section{ADVANCED SYSTEMS ENGINEERING TECHNICAL DOCUMENT}

1.2.2.2.5 The location of the pumps shall be based on the ability to meet pump NPSH requirements.

1.2.2.2.6 The BSCS shall be designated a safety related system and designed, fabricated, erected and tested in accordance with the appropriate codes and standards. The system and components shall be designed and fabricated to the ASME B\&PV Code Section III (APT-RD 0001 requirement G.11.1). As the design is further developed, appropriate design classification shall be applied to the systems and components with due consideration being given to the application and overall safety aspects of the plant. B\&W document 12-3002062 provides guidance in selecting the classifications.

1.2.2.2.7 Performance Parameters:

- Blanket Residual Decay Heat, KWt

Figure $2^{13}$

- BPCS Heat Exchanger Inlet Temperature, $C(F)$

$37.8(100)$

$0 \quad$ BPCS Heat Exchanger Outlet Temperature, $C(F)$

$76.7(170)$

o Water Flow Rate per Loop, $\mathrm{kg} / \mathrm{s}(\mathrm{lbm} / \mathrm{s})$

13 Suggest that the water-to-air heat exchangers be sized for decay heat at 200 seconds until analyses have been completed at which time a different number may be set. 


\section{ADVANCED SYSTEMS ENGINEERING TECENICAL DOCUMENT}

\subsubsection{Blanket Circulating Water System (BCWS)}

\subsubsection{Functions}

The function of the blanket circulating water system (BCWS) are:

1.2.3.1.1 To remove energy from the BSCS during normal operation when offsite power is available, and transfer the energy to the ultimate heat sink.

\subsubsection{Requirements}

1.2.3.2.1 The BCWS shall be designed to operate during normal operation when offsite power is available, and transport the energy transferred from the BSCS and generated by the BCWS pumps to the environment.

1.2.3.2.2 The location of the pumps shall be based on the ability to meet pump NPSH requirements.

1.2.3.2.4 Operational Requirements:

- BSCS Heat Exchanger Inlet Temperature, C(F)

29.4(85)

- BSCS Heat Exchanger Outlet Temperature, $C(F)$

43.3(110)

- Design Wet Bulb Temperature, $C(F)$

25(77) 
FIGURE 2

DECAY HEAT DEPOSITION IN LIAI BLANKET

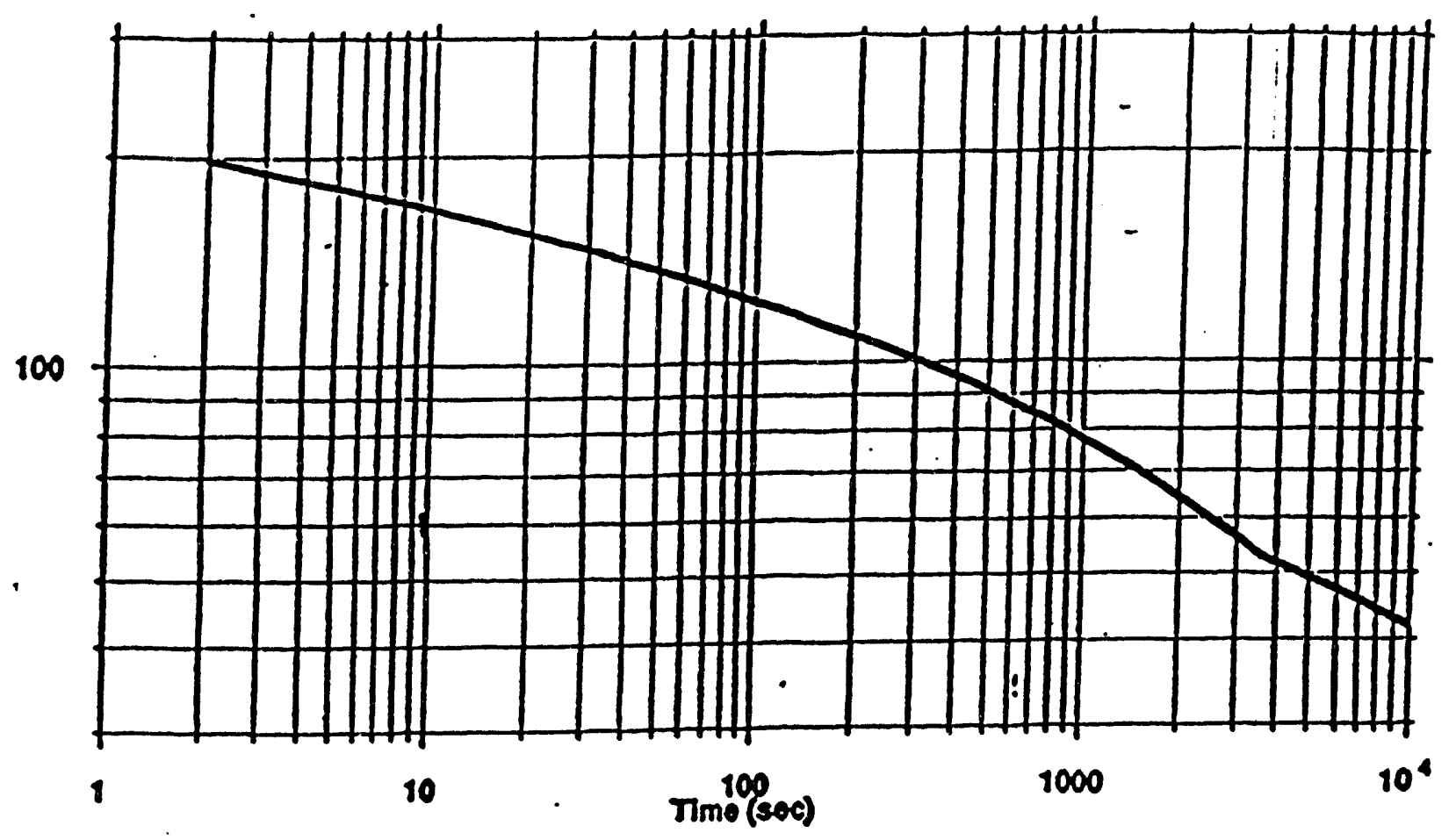




\begin{tabular}{|c|c|}
\hline & ASE - $013-0$ \\
\hline $\begin{array}{l}\text { ADVANCED SYSTEMS ENGINEERING } \\
\text { TECHNICAL DOCUMENT }\end{array}$ & \begin{tabular}{|} 
DOC NUMBER \\
$12-3002053-02$
\end{tabular} \\
\hline
\end{tabular}

\subsubsection{Functions}

The functions of the blanket residual primary cooling system (BRPCS) are to provide pumped/forced circulation of $\mathrm{H}_{2} \mathrm{O}$ coolant for the lithium-aluminum blanket assemblies and transfer of the decay heat and sensible stored energy from the lithium-aluminum blanket assemblies and BRPCS pumps to the blanket residual secondary cooling system under all plant conditions whenever sufficient AC power is not available to run the BPCS, BSCS or BCWS pumps or the BPCS, BSCS or BCWS pumps are shutdown for any reason.

\subsubsection{Requirements}

1.2.4.2.1 Two loop, each with 100 percent capacity, shall be used.

1.2.4.2.2 The point in the BRPCS piping lower than the source basin inlet or outlet penetratioris should have a means of detecting a leak that can be used to isolate the failure should one occur while the valves are open. The loop shall be maintained low to assure its operability with the BPCS drained to allow component repair.

1.2.4.2.3 $\quad 1.22 \mathrm{~m}$ (4 feet) clearance shall be allowed around all components and piping welds for inspection and maintenance. Space shall be allowed for isolation valves. Provisions shall be included to allow heat exchanger removal.

1.2.4.2.4 Provide a minimum of four pipe diameters of straight pipe at the suction of the pumps. The location of the pump shall be based on the ability to meet pump NPSH requirements.

1.2.4.2.5 The BRPCS shall be designated a safety related system and designed, fabricated, erected and tested in accordance with the appropriate codes and standards. The system and components shall be designed and fabricated to the ASME B\&PV Code Section III (APT-RD 0001 requirement G.11.1). As the design is further developed, appropriate design classification shall be applied to the systems and components with due consideration being given to the application and overall safety aspects of the plant. B\&W document 12-3002062 provides guidance in selecting the classifications.

1.2.4.2.6 Performance Requirements:

- Residual Heat, MWt

- Inlet Distributor Temperature, $C(F)$

Figure $2^{14}$

Outlet Distribution Outlet Temperature, $C(F)$

$66(150)$

O Flow Rate, $\mathrm{kg} / \mathrm{s}(\mathrm{lbm} / \mathrm{s})$

$5.08(11.19)$

14 Suggest that the components of the BRPCS be sized for decay heat at 200 seconds until analyses have been completed at which time a different number may be set. 


\section{ADVANCED SYSTEMS ENGINEERING TECHNICAL DOCUMENT}

1.2.4.3 Interface Requirements

1.2.4.3.1 An emergency power system shall be provided to operate the system when normal AC power is not available.

1.2.4.3.2 Any interfacing systems shall use isolation valves with a means for leak detection provided that will automatically close the isolation valves should a leak occur in the interfacing system pressure boundary.

1.2.4.3.3 The pressurizer and the accumulator surge lines in the BPCS shall serve as the return lines for the BRPCS going to the blanket distribution header with one surge line serving each train of the BRPCS. 


\section{ADVANCED SYSTEMS ENGINEERING TECENICAL DOCUMENT}

\subsubsection{Functions}

The functions of the blanket residual secondary cooling system (BRSCS) are to provide pumped/forced circulation cooling for the BRPCS heat exchangers and transfer of the energy to the environment for all plant conditions whenever sufficient $A C$ power is not available to run the BPCS, BSCS or BCWS pumps or the BPCS, BSCS or BCWS pumps are shutdown for any reason.

\subsubsection{Requirements}

1.2.5.2.1 Design the secondary system to a higher pressure than the primary system so that the primary system relief valves will relieve at a lower pressure to prevent the loss of primary coolant to the buildings in the event of an accident following a heat exchanger tube leak.

1.2.5.2.2 A forced draft water-to-air heat exchanger shall be used as the ultimate heat sink.

1.2.5.2.3 The location of the pumps shall be based on the ability to meet pump NPSH requirements.

1.2.5.2.5 The BRSCS shall be designated a safety related system and designed, fabricated, erected and tested in accordance with the appropriate codes and standards. The system and components shall be designed and fabricated to the ASME B\&PV Code Section III (APT-RD 0001 requirement G.11.1). As the design is further developed, appropriate design classification shall be applied to the systems and components with due consideration being given to the application and overall safety aspects of the plant. B\&W document 12-3002062 provides guidance in selecting the classifications.

1.2.5.2.5 Performance Requirements:

- BRPCS Heat Exchanger Inlet Temperature, C(F)

- BRPCS Heat Exchanger Outlet Temperature, $C(F)$

- Water Flow Rate, $\mathrm{kg} / \mathrm{s}(\mathrm{lbm} / \mathrm{s})$

1.2.5.3 Interface Requirements

1.2.5.3.1 An emergency power system shall be provided to operate the system when normal $A C$ power is not available. 
The window cooling systems are made up of those systems that remove and transport the accelerator window assembly generated energy to the ultimate heat sink, refer to Drawing $02-$ 3100895 Sheet. It is composed of the following three systems: window primary cooling system (WPCS), the window secondary cooling system (WSCS) and the window circulating water system (WCWS). All of the systems contains two loops. The main cooling systems contain two $50 \%$ loops for normal operation. Since the residual decay heat is very low, Figure 3, the passive cooling capability provided by the window primary and the window secondary cooling systems to their surroundings was felt to be adequate for residual decay heat cooling. The functions, system and safety requirements are provided for these systems in the following subsections.

\subsubsection{Window Primary Cooling System (WPCS)}

\subsubsection{Functions}

The functions of the window primary cooling system (WPCS) are:

1.3.1.1.1 To transfer the energy generated in the windows and the WPCS pumps to the window secondary cooling system.

1.3.1.1.2 To maintain subcooled conditions in the WPCS coolant during all plant conditions whenever sufficient $\mathrm{H}_{2} \mathrm{O}$ and helium can be maintained in the WPCS pressurizer.

\subsubsection{Requirements}

1.3.1.2.1 The WPCS shall use $\mathrm{H}_{2} \mathrm{O}$ as the coolant.

1.3.1.2.2 Two window primary cooling system loops, each with $50 \%$ capacity, shall be used with one pump in each loop as the safety $\mathrm{T} / \mathrm{H}$ criteria shall not be violated for a locked rotor event or a LOCA.

1.3.1.2.3 The window cooling system shall have a means of detecting leaking on the cavity side of the window and into the accelerator side.

1.3.1.2.4 The piping inside the basin shall be designed to take the maximum basin pressure from the outside.

1.3.1.2.5 The pumps shall have flywheels to provide extended coastdown (use 45 seconds until analyses are complete and better numbers are available).

1.3.1.2.6 A locked rotor event shall not cause the safety $\mathrm{T} / \mathrm{H}$ criteria to be violated.

1.3:1.2.7 The lowest point in the piping must be no lower than the nozzles on the window assembly. Any adjoining systems shall utilize normally closed isolation valves that support this criterion if they go below the minimum level during all operations. For modes of operation that require the isolation valves to be 


\section{ADVANCED SYSTEMS ENGINEERING TECHAICAI DOCUMENT}

DOC. NUMBER

opened, leak detection shall be provided that would close the isolation valves should a leak develop.

1.3.1.2.8 Arrange the piping so there are no loop seals to promote natural circulation and to allow any water in the system to drain to the window cooling channels to cool the window.

1.3.1.2.9 Arrange piping, components and window flow channels to promote natural circulation in the cooling system in the forward direction.

1.3.1.2.10 The coolant paths in the window shall have no loop seals and shall be arranged to support positive natural circulation flow (normal flow direction) in all channels.

1.3.1.2.11 $\quad 1.22 \mathrm{~m}$ (4 feet clearance shall be allowed around all components and piping welds for inspection and maintenance. Space shall be allowed for isolation valves. Provisions shall be included to allow heat exchanger removal.

1.3.1.2.12 Provide a minimum of four pipe diameters of straight pipe at the suction of the pumps. The location of the pumps shall be based on the ability to meet NPSH pump requirements.

1.3.1.2.13 For a LOCA, the expansion of the gas in the pressurizer shall not inject gas into the window primary cooling system when the window cooling system depressurizes.

1.3.1.2.14 The WPCS shall be designated a safety related system and designed, fabricated, erected and tested in accordance with the appropriate codes and standards. The system and components shall be designed and fabricated to the ASME B\&PV Code Section III (APT-RD 0001 requirement G.11.1). As the design is further developed, appropriate design classification shall be applied to the systems and components with due consideration being given to the application and overall safety aspects of the plant. B\&W document 12-3002062 provides guidance in selecting the classifications.

1.3.1.2.15 Performance Requirements:

- Power Level, MWt

- Inlet Temperature, $C(F)$

$61.6(142)$

Outlet Temperature, $C(F)$

$80(176)$

- Flow Rate per loop $\mathrm{kg} / \mathrm{s}(\mathrm{lbm} / \mathrm{s})$

$12.65(27.88)$ 
ASE-013-0

\section{ADVANCED SYSTEMS ENGINEERING TECHNICAL DOCUMENT}

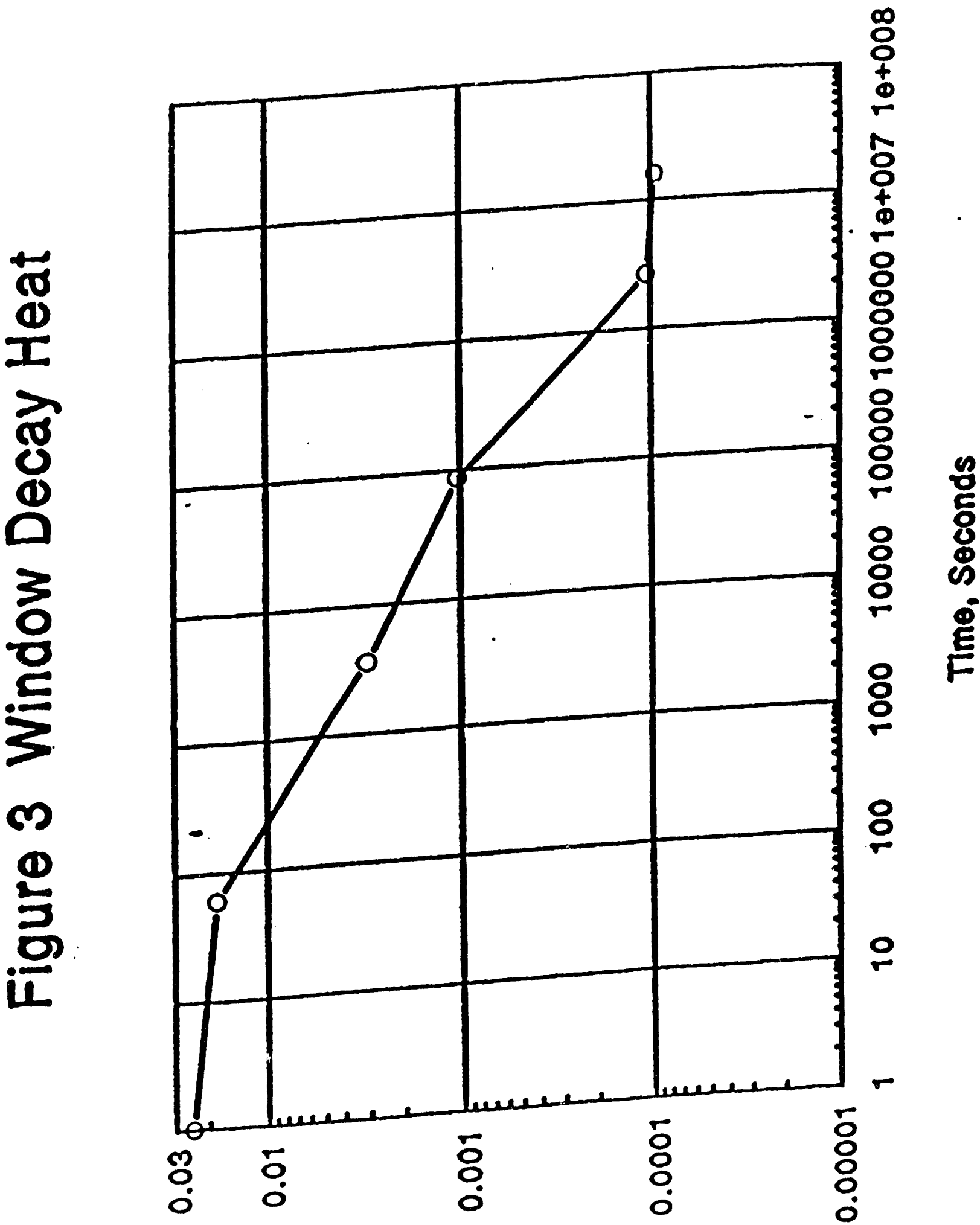




\section{ADVANCED SYSTEMS ENGINEERING TECENICAL DOCUMENT}

\subsection{Analysis/Evaluation Criteria}

Category

AOOs

DBEs

BDBES

RR

1.3.1.3.1

\section{Event Frequency Range}

1 to $10^{-2}$

$10^{-2}$ to $10^{-4}$

$10^{-4}$ to TBD $^{17}$

Less than $T B D^{19}$

\section{Criteria}

CHF/OFI with high confidence ${ }^{15}$

$\mathrm{CHF}^{16}$

Window $250 \mathrm{C}^{18}$

Containment of inventory

\section{Interfacing Requirements}

Any interfacing systems shall use isolation valves with a means for leak detection provided that will automatically close the isolation valves should a leak occur in the interfacing system pressure boundary.

15 The criterion will be based on the critical heat flux (CHF) or the onset of a flow instability (OFI) between flow channels. For the interim period, a 95/95 confidence of not exceeding the design critical heat flux ratio (CHFR) equivalent to the $1.3 \mathrm{CHFR}$ for commercial reactors is recommended.

16 If commercial conservative analysis practice is used, then the CHFR $\geq 1$ or the avoidance of a flow instability is recommended. If a best estimate statistical approach is used the equivalent of the commercial CHFR $=1.3$ or an equivalent margin to the onset of flow instability is recommended.

17 Refer to APT RD A.1.2 and SEN-35-91.

18 The $250 \mathrm{C}$ limit for the window was based on the structural integrity of the aluminum. window and must be reconsidered when the window material is selected.

19 Refer to APT RD A.1.2 arid SEN-35-91. 
1.3.2 Window Secondary Cooling System (WSCS)

\subsubsection{Functions}

The functions of the window secondary cooling system (WSCS) are:

1.3.2.1.1 To transfer the energy transferred in from the window primary cooling system and generated in the WSCS pumps to the window circulating water system whenever adequate AC power and WSCS pressure are available to run the WSCS pumps.

1.3.2.1.2 To provide natural circulation of the coolant through the window primary heat exchanger to remove the window decay heat and sensible stored energy in the window assemblies, and transfer the energy to the surroundings.

1.3.2.1.3 To maintain subcooled conditions in the WSCS coolant.

1.3.2.2 Requirements

1.3.2.2.1 The window secondary cooling system shall use two $50 \%$ loops for normal power operation, one serving each window primary cooling loop. The secondary loops shall be independent to avoid the loss of both loops with a single failure.

1.3.2.2.2 Design the secondary system to a higher pressure than the primary system so that the primary system relief valves will relieve at a lower pressure to prevent the loss of primary coolant to the buildings in the event of an accident following a heat exchanger tube leak.

1.3.2.2.3 The secondary heat exchanger shall be located such that the thermal center of the primary and secondary heat exchangers are separated by a minimum of 3.66 $\mathrm{m}$ (12 feet).

1.3.2.2.5 The location of the pumps shall be based on the ability to meet pump NPSH requirements.

1.3.2.2.6 The WSCS shall be designated a safety related system and designed, fabricated, erected and tested in accordance with the appropriate codes and standards. The system and components shall be designed and fabricated to the ASME B\&PV Code Section III (APT-RD 0001 requirement G.11.1). As the design is further developed, appropriate design classification shall be applied to the systems and components with due consideration being given to the application and overall safety aspects of the plant. B\&W document 12-3002062 provides guidance in selecting the classifications.

1.3.2.2.7 Performance Requirements:

- WPCS Heat Exchanger Inlet Temperature, C(F)

$37.8(100)$

- WPCS Heat Exchanger Outlet Temperature, $C(F)$ 
ASE-013-0

\section{ADVANCED SYSTEMS ENGINEERING} TECHNICAL DOCUMENT

$\begin{array}{ll} & 0 \quad \text { Water Flow Rate, } \mathrm{kg} / \mathrm{s}(\mathrm{lbm} / \mathrm{s}) \\ \text { 1.3.3 Window Circulating Water System (WCWS) }\end{array}$

$9.79(21.58)$

\subsubsection{Functions}

The function of the window circulating water system (WCWS) is:

1.3.3.1.1 To remove energy from the WSCS during normal operation when offsite power is available, and transfer the energy to the ultimate heat sink.

\subsubsection{Requirements}

1.3.3.2.1 The WCWS shall be designed to operate during normal operation when offsite power is available, and transport the energy transferred from the WSCS and generated by the WCWS pumps to the environment.

1.3.3.2.2 The location of the pumps shall be based on the ability to meet pump NPSH requirements.

\subsection{Operational Requirements:}

- WSCS Heat Exchanger Inlet Temperature, C(F)

29.4(85)

- WSCS Heat Exchanger Outlet Temperature, $C(F)$

- Wet bulb Temperature, $C(F)$ 
The source basin flood system is designed to support the cooling of the source in the event of a LOCA of the source or blanket primary coolant systems inside the source side of the basin. A line diagram is provided in 02-3100895, Sheet 6.

\subsubsection{Functions}

The function of the source basin flood system (SBFS) is to fill the source side of the basin before water stops dischargirig from the break in either the source piping inside the basin or the blanket piping inside the source side of the basiin. The purpose is to flood the break not allowing gas into the system allowing natural circulation to continue inside the source primary cooling system and the blanket primary cooling system.

\subsubsection{Requirements}

1.4.2.1 The system shall use light water, $\mathrm{H}_{2} \mathrm{O}$.

1.4.2.2 The piping shall be sized to fill the basin in 90 seconds. The 90 seconds is based on the estimated time for the pressurizer and accumulator to empty.

1.4.2.3 The basin flood piping shall use redundant valves in two $100 \%$ capacity parallel trains to avoid single failure of the valve components. The valves in each train shall be self powered for releasing the stored water to the source basin. The valves and the motive power (electric, pneumatic, hydraulic, etc) shall be diverse between the trains to avoid common mode/common cause failure.

1.4.2.4 The valve operators shall meet the function requirements for a passive component as defined by EPRI and DOE for the small passive reactors. That is each valve shall have sufficient stored energy to move the valve to its emergency position once as a minimum.

1.4.2.5 The flood piping shall contain no seals that could block or impair the flow of water from the storage tank into the basin.

1.4.2.6 The vent pipe seal shall be limited to $0.15 \mathrm{~m}$ (6 inches) near the return to the water storage tank to prevent the free circulation of air between the source Lasin and the top of the storage tank.

1.4.2.7 The water storage tank shall be located at least $5 \mathrm{~m}$ (16.4 feet) above the inlet to the source basin region.

1.4.2.8 The storage tank shall be inside the containment boundary.

1.4.2.9 The tank shall contain a $10 \%$ overfill margin to assure the basin is filled 
1.4.2.10 The SBFS shall be designated as a safety related system and designed, fabricated, erected and tested in accordance with the appropriate codes and standards. The system and components shall be designed and fabricated to the ASME B\&PV Code Section III (APT-RD 0001 requirement G.11.1). As the design is further developed, appropriate design classification shall be applied to the systems and components with due consideration being given to the application and overall safety aspects of the plant. B\&W documerit 12-3002062 provides guidance in selecting the classifications.

1.4.2.11 Operational Requirements for SBFS:

- Minimum Volume of Water, $\mathrm{m}^{3}$

$\operatorname{TBD}(T B D)$

- Volume of Cover Gas, $m^{3}$

- Maximum Allowable Water Temperature, $C(F)$

$\operatorname{TBD}(\mathrm{TBD})$

$38(100)$ 
Appendix 4B

Purification System Requirements

4.105 


\section{$1.0 \quad$ SILC (BNL-APT) Purification Systems}

The requirements for the SILC APT puirfication systems: 1)heavy water purification, 2) light water purification, and 3) $D_{2} O$ upgrade system are included in this section.

\section{$1.1 \quad$ Heavy Water Purification System (HWPS)}

\subsubsection{Functions}

The functions of the Heavy Water Purification System (HWPS) are as follows:

1.1.1.1 Provide continuous purification to remove soluble, particulate, and gaseous chemical and radioactive impurities (except tritium) from the Source Primary Cooling System (SPCS) and Source Residual Primary Cooling System (SRPCS).

1.1.1.2 Maintain specified oxygen concentration in the SPCS by addition of oxygen, as required.

1.1.1.3 Provide $\mathrm{pD}(\mathrm{pH})$ control and monitoring to ensure that the $\mathrm{pD}$ in the SPCS remains within design limits. Control is by nitric acid addition.

1.1.1.4 Provide an inventory of purified heavy water coolant for SPCS makeup.

1.1.1.5 Provide for processing of SPCS grade drainage.

1.1.1.6 Transfer processed heavy water to the $\mathrm{D}_{2} \mathrm{O}$ Upgrade System for removal of light water contamination.

\subsubsection{Process Requirements}

The process requirements of the system are as follows:

1.1.2.1 Separate purification systems shall be provided for each Source Primary Cooling System (i.e., two systems for the two sources).

1.1.2.2 The system shall operate during all plant normal operating modes (startup, production, shutdown and target changeout).

1.1.2.3 The HWPS shall be designed to minimize leakage of heavy water.

1.1.2.4 The HWPS shall be designed to minimize exposure of heavy water to the building atmosphere.

1.1.2.5 The HWPS shall maintain the Reactor Coolant chemistry within the limits given in 
Table 1 and provide proper interface for process sampling to assure that these specifications will be maintained.

1.1.2.6 The HWPS shall provide sufficient surge volumes, pumping capacity and flow control to balance the flow volumes entering the SPCS and returning to the HWPS.

Table 1 BNL-APT SILC Project Source Operating Chemistry Guidelines

\begin{tabular}{|c|c|}
\hline $\mathrm{pH}_{\mathrm{A}}{ }^{*}\left(25^{\circ} \mathrm{C}\right)$ & $4.6-4.8$ \\
\hline Conductivity $\left(25^{\circ} \mathrm{C}\right)$ & $1.9-3 \mu \mathrm{S} / \mathrm{cm}$ \\
\hline Nitrate & $500-630 \mathrm{ppb}$ \\
\hline Oxygen & $0.5-1.5 \mathrm{ppm}$ \\
\hline Chlorides & $<30 \mathrm{ppb}$ \\
\hline Mercury & $5 \mathrm{ppb}$ \\
\hline Peroxides & $1 \mathrm{ppm}$ \\
\hline Copper, Silver, Gold & $25 \mathrm{ppb}$ \\
\hline Flouride & $30 \mathrm{ppb}$ \\
\hline Sulfates & $25 \mathrm{ppb}$ \\
\hline Turbidity & $<0.5 \mathrm{ppm}$ \\
\hline
\end{tabular}

${ }^{*} \mathrm{pD}=\mathrm{pH}_{\mathrm{A}}+0.4$

1.1.2.7 The HWPS shall provide holdup tanks for heavy water with sufficient capacity to contain the entire required plant inventory.

1.1.2.8 The HWPS shall have a flow rate sufficient to process 3.3 SPCS volumes per day (purification half life of 5 hours).

1.1.2.9 The HWPS shall control the helium concentration to minimize the gaseous release from the coolant should a depressurization occur.

\subsection{Light Water Purification System (LWPS)}

\subsubsection{Functions}

The functions of the Light Water Purification System (LWPS) are as follows: 
1.2.1.1 Provide continuous purification to remove soluble, particulate, and gaseous chemical and radioactive impurities (except tritium) from Window Primary Cooling System (WPCS), Blanket Primary Cooling System (BPCS), and the Blanket Residual Primary Cooling System (BRPCS).

\subsubsection{Maintain specified oxygen concentration by addition of oxygen as required.}

1.2.1.3 Provide $\mathrm{pH}$ control and monitoring to ensure that the $\mathrm{pH}$ in the cooling systems remains within design limits. Control is by nitric acid addition.

\subsubsection{Process Requirements}

The process requirements of the system are as follows:

1.2.2.1 Separate purification systems shall be provided for each target assembly (i.e., two systems for the two assemblies).

1.2.2.2 The system shall operate during all plant normal operating modes (startup, production, shutdown and target changeout).

1.2.2.3 The LWPS shall maintain the coolant chemistry within the limits given in Table 2 and provide proper interface for process sampling to assure that these specifications will be maintained.

1.2.2.4 The LWPS shall provide sufficient surge volumes, pumping capacity and flow control to balance the flow volumes entering the cooling systems and returning to the LWPS.

1.2.2.5 The LWPS shall have a flow rate sufficient to process 3.3 cooling system volumes per day (purification half life of 5 hours).

Table 2 BNL-APT SILC Projected Blanket and Window Operating Chemistry Guidelines

\begin{tabular}{|c|c|}
\hline $\mathrm{pH}\left(25^{\circ} \mathrm{C}\right)$ & $5.0-5.2$ \\
\hline Conductivity $\left(25^{\circ} \mathrm{C}\right)$ & $2.5-4.0 \mu \mathrm{S} / \mathrm{cm}$ \\
\hline Nitrate & $500-630 \mathrm{ppb}$ \\
\hline Oxygen & $0.5-1.5 \mathrm{ppm}$ \\
\hline Chlorides & $<30 \mathrm{ppb}$ \\
\hline Mercury & $5 \mathrm{ppb}$ \\
\hline Peroxides & $1 \mathrm{ppm}$ \\
\hline
\end{tabular}




\begin{tabular}{||c|c||}
\hline Copper, Silver, Gold & $25 \mathrm{ppb}$ \\
\hline Flouride & $30 \mathrm{ppb}$ \\
\hline Sulfates & $25 \mathrm{ppb}$ \\
\hline Turbidity & $<0.5 \mathrm{ppm}$ \\
\hline
\end{tabular}

\section{$1.3 \quad \underline{D}_{2} \mathrm{O}$ Upgrade System}

\subsubsection{Requirements}

$\mathrm{D}_{2} \mathrm{O}$ isotopic upgrade will be provided to the source primary coolant system. 


\subsection{WASTE STREAM MANAGEMENT DESIGN (WBS 5, 1.3.1.3.1)}

\section{$5.1 \quad$ INTRODUCTION}

The BNL effort in waste management for the APT project includes management of the radioactive, hazarous and mixed, waste produced by the tritium production facility and tritium extraction facility. Waste streams from production of tritium include waste from beam expansion chambers, proton irradiation of lead-aluminum ( $\mathrm{Pb}-\mathrm{Al})$ targets, neutron irradiation of lithium-aluminum ( $\mathrm{Li}-\mathrm{Al}$ ) blankets, and processing blankets for transport to an extraction facility. Extraction waste streams include waste produced by the extraction, purification, and storage of tritium. Extraction waste also includes the spent $\mathrm{Li}-\mathrm{Al}$ melts.

The following sections categorize the types of radioactive, hazardous, and mixed waste resulting from operation of the APT. Waste processing operations are outlined, and estimates are made of the volume of waste and radioactivity content. Estimates are also nade of job control waste, i. e., waste that is produced in maintenance and repair operations. This first section, 5.1, summarizes the amounts of waste expected to be generated and lists the assumptions used to estimate the amount of waste. The second section, 5.2, describes waste management for tritium production in the APT. The third section, 5.3, addresses waste produced by extraction-purification of tritium from the $\mathrm{Li}-\mathrm{Al}$ blankets. The last two sections, 5.4 and 5.5, describe the waste preparation required for transporting waste to a storage or disposal facility, and items that will need further study as the design progresses. Appendix 5.A defines the terms used in this document. Appendix 5.B lists the induced radioactivity in the target and blanket arrays and the gamma generation rate from the irradiated target assembly (these numbers are based on an early design and will be changed as design progresses). The remaining Appendices list applicable DOE and Department of Transportation Orders, typical casks used for waste transportation, and examples of waste volume estimates.

In addition, other waste generation is also considered, such as the spent deionizers and filters used to control water chemistry in the light and heavy water cooling systems, and in the basin used to disassemble or temporarily store irradiated components.

Waste streams resulting from operation of the accelerator, from fabrication of target and blanket assemblies, and from decommissioning the facility are not included in this task.

\subsubsection{Volume Estimate of Waste Generated}

Present and increasing environmental sensitivity concerning radioactive and hazardous waste will require that detailed attention be paid to the waste being generated in the initial design stages of any facility. New facilities should be designed not only to minimize the quantity of waste generated, but must also be designed to be able to package the waste into forms acceptable for transport and disposal in approved waste disposal facilities. The handling and packaging of waste should be the responsibility of the waste generator. A central waste handling facility would be used only when justified by logistic and economic reasons. To express this philosophy 
another way, experience at nuclear facilities has shown that if individual waste generators are not made accountable and responsible for treating the waste they generate, waste generation rates are much larger than necessary.

It must also be assumed that by the time that the APT begins operation, waste treatment, handling, volume reduction, and transport of radioactive waste will have to meet all of the regulations applied to waste generated by commercial nuclear power facilities.

A best estimate has been made of the volumes of low-level radioactive waste, hazardous waste and mixed waste. The estimates are based on:

- The design concepts of the target and blanket arrays, and the window and beam expansion chamber presented at the April 29, 1993 APT meeting at Brookhaven National Laboratory.

- Disassembly of target and blanket arrays in a disassembly basin to remove cooling water headers, water plenums, support structures, and blanket pressure tubes. It is assumed that these pieces will be cut or sawed into aluminum scrap and compacted so that the resulting material is about one-half of normal aluminum density.

- A crucible loading of $\mathrm{Li}-\mathrm{Al}$ targets weighing about 0.5 metric tons (MT). The portions of the crucibles that do not contain the melts will be cut into scrap and compacted to about one-half the melt volume.

- Savannah River Site projections of low-level, hazardous, and mixed waste produced in the new design for a tritium extraction facility.

The estimated waste volumes are shown in Tables 5.1, 5.2, and 5.3. Appendix 5.F shows two examples of how these volumes and weights are estimated. These tables show that about 45 cubic meters of compacted metallic low-level waste will be generated annually when (1) the blanket and target arrays and (2) the window and beam expander tube are discharged. Most of this waste will be radioactive aluminum and possibly other metallic structural waste. The total weight, excluding that of shipping containers, is estimated to be 37.3 metric tons. This waste is compacted so that when dried and placed into shipping containers the volume would be one-half metal and one-half air, equivalent to one-half the normal metal density. This waste will be transported in approved shipping containers to an approved low-level waste disposal facility. Job control waste will add about 100 cubic meters of waste, which can be compacted to 25 cubic meters. The small volume of non-compactable filter and resin waste from water purification is included in the 25 cubic meter total.

In addition, every year about 4 cubic meters of $\mathrm{Pb}-\mathrm{Al}$ targets in pressure tubes will be discharged and cut away from the cooling headers and plenums. The weight of this waste is about 21.5 metric tons. This waste contains radioactive lead and is classified as mixed waste. 
It will be necessary to store this waste onsite in secure, monitorable and shielded containers until a mixed waste disposal facility becomes available. Details are shown in Table 5.1. Disposal of the small amount of hazardous waste is discussed in Section 5.2.8.

Table 5.2 gives expected annual volumes and weights of low-level, mixed, and hazardous waste from operation of the tritium extraction-purification facility. About 60 cubic meters per year of low-level waste would result from processing the $\mathrm{Li}-\mathrm{Al}$ in stainless steel crucibles. A much larger amount of low-level waste, 750 cubic meters, is estimated to result from job control waste, such as clothing, plastic suits, shoe covers, paper, plastic, tools, etc. containing tritium contamination. It is possible that some of the job control waste can be compacted; however, compaction of tritium containing waste can result in undesirable tritium releases. In addition, a small amount of waste, one cubic meter per year, is expected to result from replacement of failed or used equipment in the extraction facility. This is included in the quantity of job control waste. A small amount of mixed and hazardous waste, about 4.6 cubic meters per year, is also generated in this facility.

Total waste generated, shown in Table 5.3, is expected to be about 607 cubic meters of compacted waste per year, with a weight of 620 metric tons.

Details of the expected waste generation are given in the following sections of this report.

\subsubsection{Assumptions}

Guidelines used to describe the waste streams incurred during the operation of the APT are listed below.

1. Waste generated in the operation of the APT is estimated on the basis of a target assembly (source array) discharge cycle of once every year, a blanket discharge cycle once every year, and a window replacement cycle of once a year. The schedule is given below. The letter " $\mathrm{D}$ " stands for discharge, disassembly, packaging, and shipment to the extraction process for the blanket assemblies, or discharge and storage of the target assembly.

$\begin{array}{llccccccccc} & \text { YEAR } & \underline{1} & \underline{2} & \underline{3} & \underline{4} & \underline{5} & \underline{6} & \underline{7} & \underline{8} & \underline{9} \\ \text { Beam Port \#1 } & \text { BEAM } & \text { ON } & \text { OFF } & \text { ON } & \text { OFF } & \text { ON } & \text { OFF } & \text { ON } & \text { OFF } & \text { ON } \\ & \text { BLANKET } & - & \text { D } & - & \text { D } & - & \text { D } & - & \text { D } & - \\ & \text { TARGET } & - & \text { D } & - & \text { D } & - & \text { D } & - & \text { D } & - \\ & \text { WINDOW } & - & \text { D } & - & \text { D } & - & \text { D } & - & \text { D } & - \\ \text { Beam Port \#2 } & \text { BEAM } & \text { OFF } & \text { ON } & \text { OFF } & \text { ON } & \text { OFF } & \text { ON } & \text { OFF } & \text { ON } & \text { OFF } \\ & \text { BLANKET } & - & - & \text { D } & - & \text { D } & - & \text { D } & - & \text { D } \\ & \text { TARGET } & - & - & \text { D } & - & \text { D } & - & \text { D } & - & \text { D } \\ & \text { WINDOW } & - & - & \text { D } & - & \text { D } & - & \text { D } & - & \text { D }\end{array}$


TABLE 5.1

ESTIMATED AMOUNTS OF WASTE GENERATED ANNUALLY IN THE TARGET AND BLANKET (1)(2)

\section{Type of Waste}

High-Level

Transuranic

Low-Level (Total)

Cooling water headers, plenums

Pressure tubes, headers, plenums

Al fines, scrap metal, filters

Job Control Waste, Consumables

\section{Mixed Waste}

Hazardous Waste

\section{Volume

$$
\mathrm{M}^{3} / \mathrm{Vr}
$$ \\ 0}

Source of Waste

-..

$--$

Target Array
Blanket Arrays
Accelerator
Disassembly Basin
Handling,
Disassembly,
Coolant Purification

Pb-Al Targets and Pressure Tubes

Target Area

\section{0}

144.6

2.6

40

1

1

100 (3)

4

0.06

\section{Weight \\ MT / yr (4)}

0

0

87.3

3.6

30

1.3

2.4

50

21.5

0.12

\section{Disposition}

-.-

$--$

-..

Approved LLW Fac.

Approved LLW Fac.

Approved LLW Fac.

Approved LLW Fac.

Approved LI.W Fac.

Reference

Section

$$
\text { -.. }
$$

\section{$--$}

$$
\text { -.. }
$$

5.2.2 and App. 5.F

5.2 .3

5.2 .4

5.2 .5

5.2.6 \& 5.2.7

Mixed Waste Stor.

5.2.2 Fac.

Approved Hazardous Waste Disposal Fac.
Assumes blanket array, window, beam expansion chamber and $\mathrm{Pb}-\mathrm{Al}$ target array are discharged once a year. The volume of all metal, except for $\mathrm{Pb}-\mathrm{Al}$ targets, is the compacted volume.

Does not include Li-Al, which is shown on iable 2.

The job control waste value is not the compacted value.

Does not include weight of shipping containers such as drums and shielded casks. 
TABLE 5.2

ESTIMATED AMOUNTS OF WASTE GENERATED ANNUALLY IN THE TRITIUM EXTRACTION

\section{ESTIMATE \\ Type of Waste}

High-Level

Transuranic

Low-Level (Total)

Li-Al Melts

in Crucibles

Job Control Waste

Mixed Waste

Hazardous Waste

\section{Source of Waste}

-.-

$--$

Extraction Furnace

Extraction Furnace

Extraction Facility

Extraction Facility

Extraction Facility
Volume

$\mathrm{M}^{3} / \mathrm{Vr}$

0

0

810

) (2)

J (2)

$750(2,3,5)$

4 (3)

$0.6(3)$
Weight
MT / yr

(4)

0

0

$\underline{502}$

74

53

375

8

(1)

Reference

Disposition

Section

$---$

$--$

--

Approved' LLW Fac.

5.3.2

Approved LLW Fac.

Approved LLW Fac.

5.3 .2

Mixed Waste Stor.

Fac.

Approved Hazardous Waste Disposal Fac.

(1)

(2)

(3)

(4)

(5)
Assumes blanket array, window, beam expansion chamber, and $\mathrm{Pb}-\mathrm{Al}$ target array are discharged once

\section{a year.}

Tritium contaminated waste - will require total tritium containment.

Savannah River Site estimate for new design of tritium extraction facility.

Does not include weight of shipping containers such as drums and shielded casks.

The job control waste value is not the compacted value. The waste includes failed equipment from the extraction facility. See Text. 
TABLE 5.3

ESTIMATED TOTAL VOLUME AND WEIGHT OF LOW-LEVEL, MIXED, AND HAZARDOUS WASTE GENERATED ANNUALLY IN THE APT ${ }^{(1)}$

Type of Waste

High-Level

Transuranic

Low-Level

Mixed

Hazardous

Totals (Rounded)
Compacted Volume, $\mathrm{M}^{3} / \mathrm{yr}$

0

0

598.35

8

$\underline{0.66}$
Weight, $M T / 3 r^{(2)}$

0

0

589.3

29.5

$\underline{1.3}$

(1) Assumes blanket array, window, beam expansion chamber, and the $\mathrm{Pb}-\mathrm{Al}$ target are discharged once a year.

(2) Does not include weight of shipping containers such as drums and shielded casks.

2. The blanket and target design will be as described in the Definition Section of this report, Appendix 5.A.

3. Hazardous waste produced in the fabrication of the $\mathrm{Pb}-\mathrm{Al}$ target and $\mathrm{Li}-\mathrm{Al}$ blanket assemblies will be addressed by the fabricator.

4. Decommissioning of the APT and the associated extraction facility is not addressed in this report, but will be in the future.

5. A disassembly basin will be incorporated in the APT facility. It will provide shielding for the temporary storage of the discharged target and blanket assemblies, and will be used to disassemble these and other structural components, such as the window assembly. It will use water for shielding, and will have associated with it remote handling equipment, a compactor for metal pieces, viewers, filters to collect metal fines, and deionizers and chlorinating systems to maintain clarity of the water.

6. Production of waste from the extraction facility is based on a scaied-down version of the Savannah River Site 232-H extraction facility.

7. A waste treatment building will be incorporated in the overall design of the APT facility. Operations intended for this building will be decontamination, compaction of slightly 
contaminated compressible waste, grouting equipment, a laundry facility for slightly contaminated clothing, and waste packaging equipment to package waste in contamination-free containers. Also, as part of this building, waste assay devices will be used to insure that waste and shipping containers meet shipping and disposal regulations concerning the amount of radioactivity and external contamination.

8. A storage area for shielded casks will be required for long term storage of the irradiated $\mathrm{Pb}$-Al target arrays. The storage area will conform to regulations pertaining to mixed waste storage. Whether it will be practical to reprocess the lead has yet to be determined.

\subsection{WASTE MANAGEMENT FOR TRITIUM PRODUCTION}

\subsubsection{Summary}

A preconceptual management system for low-level and mixed waste generated in the accelerator production of tritium is outlined in Table 5.1. Principal waste types are: spent lead targets bundled in aluminum pressure tubes, the piping system for moderator flow through the $\mathrm{Pb}$ targets and the piping system for light water flow through the blanket assembly, aluminum pressure tubes holding bundles of $\mathrm{Li}-\mathrm{Al}$ rods in the blanket assembly, spent deionizer resin from moderator and coolant purification, other structural components such as the aluminum beam expander chamber and window, and aluminum and steel scrap from disassembly basin operations. With the exception of the highly radioactive spent lead targets, which are mixed waste, almost all of the other waste is solid low-level waste. Conceptual systems are described for disassembling and size reducing these waste types as needed to fit commercially available casks and containers for storage on-site as mixed waste or disposal as low-level waste in an approved off-site low-level waste facility.

\subsubsection{Target Array}

In the preconceptual design for the accelerator production of tritium, the proton beam is directed into one of two identical chambers isolated from the evacuated beam tube by an aluminum window. Each chamber contains identical, massive target and blanket arrays. One of these chambers will receive full beam power for a year, while the other chamber is idle for recharge operations and maintenance. One complete target array will be discharged every year. The target array consists of aluminum clad lead rods bundled in thirty-three pressure tubes. The total weight of lead and aluminum in each array is $25.1 \mathrm{MT}$. In addition, the end fittings and flow plenum for the heavy water moderator, which are an integral part of this array, may contain an estimated 2 to 3 MT of aluminum.

After one year in the proton beam, the entire target array is removed as a unit and taken to an underwater basin. After a suitable cooling period to allow for decay of the shortlived radionuclides, the unit is disassembled for packaging as waste. Disassembly is necessary because the overall size of the unit and its weight (25.1 MT) make packaging and shielding as a unit impractical. As discussed at the beginning of Section 5.1.1, the handling and packaging 
of the target array should be the responsibility of the operating group in charge of this operation, and not the responsibility of a central waste handling facility.

The unit will be disassembled by cutting the inlet and outlet pressure tube fittings under water. The freed thirty-three pressure tubes are mixed waste and must be packaged and shielded for long term storage on site ${ }^{1}$. An example of how this can be accomplished is to use a shielded cask such as the commercially available CNS 3-55 Type B as the storage unit. This cask has an inner diameter of $0.91 \mathrm{~m}$ (36 in.) and an internal height of $2.8 \mathrm{~m}$ (110 in.). The cask can be loaded under water and has a shielding equivalence of $17.8 \mathrm{~cm}$ (7 inches) of lead. However, its loading limit of 3.8 MT requires that seven casks be used for the 33 pressure tubes. The 20 large diameter tubes could be packaged four to a cask (5 casks), and the 13

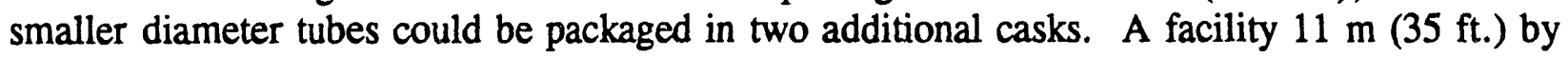

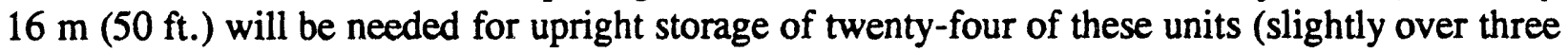
full target arrays) spaced on $2.44 \mathrm{~m}(8 \mathrm{ft}$.) centers. This spacing is necessary to allow for visual and instrumental inspection to ensure continuing integrity. Thus, a 175 square meter shielded, monitorable storage area will be required for every three years of operation of the APT.

The target tubes will be highly radioactive. Table B-2 in Appendix 5.B gives examples of the gamma emissions for two energy ranges after one year of irradiation and six months cooling time. It is estimated that the $\mathrm{Pb}-\mathrm{Al}$ target tubes will emit $7 \mathrm{E}+16$ high energy photons/sec (two million curies). More refined calculations will be required to determine if the $17.8 \mathrm{~cm}$ ( 7 inches) of lead shielding in the casks mentioned above will be sufficient.

\subsubsection{Blanket Array}

Each irradiation chamber of the accelerator tritium production system contains an array of four blanket assemblies of $\mathrm{Li}-\mathrm{Al}$ clad in $\mathrm{Al}$. These assemblies are interconnected in a "bird hour:" shape in Al pressure tubes through which light water coolant is conducted. The water is purified by an on-line ion-exchange system. The total weight of the $\mathrm{Al}$ clad $\mathrm{Li}-\mathrm{Al}$ and the supporting pressure tubes is 106.4 MT. At the end of a one year cycle of irradiation and after a suitable period of cooling, each of the four blanket assemblies is remotely cut away from the complete array and transported to the underwater basin for further disassembly into units sized for subsequent tritium removal in the extraction facility. The aluminum beam expander tube and window, weighing 1.32 MT, are removed to the basin for size reduction. Low-level waste derived from these operations is structural waste and spent deionizer resin, and are discussed in Sections 5.2.4 and 5.2.6. As discussed at the beginning of Section 5.1.1, the handling and packaging of the blanket arrays should be the responsibility of the operating group in charge of this operation, and not the responsibility of a central waste handling facility.

${ }^{1}$ When stored under water for temporary storage, the 33 pressure tubes can be placed into a rectangular array $2.1 \mathrm{~m}$ wide, $1.27 \mathrm{~m}$ deep, and $1.5 \mathrm{~m}$ high, a volume of 4 cubic meters. 


\subsubsection{Structural Waste}

The three major components of the structural waste category are the end fittings and flow plenum for the heavy water system of the target array. the end fittings, flow plenum anid pressure tubes of the blanket array, and the aluminum beam expander tube and window of the blanket assembly.

The end fittings and flow plenums for the heavy water moderator and light water coolant systems must be reduced in size for compaction and packaging in a disposal container; also, the pressure tubes cut from the $\mathrm{Li}-\mathrm{Al}$ rods must be compacted. This $34.9 \mathrm{MT}$ mass can be size- reduced by cutting in the underwater basin into thirty to forty-five $\mathrm{cm}$. lengths for compaction $^{2}$. The cutting will produce about $2.4 \mathrm{MT}$ of Al fines and small pieces of scrap metal. The total weight is $37.3 \mathrm{MT}$ of metal scrap. The design for this operation should provide for ease of collection of the cut pieces and for their placement in an underwater compactor. It should be possible to compact this waste to about one-half of its theoretical density (i.e., one-half volume metal and one-half volume air) and place it in containers the size of 55-gallon drums. Between one hundred thirty and one hundred fifty of such containers would be generated every year.

This waste is estimated to contain $200,000 \mathrm{Ci}$. in the total $37.3 \mathrm{MT}$ mass. Each drum of compacted waste would contain about $1,500 \mathrm{Ci}$. of induced activity. An example of how this waste could be shipped to a disposal site would be to load the drums into a CNS 6-80-2 Type A transport cask. This cask can be toploaded underwater and can hold up to four 55-gallon drums. It is designed to transport waste radiating up to $1,860 \mathrm{R} / \mathrm{hr}$ and has a lead shielding equivalent of $12 \mathrm{~cm}$ (5.0 inches). The compacted end fittings and plenum waste will likely exceed the cask radiation limit with four drums inside. However, the drums could possibly be shipped one or two at a time or additional cooling time in the underwater basin could be used to bring the radioactivity down to more manageable levels. Another example of a commercially available transport cask suitable for shipping this waste is the Nu PAC 6-100H Type A. The capacity of this cask is 6 drums, the Pb shielding equivalent is $10 \mathrm{~cm}(4 \mathrm{in})$. As with the CNS 6-80-2, the number of drums per shipment may have to be reduced because of the intense radioactivity of this waste. More information is needed about the type of aluminum used, its impurities, and the quality of the neutron spectrum to which it was exposed to refine the shielding calculation.

The beam expander tube and window of the blanket assembly must also be reduced in size for compaction and packaging in a disposal container. This waste segment has a weight of 1.32 MT and contains $11,000 \mathrm{Ci}$. of induced activity. If it is assumed that this waste can be compacted to about one-half its theoretical density in containers about the size of 55-gallon

${ }^{2}$ Composed of 3.6 MT of cooling water headers and plenums from the target array, $30 \mathrm{MT}$ of pressure tubes, headers and plenums from the blanket array, and $1.32 \mathrm{MT}$ from the beam and expansion chamber. 
drums, about twelve such containers would be generated every year as the blanket array is discharged. Each drum of compacted waste would contain about 1,000 Ci. As was the case with the compacted end fittings and flow plenum from the target array, the same example of the CNS 6-80-2 Type A transport cask applies.

\subsubsection{Waste From Disassembly of Targets and Blankets}

Underwater cutting operations for the target and blanket arrays will generate aluminum fines and small pieces of metal scrap that must be collected and packaged as waste. In addition, maintenance of the cutting equipment and underwater compactor will generate small amounts of odd shaped waste, tools, and broken hardware. An allowance of about one cubic meter per year seems reasonable for this type of low-level waste. This amount of waste in five to ten 55gallon drums would fit one or two CNS 4-85 Type B transport casks for shipment and disposal. An alternative transport cask is the $\mathrm{Nu}$ Pac 6-100 L which can hold six 55-gallon drums and offers $8.2 \mathrm{~cm}$ ( $3.25 \mathrm{in}$.) of $\mathrm{Pb}$ equivalent shielding. Since waste of this type may not be compactable, a means of filling excessive void space in the drums by grouting may be necessary.

\subsubsection{Solid Waste From Water System Purification}

On-line purification of both the heavy water moderator system of the target array and the light water system of the blanket array will be by ion exchange. In the absence of conceptual design details for these systems, it is assumed that a dual column unit for each water system may be used. These units, about 1.22 meters (four feet) in diameter and 1.5 meters (five feet) in height, would be changed at the end of each annual cycle of irradiation. Design of these ion-exchange columns, presumably stainless steel, should include fittings to allow for total water removal when taken out of service. Inlet/outlet ports must be closed with blank flanges or welded shut. Based on experience with reactor deionizers at SRS, a radioactivity loading of about ten curies per deionizer is likely. Deionizers, after draining and dewatering operations in a shielded enclosure, can be toploaded into a CNS 14-190H Type A transport cask. The interior dimensions of the cask are $190.5 \mathrm{~cm}$ (75 in.) in diameter and $185.4 \mathrm{~cm}$ (73 in.) in height. The cask has a $8.9 \mathrm{~cm}$ ( $3.5 \mathrm{inch}$ ) lead shielding equivalent and a capacity of $8 \mathrm{MT}$. An alternative cask is the $\mathrm{Nu}$ Pac 14-210 $\mathrm{H}$ with interior dimensions of $195.6 \mathrm{~cm}$ (77 in.) in diameter, 203.2 $\mathrm{cm}$ (80 in.) in height, and with $7.0 \mathrm{~cm}$ (2.75 in.) $\mathrm{Pb}$ equivalent shielding. Two shipments per year will be generated, equivalent to about 10 cubic meters per year. This 10 cubic meters per year is included in job control waste.

A refined calculation of the carbon-14 generation rate in the water systems, particularly the heavy water system, due to ( $n$,alpha) reactions on the oxygen- 17 , is needed to ensure that the low-level waste status of waste resin does not become an issue in the future. Alternatively, long-term retrievable storage of spent resin containers may be required until the disposal issue is resolved. 


\subsubsection{Job Control Waste From Disassembly Basin}

Job control waste resulting from operations in the disassembly basin will result in an estimated volume of waste of 100 cubic meters per year. This waste will not contain significant tritium activity, and should be easily compactable to about 25 cubic meters per year. Section 5.4.1 on the Disassembly Basin discusses this waste generation in greater detail.

\subsection{8 $\quad$ Hazardous Waste}

Another small volume of waste $\left(0.06 \mathrm{~m}^{3} / \mathrm{yr}\right)$, similar to job control waste, is miscellaneous hazardous waste generated in the maintenance and housekeeping of the production area and disassembly basin and its support systems: e.g. heating and ventilating, power distribution, plumbing, material handling, housecleaning, and refurbishing operations. Some of this waste is generated when removing the casks from the disassembly basin. Some of the waste, which is common to all manufacturing facilities, includes spent lighting equipment, oily rags, paint residues, spray cans, and circuit boards, which co.tain hazardous components and are therefore classified as hazardous waste. Such waste should be packaged in 55-gallon drums (about one-third of a drum per year) and shipped off-site for disposal in an approved hazardous waste disposal facility.

\subsection{WASTE MANAGEMENT FOR TRITIUM EXTRACTION - PURIFICATION}

\subsubsection{Summary}

A conceptual management system for low-level waste generated in the extraction of tritium from irradiated $\mathrm{Li}-\mathrm{Al}$ targets is outlined in Table 5.2 Principal waste types are the $\mathrm{Li}-\mathrm{Al}$ residue (spent melts) from the thermal extraction operation, and job control waste from maintenance of the processing cells. Conceptual systems are described for disassembling, size reducing and packaging these waste types as needed to fit commercially available casks and containers for transport off site to an approved low-level waste disposal facility. Because most of these wastes contain tritium and because of the mobility of tritium as molecular hydrogen and water vapor, requirements are more stringent for sealing waste packages than is the case with conventional low-level waste without volatile contaminants.

\subsubsection{Crucibles}

At the end of a one year cycle of irradiation, as described in Section 5.2.3, each of the four blanket assemblies of $\mathrm{Li}-\mathrm{Al}$ rods bundled in pressure tubes is remotely cut from the complete array and transported to the underwater basin for further disassembly into units sized for tritium removal in the extraction facility. Based on the dimensions of the Li-Al rods and pressure tubes, it is estimated that the $\mathrm{Li}-\mathrm{Al}$ rods constitute $70 \%$ of the total weight of 106.4 $\mathrm{MT}$, or $74 \mathrm{MT}$ of $\mathrm{Li}-\mathrm{Al}$. The underwater cuts will likely be made at each apex in the coolant manifold; pressure tubes will then be cut from the $\mathrm{Li}-\mathrm{Al}$ rods. These cuts produce a total of 339 bundled Li-Al rod segments (74 MT) distributed as follows: 


\section{BUNDLED Li-Al ROD SEGMENTS}

$\begin{array}{lllll}\text { Source } & \text { Fwd.Exp. } & \text { Aft. Exp. } & \text { Back } & \text { Total } \\ \text { Blanket } & \text { Blanket } & \text { Blanket } & \text { Blanket } & \underline{\text { MT }}\end{array}$

$\begin{array}{lllllllll}\begin{array}{l}\text { No. Bundled } \\ \text { Rod Segments }\end{array} & 32 & 64 & 32 & 64 & 44 & 88 & 15 & \text { - } \\ \text { Length } & 3.05 & 1.52 & 3.05 & 1.52 & 2.74 & 1.37 & 1.83 & \text { - } \\ \text { Weight } & 0.35 & 0.175 & 0.35 & 0.175 & 0.28 & 0.14 & 0.25 & - \\ \text { Total Li-Al, MT } & 11.2 & 11.2 & 11.2 & 11.2 & 12.8 & 12.8 & 3.7 & 74.1\end{array}$

It may be possible to place spacers in the $\mathrm{Li}-\mathrm{Al}$ rods during fabrication in order to facilitate the cutting of the longer rods. Shorter rods of uniform length would contribute to more efficient use of crucibles and ease in packaging for disposal.

The rods, transported in small lots to the extraction facility, are batched into the extraction furnace. Each batch is introduced into the furnace in a crucible that can be removed at the conclusion of the extraction cycle. Following the extraction cycle, the crucible or retort containing the spent melt is removed and prepared for packaging and shipment to an off-site disposal facility.

This crucible waste will contain gamma contaminants (about 10 to $20 \mathrm{Ci}$. of $\mathrm{Zn}^{65}$ per spent melt) and volatile tritium (about $100 \mathrm{Ci}$. per melt), both as the oxide and gaseous or hydrided tritium in the melt and on all surfaces of the crucible or retort. To eliminate surface contamination it is recommended that the crucible design be improved over that used at SRS. If the crucibles containing the melt are reduced in size, two examples of commercial shipping containers that might be suitable are the CNS 6-75 Type A with an inner cavity of $135 \mathrm{~cm}(53$ in.) diameter and $188 \mathrm{~cm}$ (74 in.) height and a shielding equivalence of $10.3 \mathrm{~cm}$ ( 4 inches) of $\mathrm{Pb}$, or the CNS 3-55 Type B with inner dimensions of $91.4 \mathrm{~cm}(36 \mathrm{in}$.) diameter and $294.6 \mathrm{~cm}$ (116 in.) height and a shielding equivalence of $17.8 \mathrm{~cm}(7$ in.) of $\mathrm{Pb}$.

Crucible waste from a complete year of extraction will be 149 units, leading to 149 shipments of waste per year with a cask like the CNS 6-75, 75 shipments per year with a cask like the CNS 3-55 and possibly 38 shipments per year with a shielded box modified from the basic CNS 27-415.

All process steps preparing spent melts for shipment and disposal (size reduction, packaging, welding, decontamination) should be designed into the extraction facility module. Otherwise, provision must be made for containment and shielding of these melts in order to transport them to a separate waste management facility which must be equipped with an air purification system to collect the tritium released during these waste treatment steps. 


\subsubsection{Associated Purification Equipment}

The process system for purification of the tritium released in the extraction step includes in order: separation of the hydrogen isotopes from inerts through a diffuser, separation of hydrogen isotopes either by the Thermal Cycling Absorption Process (TCAP) or by cryogenic distillation, and loading of the purified product into shipping containers. Because the requirements for minimizing releases of tritium to the atmosphere have become very stringent, waste gases from the purification systems are further purified in a process stripper system to remove all but the last traces of tritium before dischaige to the atmosphere. The process stripper system also removes traces of tritium from the exhaust gas from the extraction operation where frequent small releases of tritium occur in the crucible/furnace handling steps. Non-routine equipment replacement will result in about one cubic meter of waste per year. (Reference: Personal Communication with L. K. Heung, Westinghouse Savannah River Company, 5/26/93).

The stripper system employs catalyst beds to convert traces of tritium to HTO and beds of zeolite to trap converted water vapor. In addition, the furnace in the extraction cell is equipped with a metal filter to collect metals and metal compounds that sublime under temperatures employed in the heating cycle. These deposits also trap some tritium through hydride/hydrate formation. Exhaust gases from all the glove box and process cell atmospheres are cleaned by catalyst and zeolite beds. Gases from regeneration of stripper systems are treated before release to the atmosphere. These tritium trapping systems have sufficient capacity and durability and do not require periodic replacement. These systems must be addressed as waste only upon decommissioning or major overhaul of the system.

\subsubsection{Job Control Waste and Failed Equipment}

Operation of the tritium extraction and purification process generates job control waste. This waste is peripheral to the process itself and, consequently, more difficult to define and estimate. One of the categories of such waste is room waste from the areas occupied by personnel who are operating the facility, i.e. those working at glove boxes and remote cells. Such areas are defined as regulated and waste originating in them can be treated as if only slightly contaminated. This type of waste can account for about half of the job control waste.

Another kind of job control waste is maintenance waste. This waste includes replaced gloves from glove boxes, replaced interior manipulator parts, replaced tools, small equipment and supplies that are used within the containment boxes, and waste from repair of equipment within the containment boxes. This type of job control waste can contain a considerable amount of tritium contamination. An intermediate category is the waste generated at the face of the containment boxes when containment breaks are necessary to change equipment or repair minor leaks and line breaks. Such waste includes protective clothing, plastic suits, step off pads, and temporary entry huts at the face of a planned break in a containment barrier.

About $750 \mathrm{~m}^{3} / \mathrm{yr}\left(26,000 \mathrm{ft}^{3} / \mathrm{yr}\right)$ of job control waste can be expected in the operation of a tritium extraction process of this size. (Reference: Personal communication with D. E. 
Ward, Westinghouse Savannah River Company, 5/21/93). The 50\% of the waste that is only slightly contaminated is compactable and should be compacted into steel drums or B-25 boxes in the waste management facility. With a compaction ratio of 4 to 1 anticipated for such waste, the $375 \mathrm{~m}^{3} / \mathrm{yr}\left(13,000 \mathrm{ft}^{3} / \mathrm{yr}\right)$ of this waste should fill about 50055 -gallon drums or $40 \mathrm{~B}-25$ boxes.

The other $50 \%$ of the waste, $375 \mathrm{~m}^{3} / \mathrm{yr}\left(13,000 \mathrm{ft}^{3} / \mathrm{yr}\right)$, is a mix of compactable and non-compactable. Compacting such waste that contains tritium is not advisable in a separate waste management facility because of the risk of release of the volatile tritium during compaction. The recommended course is to package this waste in drums, clean the exterior, transport to the waste management facility and weld groups of 12 drums into B-25 containers for shipment for disposal as low-level waste. A total of about 180 B-25 containers should be generated per year.

\subsubsection{Mixed Waste}

In addition to job control waste, the extraction-purification facility is expected to generate about $4 \mathrm{~m}^{3}$ of mixed waste per year, based on the Savannah River Site experience and predictions. This waste would consist of solvents, possibly oil and other materials classified as hazardous, that are contaminated with trace quantities of tritium. It includes the silver-palladium diffusers and possibly the metal alloys used for metal hydride storage. The metal hydride storage beds contain nickel which is under heavy scrutiny as an environmental hazard. Nickel is on some state lists of hazardous materials and may be added to the EPA lists by the time APT production begins.

This waste would not be compacted, but instead would be contained in about 30 sealed drums, which would be placed in storage in a mixed waste storage facility. Storage would continue until a mixed waste disposal facility becomes available.

\subsubsection{Hazardous Waste}

Another small volume of waste $\left(0.6 \mathrm{~m}^{3} / \mathrm{yr}\right)$, that is similar to job control waste is miscellaneous hazardous waste generated in the maintenance and housekeeping of the extraction facility and its support systems: e.g. heating and ventilating, power distribution, plumbing, material handling, housecleaning, and refurbishing operations. Some of the waste, which is common to all manufacturing facilities, includes spent lighting equipment, oily rags, paint residues, spray cans, and circuit boards, which contain hazardous components and are therefore classified as hazardous waste. Such waste should be packages in 55-gallon drums (ai jut three per year) and shipped off site for disposal in an approved hazardous waste disposal facility.

\subsection{WASTE PREPARATION FOR TRANSPORTATION}

The primary objectives in preparing radioactive waste for transportation are to: 
- Reduce the volume of waste by sawing, cutting, or compaction.

- Collect the byproducts of volume reduction in filters or sieves.

- Package the waste in containers that will fit into shipping casks. Appendix 5.E lists some typical shipping casks.

- Provide assay equipment to measure the type and concentration of radionuclides in the waste.

Most of these operations will be conducted in the facilities that generate the waste. Some of these operations will be conducted in a central waste handling facility when justified logistically and economically.

\subsubsection{Disassembly Basin}

Much of the preparation for shipping can be accomplished in a disassembly basin. This basin will be 4.57 to $6.1 \mathrm{~m}$ ( 15 to 20 feet) deep to provide shielding for the operators, and will be provided with underwater manipulators, underwater saws and cutters, and an underwater compaction press. The basin will be provided with filters and deionizers to maintain clarity of the water, and will have special filters in close proximity to the cutting and sawing machines to collect the finely divided metal scrap produced in these operations.

The disassembly basin will also be provided with cranes to lift and position heavy, shielded casks for underwater loading of highly radioactive aluminum and structural components. The cask will be lifted into a shielded area for draining and drying, and the shielded lid will be put on. This cask will be an approved shipping container for low-level radioactive waste. Brief descriptions of typical casks are given in Appendix 5.E.

Another important use of the disassembly basin will be to reduce the size of the $\mathrm{Pb}-\mathrm{Al}$ target array, and prepare the target tubes for storage in lead-lined casks as mixed waste (see Section 5.2.2). The target tubes will be intensely radioactive, even after six months of cooling (Table B-2, Appendix 5.B). Size reduction and cask loading of these heavy target tubes in the disassembly basin will require massive underwater equipment.

Operation of the disassembly basin will generate job control waste, some of which will be contaminated with target and blanket radioactivity. A typical cask loading operation for target tubes will be:

1. Disassemble the target tubes from the target array.

2. Place target cask under water in disassembly basin.

3. Load individual target tubes into casks.

4. Remove cask from basin to a drying and shipment facility (a shielded facility).

5. Drain water from cask and close drain valves. 
6. Add sufficient absorbent material to absorb free standing water.

7. Place lid on cask and secure it.

8. Wash cask.

9. Smear cask surface to insure no external contamination.

The job control waste will consist of operator clothing, shoe covers, plastic sheeting, sponges, mops, tools, and equipment that has served its useful life. It is estimated that the volume of this job control waste will be about 100 cubic meters per year. It will not contain significant tritium activity and therefore will be compactable to about a four to one ratio.

The underwater cutting, collecting, and compacting operations play an important role in the volume reduction of waste. The cutting operations produce finely divided radioactive metal which must be collected on filters or sieves, and these devices will also be loaded into shipping casks.

\subsubsection{Waste Treatment Facility}

A waste treatment building will be required to prepare low-level radioactive waste for transport and disposal apart from the waste treated in the disassembly basin. This facility would handle prepackaged waste such as plastic suits, shoe covers, other protective clothing, tools, process equipment such as contaminated valves, air filters, and deionizer beds. The facility would have as major components:

- Assay equipment to monitor radiation levels of the waste as it arrives, during the various processes, and when the waste is finally packaged for shipment.

- A dry compactor for slightly contaminated waste described in Section 5.3.4 to be placed in drums or B-25 boxes. Tritiated waste will not be compacted.

- Equipment to drain and dry deionizer beds and to contain the contaminated liquid obtained from this process.

- Loading stations for 55-gallon drums and B-25 boxes.

- Grouting facilities or stations to be used to stabilize loose components and absorb free standing water. Liquid waste from the laundry and other decontamination solutions must be solidified by grouting for disposal.

- $\mathrm{X}$-ray equipment to view loaded drums and boxes to assure that free standing water is not present.

- Inspection stations for drums, boxes or other containers prior to transport. Waste has to be characterized by: 
- Physical and chemical characteristics.

- Volume

- Weight

- Identification of major radionuclides and their concentrations

- Final package description, package weight, external volume, and radiation level.

- A laundry facility for slightly contaminated protective clothing.

The waste treatment facility is not meant to be a catch-all for waste generated in the different APT operations. Each waste generator should be responsible for minimizing and properly packaging waste generated in that facility. However, logistical and economic reasons may dictate that waste treatment of certain wastes be done in a central facility.

Because of the variety of wastes involved, the tritium content, and treatment operations, potential for release of radioactivity is higher than in most other facilities. The waste treatment facility must be designed to very high standards. It must not be just an add-on but an important part of the overall design.

\subsubsection{Heavy Water Management}

Heavy water $\left(\mathrm{D}_{2} \mathrm{O}\right)$ is used in the target array as a coolant and to slow down the fast neutrons generated in the lead. It will contain increasing levels of tritium as operation proceeds. As tritium concentrations rise, tritium containment becomes more difficult, and maintenance and repair operations on the heavy water system become more time consuming and expensive. The coolant will be recycled until tritium level rises to unacceptable levels (e.g., NPR 1.7 Ci/l, BNL High Flux Beam Reactor $3 \mathrm{mCi} / \mathrm{cc}$ ) at which time half the inventory will be replaced with fresh $\mathrm{D}_{2} \mathrm{O}$. The spent $\mathrm{D}_{2} \mathrm{O}$ will be sent to a clean-up facility for treatment. The tritium concentration should be based on AL.ARA principles for worker exposures (see Heavy Water Reactor Facility report HWR-SSD-RD Reg. No. H567). This heavy water is not a waste stream since it will be returned at reduced tritium concentrations and reused in the APT.

It is estimated that about 20,000 liters per year (100 55-gallon drums) will be removed for detritiation. Transport to a detritiation facility will be in sealed drums. Transport will be considered a radioactive shipment and must meet DOE and the Department of Transportation regulations for radioactive shipments.

\subsection{ITEMS THAT NEED ADDITIONAL STUDY}

1. The disposal of spent lithium-aluminum melts as low-level waste in a tritiumfree condition is not a demonstrated technology. Previous experience with crucibles containing spent melts has shown that tritium contamination usually exists on the outside of the crucible. A significant design effort should address this point. 
2. It appears that structural material such as steel or stainless steel may be required to support the massive target and blanket arrays. These support structures will decrease the neutron absorption rate in the $\mathrm{Li}-\mathrm{Al}$ blankets, and increase the radiation levels in the waste components. If these materials are required, a re-evaluation of waste volume and radiation levels must be made.

3. A more complete projection of the buildup of radionuclides in target, $\mathrm{Li}-\mathrm{Al}$, $\mathrm{Al}$ in pressure tubes, and structural components supporting these systems is needed to develop accurate shielding requirements for handling and shipping low-level waste. Impurities in the $\mathrm{Pb}$ and $\mathrm{Al}$ used in these systems will play a large role in defining the specific radionuclides. Cooling time requirements and self-shielding factors can be developed out of these projections so that shielding needs can be accurately calculated.

4. A monitorable, dry, and secure storage area will be required for the discharged lead target arrays. Either casks should be designed to contain the individual target arrays, or the building used for storage will have to be shielded.

5. Determine the feasibility of reprocessing the lead targets to be reused in future target arrays, and determine the feasibility of irradiating the $\mathrm{Pb}-\mathrm{Al}$ targets for more than one year.

6. The disassembly basin could eventually develop a small concentration of tritiated water unless steps are taken to dry and dehydrate the interior surfaces of the coolant system of the target array. Alternatively, a treatment system to detritiate the disassembly water will have to be developed.

7. A plan for decontamination and decommissioning will have to be developed and the resulting waste streams determined. 


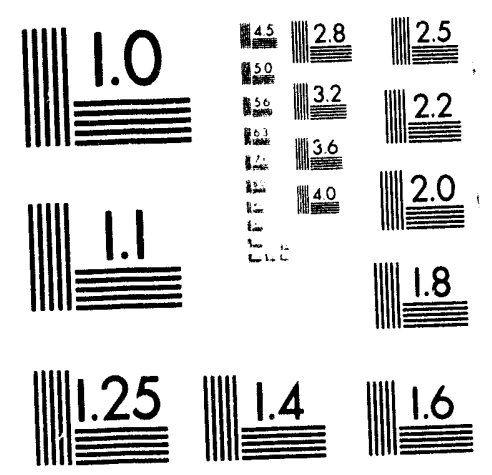




$$
\begin{aligned}
& \omega \\
& \stackrel{\rho}{\rho} \\
& \omega
\end{aligned}
$$




\section{APPENDIX 5.A}

\section{DEFINITION OF TERMS}

\section{TARGET (OR SOURCE) ARRAY}

This array produses neutrons by spallation in lead. The array is cooled by a flow of heavy water, which also moderates the energy of the neutrons to produce more absorption in the $\mathrm{Li}$ - $\mathrm{Al}$ blankets. There are 33 pressure tubes in five rows, which contain a total of $1859 \mathrm{~Pb}$ $\mathrm{Al}$ rods and 60 aluminum shim rods. The dry weight of the array is 25.1 metric tons. During operation, the array contains 5.2 metric tons of heavy water. There are two target arrays, one for each of the two accelerator beam ports. The design concepts of the target, blanket, and window are those presented by Babcock \& Wilcox at the April 29, 1993 APT Meeting at Brookhaven National Laboratory.

\section{BLANKET ARRAYS}

The blanket arrays are four separate assemblies of pressure tubes containing $\mathrm{Li}-\mathrm{Al}$ rods cooled by light water. The lithium is $3 \mathrm{wt} \%$ of the aluminum and is enriched to $50 \%$ in $\mathrm{Li}^{6}$. Tritium is produced by absorption of low energy neutrons in the $\mathrm{Li}^{6} ; \mathrm{n}+\mathrm{Li}^{6}=$ tritium thelium. There are two complete sets of blanket arrays, one set for each of the two beam ports. The four blanket assemblies in one array are described below:

\section{Type of Blanket}

Source

Back

Forward Expander Tube

Aft Expander Tube

Total

\section{WINDOW ASSEMBLY}

Each of the two beam ports has a water-cooled aluminum window to protect the accelerator tube from spallation products. The window is convex on the accelerator side. The estimated weight is 1.32 metric tons.

\section{WASTE CATEGORIES}

Radioactive Waste

Solid, liquid, or gaseous material that contains radionuclides regulated under the Atomic Energy Act of 1954, as amended, and that is of negligible economic value considering the cost of recovery.

$\begin{array}{cccc}\begin{array}{c}\text { No. of Pressure } \\ \text { Tubes }\end{array} & \begin{array}{c}\text { No. of } \\ \text { Li-Al Rods }\end{array} & \begin{array}{c}\text { Shim } \\ \text { Rods }\end{array} & \begin{array}{c}\text { Wt } \\ \text { MT }\end{array} \\ 15 & 1497 & 36 & 32 \\ 32 & 499 & 12 & 5.4 \\ \underline{44} & 1497 & 36 & 32 \\ 123 & \underline{1497} & \underline{36} & \underline{37} \\ & 4990 & 120 & 106.4\end{array}$




\section{Low-Level Waste}

Waste that contains radioactivity and is not classified as high-level waste, transuranic waste, or spent nuclear fuel. (Note: High-level waste results from processing spent nuclear fuel used in fission reactors; transuranic waste contains alpha-emitting transuranic radionuclides with half-lives greater than 20 years and concentrations greater than 100 nanocuries per gram of waste at the time of assay). The irradiated Li-Al blanket assemblies are considered low-level waste.

\section{Hazardous Waste}

Those wastes designated as hazardous by EPA regulations (10CFR261) and by individual state regulations. Examples are: lead, mercury, and certain organics such as waste oil.

\section{Mixed Waste}

Waste containing both radioactive and hazardous components. An example is irradiated lead. There are no approved disposal facilities for mixed waste; long-term storage is required until disposal facilities are approved and built.

\section{$\underline{\text { Job Control Waste }}$}

Waste produced during normal operation of the facility. It includes clothing, plastic suits, shoe covers, tools, equipment that has served its useful life, failed equipment, plastic sheeting used for containment during maintenance work, housekeeping waste, and in general any waste produced during normal operations. It does not include waste from accidental spills or accidental release of radioactivity, or waste produced in decommissioning the facility.

\section{Clean Waste}

Waste from areas of potential radionuclide contamination which has no detectable radiation. This waste must be verified as clean by monitoring facilities prior to disposal in a sanitary landfill.

\section{PYROPHORIC MATERIAL}

A material which can cause fires through friction or exposure to the atmosphere. It can be ignited readily, and when ignited, burns vigorously. An example is very fine, dry aluminum powder, which can be produced in disassembly operations of aluminum components unless done under water. 


\section{DISPOSAL OR STORAGE OF RADIOACTIVE WASTE}

Disposal

Emplacement of waste in an approved disposal facility with no intent of retrieval. Deliberate and costly action would be required to regain access to the waste.

\section{Disposal Facility}

The land, structures, and equipment used for disposal of waste. Associated with the facility is equipment for monitoring surface and ground water and the atmosphere for radioactivity. The facility would be provided with security to prevent unauthorized access or retrieval of the waste.

\section{Storage}

Emplacement of waste in dry, monitorable, secure structures, with the intent of future retrieval and removal.

\section{DEIONIZERS}

Vessels containing a mixture of chemicals and ion-exchange resins used to remove contaminants and control the $\mathrm{pH}$ and other quantities associated with water treatment. Water treatment will be required in the heavy and light water cooling systems to remove activated corrosion products and to control aluminum corrosion, and in the disassembly basin to control algae, improve clarity, and reduce corrosion.

\section{DECOMMISSIONING}

Decommissioning is a term used to indicate a reduction of the facilities in an area to near its original state before construction began or before radioactivity was introduced.

\section{$\underline{B-25} \mathrm{BOX}$}

A carbon steel box with a sealable metal lid, which has a capacity of about 95 cubic feet. It is used to package low-level waste prior to shipment in shielded containers.

\section{SHIPPING CASK}

A shielded container used to transport low-level waste to a disposal or storage facility. Shipping casks used on state and national highways have to meet DOE, EPA, and Department of Transportation regulations. 


\section{CURIE}

The curie is the measure of rate of disintegration of a radionuclide, equal to $3.7 \times 10^{10}$ disintegrations per second. Disintegration is defined as alpha, beta plus, beta minus, or gamma ejection. It is directly related to the half-life of the radionuclide. For half-lives greater than 700 seconds, the curies per gram of an element may be calculated as follows:

[1.13 $\times 10^{13}$ divided by (atomic weight in grams $\mathrm{x}$ half-life in seconds)].

Curies per gram for some of the radionuclides produced in the APT are:

$\begin{array}{lcl}\frac{\text { Element }}{\text { Tritium }} & \text { Half-life } & \text { Curies/gram } \\ \mathrm{Na}^{22} & 12.26 \mathrm{y} & 9.67 \times 10^{3} \\ \mathrm{Zn}^{65} & 2.6 \mathrm{y} & 6.24 \times 10^{3} \\ \mathrm{~Pb}^{210} & 244 . \mathrm{d} & 8.25 \times 10^{3} \\ & 22.3 \mathrm{y} & 7.63 \times 10^{1}\end{array}$

$\underline{\text { REM }}$

Roentgen equivalent man, a unit of radiation dose to a person. It is the amount of energy absorbed in tissue equal to 0.01 joules/kilogram.

\section{FREE STANDING WATER}

Disposal facilities for radioactive waste will not accept containers with free standing water. Spent deionizers, for example, must be thoroughly drained, and enough absorbent material added to the container to insure that free standing water will not be present during shipping, storage, or disposal.

\section{CINDER90}

A computer code that calculates the production of proton-induced spallation products and neutron-induced radionuclides in the target and blanket arrays of the APT. The products are calculated as a function of irradiation and cooling times in terms of kilograms, curies, decay heat, and gamma energy. 


\section{APPENDIX 5.B}

\section{CINDER90 OUTPUT}

Reference: Letter, M. Todosow to Pierre Grand, April 16, 1993

The CINDER90 code is used to calculate radioactivity (Curies) and decay power (watts) for the lead-aluminum target array and the Li-Al blanket arrays. Separate calculations were done for the lead and the Li-Al pressure tubes, and for the aluminum window and the conical portion of the beam expander chamber liner. Corrections were estimated to account for a year of irradiation time of the blanket assemblies, instead of six months, and to account for the heavier $\mathrm{Li}-\mathrm{Al}$ blankets around the target array and around the beam expander chamber. No corrections were applied to the results for the lead target array except to delete the polonium contributions.

The calculated and corrected values are given in APPENDIX 5.B, Table B-1. All curie and heat generation values have been rounded to one significant figure. 


\section{APPENDIX 5.B}

\section{TABLE B-1}

\section{RADIOACTIVITY AND HEAT GENERATION IN APT TARGET/BLANKET ARRAYS, AND STRUCTURAL COMPO-}

\section{NENTS}

Material

$\stackrel{n}{N}$
Quantity metric tons

Pb Al Li

$\mathrm{Pb}-\mathrm{Al}$ Target

Target Pressure Tubes

Li-Al Blanket

Blanket Pressure Tubes

$\mathrm{Li}-\mathrm{Al}$ in Expansion

Chamber Liner

Al Window

Beam Expander Chamber

$\begin{array}{ccl}24.2 & 1.1 & - \\ - & 1.17 & - \\ - & 20.6 & 0.5 \\ - & 2.3 & - \\ - & 56 & 1.4 \\ & & \\ - & 0.12 & - \\ - & 1.2 & -\end{array}$

Radioactivity, curies

After 6 mos.

At Shutdown of cooling.

$\begin{array}{ll}2 \times 10^{8} & 2 \times 10^{6} \\ 3 \times 10^{7} & 2 \times 10^{4} \\ 1 \times 10^{5} & 8 \times 10^{4} \\ 2 \times 10^{6} & 2 \times 10^{3} \\ 5 \times 10^{6} & 1 \times 10^{4} \\ & \\ 1 \times 10^{6} & 7 \times 10^{3} \\ 2 \times 10^{6} & 2 \times 10^{3}\end{array}$

Heat Generation, watts

$$
\text { After } 6 \text { mos. }
$$

At Shutdown of cooling

$\begin{array}{cc}2 \times 10^{6} & 9 \times 10^{3} \\ 7 \times 10^{5} & 3 \times 10^{2} \\ 1 \times 10^{3} & 1 \times 10^{3} \\ 3 \times 10^{4} & 3 \times 10^{1} \\ 6 \times 10^{4} & 7 \times 10^{2} \\ \cdot & \\ 2 \times 10^{4} & 9 \times 10^{1} \\ 3 \times 10^{4} & 2 \times 10^{1}\end{array}$

Note: These numbers are based on an early design and will be changed as design progresses. 


\section{APPENDIX 5.B}

TABLE B-2 $^{(1)}$

GAMMA EMISSION RATES IN LEAD-AL-H ${ }_{2} 0$ TARGET MATERIAL AFTER ONE YEAR IRRADIATION BY $200 \mathrm{mAmpS}$ OF PROTONS -- CALCULATED WITH CINDER90 USING 5/93 LIBRARIES

Number of Gammas/cc-sec

Energy Range, MEV

Irradiation Time, days

Cooling Time, days

$0.3-0.5$

$1.0-1.33$

$\underline{365}$

$3.3 \mathrm{E}+11$

$3.3 \mathrm{E}+11$

$\underline{182.5}$

Total of 25 Groups

$3.6 \mathrm{E}+12$

$1.6 \mathrm{E}+9$

$9.6 \mathrm{E}+8$

$3.1 \mathrm{E}+10$

Total gamma emission rate for the assumed volume of $3.3 \mathrm{E}+6 \mathrm{cc}$ is $1.0 \mathrm{E}+17 / \mathrm{sec}$, or $2.8 \mathrm{E}+6$ curies after six months of cooling.

(1) Reference: Personal communication, M. Todosow to C. Goodlett, May 30, 1993. 


\section{APPENDIX 5.C}

\section{DEPARTMENT OF ENERGY ORDERS AND CODE OF FEDERAL REGULATIONS APPLICABLE TO LOW-LEVEL, HAZARDOUS, AND MIXED WASTE}

1. DOE ORDER 5820.2A of 9-26-88, Radioactive Waste Management -

PURPOSE: To establish policies, guidelines, and minimum requirements by which the Department of Energy manages its radioactive and mixed waste and contaminated facilities. Chapter III of DOE Order 5820.2A establishes policies, requirements, and guidelines for managing the Department's low-level radioactive waste. Waste has to be characterized by the facility managers to describe:

(1) The physical and chemical characteristics of the waste.

(2) Volume of the waste (total of waste and any solidification or absorbent media).

(3) Weight of the waste (total of waste and any solidification or absorbent material).

(4) Major radionuclides and their concentrations.

(5) Packaging description, package weight, and external volume.

Chapter VI of this DOE Order, titled Waste Management Plan Outline, states seven requirements for waste management documentation.

2. DOE ORDER 5880.1B of 9-23-86, Environmental Safety and Health Program for Department of Energy Operations.

This order establishes an overall framework for safety, environmental, and health protection, including criteria for radiation exposure and radioactive effluent releases for operating facilities and sites.

3. DOE/LLN-63T of 9-23-86, Guidance for Conduct of Waste Management Systems Performance Assessment.

This document provides information on meeting the systems performance requirements of Chapter III $3 \mathrm{~b}(2)$ of DOE ORDER 5820.2A.

4. RESOURCE CONSERVATION AND RECOVERY ACT of 1967, as amended.

Public Law 94-5809 establishes safe and environmentally acceptable management practices for solid waste. 
5. CODE OF FEDERAL REGULATIONS - 10CFR61 of 12-27-82, Licensing Requiremenis for Land Disposal of Radioactive Waste.

This code establishes technical requirements for the land disposal of commercial low-level waste, including site selection, site description, facility operation, and closure.

6. CODE OF FEDERAL REGULATIONS - 10CFR962 of 5-1-87, Radioactive Waste and By-Product Material.

This code establishes the policy that all DOE radioactive waste that is hazardous under the Resource Conservation and Recovery Act will be subject to regulations under both RCRA and the Atomic Energy Act.

7. CODE OF FEDERAL REGULATIONS - 10CFR261 of 5-19-80, Identification and Listing of Hazardous Waste.

This code identifies those solid wastes that are subject to regulations as hazardous waste.

8. STANDARDS APPLICABLE TO GENERATION OF HAZARDOUS WASTE.

This code establishes manufacturing, packaging, labeling, and record keeping requirements for hazardous waste.

9. CODE OF FEDERAL REGULATIONS - 10CFR264, Standards Applicable for Owners and Operators of Hazardous Waste Treatment, Storage, and Disposal Facilities.

This code establishes minimum national standards defining the acceptable management of hazardous waste.

10. DOE/EP-0096 of 7-83, A Guide for Effluent Radiological Measurements of DOE Installations.

11. DOE ORDER 5400.3 of 2-22-87, Hazardous and Radioactive Mixed Waste Program.

This order establishes DOE hazardous and mixed waste policies and requirements of the Resource Conservation and Recovery Act within the framework of the environmental programs established under DOE ORDER 5400.1 (General Environmental Protection Program). 


\section{APPENDIX 5.D}

\section{APPLICABLE WASTE TRANSPORTATION ORDERS}

1. DOE ORDER 5480.3 of 7-9-85, Safety Requirements for Packaging and Transportation of Hazardous Materials, Hazardous Substances, and Hazardous Waste.

2. CODE OF FEDERAL REGULATIONS - 10CFR71 of 8-5-83, Packaging and Transportation of Radioactive Material.

This code establishes (1) requirements for packaging and preparation for shipment and transportation of licensed material, and (2) procedures and standards for NRC approval of packaging and shipping procedures.

3. CODE OF FEDERAL REGULATIONS - 10CFR263 of 5-19-80, Standards Applicable to Transportation of Hazardous Waste.

4. CODE OF FEDERAL REGULATIONS - 49CFR177, Transportation of Hazardous Materials on Public Highways.

5. CODE OF FEDERAL REGULATIONS - 49CFR174, Transportation of Hazardous Materials on Rail Carriages. 
APPENDIX 5.E

TYPICAL CASKS FOR TRANSPORT OF RADIOACTIVE MATERIALS

\begin{tabular}{|c|c|c|c|c|c|c|}
\hline \multirow{9}{*}{ N } & NO. OF 55-GAL $\frac{\text { CAPACITY }}{\text { DRUMS }}$ & & SHIELD & $\begin{array}{l}\text { MAX. RAD. } \\
\text { LEVEL R/hr }\end{array}$ & $\begin{array}{l}\text { MAX PAYLOAD, } \\
\text { pounds }\end{array}$ & $\begin{array}{l}\text { UNDER WATER } \\
\text { LOADING }\end{array}$ \\
\hline & & & & & & \\
\hline & $\begin{array}{l}1 \\
3\end{array}$ & 17 & 6.2 & 6000 & 550 & YES \\
\hline & $\begin{array}{l}3 \\
4\end{array}$ & 60 & 7 & 15,000 & 9220 & NO \\
\hline & $\begin{array}{l}4 \\
6\end{array}$ & 88 & 3.38 & 35 & 5700 & NO \\
\hline & $\begin{array}{l}6 \\
4\end{array}$ & 85 & 4 & 235 & 10,300 & NO \\
\hline & $\begin{array}{l}4 \\
8\end{array}$ & 91 & 5 & 1860 & 7500 & YES \\
\hline & $\begin{array}{l}8 \\
1\end{array}$ & 130 & 4.5 & 880 & 14,680 & YES \\
\hline & $\begin{array}{r}1 \\
21\end{array}$ & 9 & NONE & 0.2 & 550 & NO \\
\hline & & 340 & 1.5 & 3 & 27,250 & NO \\
\hline
\end{tabular}




\section{APPENDIX 5.F}

\section{EXAMPLES OF VOLUME AND WEIGHT ESTIMATES}

(1)

\section{WINDOW AND BEAM EXPANDER TUBE -- LOW-LEVEL WASTE}

- Conceptual design is the Babcock and Wilcox design of April, 1993.

- The array consists of:

- Truncated conical expander tube

- Sealed beam window

- Cooling jackets for tube and window

- Support structures

- Connection flanges

- Inlet and outlet manifolds

- Estimated dry weight is 1.32 metric tons.

- General envelope:

- Major Diameter - 2.67 meters

- Minor Diameter - 1.56 meters

- Length - 8 r.ueters

Because this structure is large and relatively hollow, it is assumed that cutting and compaction will result in a large compaction ratio. It is also assumed that the major structural component of the array is aluminum with a density of $2.7 \mathrm{grams} / \mathrm{cc}$. Therefore: Estimated solid volume $=(1.32 \mathrm{MT}) / 2.7 \mathrm{~g} / \mathrm{cc}=0.49$ cubic meters. After compaction, it is assumed that there will be one part aluminum and one part air in the final volume of waste. Therefore, there is one cubic meter of low-level wasti generated from this structure.

VOLUME ESTIMATES FOR THE COOLING WATER HEADERS AND PLENUMS FROM THE TARGET ARRAY.

- Conceptual design is the Babcock and Wilcox design of April, 1993.

- The target array consists of:

- 33 Pressure tubes containing lead and shim rods

- Inlet and outlet headers

- Plenums (flow distributors)

- Structural supports 
- Dry weight is 25.1 metric tons.

- General envelope is 4.005 meters high by 4.5 meters wide by 3.785 meters deep.

- In a typical pressure tube:

$$
\text { Area, } \mathrm{cm}^{2} \text { Density, } \mathrm{g} / \mathrm{cm}^{3} \quad \% \text { by Weight }
$$

$\begin{array}{llrc}\mathrm{Pb} & 173 & 11.3 & 88 \\ \mathrm{Al} \text { cladding } & 40 & 2.7 & 5 \\ \mathrm{Al} \text { pressure tube } & 55.6 & 2.7 & 7\end{array}$

- Estimated weight of the pressure tubes is $(0.07) \times(25.1)=1.76$ metric tons, or 1.76 metric tons $/ 2.7 \mathrm{~g} / \mathrm{cc}=0.65$ cubic meters

It is assumed that the volume of the headers and plenums is twice that of the pressure tubes, or 1.3 cubic meters of solid aluminum. After compaction, it is assumed that the final volume will be one-half air and one-half aluminum (therefore, equivalent to one-half the theoretical density of aluminum metal). The estimated waste volume is therefore 2.6 cubic meters per year. 



\subsection{TARGET WINDOW DESIGN (WBS 5.1.3.1.4.1)}

The description of the window cooling system design has been integrated with Section 4, Target Cooling and Heat Removal System Design, since it logically fits into that section. Details on window and beam expander cooling are given in Section 4.2.3. The heat removal system design is described in Section 4.3.3. 


\subsection{TARGET SAFETY SYSTEMS (WBS 5.1.3.1.5.1)}

\subsection{OVERVIEW}

Details of the design of target cooling systems are presented in section 4 of this report. The details of beam trip logic and confinement design are discussed in LANL reports. The purpose of the present section is to provide an integrated discussion of the safety functions necessary to prevent radioactive releases and prevent and/or mitigate target damage.

First, the overall safety strategy is discussed. In order to do a good job of allocating analytical resources to the design effort and allocating capital resources to the facility itself, it is necessary to distinguish between the safety issues important to the APT facility and the safety issues important to a comparably productive reactor facility. Highlights of this distinction will be mentioned briefly. Next a discussion of the principal safety functions will be provided. Finally, a discussion will be given of selected scenarios, ranging in severity from normal operations to target damage events. This includes a high-level logic model of the scenarios, and a discussion of the phenomenology associated with representative event sequences.

\subsubsection{Performance Allocation To Achieve Safety Objectives}

Because of APT's relatively small inventory of radionuclides, it is doubtful whether a release which is "large" in the reactor sense can occur at the APT. Nevertheless, it is desirable to establish minimization of radiological releases as a goal early in the design process. Even though a high level of target safety is achievable, the defense-in-depth principle suggests that it is prudent to achieve significant confinement performance following target damage, as well as reliable target protection. The following discussion argues that because of essential differences between APT and LWR technology, it is possible to engineer confinement systems for APT which achieve a degree of protection that would be extremely difficult to achieve in LWRs.

There is more than one way to allocate safety performance over different design elements in order to drive down the assessed frequency of large radiological releases. For example, there is significant uncertainty in our understanding of the phenomenology of post-core-melt phenomena, so it is typical in the U.S. to approach the large release goal by first driving down core damage frequency as low as possible, and then taking relatively limited credit for containment. Core melt is not a design basis for containments of U.S. LWRs; core melt can result in very severe loads, so placing core melt within the design basis would require extremely robust containments and very high capital costs. Therefore, whatever credit is taken for LWR containment in accident analysis must be based on best-estimate calculations subject to significant uncertainty. A conditional containment failure probability goal of 0.1 is frequently mentioned; this goal means that containment should have a $90 \%$ chance of working, given a core melt. If core melt were within the actual design basis, the success likelihood should be nearly $100 \%$.

The strategy of treating confinement as a last resort, and taking credit only for limited success likelihood, presently appears to be unnecessary for the APT. Based on existing 
calculations and design information, no loads on the APT confinement have been identified which could not be included in the design basis (barring beam trip failure). One element of the present strategy is therefore to place foreseeable loads within the confinement design basis, and then to take significant credit for the confinement function. This is very different from the reactor strategy. In addition to a reliable confinement function, highly reliable means for preventing target damage will also be provided. This corresponds to a very high degree of defense in depth. The feasibility of containing releases from the target is one of the main reasons for considering an accelerator production facility in the first place.

It should also be recognized that unlike reactor core melt accidents, APT accidents cause damage primarily to portions of the facility which are frequently reprocessed anyhow. The present assumption is that the entire blanket, the $\mathrm{Pb}$ target, and the window will be replaced after each one-year cycle. If confinement is designed to support cleanup of target damage accidents, and if the isolation function is extremely reliable, many loss-of-facility accidents will be precluded. (As used here, the phrase "loss-of-facility accident" refers to an event such as TMI that leads to a minimal radiological release but stops production indefinitely.) That is, it is inappropriate to assume a priori that significant target damage will automatically decommission an entire target area, let alone the entire facility. A distinction should be made between events which actually lose the facility, and events which merely create a need for special care in target handling. This is related to the point made earlier regarding the design basis of confinement, but is distinct. Unlike reactor core damage events, many target damage events would allow fairly expeditious recovery.

An example of an event which would compromise more than the target area is transport of radioactive material up the length of the accelerator. Significant credit will be taken for confinement, but not over the length of the accelerator. There is a need to provide very reliable confinement isolation features to prevent transport of radioactive material up the length of the accelerator.

Robust confinement is an important element of the safety case. Successful target protection, comprising beam trip/control and cooling, will reduce challenges to the confinement function, and correspondingly provide a defense in depth benefit. The reliability of target and accelerator protection will be driven not only from safety considerations, but also from operability considerations.

\subsubsection{Functional Requirements}

\section{$\underline{\text { Li-Al Blanket Requirements }}$}

According to information presently available, there is very little decay heat in the $\mathrm{Li}-\mathrm{Al}$ blanket. Cooling is necessary if and only if the beam is on and there is externally-driven heat production in the target. At the present stage of design, it is assumed that no achievable neutronic anisotropy can produce unacceptable heat loadings if the normal cooling is operational. It is assumed that the $\mathrm{Li}-\mathrm{Al}$ blanket must be protected from the proton beam: the beam must not 
be allowed to wander onto the blanket, and the beam must not be allowed to punch through the $\mathrm{Pb}$ target.

These assumptions mean that the production blanket is presumed safe if one of the following conditions holds:

Beam footprint is within specs (properly steered and properly defocussed on the target), $\mathrm{Pb}$ target is not geometrically disturbed, blanket is cooled with normal cooling;

Beam is off, and $\mathrm{Pb}$ target is not geometrically disturbed, independently of blanket cooling.

The following conditions would damage the blanket unacceptably, and would be presumed to lead to an in-confinement release:

Loss of blanket cooling, either LOCA or loss of forced flow, with concurrent failure to shut off the beam.

Beam impingement on the $\mathrm{Li}-\mathrm{Al}$ blanket, regardless of cooling status.

This means that the key elements of $\mathrm{Li}$ - $\mathrm{Al}$ blanket protection are beam shutoff, invoked for loss of cooling or beam upsets, and normal cooling, which is essential only if beam is on. As discussed below, the reliability of beam shutoff will be made near-absolute for several reasons.

\section{Pb Target Requirements}

(1) There may be significant decay heat in the $\mathrm{Pb}$ target. Considerable normal cooling is necessary with the beam on, and auxiliary cooling is necessary with the beam off.

(2) The beam must meet isotropy requirements (peaking factor requirements) or unacceptable local heating will result regardless of cooling (beam must be tripped promptly if anisotropy occurs).

Therefore, the $\mathrm{Pb}$ target is safe if and only if

Beam is on, within control envelope, and normal cooling is operative

Beam is off and at least one loop of cooling is operative (natural or forced circulation in one primary loop and its corresponding secondary loop; this could be normal cooling, RHR, or natural circulation)

Beam is off, target pit is flooded, and heat is either being removed from confinement or passive structures are absorbing sufficient heat to cool target. 
As discussed in section 4, the present concept calls for mitigating a target LOCA by flooding the entire target cavity to a level above the break. Such an event would require replacement of the target in any case.

An in-confinement release is presumed to occur in the event of such a LOCA with concurrent failure to trip the beam promptly.

Beam Trip Requirements

The beam is required to trip promptly if either the $\mathrm{Pb}$ target or the $\mathrm{Li}-\mathrm{Al}$ blanket suffers loss of cooling, either due to LOCA or active system failures.

The beam is required to trip promptly if beam parameters depart from acceptable values (focus, mis-steer, ...). Abnormal radiation would be considered one indication of this.

The beam is required to trip promptly on evidence of geometric disruption of either target or the window, or on evidence of abnormal confinement conditions.

The beam will also be interlocked to many doors and other barriers for personnel protection, and may be interlocked to confinement status. These permissives are part of the scope of accelerator and confinement design.

\section{Confinement Requirement}

In normal operation, confinement will be isolated to the extent that the atmosphere will be filtered and held up (detained to allow decay of activation products) before release.

Confinement isolation will be required if confinement parameters indicate that an accident situation exists:

Steam is present

Temperature sensors suggest off-normal conditions

Accelerator is threatened by downstream conditions

Target or blanket is overheated

Window parameters exceed allowable values

Confinement atmosphere heat removal will be required in the event of some energetic releases to confinement. Since tritiated $\mathrm{D}_{2} \mathrm{O}$ could also be released, provision must be made for cleanup of the atmosphere and purification of the water released.

The confinement sump system will be required to recirculate water surrounding the $\mathrm{Pb}$ target following a LOCA. This entails taking suction from the sump, passing the water through 
a heat exchanger, and returning it to the Source Basin Flood System. A cleanup function would have to be part of this system, since cleanup of contamination would be part of its design basis.

\subsubsection{Design Basis Considerations}

As shown on Figure 7.1, two levels of design basis are under consideration.

One level of design basis is associated with the source cooling systems. As discussed in more detail in section 4, and reviewed below, the design intent of the source cooling systems is that any single break in the primary or secondary will be coolable by passive means, given credit for a timely beam trip. Successful performance of this function will provide a path for continuous removal of decay heat from the target and from confinement, and thereby prevent target overheating to the point of radioactive release. On Figure 7.1, this regime is the lightly shaded area labelled "Within SPCS Design Basis." It includes all scenarios in which beam trip succeeds when challenged, and cooling succeeds.

A distinct design basis is associated with the confinement. Failure of the target auxiliary cooling function should not occur, but for defense-in-depth reasons, the present intention is to engineer confinement to limit releases even in the event of target overheating, for most or all scenarios in which beam trip has not failed. On Figure 7.1, this regime is the shaded area labelled "Beyond SPCS Design Basis But Within Confinement Design Basis." It includes all scenarios in which beam trip succeeds when challenged, but target/blanket cooling fails and some target overheating occurs. In such scenarios, there might be an airborne source term in confinement, and there is the potential for impingement of overheated (molten) source material on the floor of confinement. This would probably need to be cleaned out before the target area was placed back into service. By placing these scenarios within the design basis of confinement, we are proposing to take credit for retention of the source term under the conditions prevailing in these scenarios, and credit for eventual restoration of the target area to full function.

If beam trip fails, or if an extremely unlikely sequence of failures leads both to target overheating and failure to contain releases, then the situation is beyond all design bases. This does not mean that those scenarios are necessarily catastrophic, but only that they are (a) not considered in formal safety analysis, (b) extremely rare, and (c) not presently considered worth analyzing.

Figure 7.1 summarizes the above discussion by classifying scenarios into their respective design basis regimes. 


\subsection{SAFETY FUNCTIONS}

\subsubsection{The Beam Trip Function}

Several ways of shutting down the accelerator beam will be implemented. These include (1) loss of "run permit, " which would correspond to loss of permits (pump status, safety interlock status) necessary to allow beam, (2) "fast protect, " which is intended to shut down the beam very quickly when the accelerator itself is threatened by an off-normal condition, and (3) the beam trip function associated with target protection. It is possible that certain events (magnet malfunctions) would lead to beam trip by any of these three routes, but the present discussion is aimed at the latter function, which will be a safety-grade system credited in the safety analysis of the facility.

It has been established that target safety depends on prompt beam trip when either target parameters or beam parameters deviate beyond acceptable limits. The definition of "prompt" depends on the characteristics of the initiating event that challenges the beam trip function. For each initiating event, there will correspond a time delay (before successful beam trip) which will be assumed in safety analysis. Delay of beam trip beyond this time limit may threaten target integrity, and indefinite delay of beam trip subsequent to loss of target cooling will become increasingly difficult to analyze (although it is clear that significant damage will ensue from deposition of large amounts of beam energy without heat removal). Partly for this reason, the design intent articulated in Section 4 (and in the accelerator report) for the safety-grade target protection beam trip function is that upstream of the hardware at the accelerator itself, the system will withstand triple hardware failures (sensors or processors). Additionally, if it proves necessary, two physically distinct (diverse) means of accelerator shutdown will be implemented. These measures are considered to place beam trip failure in the "residual risk" category.

Section 4 presents tables showing target parameters to be measured for purposes of implementing beam trip for target protection. These tables are based on consideration of events initiated within the target itself. It will also be necessary to measure beam parameters for target protection, because no convincingly reliable way of inferring beam anisotropy from target parameters has been identified. The need to design this capability has been identified, but concepts for implementing it are so far only at the discussion stage (e.g., the "harp" concept, discussed in the accelerator report, and infrared monitors discussed elsewhere). Also under discussion are measurements of confinement parameters for purposes of beam trip.

\subsubsection{Source Cooling Systems}

\subsubsection{General}

The SILC Cooling Systems involve four groups of systems: the Source Cooling Systems (SCS), the Blanket Cooling Systems (BCS), the Window Cooling Systems (WCS) and the Source Basin Flood System (SBFS). The function, design safety aspects, construction 
requirements, redundancy, and instrumentation are thoroughly described in Section 4.0. Therefore, in this section such "detailed" presentation is omitted. Instead, those system features will be emphasized which are deemed to be relevant for accident prevention and mitigation. Since, in the present design stage, the focal point of safety analysis is associated with the prevention/mitigation of accidents associated with the neutron source, even this discussion will be restricted to the main safety features of the SCS and SBFS.

\subsubsection{Safety Features of the Source Cooling System (SCS) and the Source Basin Flood System (SBFS)}

\section{(a) Source Cooling System (SCS)}

The Source Cooling System (SCS) consists of five systems, which are distributed into two groups as follows:

Group 1. Source Primary Cooling System (SPCS)

Source Secondary Cooling System (SSCS)

Source Circulating Water System (SCWS)

and

Group 2. Source Residual Primary Cooling System (SRPCS)

Source Residual Secondary Cooling System (SRSCS)

The two groups essentially constitute a dual pathway (Source "Main" and Source "Residual" Cooling Systems) to remove and transport heat generated in the source to the ultimate heat sink. To provide single failure protection, each of the systems contain dual loops. The heat removal capacity of a loop in the Source Main Cooling System is 50\% at normal target operation. The heat removal is maintained by forced circulation.

Under accident conditions, e.g., when AC power is unavailable or the SPCS is depressurized, the Source Main Cooling System also provides a passive cooling function by natural circulation of the coolants in the systems, SPCS and SSCS. Then the associated heat removal capacity for a loop is $100 \%$ at the decay heat level.

Under accident condition an alternative cooling path (two $100 \%$ loops) is provided by the Source Residual Cooling System, which is operating by forced cooling. This active form of operation requires the availability of an Emergency AC Power System.

Each loop of the SPCS has either a pressurizer or an accumulator. Under normal conditions, their function is to maintain the SPCS and the SRPCS in a subcooled state providing the required NPSH for the circulating pumps. Under accident conditions, their passive safety function is to provide rapid fluid inventory control. Their gas inventory is designed to be insufficient to inject gas into the system should the SPCS depressurize as it would with a 
LOCA. This design feature, coupled with appropriate SPCS/SRPCS and SBFS piping arrangement, ensures that during a LOCA, fluid will remain in the unbroken loop.

The combination of the active-passive cooling paths and other safety features of the source cooling system result in several successful source damage prevention/mitigation strategies. They will be discussed in section 7.3.1.

\section{Natural Circulation in Unbroken SPCS Loop}

It is the intent of the APT SILC cooling system design that a break in the primary coolant system can be mitigated to keep at least one of the two SPCS loops full of water. If the break is low, in the spallation source region, the source basin flood tank will submerge the break while the pressurizer and accumulator replenish the loss of coolant through the break. Complete success of the basin fill strategy would result in two full coolant loops, through which natural circulation will be established, affording a heat rejection path from the primary coolant system to the secondary coolant system. Partial success would lead to single-trip natural circulation. If a break is not flooded, both loops will drain into the source basin without enough coolant inventory to submerge the break before draining the SPCS dry.

If the break is high enough in the SPCS that flooding the basin would not submerge the break, the accumulator and pressurizer will inject their inventory into the SPCS until the liquid in the unbroken loop pulls a vacuum on pressurizer/accumulator, thus preventing the unbroken loop from draining. Of course, the broken loop would drain dry to the confinement floor. Successful stabilization of the liquid inventory in the unbroken loop would ensure one natural circulation path for the spallation source for rejection of decay heat.

Detailed analysis will be necessary in order to quantify the functional reliability of this system. It may turn out that failure is possible only if the SBFS valves fail to open, or it may turn out that there are initial hydraulic conditions following which natural circulation would not be established. It is the present design intention that the nominal behavior of the system following successful basin flooding will be unambiguously successful; the question is whether there are probabilistically significant initial conditions which would compromise the design intention. This will be investigated further. It is expected that very high functional reliability will be convincingly demonstrated.

\section{Source Residual Primary Cooling System (SRPCS)}

The Source Residual Primary Cooling System (SRPCS) is intended to provide pumped flow of D2O to the source at a rate sufficient to remove decay heat. Two loops are provided, each with $100 \%$ capacity. In order for the SRPCS system to work, the spallation source would have to remain full of coolant, since the SRPCS takes suction off the outlet header. Circumstances that result in uncovery of the source outlet header or allow for ingesion of air/steam into the SRPCS suction may be sufficient to defeat its function. Among these are failure to flood a break low in the basin which would drain the SPCS, a loop seal in the intact 
loop that prevents natural circulation and results in boiling of the SPCS, and air ingression into the source outlet header from an uncovered break. In addition, since the SPRCS is an active system, it may be unavailable for other reasons.

\section{(b) Source Basin Flood System (SBFS)}

The Source Basin Flood System (SBFS) was designed to guarantee that a break in any primary cooling system inside the source section of the basin (SPCS/SRPCS and the corresponding blanket/window cooling systems, BPCS/BRPCS, WPCS/WRPCS) would be submerged, in order to prevent draining both loops and causing a loss of passive and active cooling in the affected systems. In addition, the system may help to mitigate LOCAs occurring above the flood height, by serving as a significant heat sink.

The SBFS comprises a Flood Tank and two trains of valves which open to drain the tank into the basin. Two recirculating cooling loops provide more than adequate capacity for removal of the decay heat. The Flood Tank contains enough water to cover by one foot all of the cooling system headers associated with the source, blanket and window cooling systems. The system is sized to flood the source side of the basin in about 90 seconds following a signal for a base source side LOCA. The storage tank contains $5000 \mathrm{ft} 3$ of water; $2500 \mathrm{ft} 3$ of water is required to cover all of the headers in the source, blanket, and window primary coolant systems by one foot. The system has two basin drain pumps to return water to the storage tank and has a heat exchanger to remove about $1 \mathrm{MW}$ of heat from the recirculating basin water. Whether or not this heat transfer capability makes it into the final design is undecided, because such a third-level system heat exchanger is not mandated by current day standards.

The SBFS serves essentially as a back-up to all of the decay heat removal systems. Note that the presence of water in the basin thermally couples the cooling capacity of window and blanket cooling systems to the source; analysis is expected to show that given this couple the cooling capability of the BPCS could be used to cool the source in the event that all the other source cooling systems were unavailable.

\section{Source Basin Flood and Recirculation System}

The SBFS is designed to support the cooling of the source in the event of a LOCA in the source or blanket primary coolant systems inside the source side of the basin. It may serve to mitigate LOCA's outside the basin as well. The system was included to provide assurances that any break inside the source basin would be submerged, thus ensuring that at least one primary coolant loop would remain full of coolant.

\subsubsection{Confinement Safety Function}

As mentioned in the Introduction to this section, many relatively severe events for the APT can be mitigated within the design basis of the APT confinement. For some reactor technologies, containments are designed for loads associated with design basis LOCA's, after 
which the core is cooled by the ECCS system. Loads associated with failure of a LWR's ECCS system are not considered within its containment design basis.

APT has the advantages of lower decay heat and lower radiological source term (compared to a comparably productive reactor). In addition, the possibility of energetic confinement events, such as steam explosions, missile generation, and hydrogen detonation have been eliminated through design. This means that "severe accidents" for APT, i.e., those events that can lead to credible and probable scenarios of eventual target damage, are not severe in the reactor sense of the word, and can be more easily contained than the analogous events associated with severe reactor accidents. As a result, the APT SILC technology has the opportunity to avoid the controversy associated with confinement failure simply by recognizing the loads and designing the confinement to contain these loads. Therefore, the objectives of the confinement are to:

(1) assist in passive decay heat rejection by the construction of structures to promote coolability (mitigate),

(2) retain radionuclides that may be released from a damaged spallation source (principally mercury) or Li/Al target (for example, by capture in water pools) and

(3) contain or vent the pressure load associated with steam generation due to decay heat that is not adequately accommodated by the cooling systems that have been designed specifically for this purpose (contain).

Several classes of events have been defined to structure the consideration of accidents in the formulation of a design basis for confinement. These classes are designated Type 1 (source and blanket cooled), Type 2 (failures of cooling potentially leading to source or blanket overheating), and Type 3 (beam trip failure or other exceptional load).

The Type 1 event classification includes LOCA-type occurrences in the source and blanket regions with successful beam trip and decay heat rejection by active or passive functioning of primary coolant loop systems. These events are within the design basis of the primary cooling systems and would result in no target damage beyond the LOCA itself. Decay heat would be transferred from the heat generating regions to the environment by systems such as the residual heat removal system, natural convection in the primary cooling system. Any confinement loads associated with these events would be small pressurization as a result of releasing the energy stored in the pressurizer and accumulator.

The Type 2 event classification would include LOCA-type events in the source or blanket regions with successful beam trip but failure of some or all of the cooling systems, resulting in overheating of the target (source or blanket) and eventual target damage. Decay heat would go into steam pressurization of the confinement and overheating of the target, with concomitant release of radionuclides from the primary system into the confinement. Depending upon the location of the break, the radionuclide release may be scrubbed by an overlying water pool with the potential for retention of nearly all condensed-phase radion:uclides in the water. With the beam tripped, the only heat source is decay heat; target damage would require dryout 
of the source pressure tubes. Whereas all the shutdown heat (or decay heat) for Type 1 events is rejected to the environment by one primary cooling system or another, the shutdown heat in Type 2 events is not: primary cooling fails, and the shutdown heat is mostly rejected to the primary confinement as steam. It is desirable to include Type 2 events within the design basis of the confinement (they are clearly beyond the design basis of the primary coolant systems) since only decay heat must be accommodated. If they can be accommodated by design without excessive cost, a significant additional layer of defense will have been added. The accommodation of Type 2 events within the design basis of the confinement would help to ensure that eventual radionuclide releases to the environment could be extremely small off-site and perhaps within occupational limits on-site.

The Type 3 event classification would include LOCA-type events or comparably severe initiators with failure to trip the proton beam. It is considered unlikely that failure of beam trip could persist for long; the probability of such an event should be made to reside in residual risk by designing the instrumentation and control systems for the APT such that beam trip reliability is nearly "perfect." The confinement load from such an event (failure to trip beam with a flooded target room) is potentially large, but such a load would be limited by the window survivability under rapid pressure loading. It would be nearly impossible to mitigate "prolonged untripped beam on target with no heat removal" through confinement design with any degree of cost-effectiveness; this event is more appropriately addressed through beam trip reliability nan thirough mitigation or confinement.

\subsection{EVENT SEQUENCES}

This subsection provides a high-level discussion of selected event sequences in the SILC target/blanket region. A preliminary logic model of accident sequences is presented; when this structure is complete, it will include essentially all accident types analyzed. The purpose of this development is to provide an integrated analysis showing how various safety systems work tog ther to achieve overall facility safety. In section 7.3.1, event sequence diagrams and event trees are presented. These catalog the possibilities that could ensure from selected initiating events: all systems might work, some might fail, etc. Section 7.3.2 follows up this catalog of outcomes with a discussion of the thermal hydraulics of selected level of safety (defense in depth) is achieved by the design features developed so far, and to suggest what areas of the design might conceivably be improved if this were deemed cost-effective. It also suggests areas in which additional information would improve the modelling. Ultimately, a more detailed and more comprehensive model will be necessary in order to support design decisions and safety analysis; the present development is all that is warranted at the stage of design reported in this document.

\subsubsection{Event Sequence Diagrams and Event Trees}

In this section, the SILC Target/Blanket systems and confinement systems are discussed from the point of view of accident prevention and mitigation. This discussion covers events initiated during production (not during handling or cold shutdown). For purposes of this 
discussion, an "initiating event" is a departure of one or more systems from the normal operating envelope, such that response of the safety systems is required. For example, a beam focus event would be considered an initiating event, because it would require at least the safety function "beam trip." Similarly, loss of normal target cooling would require "beam trip" and "cooling." The events considered here are not necessarily a complete set; a more comprehensive hazard evaluation is planned for next fiscal year. It is believed that the present collection comprises a range of events that is suitable for purposes of formulating a design basis.

Figures $7.2 \mathrm{a}$ and $7.2 \mathrm{~b}$ through $7.6 \mathrm{a}$ and $7.6 \mathrm{~b}$ present event sequence diagrams and event trees for various initiating event types. For each initiating event type, there is an $(a, b)$ pair of figures, in which the (a) figure presents an event sequence diagram and the (b) figure presents the event tree. The success strategies are most easily grasped from the event sequence diagrams (a); the consequences of failure are most easily grasped from the event trees (b).

Consider Figure 7.2a. This figure discusses the facility response to a "generic transient, " by which we mean an initiating event that does not immediately breach any coolant boundaries. Figure 7.2a shows "initiating event" on the left and "success" on the right. Each distinct pathway from "initiating event" to "success" corresponds to a distinct set of systems whose proper functioning would lead to "success," which in this case means successful target cooling. All success paths lead through "beam trip." This means that in general, beam trip is required. This does not imply that beam trip failure leads immediately to disaster, but it implies at least that beam trip failure is unanalyzed and, some of the time, would create a problem. Given successful beam trip, there are numerous ways to cool the target. The topmost pathway leads through SPCS(1), meaning one of the two trains of the Source Primary Coolant System, the normally-operating heat removal system. The next pathway down leads through the other train of that system. Then there is a pathway characterized as "SPCS Nat. Circ. (1)." This pathway removes heat by natural circulation through some of the same hardware, but without any pumps or support systems. As shown on the figure, there is effectively twofold redundancy in this passive heat removal capability for transient initiating events. Below these, there are two paths correspondin $\tilde{\varepsilon}$ to the two loops of the Source Residual Primary Cooling System, and below those, there are paths which take credit for heat removal following basin flooding. With the basin flooded, the source can be cooled externally by the surrounding water, and heat can be removed from the surrounding water either by the source basin flooding system circulating pump loop, or possibly by cooling the blanket, which is submerged by the same pool of water.

Certain pathways on Figure 7.2a are enclosed in a dotted line, and this region is labelled with the descriptor "Analyzed in SAR." This means that the enclosed paths are the complement of systems that would be considered safety class for purposes of accident analysis. It will be noted that the safety-class cooling function will require no active support systems.

Turn now to Figure 7.2b. This event tree classifies generic transient scenarios including system failures. The classification was discussed in a previous subsection: Type 1 scenarios involve a successfully cooled target, $2 \mathrm{a}$ means a submerged source externally cooled, $2 \mathrm{~b}$ means the source is not submerged and is not being cooled by any of its coolant loops, and 
3 means beam trip failure. This classification scheme is preliminary; it was developed for the purposes of scoping out what the magnitude and frequency of challenges to confinement might be. In a later subsection, a discussion will be given of the phenomenology of type $2 a$ and $2 b$ examples. Scenario classes such as these are generally called "plant damage states (PDS)." It is customary to classify scenarios according to a scheme such as this, in which each distinct class of scenarios is characterized by the most important phenomenological attributes. The important discriminators in the scheme shown here are whether beam trip succeeded, whether the primary loops are working, and whether the source basin was flooded. These presently appear to be decisive in the phenomenology. Further analysis might lead to revision of this scheme.

Each path from the left of this figure to an end state on the right is a distinct scenario. On any path, a step down at a branch point under a particular system heading means that the system failed in that scenario. The absence of a branch point means that the system was not needed in that scenario. A path going through a branch point straight to the right with no step down means that the system succeeded. For example, the topmost path on this tree happens to be a straight line from Initiating Event to "speedy return to service." This path leads through successful Beam Trip and successful SPCS. Following success of these two systems, there are no more branch points on that path, because overall success is ensured by those two successes. If Beam Trip fails, we go straight off the figure to plant damage state 3. For present purposes, this means "unanalyzed." If Beam Trip succeeds, but SPCS fails, we next query SPCS nat circ or SRPCS. If this succeeds, the plant damage state is OK. If this fails, the next system queried is the SBFS (basin flooding). If this fails, we classify the scenario as $2 b$. This would eventually challenge confinement. If flooding succeeds, we are at worst $2 a$. If SBFS circ succeeds, we are OK; if BPCS succeeds, we are at 1.

There are initiating events whose occurrence might disable one or more of the success paths shown on Figure 2a. One special case of this is loss of normal offsite power, which is treated on another figure. Other special cases might, for example, disable secondary loops in the SPCS, thereby removing some paths. These special cases would be accommodated in more detailed modelling.

Consider Figures 7.3a and 7.3b. These figures treat the initiating events "loss of normal offsite power" and "loss of primary flow." These differ from Generic Transient only in that we know a priori that normal forced SPCS cooling is lost; correspondingly, it does not appear on the ESD as a success path. Similarly, Figures 7.4a and 7.4b treat blackout, which takes down all active cooling, including whatever pumped systems are normally backed up by onsite AC supplies such as diesel-driven generators or gas-turbine-driven generators. Active cooling systems correspondingly do not appear on the ESD as a success path.

The remaining figures treat loss of coolant accident (LOCA) sequences. These are leaks in the primary coolant system that are severe enough to challenge safety functions. The SILC target coolant system is so designed that if at least one of its two loops retains sufficient water, heat can be removed entirely by natural circulation. However, break locations can be postulated that require external flooding in order to guarantee that at least one loop retains 
sufficient water. A break near the bottom of the system would allow air to enter both loops, so heat removal by loop circulation would stall. For this purpose, the source region is enclosed in a "basin" whose volume is to be flooded in the event of a LOCA.

Figures 7.5a and 7.5b treat "in-basin" LOCAs. Complete success (Figures 7.5a,b) requires beam trip, successful operation of the pressurizer and/or accumulator (depending on the location and characteristics of the break), flooding of the basin, and heat removal either by natural circulation, by the SRPCS (an active system), or by the SBFS circulating system (another active system). The blanket cooling systems are shown as possible success options as well; the shading of that block on this figure indicates that its present status is uncertain. Figure $7.5 \mathrm{~b}$ shows the event tree; again, beam trip leads to a plant damage state of 3, failure of basin flooding leads to $2 b$, and flooding but no heat removal path leads to $2 a$. (This figure, in fact, is the set of scenarios that led to the present PDS scheme.)

If a break occurs high up in one loop of the primary coolant system loops (above the point where the two loops become separate), then air cannot enter the unbroken loop, so loop circulation can continue even if flooding fails. However, in the event of some sort of failure in loop circulation, the basin flood can still provide a means of heat removal, as it did for transients. This situation is covered by Figures 7.6a and 7.6b.

\subsubsection{Accident Phenomenology}

Five accidents are discussed below:

(1) Large break LOCA: one active cooling system responding,

(2) Single assembly flow blockage with delayed beam trip,

(3) Small break LOCA with delayed beam trip,

(4) Large break LOCA: total failure of active cooling systems, passive cooling systems available, and

(5) Large break LOCA: total failure of active cooling systems plus non-mechanistic failure to establish natural circulation in the unbroken loop.

Events 1 and 4 are within the design basis of the cooling systems; they result in minimal or no release of radionuclides to the confinement. Event 3 has not been analyzed. Events 2 and 3 involve "delayed " beam trip; these are beyond-design-basis by definition, since "delay" means "relative to the timing assumed in safety analysis." Event 5 involves multiple failures and non-mechanistic evolutions leading to significant target damage, but is still within the proposed design basis of confinement. Its in-confinement source term is the worst of the five events considered here, but the event still does not unacceptably challenge the confinement. 


\section{(1) Large Break LOCA: One Active Cooling System Responding}

This scenario corresponds to the topmost success path in the ESD (Figure 7.5a) and the topmost success path on the event tree (Figure 7.5b). In this scenario, all plant protection safety systems function as designed. The worst single failure in an active system responding to the initiating event is assumed to occur. The source term for this event will consist of a small fraction of the circulating inventory of tritium released from the D2O coolant that is expelled into the confinement. The source term to the environment will be a small fraction of this and is expected to be determined by the confinement leakage rate.

\section{(2) Single Assembly Flow Blockage with Delayed Beam Trip}

This scenario corresponds to a complex application of the Generic Transient ESD and event tree. A delay of beam trip is considered beyond design basis, and a priori would put the target into PDS 3, but if the beam trips before massive damage occurs (and this is expected), some of the transient success paths should operate.

For example, consider a total blockage of a single $\mathrm{Pb}$ source pressure tube. It is an objective of the SILC target design effort that the source pressure tubes will be designed to prevent total blockage. In the present design of the $\mathrm{Pb}$ source assembly, approximately $20 \%$ of the cross-sectional area of the pressure tubes is open for coolant flow between the wire-wrapped source rods. No mechanism has been identified by which foreign matter could block an entire pressure tube. Such a condition would be discovered during installation inspection procedures. It is currently expected that not only will each source pressure tube have outlet temperature instrumentation, but also the entire Source Primary Coolant System (SPCS) will be heavily instrumented with temperature, pressure, flow rate, and liquid level instrumentation. As a result, such a blockage event would be immediately identified as an off-normal condition. Pressure and temperature signals in and around the blocked pressure tube would immediately signal to trip the proton beam once they exceeded the range of operating limits set by technical specifications. Assuming that this is when the coolant temperature in the affected pressure tube reaches saturation, the beam would be tripped and the primary coolant system flow would be continued. At decay heat levels in the source rods, saturated boiling of the source coolant in the blocked pressure tube would continue with cold coolant reflooding into the pressure tube from the upper header to replenish the coolant lost by boiling. Since the heat flux at the top of the source rods would be less than the critical heat flux, reflooding of the pressure tube would occur (top success path). If deemed necessary, the source basin flood system could be actuated to flood the source basin, thus aiding in decay heat removal and ensuring that no target damage occurred (lower success paths leading to PDS 2a). There would be no melting of source material $(\mathrm{Pb})$, no breach of the SPCS, and no release of activity to the confinement. Production could resume if the blockage were removed. 


\section{(3) Small Break LOCA with Delayed Beam Trip}

This is treated on Figures 7.5a and 7.5b, complicated once again by the postulated "delay" in beam trip. If trip is assumed to be delayed indefinitely, the source goes to PDS 3. In the following discussion, the beam trips before massive damage occurs, partly because the LOCA is small enough that the scenario evolves slowly. This discussion corresponds to the topmost success path on Figures 7.5a and 7.5b.

The small break LOCA with delayed beam trip is a beyond-design-basis event. A small break LOCA is assumed to occur in one source pressure tube inside the floodable source basin room. The SBLOCA proceeds undetected and the proton beam remains on target. D2O is lost from the break and accumulates in the source basin. As liquid inventory is lost, D2O is discharged into the SPCS by the pressurizer/ accumulator system to make up the losses. While the accident continues undetected, the liquid levels in the pressurizer and accumulator would decrease and, simultaneously, the gas space pressures in the accumulator and pressurizer would decrease. Any tritium in the circulating D2O inventory would also be released to the confinement. Eventually, the detection of airborne radiation in the confinement atmosphere by the confinement radiation instrumentation, the detection of decreasing levels of pressure and liquid inventory in the pressurizer and accumulator by instrumentation in the SPCS, or a combination of multiple signals would indicate that a break had occurred. The beam and the SPCS pumps would be tripped. The basin flood system would be actuated, filling the source target basin within 90 seconds and submerging the break location. Once the SPCS pumps had coasted down, the break flow would stop and the SRPCS would be actuated (if not already running) to remove decay heat from the source target. Both SRPCS loops are sized for full decay heat removal capacity to ensure success of cooling the source bundles. The two loops of the SPCS would remain full of D2O and the accident would be terminated with no damage to the lead spallation target assembly. The source basin recirculation heat exchanger with a $1 \mathrm{MW}$ heat transfer capacity would also be available to assist in decay heat removal from the source pressure tubes. Absent any damage to the source rods due to overheating, the release of radioactivity from the SPCS to the confinement would be some fraction of the circulating inventory of tritium in the D2O coolant, a quantity that will be limited by technical specifications. A likely upper bound on this would be $50 \%$ of the circulating inventory of tritium, based upon capacities of the SPCS piping and the capacities of the pressurizer and accumulator. No release of spallation or fragmentation products from the neutron source is predicted for this accident, since there would be no melting or breach of the cladding on the spallation rods.

(4) Large Break LOCA: Total Failure of Active Cooling Systems, Passive Cooling Systems Available

This scenario corresponds directly to the path shown on the LOCA ESD (Figure 7.5a) as "analyzed in SAR" and to the topmost OK path on the accompanying event tree (Figure 7.5b). Given that there was a large break, the source will presumably need to be replaced, so the meaning of "OK" in this context is simply that target overheating does not occur and 
radionuclides are not released from the target. There will be some radionuclides normally present in the coolant, so its release to confinement as a result of the leak means that some retention capability is called for in this event, but the challenge posed to the confinement function will be well within its capability.

(5) Large Break Loss-of-Coolant Accident (LOCA): Total Failure of Active Cooling Systems Plus Non-Mechanistic Failure to Establish Natural Circulation in the Unbroken Loop

The only system that is assumed to function is the Source Basin Flood System. This means that the scenario goes to PDS $2 \mathrm{a}$ on Figure $7.5 \mathrm{~b}$. It is postulated that natural circulation (bulk flow through the pressure tubes) in the unbroken loop is not established. The probability of this accident will place it into the residual risk category. However, it is proposed to be within the design basis of the confinement. Although this accident is of such low frequency as to be of dubious value in estimating on-site and off-site radiation doses (residual risk events are considered to be of such low probability that their risk is acceptable), it may be useful to consider such events while the designs of the cooling systems and the confinement continue to evolve, in order to enhance further the passive safety of the facility by uncovering any relative vulnerabilities and allowing the design to accommodate and/or eliminate them.

A preliminary source temperature history for this case is shown in Figure 7.7. Assuming that the beam and pumps are tripped at time zero, the pump coast down period will end at 45 seconds. Since the decay heat during this time is only about $1 \%$ of the operating power, the source actually cools to $62^{\circ} \mathrm{C}$ during the pump coast down period. From 45 seconds to 90 seconds, the time at which the basin is completely flooded, it is assumed that the source heats up adiabatically. At 90 seconds, the average temperature of spallation source is calculated to be $65.5^{\circ} \mathrm{C}$.

After the basin has been flooded with cold water, the following mechanisms for the heat transfer from the source rods to the water in the basin are considered. The source rods transfer heat to the pressure tubes via conduction and natural convection (natural convection within each pressure tube, wherein the hot fluid from the central region rises upwards and cold fluid along the walls of the cold pressure tube moves downwards). The pressure tubes transfer energy to the basin water via natural convection on the basin side. It is important to note that due to the high thermal conductivity of the aluminum pressure tubes, the thermal resistance of the pressure tubes is negligible.

Since the failure of all active systems is assumed, the water in the basin is assumed to heat up adiabatically due to heat transfer from the source pressure tubes. Transient heat transfer calculations show that the source reaches the saturation temperature of $101.42^{\circ} \mathrm{C}$ at 22.8 hours. From this time onwards, the heavy water within the source would boil off. At approximately 31 hours into the accident, the water inventory from the unbroken loop drains as the upper header is uncovered. This D2O inventory (at $62^{\circ} \mathrm{C}$ ) would sweep through the source pressure tubes and the upper header rapidly, displacing the saturated water with the cold water from the 
unbroken loop. This would result in a rapid cool-down of the source pressure tubes, but only for a very short time. The source rods and water would quickly reheat to saturation in less than 30 minutes.

Calculations show that at 37.2 hours, the basin water would have reached $100^{\circ} \mathrm{C}$. Therefore, from this time forward, heat would be transferred from the pressure tubes to the basin water via boiling heat transfer. At 43.6 hours into the accident, the D2O inventory in the upper header of the source would have been boiled off and the source rods would begin to be uncovered. At 48.4 hours the source would have boiled dry. Until this time, the temperature of the spallation source had not exceeded the D2O saturation temperature. From this time onwards, the source rods heat up. At 50.4 hours into the accident, while the average source temperature has only reached $218.7^{\circ} \mathrm{C}$, the centerline temperature in the pressure tubes has reached the melting point of lead $\left(327.4^{\circ} \mathrm{C}\right)$. At this time, $\mathrm{Pb}$ in the central regions of the pressure tubes will begin to melt. When the average source temperature reaches $302.9^{\circ} \mathrm{C}$, heat transfer from the source rods to the pressure tubes would be equal to the decay heat, assuming that the source had operated continuously for one year prior to the accident. This occurs at 57.3 hours. Since the decay heat would be continuously decreasing with time, from this time onwards the source rods would cool. By this time, $26.8 \%$ of the lead in the source rods would have melted, relocated to the bottom header, frozen, and quenched. Since beyond this time the average source temperature would continuously decrease, the system would be coolable. It is noted that due to the design of the structures above the basin and the basin flood tank, all the steam produced due to the boiling of basin water would be condensed and returned to the basin. Therefore, the basin would remain flooded. It is also noted that after three days, only $2854 \mathrm{~kg}$ of water in the basin would have been boiled off. If the assumption were made that the water boiled off from the basin were not returned but just lost as steam, the decrease in the basin water level after three days would be approximately $15 \mathrm{~cm}$.

Until this point, it has been assumed that none of the forced cooling systems has been operational or available to aid in decay heat removal from the spallation source pressure tubes. This is, of course, an extreme assumption. Only the source basin flood system was assumed to work. The systems that have been neglected include both Source Residual Primary Cooling System (SRPCS) loops (1 MW capacity each), the Source Basin Flood System (SBFS) recirculating heat exchanger (1 MW capacity), both Window Primary Cooling System (WPCS) loops (0.5 MW each), and the Blanket Primary Cooling System (BPCS) loop which is submerged in the flooded basin (ultimate total heat capacity is $28 \mathrm{MW}$ ). Resumption of any one of these six coolant systems at any time prior to 42 hours into the accident would be sufficient to maintain the source basin subcooled and to prevent the dryout of the spallation source rods in the SPCS pressure tubes, thus ensuring long-term coolability of the rods and recovery from the accident with no overheating damage to the spallation source. Resumption of one of these systems after the 42-hour point might lessen the extent of uncovery of the spallation source rods, potentially avoiding target overheating and minimizing the extent of damage to the rods.

As the lead in the source pressure tubes begins to melt (at $50.4 \mathrm{hrs}$ ), it relocates downward under gravity, and freezes and quenches in the inlet header, which is full of water. 
None of the quenched debris from the previously molten lead from the damaged spallation rods is expected to be released from the piping of the primary cooling system; once the melt is quenched, it is assumed to remain in the inlet header in a coolable configuration. If any of the source pressure tubes were to fail due to contact with the melt at any time prior to 57 hours (termination of melting), the basin water would flood into the break location, flood the source pressure tubes to the level of the basin water, and quench the overheated rods. This would immediately terminate the melting process and there would be no further release of radionuclides to the confinement. Provisions are being considered to preserve this possibility in the design of the SILC target for accident management purposes.

\section{Source Term To Confinement}

During the melting period, the lead is calculated to heat only to its melting point of $327^{\circ} \mathrm{C}$. The molten lead from the damaged spallation rods would remain molten only as long as it took to fall under gravity into the water in the inlet header. This would be on the order of one second (calculated to be $0.65 \mathrm{sec}$ for a 2 meter fall). There is more than $2000 \mathrm{~kg}$ of D2O in the lower header, an order of magnitude more water in the lower header to freeze and quench the $\mathrm{Pb}$ debris than would be necessary. The melting of the spallation source would continue for seven hours (until 57.3 hours into the accident), at which time the heat losses would exceed the decay heat (which is continuously decreasing); thus, from 57.3 hours on, the source temperature would continue to decrease and melting would be arrested. The peak average-temperature of the spallation source was calculated to be just $303^{\circ} \mathrm{C}$. Over this period of seven hours of melting, it is calculated that $27 \%$ of the lead would have been melted (6600 kg of lead) and that it would have required the vaporization of $162.5 \mathrm{~kg}$ of water to freeze and quench this mass of debris in the inlet header. Since the cross-sectional area for upflow in all the source pressure tubes is $0.36 \mathrm{~m} 2$, this results in an average steam velocity through all the spallation source pressure tubes of approximately $3 \mathrm{~cm} / \mathrm{s}$. (Note: the cross-sectional area for flow in all of the 33 source pressure tubes is $0.36 \mathrm{~m} 2$ and the coolant volume in all the tubes is $0.753 \mathrm{~m} 3$ ). Some of the parameters needed for the VSWAG code calculations of radionuclide release are summarized below:

Gas stream:

Melt temperature:

Average lead melting rate:

Total steam flow rate:

Total cross-sectional flow area

in all pressure tubes:

Total flow volume in all

pressure tubes:
Steam at 1 bar and $100^{\circ} \mathrm{C}$

$327^{\circ} \mathrm{C}$

$0.26 \mathrm{~kg} / \mathrm{s}$

$6.45 \mathrm{gm} / \mathrm{s}, 0.011 \mathrm{~m} 3 / \mathrm{s}, 3.0 \mathrm{~cm} / \mathrm{s}$

$0.36 \mathrm{~m} 2$

$0.75 \mathrm{~m} 3$

The driving force for the volatilization and transport of radionuclides from the molten lead would be minimal at best. Since the lead relocation process (free fall) will limit the time during which the lead will be molten to the order of seconds, rate-limiting processes such as mass diffusion in the molten lead will play a dominant role in limiting the vaporization release 
of radionuclides such as $\mathrm{Hg}$, and these factors must be considered in calculation of the source term.

Those radionuclides that would be released from the melt would be carried upwards through the densely packed pressure tubes by the steam flow from the lower header of $3 \mathrm{~cm} / \mathrm{s}$, through the upper header and the SPCS piping, through the pump and heat exchanger, and finally out the break location and into the confinement air space.

The source term to confinement is therefore dominated by the radionuclide burden of the D2O coolant at the time of the accident, plus the vaporization release from lead for the limited time during which it is both liquid and exposed to air or steam.

\subsubsection{Key Phenomenological Points}

Even at the present stage of the design, certain conclusions can be drawn from the preliminary accident analyses presented above.

1. The time available for production of an airborne, in-confinement source term from the lead is limited to the time that the lear is molten, and in nearly all cases, this time will be relatively short. The allowaole design basis leakage limit for confinement will be influenced by this parameter.

2. Calculations presented in the previous subsection showed that even with the postulated failure of all loop-circulation mechanisms for heat removal, overheating would not occur for times on the order of 42 hours, given a flood. This point is re-emphasized in Table 7.1, which summarizes outcomes for different evolutions of LOCA scenarios. Outcomes are tabulated for the four possibilities (Basin Flood Occurs/Does Not Occur). The heat-sink property of the flood makes it a desirable design feature event if the loop-circulation function is lost.

3. It appears to be relatively easy to allow for essentially all beam-off flooded scenarios within the confinement design basis, and it appears to be possible to allow for all beam-off unflooded scenarios as well.

\section{$7.4 \quad \underline{\text { SUMMARY }}$}

The following key points emerge from the preceding discussion.

- Given a transient or LOCA initiating event, there are numerous success paths for prevention of target damage.

- The beam trip function must be extremely reliable in order for these success paths to operate. 
- Successful basin flooding together with successful beam trip will make it very difficult for serious target overheating to occur.

- Failure of gravity-driven basin flooding following certain breaks could lead to some in-confinement release, but relatively easy challenges to the confinement function, and the present intention is to allow for this within the confinement design basis. 
Table 7.1

Target Damage End States for LBLOCA

as Function of Source Basin Flood Status;

Credit for Heat Removal by Design Basis Natural Circulation

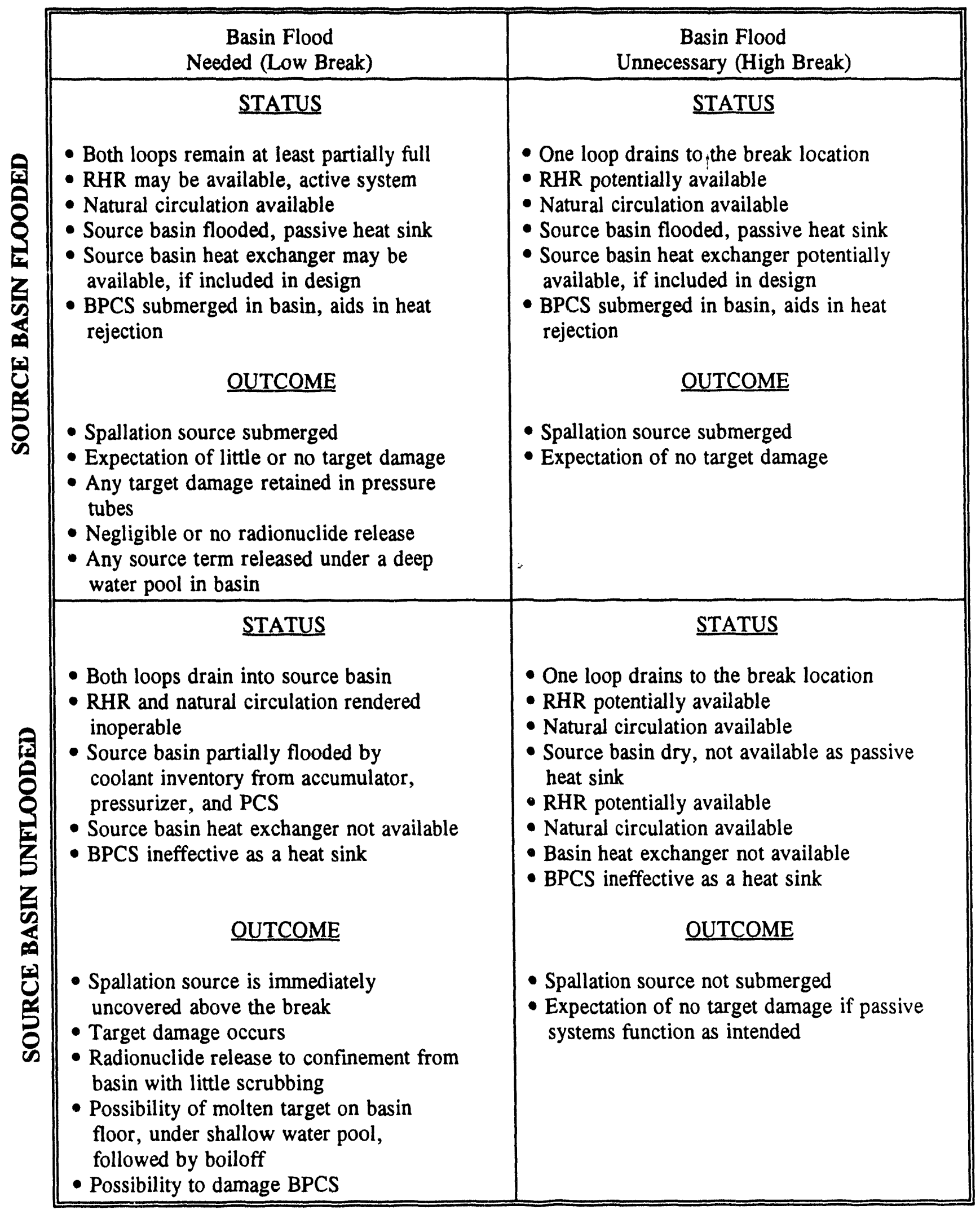


FIGURE 7.1

\section{EVENT SEQUENCES AND DESIGN BASES}

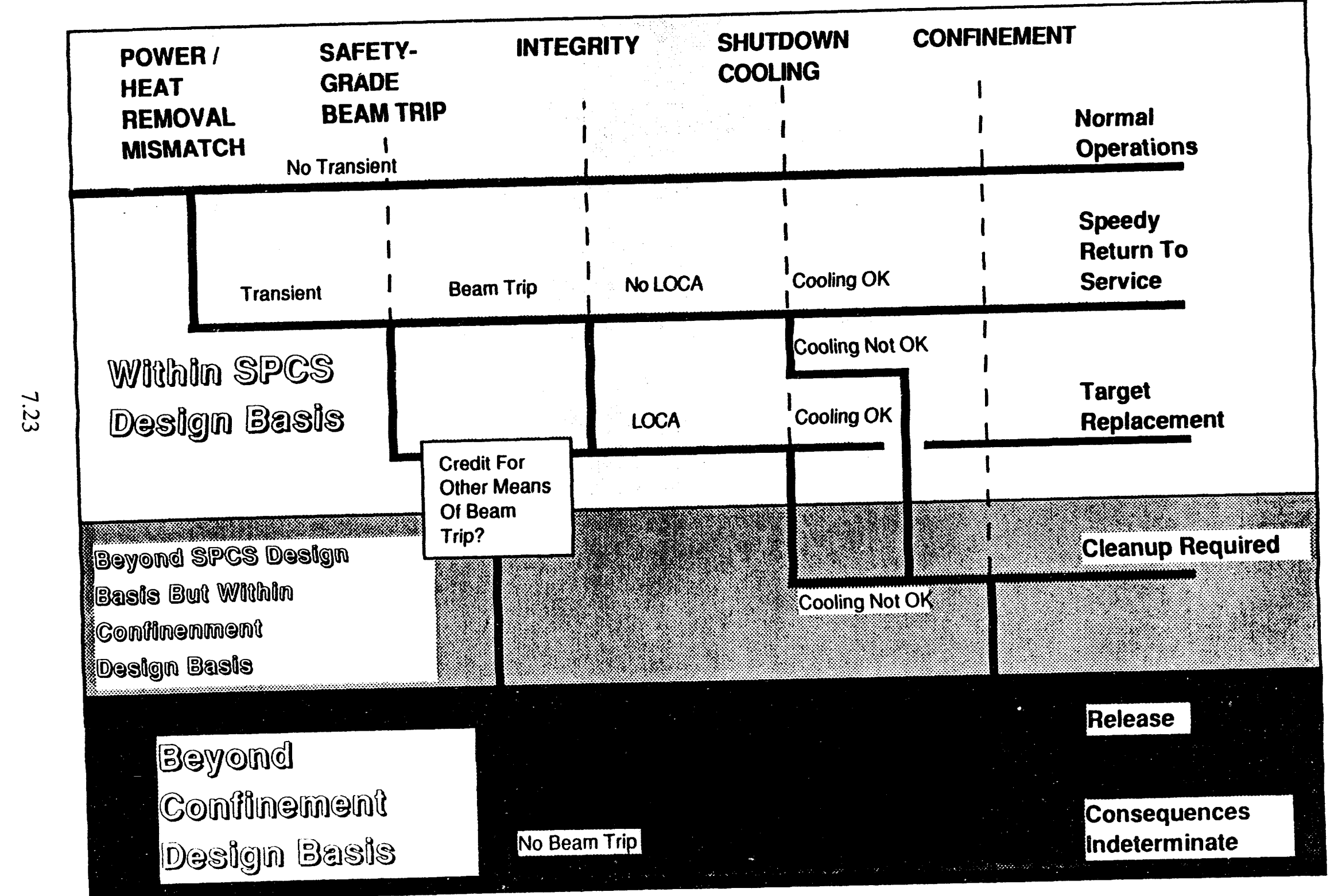


FIGURE 7.2a

\section{GENERIC TRANSIENT EVENT SEOUENCES}

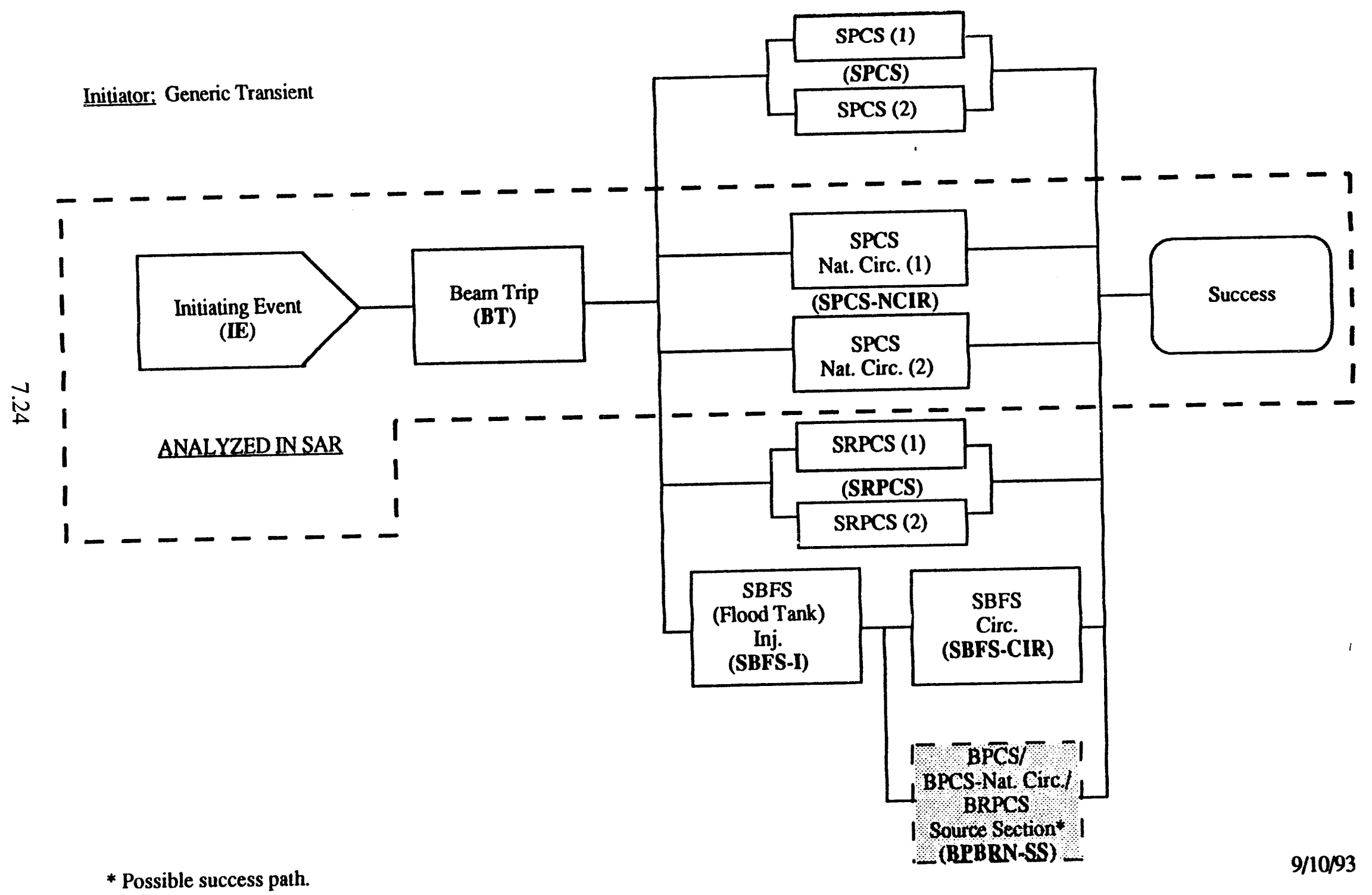




\section{FIGURE 7,2b}

\section{GENERIC TRANSIENT EVENT TREE}

Initiator: Generic Transient

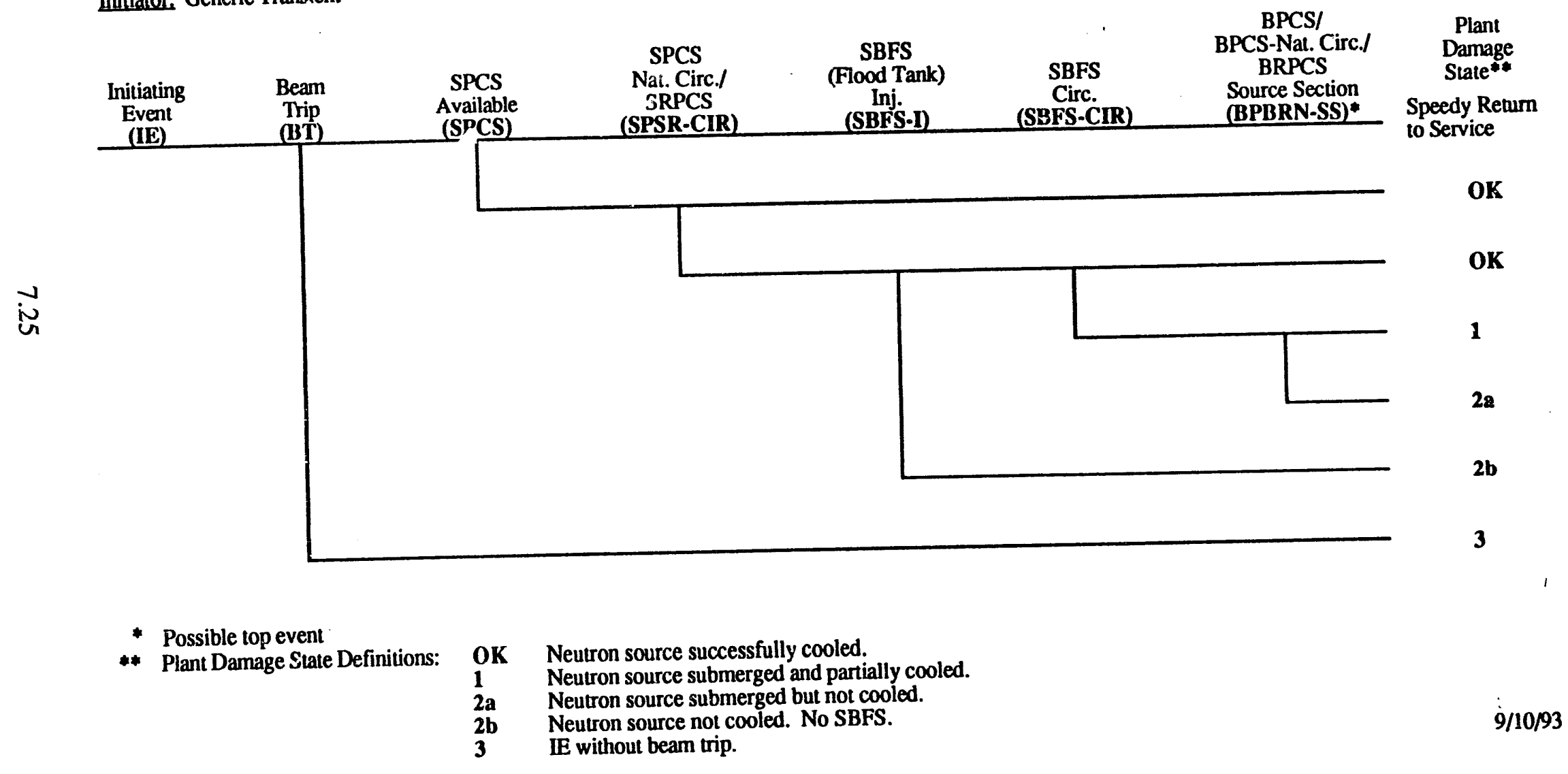




\section{EIGURE 7.3a \\ LOOP LOFA SUCCESS SEOUENCES}

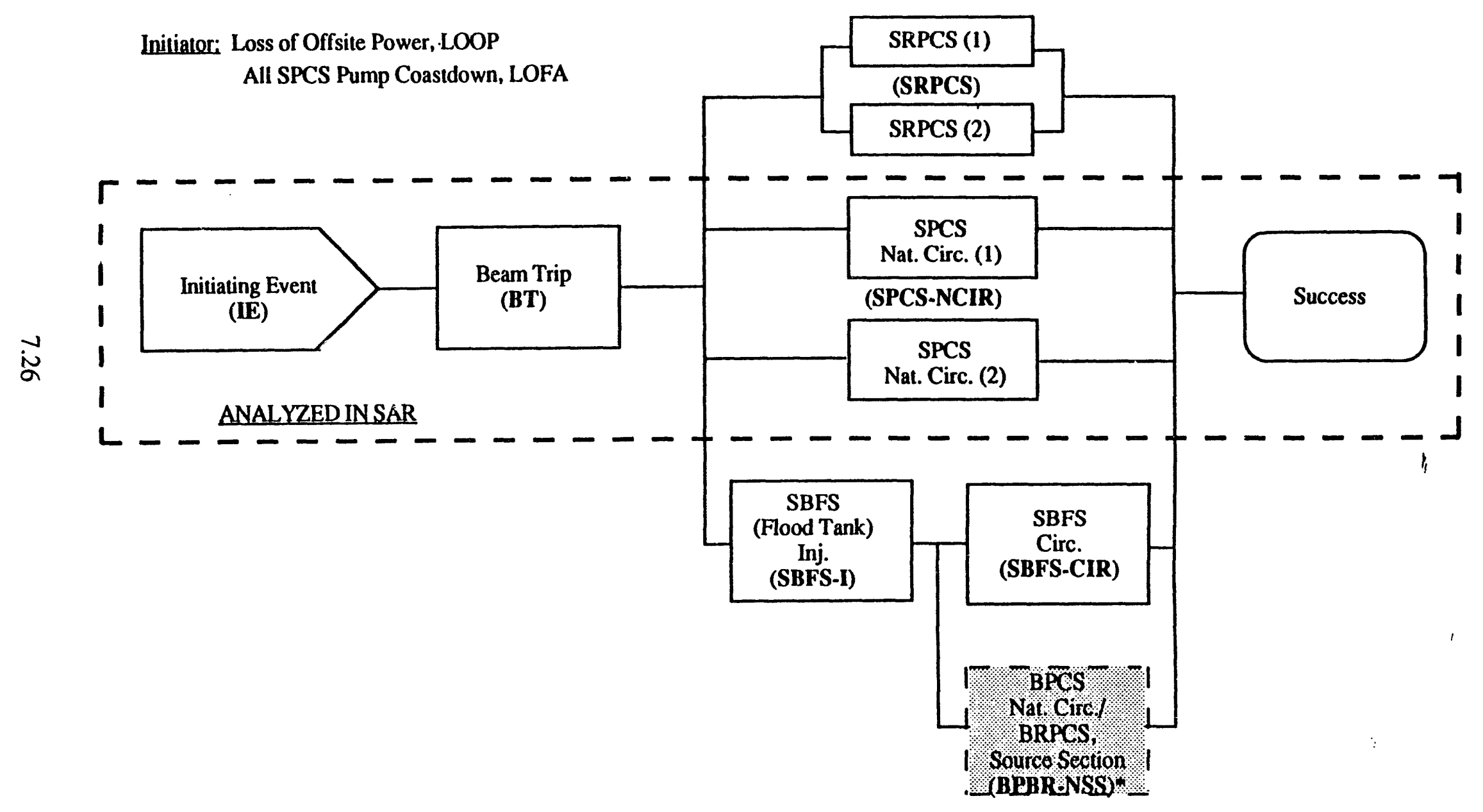

* Possible success path 


\section{FIGURE 7.3b \\ LOOP. LOFA EVENT TREES}

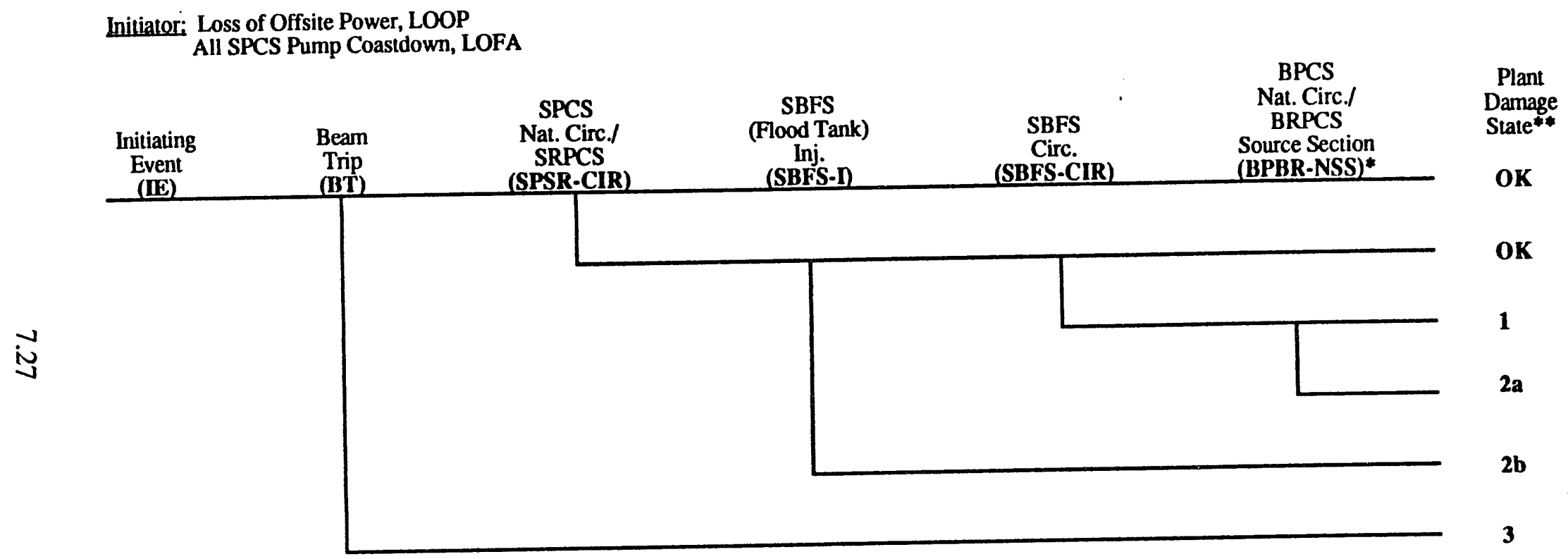

* Possible top event

** Plant Damage State Definitions:

OK Neutron source successfully cooled.

1 Neutron source submerged and partially cooled.

2a Neutron source submerged but not cooled.

2b Neutron source not cooled. No SBFS.

3 IE without beam trip. 
FIGURE 7.4a

BLACKOUT SUCCESS SEOUENCES

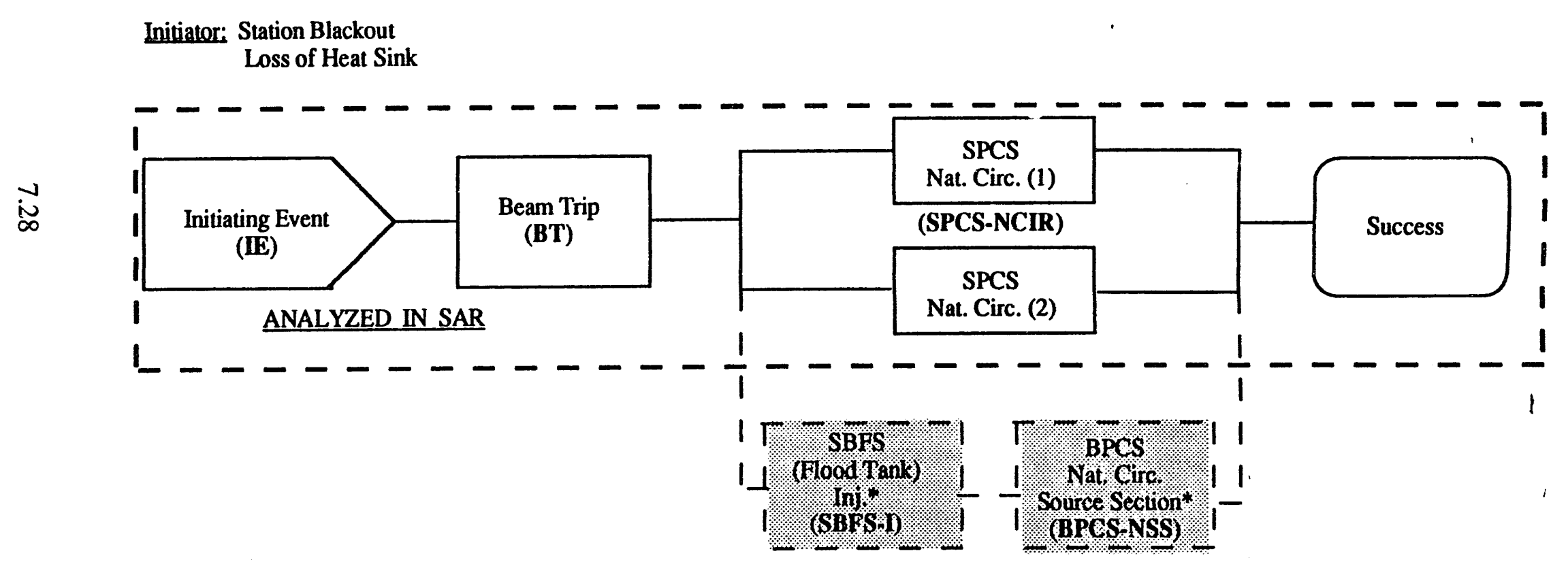

* Possible success path 


\section{EIGURE 7.4b \\ BLACKOUT, LOSS OF HEAT SINK EVENT TREES}

Initiator: Station Blackout, All Source/Blanket/Window Cooling Systems' Pumps Unavailable Loss of Heat Sink

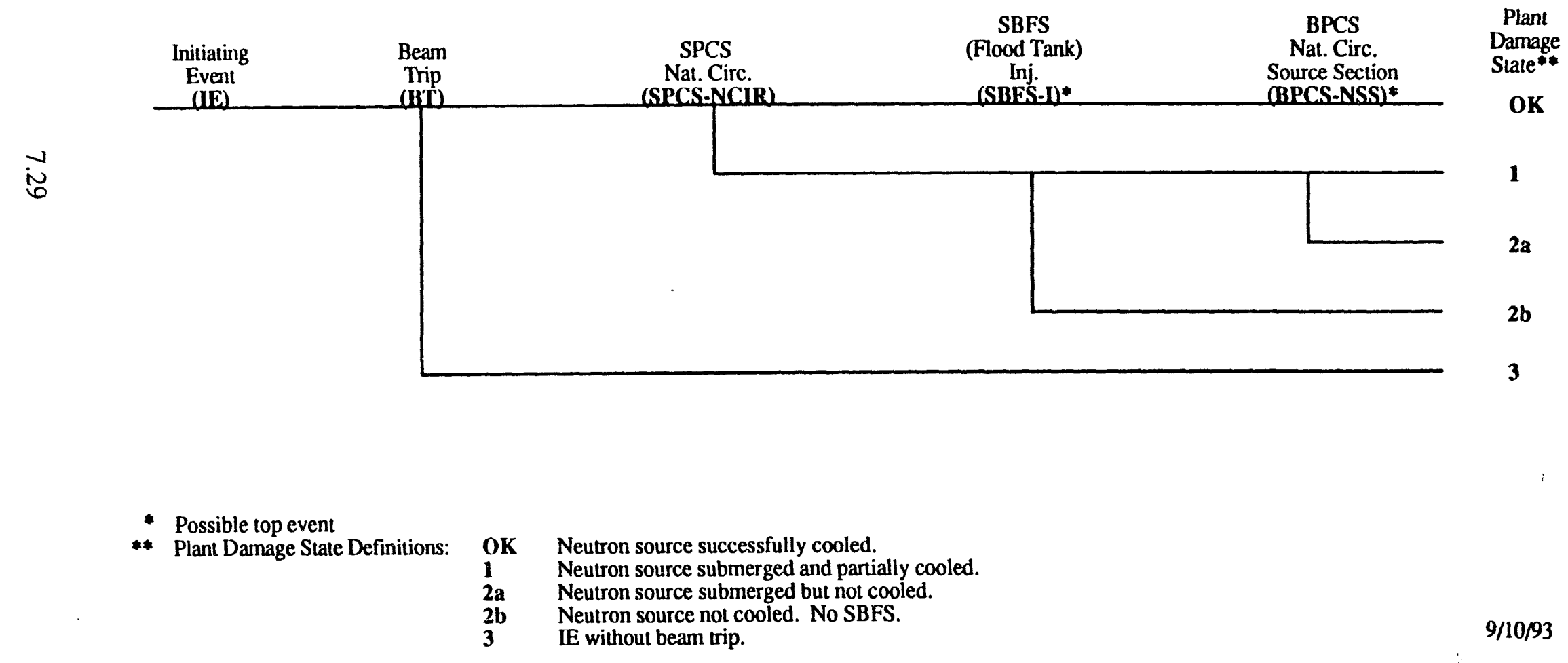




\section{EIGURE 7.59 \\ IN-BASIN LOCA SUCCESS SEOUENCES}

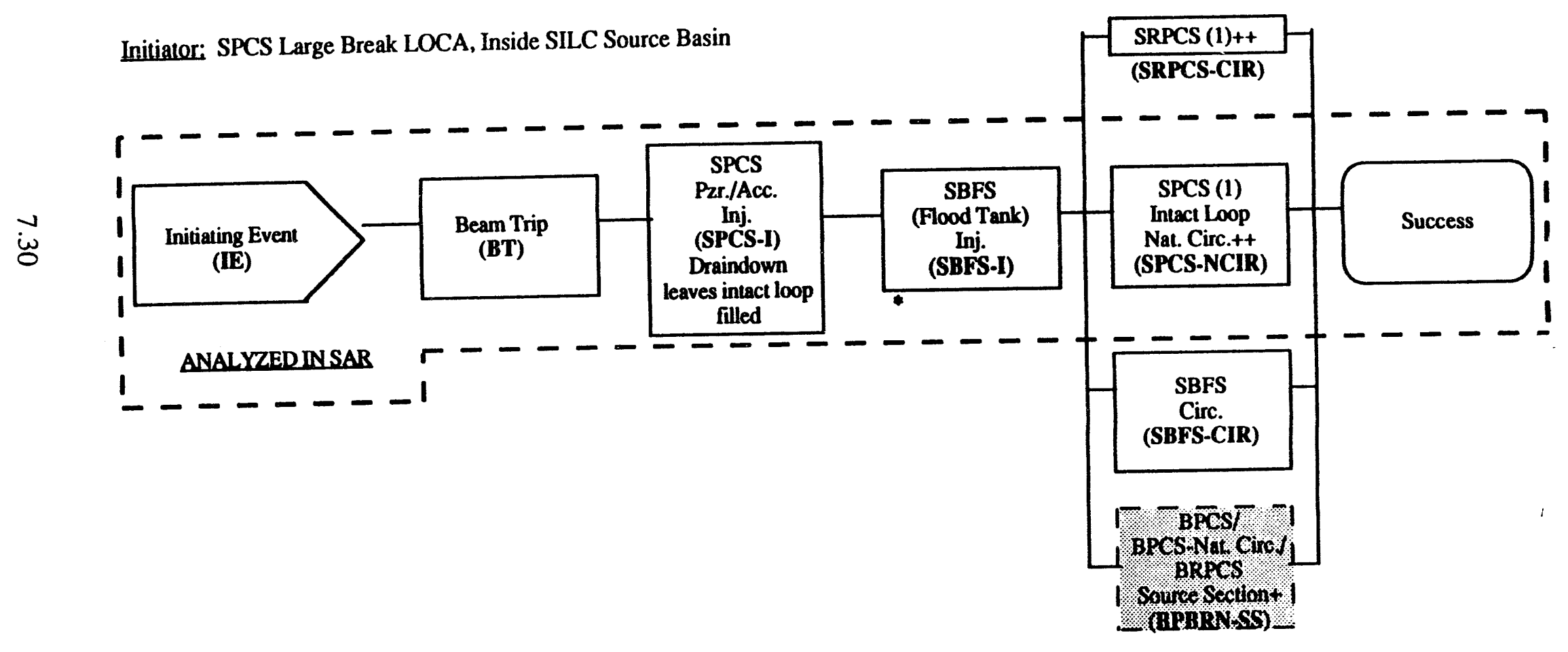

* Basin source section integrity

+ Possible success path 


\section{FIGURE 5b}

\section{IN-BASIN LOCA EVENT TREE}

Initiator: SPCS Large Break LOCA, Inside SILC Source Basin

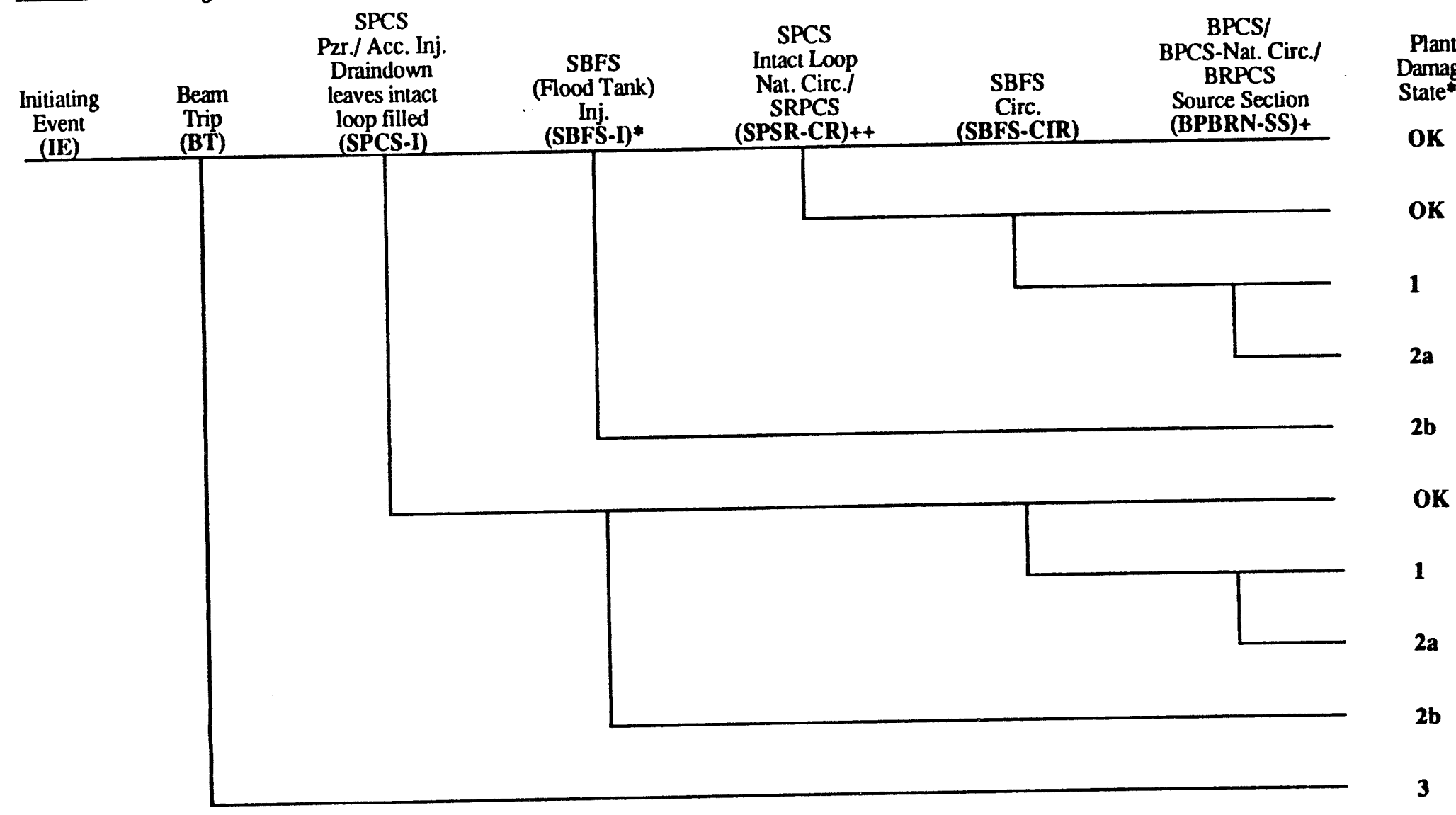

+ Possible top event

+ Given successful break flooding, second loop may also be available

* Basin source section integrity

** Plant Damage State Definitions:

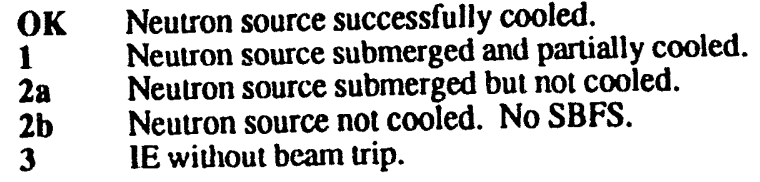




\section{FIGURE 7,6a \\ EX-BASIN LOCA SUCCESS SEOUENCES}

Initiator: SPCS Large Break LOCA, Outside (Above) SILC Source Basin

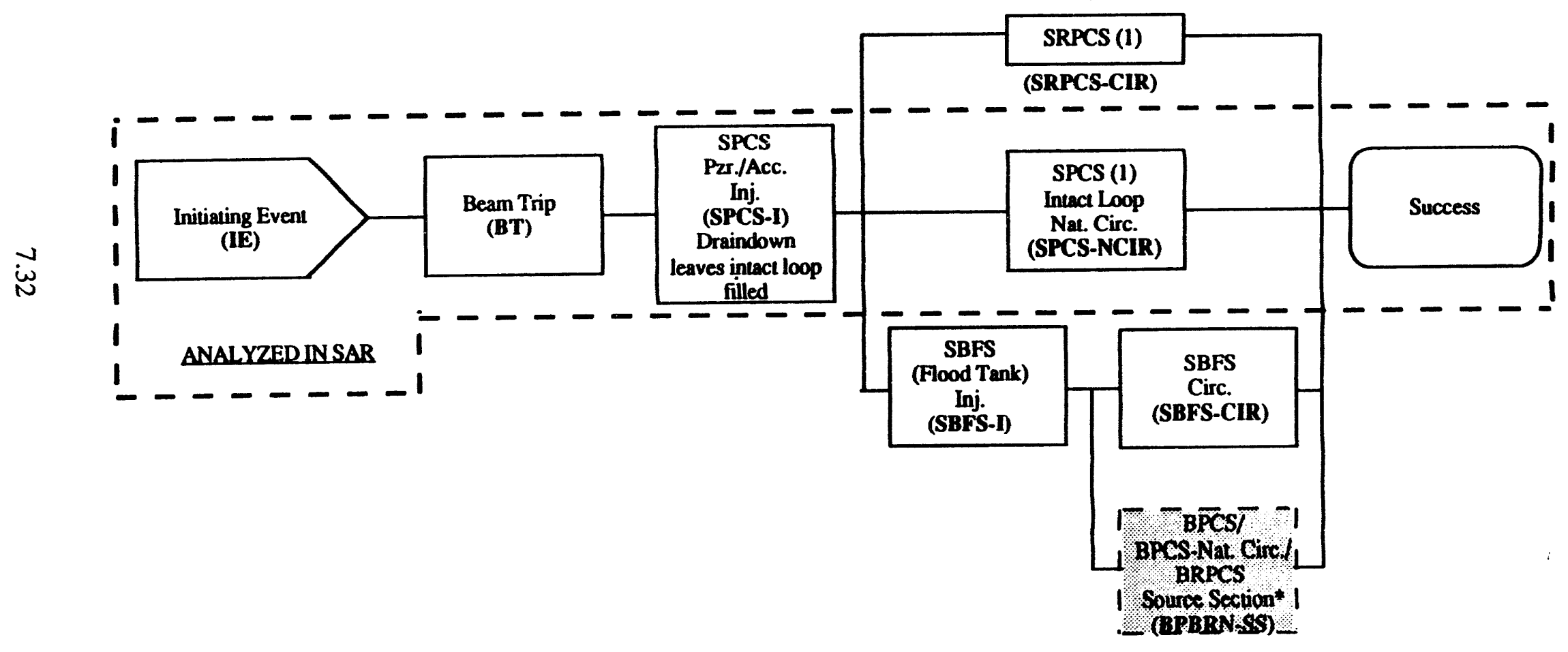

* Possible success path 


\section{FIGURE 6b \\ EX-BASIN LOCA EVENT TREE}

Initiator: SPCS Large Break LOCA, Outside (Above) SILC Source Basin

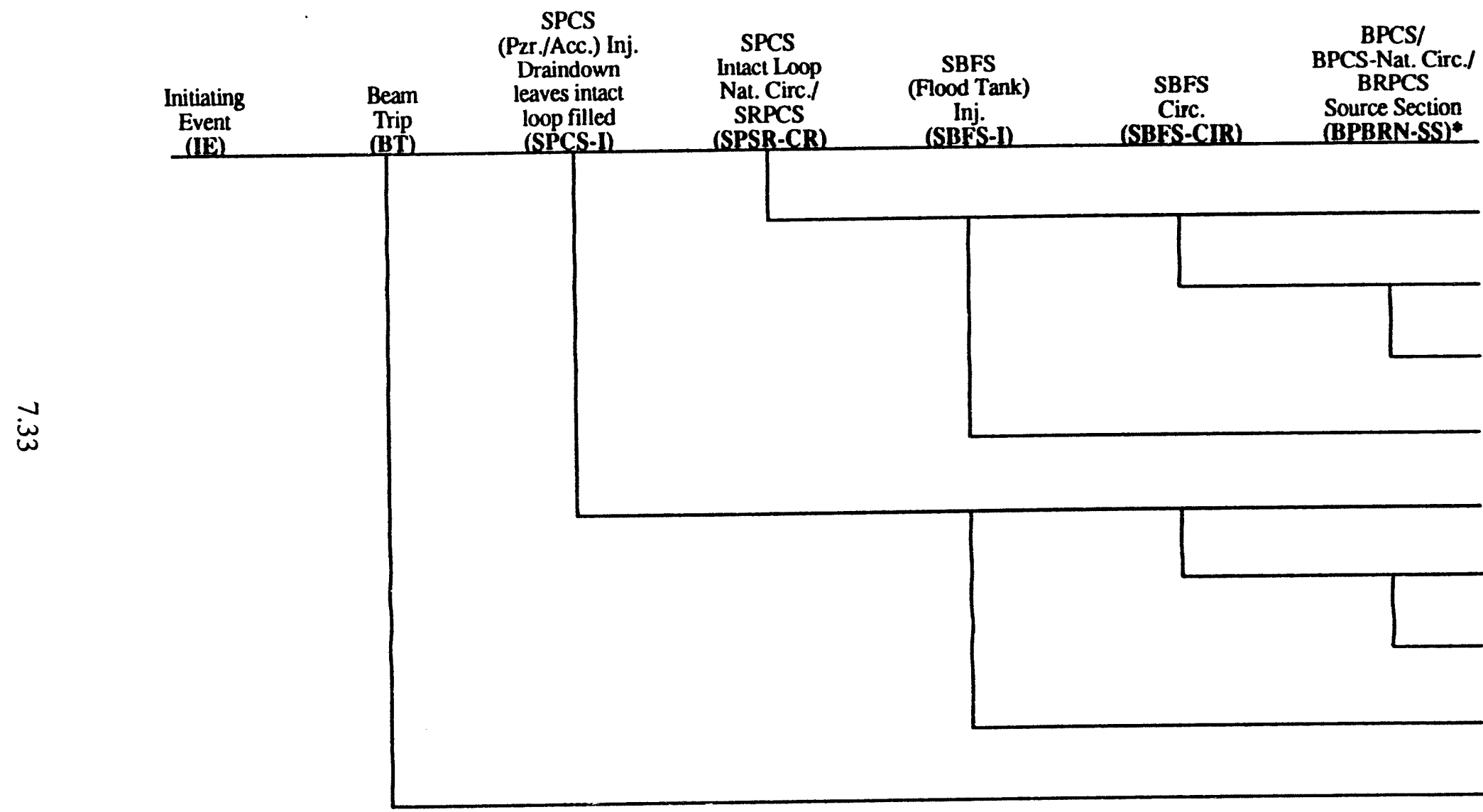

SPCS

(Pzr./Acc.) Inj

leaves intact

SPC: Loop

Circ.

Flood Tank)

Inj.

(BT) (SPCS-I) (SPSR-CR

Plant

Damage

State

OK

OK

1

2

$2 b$

OK

1

2a

2b

- Possible top event

* Plant Damage State Definitions:

OK Neutron source successfully cooled.

1 Neutron source submerged and partially cooled.

2a Neutron source submerged but not cooled.

2b Neution source not cooled. No SBFS.

3 IE without beam trip. 


\section{FIGURE 7.7}

APT SILC SYSTEM: LBLOCA IN COLD LEG, IMMEDIATE BEAM TRIP, NO NATURAL CIRCULATION IN UNBROKEN LOOP

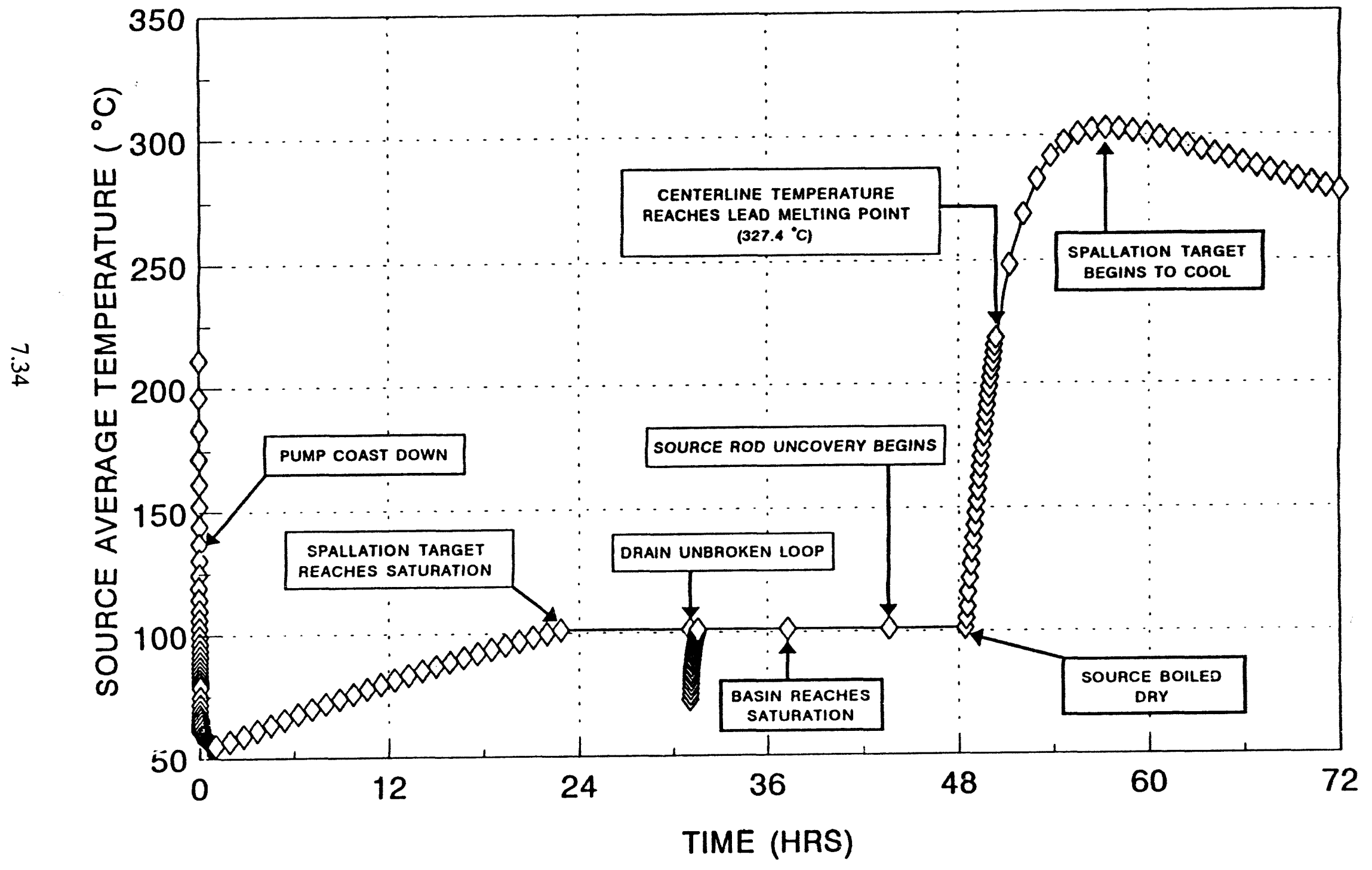




\subsection{FABRICATION PROCESS DESIGN (WBS 5.1.3.1.6.1)}

A final report (WSRC-TR-93-432, ATD/APT93-0026 (REV.0)) has been submitted to BNL from Westinghouse Savannah River Laboratory. The report provides fabrication options for the $\mathrm{Pb}-\mathrm{Al}$ and $\mathrm{Al}-\mathrm{Li}$ target designs. The preliminary conclusions are that an effective and practical target design is feasible with current technology. The final report will be issued to DOE by October 1, 1993. 


\subsection{EXTRACTION PROCESS DESIGN (WBS 5.1.3.1.7.1)}

\section{$9.1 \quad$ INTRODUCTION}

This section describes a tritium extraction and purification process which includes tritium extraction from irradiated lithium-aluminum ( $\mathrm{Li}-\mathrm{Al})$ rods, and gas separation to produce high purity tritium. While the extraction step is designed specifically for the SILC process, the gas separation steps are applicable to any other tritium handling process.

The process described here is an updated version of that used at the Savannah River Site (SRS) for almost forty years. This process is recommended to take advantage of proven technology, since the Li-Al rods in the SILC target are similar in composition and design to those which were used at SRS.

The overall process is divided into several process steps. Each step will be described by: (a) function, (b) operating philosophy, and (c) equipment. Waste generation is also discussed where appropriate.

\section{$9.2 \quad$ ASSUMPTIONS}

The following basic assumptions are used in this report:

- The extraction-purification facility will be part of the APT facility to facilitate transfer of irradiated rods and eliminate need for their packaging and transportation off site.

- Aluminum clad Li-Al rods are packaged in bundles that are ready for drying and then loading into crucibles for gas extraction in a furnace.

- The amounts of tritium, helium-4 and helium-3 extracted are measured for material accountability.

- Tritium product purity better than $99 \%$ tritium can be produced by the process.

- All other gases that are of no value will be released to the environment through a stack, provided that the tritium content is environmentally acceptable .

- Tritium release to the environment will be minimized.

- $\quad$ Solid waste will be minimized. 


\subsection{GENERAL PROCESS DESCRIPTION}

(See Figure 9.1)

After irradiation in the accelerator, aluminum-clad, lithium-aluminum alloy rods in crucibles are received by truck in shielded transport casks, or via a channel, for extraction of the tritium. The rods in the crucible are heated to melting in a vacuum furnace to release tritium, helium, and impurity gases such as protium, deuterium, water, and methane. After extraction, the crucible with the spent melt is removed from the furnace and is sealed, encased in a secondary container, and transferred to an Intermediate Level Tritium Storage Facility. The extracted gas mixture is processed through a uranium bed at $450^{\circ} \mathrm{C}$ to ensure conversion of any tritiated water to a mixture of elemental hydrogen isotopes. After collection and accountability, the hydrogen isotopes are separated from Helium-3 (produced by tritium decay), Helium-4 (produced by the lithium/neutron reaction), and impurity gases by absorption in a palladium/kieselguhr purifier and/or permeation through a heated palladium-silver alloy diffuser. By-product helium waste gas is processed through catalytic reactors and zeolite to remove tritium as water before the gas is stacked. Tritium is separated from other purified hydrogen isotopes by the TCAP (thermal cycling absorption process) or cryogenic distillation. The purified tritium is stored in metal hydride beds for later use or off-site shipment. Raffinate (protium and deuterium) from the TCAP and distillation processes is stacked if the tritium content is acceptable.

Tritium pumping and storage capability is provided in virtually all of the processing operations. Improved pumping systems, either metal hydride beds or mechanical pumps free of oil and mercury contamination, will be used throughout the facility. Metal hydride beds will be used extensively for storage of hydrogen isotopes, where appropriate, to provide increased safety, better space utilization, and reduced potential for accidental releases.

Process equipment is installed inside gloveboxes filled with a nitrogen atmosphere. The gloveboxes provide secondary confinement for any tritium which might leak out from the process.

Stripper systems are provided to remove tritium from recirculating nitrogen in the confinement gloveboxes and to recover tritium from process waste gases and glovebox nitrogen purged to the stack. These systems operate by passing the exhaust gases over a catalyst bed to oxidize elemental hydrogen isotopes to tritiated water and then adsorbing the water on a zeolite molecular sieve. Zeolite beds are regenerated in place by heating under recirculating hydrogen gas which passes through a heated uranium bed to reduce the tritiated water to elemental hydrogen isotopes. Tritium in the isotopic mixture will be recovered in the TCAP or cryogenic distillation system.

The overall process will be divided and described in 14 process areas:

1) $\mathrm{Li}-\mathrm{Al}$ rod receiving and spent melt handling 
2) extraction furnace

3) gas accountability

4) inert separation

5) product evacuation

6) TCAP (thermal cycling absorption process)

7) cryogenic distillation system

8) load/unload station

9) glovebox stripper system

10) purge stripper system

11) process stripper system

12) zeolite bed recovery system

13) heating and cooling systems

14) exhaust stack system

\subsection{Li-Al ROD RECEIVING AND SPENT MELT HANDLING (See Figure 9.2)}

\subsubsection{Function}

This area receives the irradiated $\mathrm{Li}-\mathrm{Al}$ rods in bundles, dries the bundles, loads the bundles into crucibles, loads the crucibles into the extraction furnace, removes the crucible with the spent melt after evtraction, and prepares the spent melt for waste disposal.

\subsubsection{Operation Philosophy}

Irradiated rods will be received in an area adjacent to the extraction furnace. The rods are in bundles which are sized to fit the crucible. The bundles were assembled in the basins where the pressure tubes and rods are handled, and were cooled for at least 60 days to permit the decay of radiation induced radioactive impurities. The bundles may have been shipped in shielded containers or trailers, depending on the transportation method.

The bundles will be placed in drying pits to remove moisture, where they are dried with filtered, dry air which is then exhausted to the stack.

After drying, a bundle is ready for extraction. It is placed in a crucible which is then sealed and leak checked. The crucible is placed in the furnace for extraction.

After extraction, the crucible containing the spent melt is removed from the furnace and may be placed in a secondary container for disposal, if required. 


\subsubsection{Equipment}

Bundle Drying and Storage Pits. A sufficient number of pits are provided to dry and store bundles of the $\mathrm{Li}-\mathrm{Al}$ rods. The rods are dried with filtered air. The dimensions of the pits are dependent on the size of the bundles.

Crucible Storage Pits. A sufficient number of pits are also provided to store the crucibles. The crucibles may be empty, loaded with bundles to be extracted, or containing extracted melt (spent melt).

Spent Melt Secondary Container. The crucibles containing spent melt might have to be placed in secondary containers. This will be dependent on waste disposal requirements.

Crucible. The crucible is a closed crucible. Its diameter and height are sized to contain a bundle of $\mathrm{Li}-\mathrm{Al}$ rods, and to achieve the highest packing density of the rods. After extraction, the crucible containing the spent melt will be removed and disposed of as a solid waste. The objective here is to minimize the volume of the solid waste. The Li-Al rods should be closely packed in the crucible. Closely packed rods leave small unfilled volume in the crucible after extraction. Therefore the waste volume is reduced.

Making all the rods the same length is desirable, because that permits the use of one size crucible to achieve minimum waste volume all the time. If there are several lengths of the rods, the crucible heights may vary, but the diameter of the crucibles should be the same. The height of the furnace must accommodate the highest crucible.

The crucible should be made from stainless steel. It has a lid which can be welded on after the bundle is loaded. The lid has a valved port for connecting to the vacuum line for extraction. The purpose of the valve is to close the crucible when it is disconnected from the vacuum line after extraction to minimize the potential for tritium release. The valve does not need to be leak tight and it can be a spring loaded plate, closing upon disconnecting the vacuum line. The port might also be capped after the crucible is lifted out of the furnace.

The crucible has a yoke for its lifting in and out of the furnace.

Welder. A remotely operated automatic welder will be used to weld the lid onto the crucible.

Crane. A remotely operated crane will be used to lift and position the $\mathrm{Li}-\mathrm{Al}$ bundles, the crucibles, the spent melts in crucibles, the furnace retort (see furnace section), and the lids. The crane must be able to handie the heaviest load anticipated, which will be 15 metric tons. 


\subsubsection{Waste}

Crucibles containing the spent melt are the main source of waste in this step of the operation. Volume of waste is dependent on the production rate.

\subsection{EXTRACTION FURNACE} (See Figure 9.2)

\subsubsection{Function}

The vacuum extraction furnace system provides the heating capability required to extract the tritium, other hydrogen isotopes, and helium from the irradiated $\mathrm{Li}-\mathrm{Al}$ rods.

\subsubsection{Operation Philosophy}

A loaded crucible is placed in the retort of the extraction furnace. The vacuum port of the crucible is connected to the extraction vacuum system which withdraws the gases coming out of the rods during extraction. The retort is also vacuum tight, that provides a secondary containment for the tritium which might leak or diffuse out of the crucible. The vacuum extraction furnace is heated to operating temperatures by external electrical resistance heaters.

Furnace Preparation. A loaded crucible is normally placed into the furnace immediately after the crucible containing the spent melt from the previous extraction is removed. Proper furnace sealing is verified by a pressure rate of rise between the lid "O" rings. Following retort and crucible evacuation to the process stripper stack tank a pressure rate of rise is taken to confirm the integrity of the extraction system before beginning an extraction.

Extraction. The following contains parameters to be determined by the final design. The furnace is heated at a controlled rate to maintain an acceptable furnace pressure by generating gas at a relatively uniform rate that is consistent with the system pumping capacity. The evolved gas is collected ano analyzed to account for the tritium and helium from the rods. When the gas evolution has decreased to an acceptable rate, argon over-pressure is added, and the temperature is increased to melt the charge. After melting temperature has been maintained for an adequate time, the temperature is reduced below the melting point, the crucible is evacuated, and a final pressure rate of rise is taken to verify that the residual gas generation rate is acceptable before terminating the extraction.

During extraction the pressure in the crucible should be kept below about 50 torr. The temperature is programmed so that the gas evolving rate does not exceed the capacity of the vacuum system. The $\mathrm{Li}-\mathrm{Al}$ rods are heated to melting at the end of the extraction. 
Retort Cooling and Flush Gas (Ar). Inert gas is added to the retort and crucible to accelerate cooling. After the furnace has cooled, the cooling gas and subsequent flushes, which reduce residual tritium in the furnace retort, are evacuated to the process stripper stack tanks.

\subsubsection{Equipment}

Hot Wall Furnace Retort. The hot wall furnace retort is dimensioned to fit the crucible and can be made out of stainless steel or other equivalent material. The crucible will be lifted in and out of the retort through a top opening. The top opening will be closed by a lid with $O$ ring seals. The retort has a vacuum feedthrough which will be connected to the outlet of the crucible, and two gas openings for the argon purge. The inlet should be guided to the bottom of the retort to increase purge efficiency.

Manipulator. A remotely operated manipulator will be used to connect and disconnect the vacuum lines to the crucible, and to position the lid on the crucible.

Furnace. The furnace is heated by electric resistance heaters and consists of the heaters, insulation and an air cooled jacket. The heater should be divided into about 4 zones for the control of the temperature profile.

Metal Trap. A metal trap will be installed in the vacuum line outside the vacuum feedthrough to trap any volatile metals which might be leaving the $\mathrm{Li}-\mathrm{Al}$ at the extraction temperatures. The trap will be replaced as needed, depending on activity.

\subsubsection{Waste}

The metal trap will have to be replaced after a number of extractions, due to the accumulation of the radioactive metals.

\subsection{GAS ACCOUNTABILITY}

(See Figure 9.3)

\subsubsection{Function}

This system pumps the extraction gases from the crucible. These gases pass through a decomposer to reduce any waters present. The gases are then collected in a tank for accountability purposes.

\subsubsection{Operation Philosophy}

Extraction gas is pumped through two uranium bed (U-bed) decomposers to reduce waters. The gas is then collected in one or both extraction tanks. When a U-bed becomes depleted, the current extraction run will be completed and the depleted bed will be replaced. 
After the new bed is installed, the system valving will be re-aligned so the new bed is the downstream bed. A means of routine replacement should be devised that does not breach glovebox containment. Spent U-beds will be removed from the glovebox and sent to storage or disposal per standard procedures.

\subsubsection{Equipment}

Pumps. This system consists of a pumping system capable of evacuating the crucible and associated piping to $<100$ microns within 45 minutes. Oil-free and $\mathrm{Hg}$-free dry pumps, such as Normetex pumps and Metal Bellows pumps, should be used.

U-Beds. The product evacuated from the furnace will pass through two depleted U-beds to reduce the waters $\left(\mathrm{H}_{2} \mathrm{O}, \mathrm{D}_{2} \mathrm{O}, \mathrm{T}_{2} \mathrm{O}, \mathrm{HDO}\right.$, DTO, HTO) to elemental hydrogen isotopes $\left(\mathrm{H}_{2}\right.$, $\left.\mathrm{D}_{2}, \mathrm{~T}_{2}, \mathrm{HD}, \mathrm{DT}, \mathrm{HT}\right)$. The waters react with the uranium to form hydrogen gases and uranium oxide by the following reaction:

$$
2 \mathrm{H}_{2} \mathrm{O}+\mathrm{U} \stackrel{450^{\circ} \mathrm{C}}{\longrightarrow} \mathrm{UO}_{2}+2 \mathrm{H}_{2} .
$$

The U-beds are heated to promote the reaction and prevent the hydriding of the uranium. The U-bed temperature is monitored and controlled by a series of thermocouples. Each U-bed has a shell which can be evacuated or back filled with nitrogen or an inert gas.

The second U-bed is a backup reactor that will reduce any waters that pass through the first bed and provide indication when the first U-bed has been depleted. The U-beds are piped such that either bed can be first in line.

Cooling water will be required for the U-beds. The U-beds are also piped to allow them to be either upstream or downstream of the pumping system. During the first part of an extraction run, when the pressures are relatively high, the system will be valved so that the U-beds are upstream of the pumping system. This is done so the waters are cracked prior to reaching the pumps to minimize damage. Toward the end of the extraction run, when the pressure drop across the U-beds becomes so great as to hinder pumping, the system will be re-valved to place the U-beds downstream of the pumping system. By this time, most of the hydrates from the target surface have been processed so minimal water will pass through the pumps, thus minimizing water holdup in the pump and possible pump damage. This second arrangement will allow for evacuating the furnace below 100 microns.

Tanks. The system will contain two tanks that receive the extraction gas. These tanks are sized so that the tanks can hold the gas from one extraction run without exceeding the maximum allowable operating pressure. Once all the extraction gas is collected in the tank and has come to thermal and pressure equilibrium, the tank is sampled and the temperature(s) and pressure of the tank recorded. From the sample results and PVT (Pressure, Volume, 
Temperature) calculations, a Material Balance Ratio (MBR) is calculated. The MBR should be equal to 2 according to the following correlation:

$$
\begin{aligned}
& { }^{6} \mathrm{Li}+{ }^{1} \mathrm{n} \rightarrow{ }^{3} \mathrm{~T}+{ }^{4} \mathrm{He} \\
& \text { MBR }=\text { Moles }{ }^{4} \mathrm{He} /\left(\operatorname{moles} \mathrm{T}_{2}+(1 / 2) \text { moles }{ }^{3} \mathrm{He}\right)=2
\end{aligned}
$$

Any discrepancy greater than allowable must be resolved prior to transfer of the extraction gas to the next phase of the process. The quantity of tritium extracted is compared with the theoretical tritium loading of the charge (as reported by Accelerator) to determine the batch yield. Each tank has a Tritium Activity Monitor (TAM) capillary and a Mass Spectrometer (MS) capillary. The TAM is used solely to determine tritium content, while the MS is used to determine the entire composition of the extraction gas.

Tie-ins. Connections are provided to Product Evacuation, Process Stripper, and nitrogen header systems. These connections are primarily used to prepare the system for maintenance.

\subsubsection{Waste}

The depleted uranium oxide beds containing about $50 \mathrm{~kg}$ of $U$ per year. are the main source of solid wastes in this process step.

\subsection{PURIFICATION OF HYDROGEN ISOTOPES}

(See Figure 9.4)

\subsubsection{Function}

The inert separation system separates hydrogen isotopes from other gases. Normally, the system receives feed from the accountability tanks after the MBR has been calculated and any discrepancies resolved. In addition, the system can also receive feed from Product Evacuation, Load/Unload stations, Z-bed Recovery, and the Process Stripper systems. The products from this step are pure hydrogen isotopes and near tritium-free inert gas which can be sent to the process stripper system for stacking.

The inert separation system consists of a flow-through, palladium/kieselguhr $(\mathrm{Pd} / \mathrm{k})$ bed, feed pump systems, a 2-stage palladium/silver $(\mathrm{Pd} / \mathrm{Ag})$ diffuser, storage hydride beds and draw-off pumping systems necessary to move the gas.

\subsubsection{Process Philosophy}

The flow-through bed provides for the bulk separation of hydrogen and non-hydrogen gases. The gas in the accountability tank is drawn through the flow-through bed. The hydrogen 
is absorbed by the palladium. The non-hydrogen gas passes through and is fed to the diffuser down stream. After absorption, the hydrogen is desorbed from the palladium by heating, and stored in metal hydride storage beds.

The non-hydrogen gas passing through the flow-through bed may still contain small amounts of hydrogen. This gas is fed to the diffuser to remove most of the remaining hydrogen from the gas stream. Normally, the two stages are operated in series. But the stages are piped in such a manner as to allow any one stage to be valved out of the system and still maintain operation of the diffuser system. The hydrogen removed from the diffuser is also stored in hydride beds. The non-hydrogen gas which now contains very little tritium is sent to the stack through the process stripper system to further reduce the tritium level.

\subsubsection{Equipment and Operation}

Flow-through Bed. There will be two flow-through beds. Each flow-through bed is a U-shape column which is packed with $\mathrm{Pd} / \mathrm{k}$, palladium deposited on kieselguhr. (Kieselguhr is a diatomite used for its high porosity.) The diameter and length of the column are determined mainly by the desired capacity. Each liter of Pd/k (50 wt\% Pd) can absorb about 25 standard liters of hydrogen at room temperature. The bed should be sized to absorb the hydrogen from one batch of extraction. The column is jacketed and thermally insulated with heating and cooling capabilities. The operating temperature for desorption is about $150^{\circ} \mathrm{C}$, and the temperature for absorption is $20^{\circ} \mathrm{C}$ or less. Lower absorption temperatures can produce lower hydrogen concentration in the non-hydrogen gas stream.

The two beds are connected in parallel. This allows one bed to be "on-line" to absorb hydrogen, while the other is being regenerated by desorption. The desorbed hydrogen is transferred to the storage beds.

When a bed is on-line, the feed is drawn to the bed. As the feed passes through the flow-through bed, the bulk of the hydrogen isotopes is removed from the gas stream and is absorbed on the palladium. Hydrogen absorption on palladium is an exothermic reaction. Cooling is required to remove the heat of absorption. The absorption takes place in a short section of the column, which is called the absorption front. This absorption front moves down the column as the column is being saturated with the hydrogen. The location of the front is indicated by a temperature peak due to the heat of hydrogen absorption. When the temperature peak arrives at the end of the column, the column is saturated and needs to be regenerated by desorption.

The column is regenerated by heating to about $150^{\circ} \mathrm{C}$. The absorbed hydrogen generates a pressure which transfers the hydrogen to the storage beds. After regeneration, the bed is cooled down and is ready to be on-line again. 
Feed Pumps. The feed gas is pulled through the on-line flow-through bed by one of two parallel mechanical pumping systems. These pumping systems discharge to the diffuser. Each system consists of two mechanical pumps in series capable of maintaining $<50$ microns on the suction and at least 760 torr in the diffuser tube.

Diffuser. The diffuser consists of two diffuser stages. Each stage is heated to prevent damage to the $\mathrm{Pd} / \mathrm{Ag}$ tube. If the tube is exposed to hydrogen isotopes while cold, the tube can hydride and fail. The stages are piped such that the two stages can be operated in either series or parallel. The feed stream passes through the tube side of the diffuser stages. Hydrogen isotopes diffuse through the heated diffuser tubes into the shell. All other gases remain in the tube and are collected in the by-product storage tanks.

Draw-off Pumps. The pressure in the shell side of the diffuser is maintained in the very low micron range by separate mechanical pumps, one pump for each stage. The discharge of these two mechanical pumps is piped to the $\mathrm{Pd} / \mathrm{k}$ hydride storage beds.

Hydride Storage Beds. The hydride beds described in the Hydrogen Isotopes Evacuation and Storage Section will be used to receive and store the purified hydrogen isotopes produced in this step.

By-product Pump. By-products $\left({ }^{3} \mathrm{He}\right.$ and $\left.{ }^{4} \mathrm{He}\right)$ and the other non hydrogen gases are removed from the diffuser tubes by means of a mechanical pump which discharges into one of two by-product storage tanks. Should $\mathrm{He}^{3}$ gas recovery be desired, an additional process step will have to be added.

By-product Tanks. The system has two by-product tanks. When one by-product tank is full, it is sampled by means of a MS capillary. If the tritium concentration is too high in the by-product tank, that gas must be reprocessed by the diffuser. If the gas is within limits for tritium content, it is sent to the stack through the process stripper system.

Relief system. A relief tank is provided to protect low pressure instruments and equipment from excessive pressure that could be generated by desorbing the hydride beds with closed valves.

Tie-ins. Connections are provided to Product Evacuation, Process Stripper, and nitrogen header systems. These connections are primarily used to prepare the system for maintenance.

\subsubsection{Waste}

The flow-through bed is expected to last for more than 20 years under normal operating conditions. The diffusers may require replacement once every 3 years. The service lives of the 
mechanical pumps are to be determined and are dependent on type and make. The by-product gas is sent to the stack.

\subsection{EVACUATION AND STORAGE OF HYDROGEN ISOTOPES}

\subsubsection{Function}

The Product Evacuation system is used to collect and store hydrogen isotopes from all sources within the extraction and purification facility. This system is used to evacuate hydrogen isotopes from the flow-through beds and from other systems in preparation for maintenance and to store the isotopes until needed for feed for either TCAP or cryogenic distillation.

\subsubsection{Process Philosophy}

Four metal hydride storage beds are used to receive and store hydrogen isotopes of various compositions. The hydrogen may be from the discharge of a mechanical pump or from another metal hydride storage bed. The hydrogen isotopes are stored in these beds until they are needed for isotopic separation.

\subsubsection{Equipment and Operation}

Pumps. The Product Evacuation system consists of two high vacuum headers, each with its own pumping system. The pumping systems should be capable of evacuating the high vacuum headers to the very low micron range $(<50$ microns). The pumps will discharge into one of six hydride beds. Each header will be tied to several of the other process systems to provide a means of removing product from that system. The headers are cross connected to maintain pumping capability if one pump system is not operational.

Hydride Beds. Four isotope storage beds using Lanthanum-Nickel-Aluminum (LANA) hydride provide for the collection and storage of hydrogen isotopes and provide feed to either TCAP or Cryogenic Distillation as needed. Four beds are provided to allow for two beds to be receiving material, one bed to be desorbing and transferring material to either TCAP or Cryogenics, and the fourth bed to be desorbed and ready to receive material.

All hydride beds will be provided with MS and TAM connections, pressure, and temperature instrumentation.

Tanks. Two tanks are included in the system which are to be used as a back-up means for inventory.

All tanks will be provided with MS and TAM connections, pressure, and temperature instrumentation capable of being calibrated in place for accountability and process use. 
Relief System. Two relief systems (one for each two storage beds) are provided to protect low pressure instrumentation and equipment from excessive pressure that could be generated by desorbing the hydride beds with closed valves. In addition, each hydride bed has an expansion volume associated with it to provide a means to contain the stored gases upon loss of cooling.

Tie-ins. Connections are provided to Product Evacuation, Process Stripper, and nitrogen header systems. These connections are primarily used to prepare the system for maintenance.

\subsubsection{Waste}

The metal (Lanthanum-Nickel-Aluminum) hydride storage beds are expected to serve at least 5 years before they need to be replaced due to helium in-growth. They will be disposed as low-level waste under present regulations.

\subsection{TCAP HYDROGEN ISOTOPES SEPARATION (option 1)}

(See Figure 9.5)

\subsubsection{Function}

TCAP stands for Thermal Cycling Absorption Process. The TCAP system is used to separate hydrogen isotopes. It has the same function as the cryogenic distillation system discussed in section 9.10. The extracted gas, after the inert separation step, is separated by TCAP into a high purity tritium product and a near tritium-free raffinate. The raffinate is sent to the stack if the tritium level is confirmed to meet environmental requirements. TCAP is a new and advanced process, which has been demonstrated extensively for separating deuterium from protium. A TCAP unit has been installed at SRS for separating tritium from deuterium and protium, but tritium data is not yet available.

\subsubsection{Process Philosophy}

The TCAP is a semi-continuous gas chromatographic process. The TCAP process consists of a Pd/k (palladium deposited on kieselguhr) packed column, a kieselguhr packed PFR (Plug Flow Reverser), control volumes for feed, product $\left(\mathrm{T}_{2}\right)$ and raffinate $\left(\mathrm{H}_{2}\right)$, and storage bed for feed, product and raffinate. The $\mathrm{Pd} / \mathrm{k}$ column is alternately heated and cooled during operation. The isotope mixture to be separated is made to flow between the $\mathrm{Pd} / \mathrm{k}$ column and the PFR by the heating and cooling. Small amounts of feed, product and raffinate are introduced to the mid point of the column, and withdrawn from the bottom and top of the column, respectively. 
The general operation of the system starting with the cold cycle is as follows:

1) The feed control volume (FCV) is filled from the feed storage bed to a target amount of gas.

2) With the $\mathrm{Pd} / \mathrm{k}$ column cold and at low pressure, the gas in the FCV is released to the mid point of $\mathrm{Pd} / \mathrm{k}$ column and is absorbed by the palladium.

3) While the $\mathrm{Pd} / \mathrm{k}$ column is still under cooling and at low pressure, the gas in the PFR (Plug Flow Reverser) is permitted to flow into the top of the $\mathrm{Pd} / \mathrm{k}$ column. Separation of the isotopes occurs as the gas flows in the column due to the isotopic effect of the palladium. The heavier isotope tritium is concentrated in the bottom of the column while the lighter isotope protium is concentrated in the top of the column. The PFR is isolated from the Pd/k column when target amount of gas has been transferred.

4) The column is heated to desorb the gas to increase the pressure.

5) The product control volume (PCV) and the raffinate control volume (RCV) are filled to target amounts of product and raffinate, withdrawing gas from the bottom and top of the $\mathrm{Pd} / \mathrm{k}$ column, respectively.

6) While the $\mathrm{Pd} / \mathrm{k}$ column is still under heating and at high pressure, the gas is permitted to flow from the Pd/k column to the PFR, until target amount of gas has been transferred. This step may be considered as a regeneration step for the $\mathrm{Pd} / \mathrm{k}$ column. The concentration profile in the gas is mostly preserved during this gas transfer.

7) During step 6, the product gas and the raffinate gas in the PCV and the RCV are sent to the product and raffinate storage beds.

8) The $\mathrm{Pd} / \mathrm{k}$ column is cooled to repeat the sequence.

Depending on capacity requirements, two TCAP units might be installed. Two units permit full utilization of the heating and cooling system, since the heating and cooling of the two $\mathrm{Pd} / \mathrm{k}$ columns can be operated $180^{\circ}$ off phase.

\subsubsection{Equipment}

Pd/k Column. The diameter and length of the $\mathrm{Pd} / \mathrm{k}$ column are dependent on the capacity required. There are three openings to the column, located at the top, the bottom and the middle of the column, for product and raffinate withdrawals, and feed introduction. The 
column is enclosed in a jacket which provides for the circulation of the heating and cooling media.

PFR (Plug Flow Reverser). A typical design of the PFR is a $10 \mathrm{~cm}$ diameter, 6 meter long column folded into 4 passes which stands about 1.5 meter high. The PFR is filled with kieselguhr to increase its plug flow characteristic for the gas. It is not heated or cooled.

Feed and Storage Beds. The system has a total of six storage beds, two each for feed, product and raffinate. Two beds allow for one to be on-line while the other is in the storage mode or discharging the gas to the next step of the operation. These beds have the same design as the hydride storage beds in the product evacuation system.

Relief System. Two relief tanks are provided to protect low pressure instrumentation and equipment from excessive pressure that could be generated by desorbing the hydride beds.

Tie-ins. Connections are provided to Product Evacuation, Process Stripper, and nitrogen header systems. These connections are primarily used to prepare the system for maintenance.

\subsubsection{Waste}

There is no routine waste in this process step. The storage hydride beds will have to be replaced about every 5 years, due to the accumulation of decay helium in the metal matrix, that gradually reduces the reversible storage capacity of the beds. The TCAP Pd/k column should last for about 20 years.

\subsection{CRYOGENIC DISTILLATION SYSTEM FOR HYDROGEN ISOTOPES SEPARATION (option 2) (See Figure 9.6)}

\subsubsection{Function}

The purpose of the cryogenic distillation system is to distill, separate, and purify the three hydrogen isotopes. Its function is the same as that of the TCAP (section 9.9). While TCAP is a new and advanced process, Cryogenic Distillation (CD) is a conventional process, and is particularly suited for recovering low levels of tritium from protium and deuterium streams. $C D$ is presented here for consideration as a complement, an alternative or back-up to the TCAP for separation of hydrogen isotopes.

The system consists of a pumping system, storage tanks, a distillation column, recalculation system, and hydride beds. Feed for the cryogenic system is pumped from either Z-bed Recovery or from product storage if the still is to be used to separate and purify tritium as a back-up to TCAP. 


\subsubsection{Operation Philosophy}

The main purpose of the cryogenic distillation system is to recover tritium from the extraction, recycle, and Z-bed recovery gases to produce a raffinate fraction which meets the limit for tritium releases to the atmosphere. The cryogenic system will also act as a back-up to the TCAP system.

\subsubsection{Equipment}

Pumps. Two mechanical pumping systems are provided to allow for continued operation in the event of failure of one of the systems.

Feed Storage Tanks. The feed is stored in one of two Feed Storage Tanks where it is analyzed prior to use. If the feed is too high in "inerts" (gases that will freeze at operating temperatures) to allow further processing, it is transferred to the purification system to remove the non-hydrogen gases.

Feed Purification Bed. The feed is then loaded onto one or both of the feed purification hydride beds. After the entire charge is stored on the bed(s), the over-pressure of $\mathrm{N}_{2},{ }^{3} \mathrm{He}$, and other non hydrogen gases is evacuated to the process stripper or diffuser. The feed purification bed is then desorbed into a cold Cryogenic distillation column.

Cryogenic Distillation Column. The distillation column is made up of a packed column, a helium cooled condenser at the top of the column and a helium cooled and electrically heated reboiler at the bottom. This unit is insulated and enclosed in an evacuated copper vessel that is cooled with liquid nitrogen which is then vented to the exhaust system. The copper vessel is insulated and enclosed in an evacuated steel vacuum jacket.

Column cooling is by direct cooling of the condenser and reboiler surfaces with refrigerated helium coils. Column heating is accomplished by electrically heating the helium lines, by controlling the pressure within the helium refrigerator, and by electrically heating the reboiler. Liquid nitrogen pre-cools the helium refrigerator unit during system start-up and whenever needed; it is then vented to the atmosphere. Water cools the refrigeration compressors.

The gaseous supply enters the column either by pumping (hydride pump) and/or being drawn into the condenser due to the lower temperature/pressure in the reboiler from the gases being cooled (cryopumping). As the batch progresses, heat is then added to the reboiler vaporizing the mixture. Part of the still charge is recirculated through a catalyst bed during the still run. 
At the completion of the batch, the gases are drawn off of the still by controlling the temperatures at the respective boiling points of the desired gases and mixtures. The gas is then expanded/pumped to the hold tanks/hydride storage beds.

Isotope Equilibration System. The still shall include piping to an external palladium catalyst bed for circulation and re-equilibration of mixed hydrogen species (HD, HT, DT) to increase the production of pure species $\left(\mathrm{H}_{2}, \mathrm{D}_{2}, \mathrm{~T}_{2}\right)$.

Storage Tanks. The "tritium-free" gas mixtures are expanded/pumped to a storage tank for further processing. After analyses, the "clean" protium and/or deuterium are transferred to the stack system for discharge to the atmosphere. The storage tanks are piped so that any tank may be used for product storage or feed.

Hydride Storage Beds. "Pure" tritium and deuterium are expanded/pumped to a hydride bed for storage. As before, to meet availability requirements, two LANA beds for tritium storage and two LANA beds for deuterium storage are provided.

Relief Systems. Two relief systems are provided to protect the system from over pressurization. One system is used to protect the cryogenic still and the deuterium hydride bed instrumentation. The other system protects the tritium storage bed instrumentation. The relief systems are split in this manner to minimize the reblending of gases upon failure of one or more of the rupture disks. In addition, each storage hydride bed has an expansion volume associated with it to provide a means to contain the stored gases upon loss of cooling.

Tie-ins. Connections are provided to Product Evacuation, Process Stripper, and nitrogen header systems. These connections are primarily used to prepare the system for maintenance.

\subsubsection{Waste}

There is no routine waste in this process step.

\subsection{LOAD/UNLOAD STATION} (See Figure 9.7)

\subsubsection{Function}

The system consists of a pumping system, two loading/unloading positions and associated instrumentation. This system will load and unload all current types of shipping containers, and portable hydride beds. The system shall be designed for easy modification to accommodate future shipping container designs. The system will also analyze all product prior to loading into shipping containers and after unloading. 


\subsubsection{Operation Philosophy}

The shipping container is installed onto the loading position and the system evacuated and a pressure rate-of-rise taken to verify that the connection is leak tight. When the system is ready the valve on the container can be opened either to unload the container or to prepare the container for loading. If the container is being unloaded, the contents must be sampled and inventoried after opening the container valve and before the material is transferred to the purification system, product evacuation, or the process stripper to verify the content.

If the container is to be loaded, the container must be evacuated and flushed prior to loading. Pure tritium (or any blend of gases) will be loaded into the storage container to the desired pressure and the valve on the container closed. The system would then be evacuated and a pressure rate-of-rise performed to ensure that the valve does not leak across the seal. The container can then be removed from the loading position and a plug installed on both the container and the loading line. Tritium loaded to PC's or hydride beds will be determined by PVT measurements of the source tank.

Tritium and deuterium can be obtained from either TCAP, Cryogenics, or Product Storage. By-product is received from by-product purification system.

\subsubsection{Equipment}

Pumps. The pumping system consists of a single system of two mechanical pumps (a Normetex pump and a metal bellows pump) in series. This pump system must be capable of evacuating the system and shipping container to the low micron range ( $<50$ microns).

Stations. Two load/unload stations shall be provided. Each station will be capable of containing current design shipping containers and be capable of being easily modified to handle future designs. In the case of hydride beds, a means of heating and cooling the hydride beds must be provided. Initial design should be based on uranium hydride beds which should be heated to $450^{\circ} \mathrm{C}$ for desorption.

Relief System. The system must either have a relief system when used to unload hydride beds or the system must be designed to safely contain the maximum pressure the hydride bed can generate.

Tie-ins. Connertions are provided to Product Evacuation, Process Stripper, and nitrogen header systems. These connections are primarily used to prepare the system for maintenance. 


\subsection{GLOVEBOX STRIPPER SYSTEM}

(See Figure 9.8)

\subsubsection{Function}

There will be two glovebox stripper systems: Primary and Secondary strippers. Additional systems may be required for the charge/discharge and spent melt/crucible loading enclosure in which the atmosphere is controlled, depending on the final design for the extraction area.

Primary Glovebox Stripper System. The function of the Primary Glovebox Stripper Systems is to recycle continuously the glovebox atmosphere from all the gloveboxes in the building to equipment that will remove hydrogen isotopes, oxygen, and water vapor. The purpose of the system is to control the concentrations of tritium in the glovebox atmosphere to as low a level as possible.

The recirculating gas must be kept slightly below atmospheric pressure inside the gloveboxes and in the corridor piping from the gloveboxes. The gas will be above atmospheric pressure as it passes through the stripper system equipment.

The stripper system equipment will include a gas blower, preheater, heated reactor, cooler and molecular sieve beds (Z-beds). Instrumentation includes ion chambers, an oxygen meter, a moisture meter, and a mass spectrometer sampling point. Valves isolate individual gloveboxes from the gas recirculating system during open glovebox maintenance.

Secondary Glovebox Stripper System. The design of the Secondary System is the same as the Primary System. It is normally in a standby operating condition to process gas from gloveboxes when a tritium release has occurred. The Secondary System can also serve as a spare Primary System.

The operation of the Secondary System differs from the Primary System in that it is normally restricted to recirculating its entire capacity to a limited number of gloveboxes.

\subsubsection{Operation Philosophy}

Molecular hydrogen and hydrogen in organics are catalytically oxidized to form water. The water is absorbed in zeolite beds. The purified gas is returned to the gloveboxes. Oxygen level is controlled by purging.

Continuous operation of the Primary Stripper System must be assured except during planned open stripper glovebox maintenance. Backup equipment should be provided as necessary. 
Nitrogen is added or removed to maintain system pressure. The excess gas from the Primary System is sent to the exhaust stack by way of the Purge Stripper System to ensure minimum tritium release to the environment.

\subsubsection{Equipment}

Blowers. The glovebox gas is transferred through the system by one of two blowers. The second blower is a redundant blower that should automatically come on line upon failure of the first. The role of "first" and "second" blower should be interchangeable.

Preheater. A preheater is used to preheat the gas stream to about $450^{\circ} \mathrm{C}$ before the gas enters the reactor down stream.

Reactor. The reactor is a heated vessel containing a palladium on alumina catalyst (such as Deoxo $\mathrm{D}^{\circ}$ by Engelhard) to promote the reaction of hydrogen isotopes with oxygen. Dry air and protium supplies are provided in case the nitrogen gas is deficient in oxygen or protium swamping to reduce tritium concentration is desired.

Cooler. The gas stream is passed through a cooler after it leaves the reactor. This cooler will cool the gas stream to below about $40^{\circ} \mathrm{C}$.

Z-Beds. Three zeolite beds are provided for each stripper system. Normally, one of the beds is online, one on standby, and the third is being regenerated. The zeolite absorbs the water from the gas stream to a capacity of about $10 \%$ of its dry weight. Upon saturation, a zeolite bed is valved off from the stripper system and regenerated by heating. The bed is heated in place to about $250^{\circ} \mathrm{C}$ to drive the water off to a Z-bed recovery system (see section 9.15).

Relief Systems. See Z-Bed Recovery section (9.15).

Tie-ins. The stripper systems are connected to Z-Bed Recovery and nitrogen headers systems. These connections are also used to prepare the system for maintenance.

\subsubsection{Waste}

There is no routine waste from this system. The reactor bed and zeolite bed are expected to last about 10 years under normal operating conditions. 


\subsection{PURGE STRIPPER SYSTEM}

(See Figure 9.9)

\subsubsection{Function}

The Purge Stripper System provides final tritium stripping from the glovebox gas before the gas is sent to the stack. It has two functions: to receive gases from the primary stripper system for the purpose of controlling the pressure and oxygen level in the gloveboxes, and to remove gases from the air locks of the gloveboxes when the air locks are used.

\subsubsection{Operation Philosophy}

The purge stripper system consists of three beds filled with palladium deposited on zeolite $(\mathrm{Pd} / \mathrm{Z})$, and two sets of mechanical pumps. The three $\mathrm{Pd} / \mathrm{Z}$ beds are connected in series. Two of them are on-line at any given time. The other one is either on standby or being regenerated. These beds are operated at room temperature. The Pd catalyzes the oxidation of tritium and the zeolite absorbs the water. In this way the functions of a catalyst and a zeolite bed are combined into one single bed.

Each set of the mechanical pumps consists of a dry scroll pump and a metal bellows pump in series. Normally only one set is in operation. The other is on standby. The pumps can evacuate the glovebox air locks to approximately 10 torr through the Purge Stripper System. The flow capacity of the system is designed to control the glovebox pressure and the oxygen level in the glovebox nitrogen. A control valve will transfer gases from the Primary Stripper System through the Purge Stripper System to the stack.

\subsubsection{Equipment}

Pumps. Two pumping systems are provided to allow for simultaneous processing of material from the primary strippers and air lock evacuations. Each pumping system consists a dry scroll pump and a metal bellows pump in series.

$\mathrm{Pd} / \mathrm{Z}$ Bed. The $\mathrm{Pd} / \mathrm{Z}$ materials are combined into a single heated vessel. Three of these vessels are required. Instrumentation includes a moisture meter after each $P d / Z$ vessel and a single tritium monitoring system monitoring the gas form and quantity in the exhaust header to stack.

Relief System. See Z-Bed Recovery Section (9.15).

Tie-ins. A connection is provided to Z-Bed Recovery used to prepare the system for maintenance. A connection is provided from hot/cold nitrogen system to provide a means of removing tritium from the nitrogen if the system becomes contaminated. 


\subsubsection{Waste}

There is no routine waste from this system. The $\mathrm{Pd} / \mathrm{Z}$ bed is expected to last about 10 years under normal operating conditions.

\subsection{PROCESS STRIPPER SYSTEM}

(See Figure 9.10)

\subsubsection{Function}

The function of the process stripper is to remove tritium from process waste streams by oxidizing elemental and other forms (methane, etc.) of hydrogen isotopes and absorbing the oxides on molecular sieves prior to exhausting the effluent gas to the atmosphere.

\subsubsection{Operation Philosophy}

Process waste gases and the by-product from the purification operation are accumulated in tanks. These gases are sent through the process stripper system to the stack. The system will remove nearly all of the tritium in the waste gases before they are released to the environment.

\subsubsection{Equipment}

Header Pumps. Two high vacuum headers are used to evacuate process equipment that contain mostly nitrogen with small quantities of tritium. Each header is evacuated by means of a mechanical pumping system. The headers can be cross-connected to allow for continued pumping capability in the event of the failure of one pumping system.

Stack Tanks. The vacuum header pumps discharge into one of two stack tanks. When a tank is full the pumps are valved to the other tank and the first tank is sampled. Based on tritium concentration the gas collected is either processed through the diffusers or the process stripper.

Stripper Pumps. The material to be stripped is pumped out of the stack tank. The gas passes through an ion chamber, moisture meter and an oxygen sensor, all of which are located on the discharge of the pumps. The readings of these sensors are used to determine whether additional oxygen is needed through adding dry air .

There are two mechanical pumps in parallel to provide the required backup capability. The material then passes through a flow meter and control valve to maintain the proper flow rate.

Catalyst Bed. Just like the glovebox stripper systems, a heated catalyst bed is used to catalyzz oxidation of hydrogen isotopes to form water. Since sufficient oxygen may not be 
present in the process stream, dry air is added upstream of the reactor as required. The quantity of air added is based upon the flow rate of the process stream and the oxygen concentration as measured by the oxygen sensor.

Z-Beds. The system has three zeolite beds. These beds are the same as those in the glovebox strippers.

Relief Systems. See Z-Bed Recovery (9.15).

Tie-ins. Connections are provided to Product Evacuation, Diffuser, and nitrogen header systems. These connections are primarily used to prepare the system for maintenance.

\subsubsection{Waste}

There is no routine waste from this system. The reactor bed and zeolite bed is expected to last about 10 years under normal operating conditions.

\subsection{ZEOLITE BED RECOVERY SYSTEM}

(See Figure 9.11)

\subsubsection{Function}

The Zeolite Bed (Z-bed) Recovery System reduces water desorbed from the Z-beds of the Primary, Secondary, Process, and Purge Stripper systems to elemental hydrogen. To provide the required recovery capacity and to provide needed backup capability, two complete recovery systems shall be provided. Each system has the capability of being piped to any Z-bed.

\subsubsection{Operation Philosophy}

When a Z-bed becomes saturated, it is isolated from the stripper system and valved into a recovery loop.

During normal recovery operations, the recovery system is back filled with a small amount of carrier gas, such as $\mathrm{H}_{2}$. Flow is then established through the Z-bed being desorbed to the recovery system. Heat is then applied at a controlled rate which drives the water from the Z-bed. The vapor laden carrier gas is then processed through a uranium bed to crack the waters. The operation of a uranium bed has been discussed in the Initial Accountability Section. The gas flows through a moisture meter and flow meter, through the pumping system and back to the Z-bed. Circulation is maintained until all of the water has been driven from the Z-bed and cracked by the U-bed. 
As the process progresses, pressure which builds up in the system is periodically relieved into to the recovery tank. When the Z-bed is completely desorbed, the entire system is pumped into the recovery tank.

The use of electrolysis to decompose the water is being developed to replace the uranium bed. If successful, the uranium beds will be eliminated, thus eliminating this waste stream.

\subsubsection{Equipment}

U-Beds. One U-bed is provided for each of the two recovery loops. See Gas Accountability section (9.6) for a description of the U-beds.

Pumps. A single mechanical pumping system is provided for each of the two recovery loops. This pumping system will normally operate in the torr range, but must have the capability of evacuating the Z-bed into the low micron range. The pumping systems are cross connected to allow use of either pumping system on each loop.

Tanks. One tank is provided for each recovery loop. At the completion of a recovery run, the tank content is sampled and the gas is transferred either to the purification system to remove non-hydrogen gases or to the isotope separation system to enrich the tritium.

Relief Systems. Each Z-bed has associated with it a cooler and rupture disk assembly to protect the system against over pressurization in the event a Z-bed is heated while isolated. A rupture disk relieves the water vapor to a condenser and collects condensate in a small vessel.

Tie-ins. The recovery system is also used to evacuate the stripper systems for maintenance. This is set up in this manner since the stripper systems are "wet" and contain large quantities of protium which is an undesirable in the process.

\subsubsection{Waste}

The uranium beds (about $300 \mathrm{~kg}$ uranium per year) will turn into uranium oxide beds and will be disposed of as low level solid waste. This waste would be eliminated if electrolysis is used.

\subsection{HEATING AND COOLING SYSTEMS}

\subsubsection{Function}

The TCAP isotope separation system requires a heating and cooling system to cycle the $\mathrm{Pd} / \mathrm{k}$ column temperature from about $-30^{\circ} \mathrm{C}$ to $120^{\circ} \mathrm{C}$. 
The cryogenic distillation column for isotope separation requires a cooling system to cool the isotope mixture to about $-250^{\circ} \mathrm{C}$.

The flow-through bed in the hydrogen purification system requires a cold temperature of about $-40^{\circ} \mathrm{C}$ and a hot temperature of about $150^{\circ} \mathrm{C}$.

The hydride storage beds, based on the current design, require a cooling temperature of about $-40^{\circ} \mathrm{C}$ and a heating temperature of about $150^{\circ} \mathrm{C}$. Future improved designs may move the operating temperature range to a new range from room temperature to about $500^{\circ} \mathrm{C}$.

\subsubsection{Operation Philosophy}

Current design uses a central nitrogen heating and cooling system to serve the TCAP $\mathrm{Pd} / \mathrm{k}$ column, the flow-through bed, and the hydride storage beds. Separate systems for different process units should be considered.

The cryogenic distillation will require a separate cooling system due to the extremely low temperature.

\subsubsection{Equipment}

The equipment required for a nitrogen heating and cooling system will include a heater (for heating), a refrigeration unit (for cooling), heat exchangers, compressors to circulate the nitrogen, instruments, controls and valving.

Because the potential exists for the systems to become contaminated, a way to remove contaminated nitrogen for stripping should be included.

The cryogenic distillation system requires a helium refrigeration system.

\subsubsection{Waste}

The heating and cooling systems do not generate any routine waste.

\subsection{EXHAUST STACK SYSTEM}

\subsubsection{Function}

The exhaust from the HVAC system, the purge and process strippers, and the stackable discharge from TCAP/cryogenic still will exit the facility through an exhaust plenum to a stack. 
The stackable material from TCAP/cryogenic still will be pumped or expanded into one of the stackable raffinate tanks. Prior to exhausting this material to the atmosphere the tank will be sampled to ensure that the tritium concentration is within permissible limits.

\subsubsection{Operation Philosophy}

This system provides a final barrier between the environment and the process. The raffinate from TCAP/cryogenics is collected and sampled one final time prior to release. The effluent from the purge and process strippers also tie in to this system upstream of the activity monitoring equipment.

\subsubsection{Equipment}

Pumps. The raffinate from cryogenics/TCAP is pumped into the stackable raffinate tank using a single mechanical pump combination. Provisions to bypass pumps and expand directly into the tank will be included in the design.

Stackable Raffinate Tanks. If the tritium concentration is high, tank contents will be returned to cryogenics or TCAP for reprocessing. If the contents falls within prescribed limits, $<5 \mathrm{ppm}$ of tritium, a small quantity is expanded into the sample volume, isolated from the tank and pumped to the stack where it combines with other gases. If the resultant activity levels are within regulatory limits, the entire content of the tank can be stacked.

The stack tanks will require pressure and temperature instrumentation along with mass spectrometer and TAM (tritium activity meter) capillaries.

Stack pump. A single mechanical pump is provided to transfer tank contents to the stack. Sufficient tankage exists to allow time for pump replacement without significant impact on the process.

Tie-ins. Instrumentation to determine both quantity and form (oxide or elemental) of tritium released are needed downstream of the point at which all gases enter the stack. Lines from stackable raffinate, purge, and process stripper should tie in upstream of the activity monitors. detected.

Interlocks must be provided to stop the stacking operation if high tritium levels are

Connections are provided to Product Evacuation and nitrogen header systems. These connections are primarily used to prepare the system for maintenance. 


\subsection{GLOVEBOX AND HOOD DESIGN}

\subsubsection{Function and Operating Philosophy}

All process equipment are installed inside gloveboxes. A nitrogen atmosphere will be maintained in the gloveboxes with continuous circulation in a closed loop directed through stripper equipment capable of recovery of tritium from the process and removal of air and moisture leakage into the gloveboxes.

Gloveboxes are equipped with nitrogen/air locks (N/AL) through which all normal tools and parts will enter and leave. The size of each N/AL are determined individually by the needs of the related glovebox. Glove ports shall allow operation, repair, or replacement of all but the largest equipment. Glovebox panel removal and use of plastic suits shall only be utilized for large replacements or unusual circumstances.

Each N/AL shall be enclosed by a hood through which room air will flow at a minimum of 150 linear $\mathrm{ft} / \mathrm{min}$. In the event a panel must be removed, the hood enclosure around the N/AL shall be closed to the room so that the room air is swept into the glovebox opening where the work is to be done, at a minimum of 200 linear $\mathrm{ft} / \mathrm{min}$ (to minimize migration of tritium out of the glovebox). The air continues to flow through the open doors of the N/AL and out the exhaust of the hood enclosure.

The nitrogen atmosphere during normal operation should be maintained in the gloveboxes at a pressure of about $-13 \mathrm{~mm}(-0.5$ inches) of water relative to the room and continuously circulated through a primary stripper system. If the tritium level monitored in a glovebox exceeds a particular setpoint, the exhaust nitrogen from that glovebox is diverted to the secondary stripper system for tritium cleanup. Additional work by operating personnel shall normally be done only after tritium levels have dropped below the original setpoint.

Hoods are those non-gloved, air ventilated enclosures that do not serve as containment for potential direct tritium releases. Examples would be: HP Counting Hood; Glovebox Evacuation Pump Hood; and the enclosures around the N/ALs.

\subsection{FACILITY TRITIUM INVENTORY}

\subsubsection{Function and Operating Philosophy}

As a general rule, each process section should be capable of being inventoried on a periodic basis. The inventory will consist of collecting all process gases in as few vessels (hydride beds or tanks) as possible. The hydride beds will be inventoried by an in-bed accountability method. The tanks will be inventoried by measuring pressure and temperature and obtaining analytical results from the laboratory on each of the tanks containing tritium. The quantity of tritium will then be calculated using P-V-T (Pressure-Volume-Temperature) 
calculations. This inventory along with the inventory from other facilities within the tritium area are summed and compared to the "book" value of tritium in the facility. Any discrepancies outside specified allowances must be resolved.

\subsection{ATMOSPHERIC RELEASE OF TRITIUM}

Based on past experience at SRS and the improved processes described in this report, the atmospheric release of tritium from this extraction and purification facility is estimated to be less than 10,000 Ci/year (see Appendix 9A).

\subsection{ITEMS FOR FURTHER DEVELOPMENT}

\subsubsection{Closed Crucible for Tritium Extraction}

Using closed crucibles instead of open crucibles can minimize the tritium release from the extraction operation. Open crucibles are used in current extraction operation. An open crucible contaminates the retort of the furnace, that results in significant amounts of tritium release every time when the retort is opened. A secondary confinement system for the furnace operation can capture the tritium and minimize the release, but will be costly. Using closed crucibles to eliminate this release of tritium is more cost effective. In addition, to minimize tritium release, the crucible should also be designed to minimize the volume of solid waste. Design development and experimental testing will be required to develop the technology.

\subsubsection{Diffuser Replacement}

The Pd/Aig diffusers, which are used to strip hydrogen isotopes from an inert stream, need replacement every few years. The replacement operation generates waste. A getter-bed type of hydrogen purification unit can be developed to replace the diffusers. The advantages of a getter-bed include less maintenance and cleaner inert gas stream.

\subsubsection{Advanced Thermal Cycling Absorption Process}

The current Thermal Cycling Absorption Process uses a $\mathrm{Pd} / \mathrm{k}$ column to separate the hydrogen isotopes. If a second column containing a packing material which has an isotopic effect opposite to that of the $\mathrm{Pd} / \mathrm{k}$ is used, the separation efficiency can be improved by orders of magnitude. Such an advanced unit will be able to produce extremely clean (tritium free) deuterium and protium streams to minimize atmospheric tritium release.

\subsubsection{Naturally-Cooled Hydride Storage Bed}

Current design of the hydride beds for tritium storage requires an extensive heating and cooling system. An improved design using natural convection for cooling and electric heaters for heating can be developed. 


\subsubsection{Electrolysis for Tritium Recovery from Tritiated Water}

Current method to recover the tritium from the tritiated water collected in the zeolite beds uses depleted uranium (or magnesium) to crack the water. The uranium becomes uranium oxide and is a source of solid waste. A new method under development uses electrolysis to crack the water. Using electrolysis can eliminate the solid waste.

\subsubsection{Non-Oxidative Tritium Strippers}

Another potential new method to strip tritium from glovebox atmosphere is to use getter beds. These getter beds can strip tritium in its elemental form (without changing tritium to oxide), which will reduce waste and eliminate the hazard of handling tritiated water. 
Figure 9.1

\section{TRITIUM EXTRACTION AND PURIFICATION \\ FOR \\ ACCELERATOR PRODUCTION OF TRITIUM \\ PROCESS FLOW SHEET}

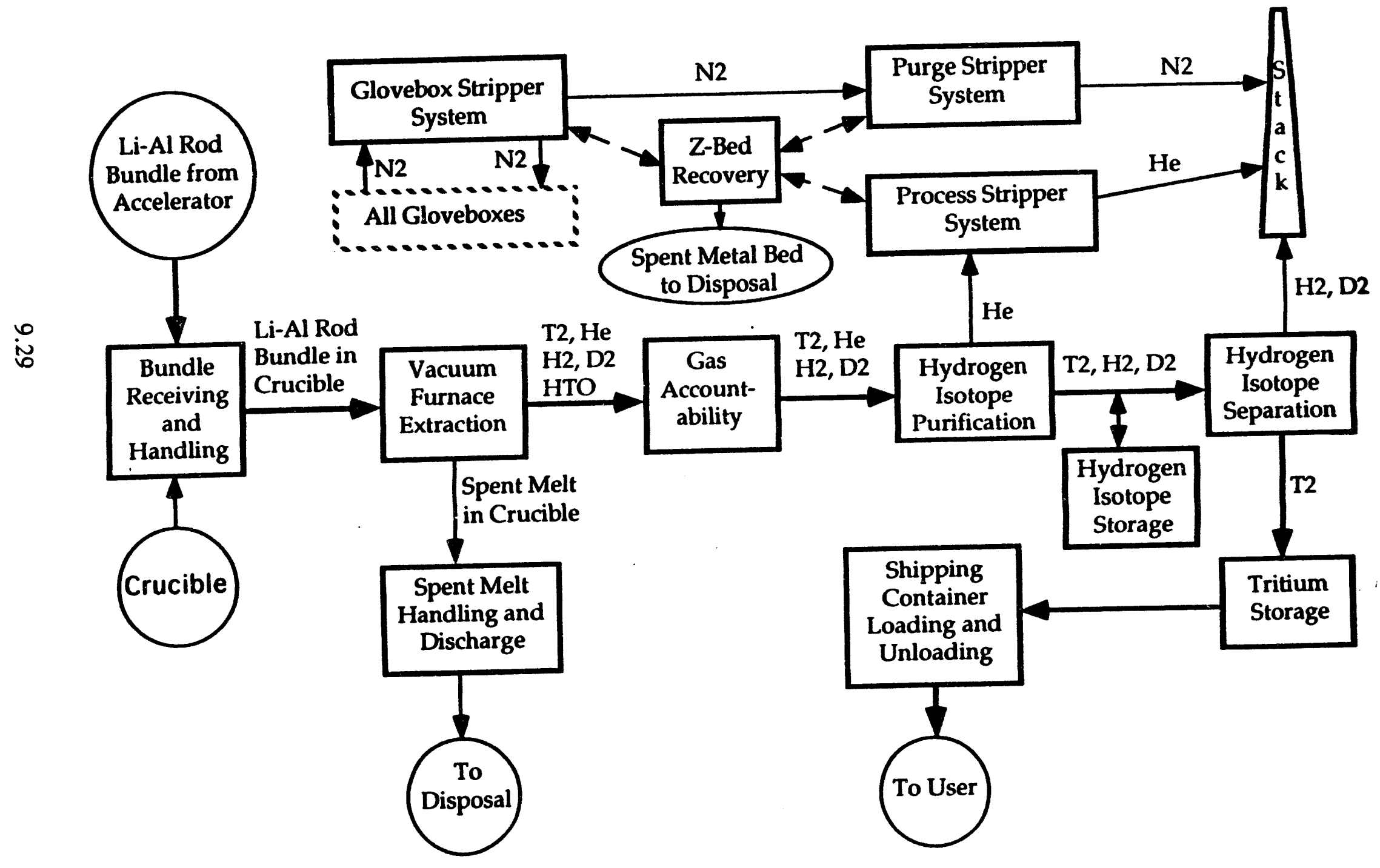


Figure 9.2

\section{Li-Al Rod Bundle Receiving, Extraction and Spent Melt Handling}

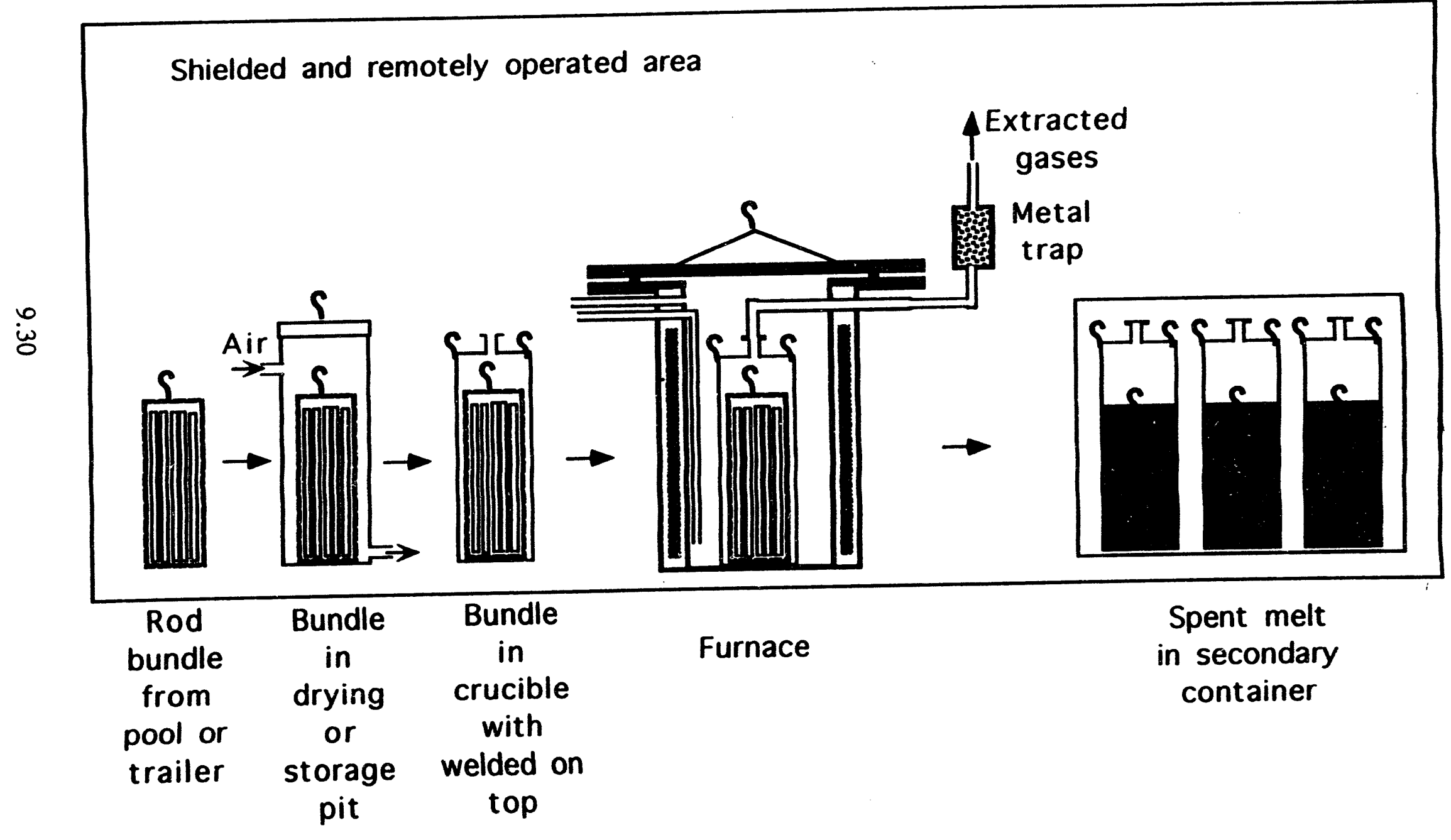


Figure 9.3

\section{Gas Accountability}

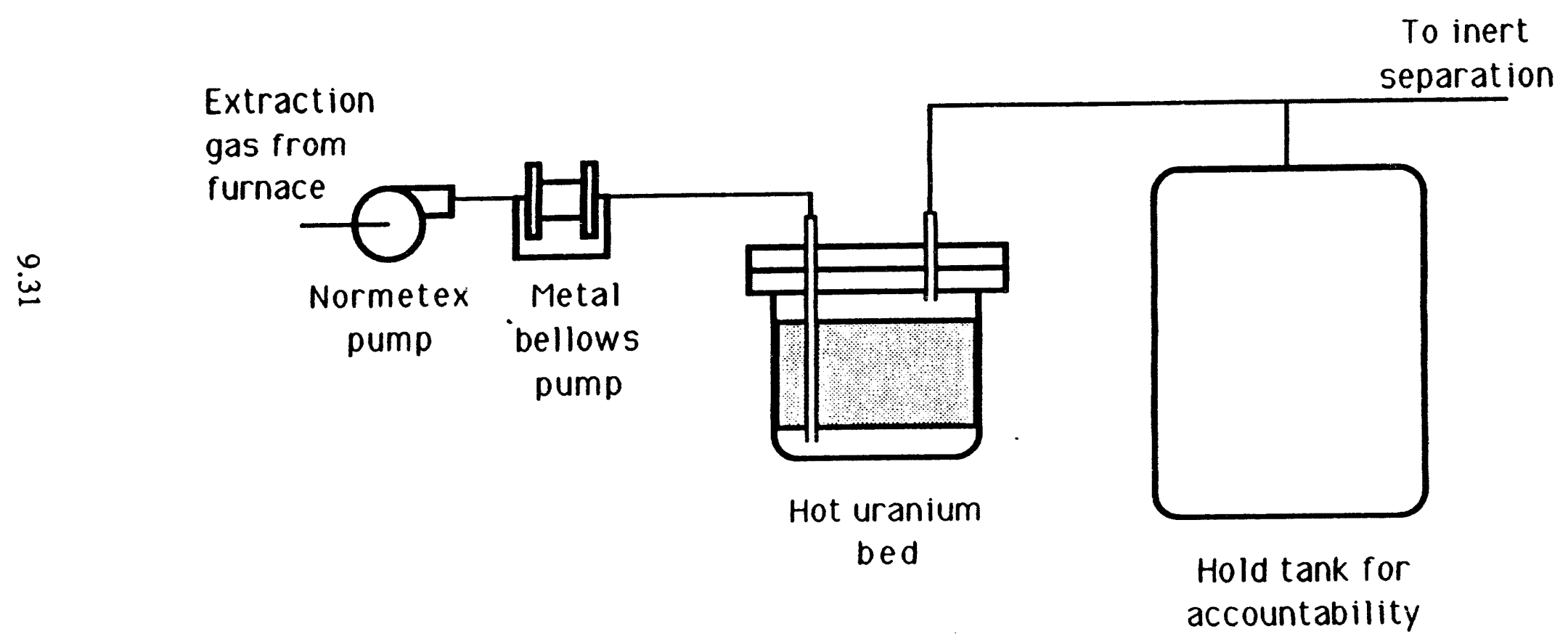


Figure 9.4

Inert Separation

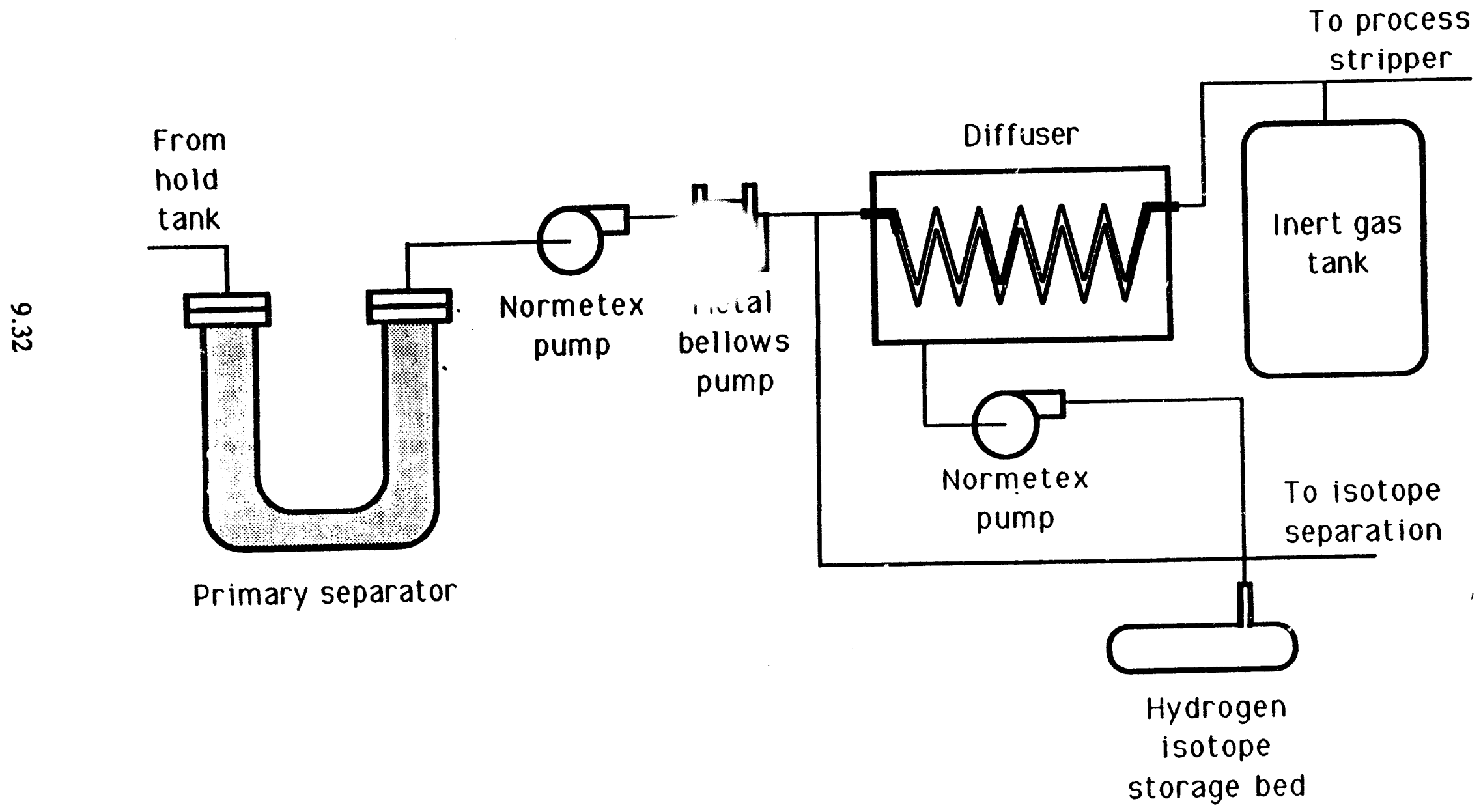


Figure 9.5

Hydrogen Isotope Separation

(Thermal Cycling Absorption Process)

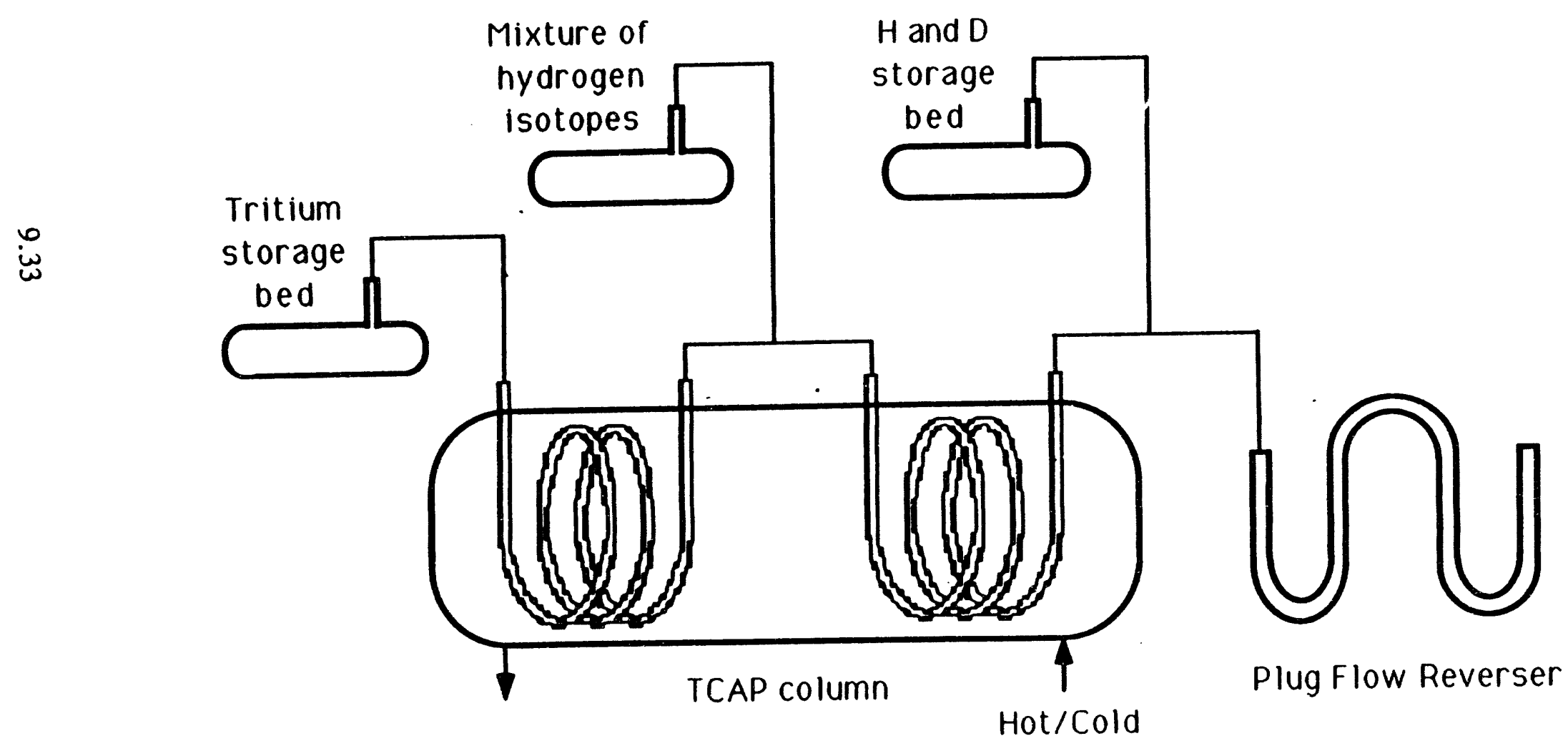


Figure 9.6

Cryogenic Distillation for Hydrogen Isotope Separation

$\varliminf_{\triangleright}^{\infty}$

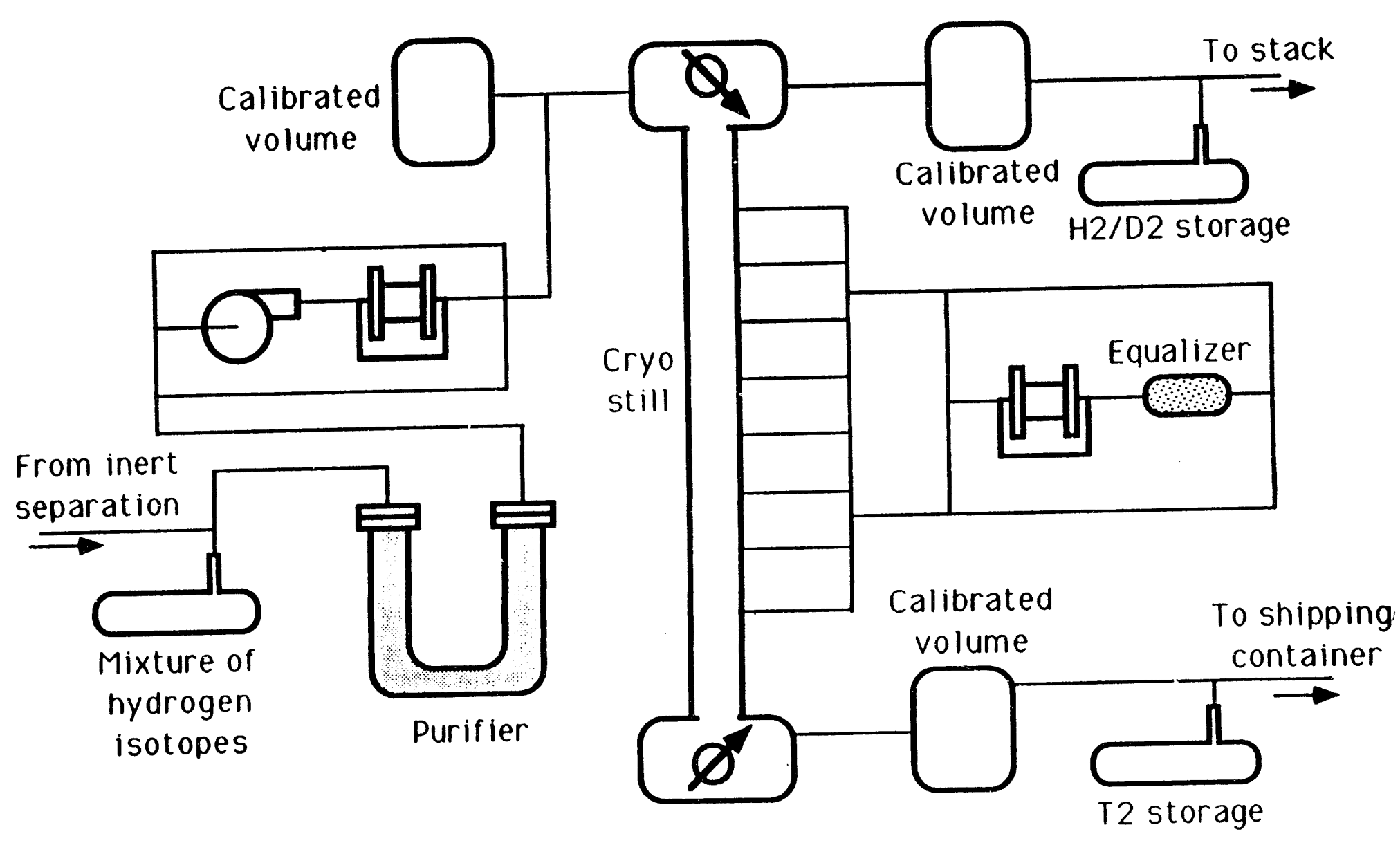


Figure 9.7

\section{Shipping Container Loading and Unloading}

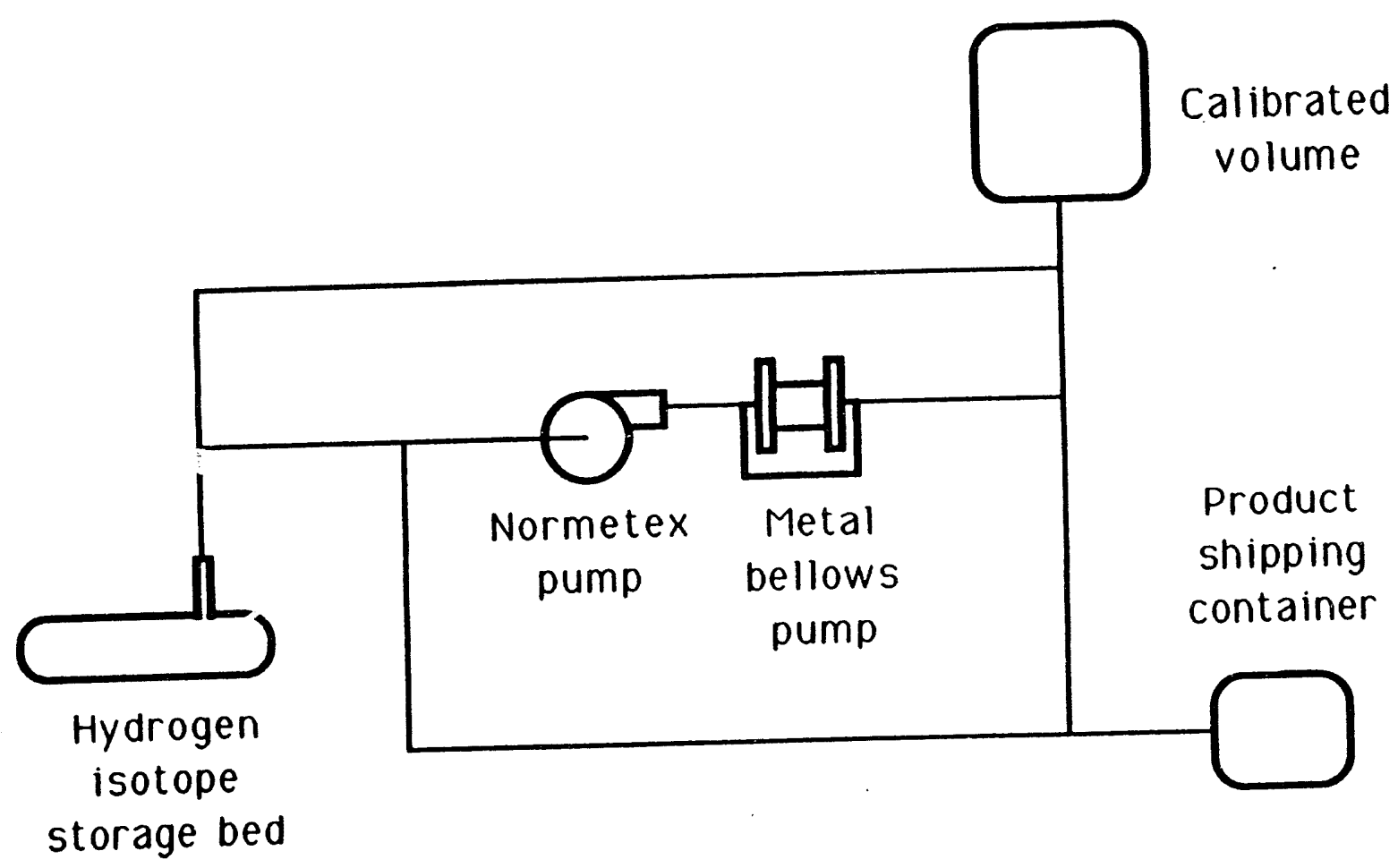


Figure 9.8

Glovebox Stripper System

$\underset{\sigma}{o}$

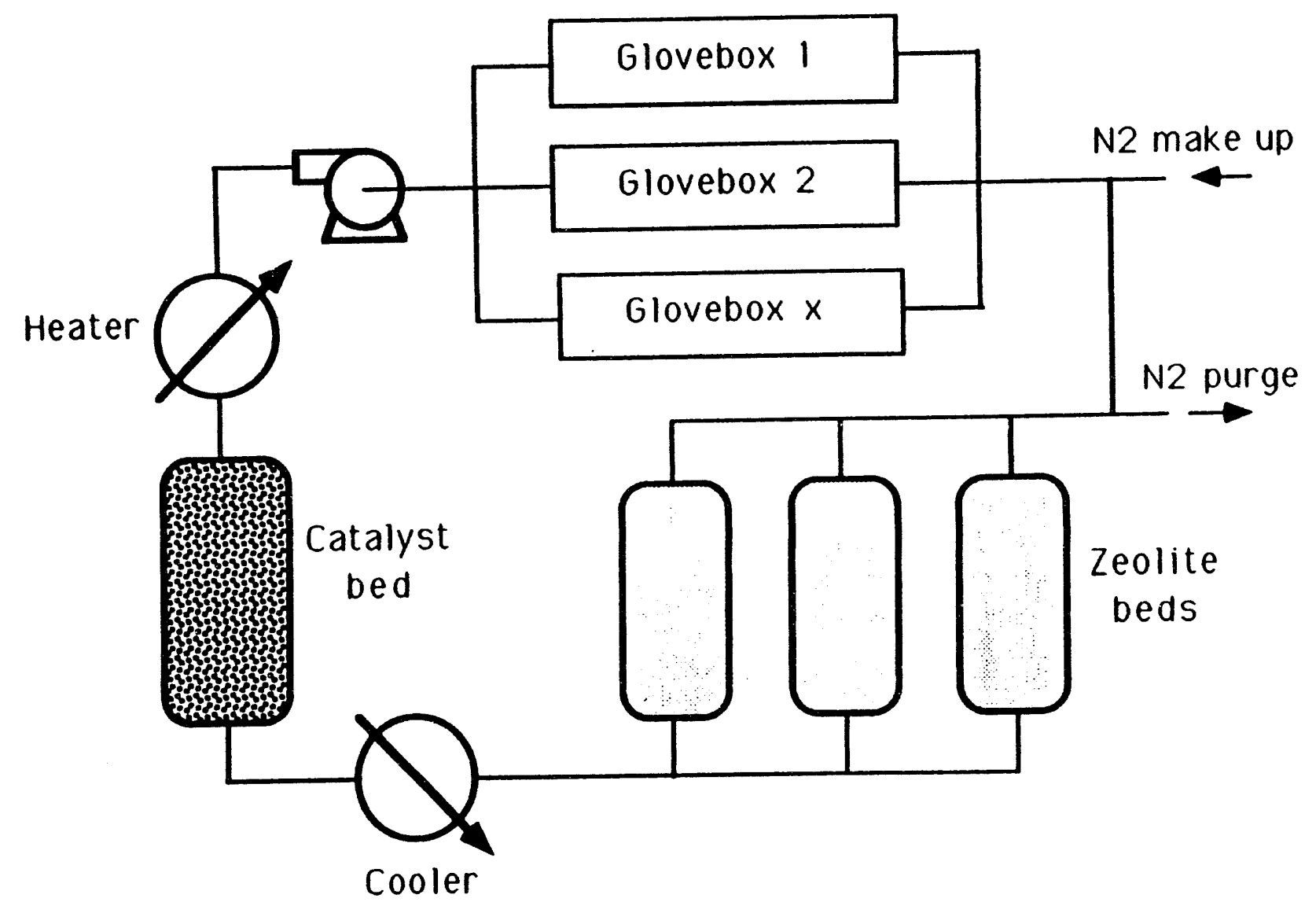


Figure 9.9

\section{Purge Stripper System}

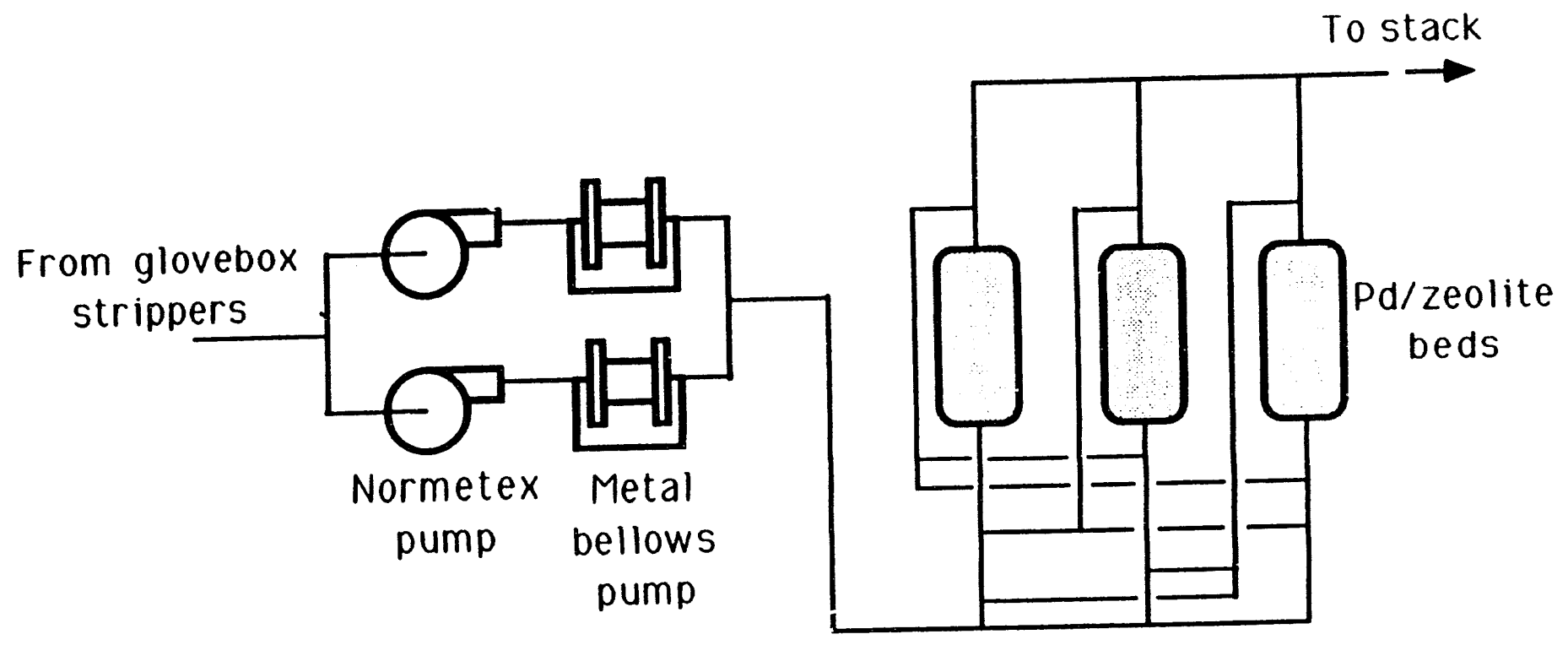


Figure 9.10

Process Stripper System

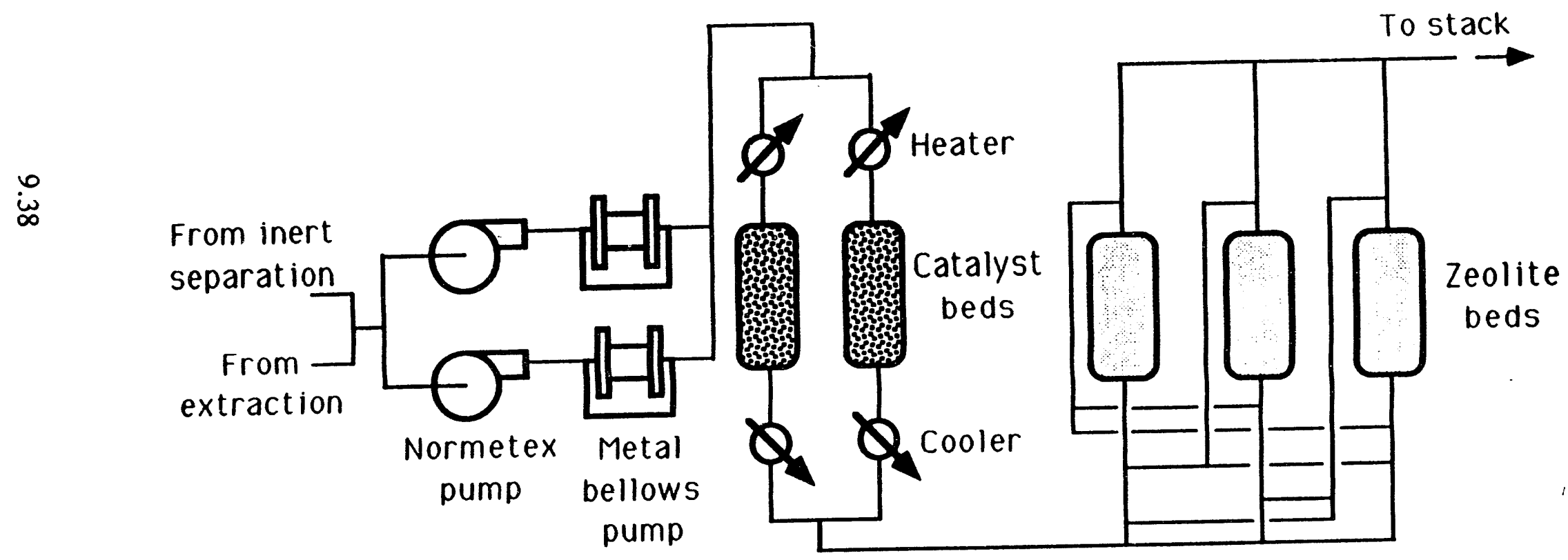


Figure 9.11

\section{Z-Bed Recovery System}

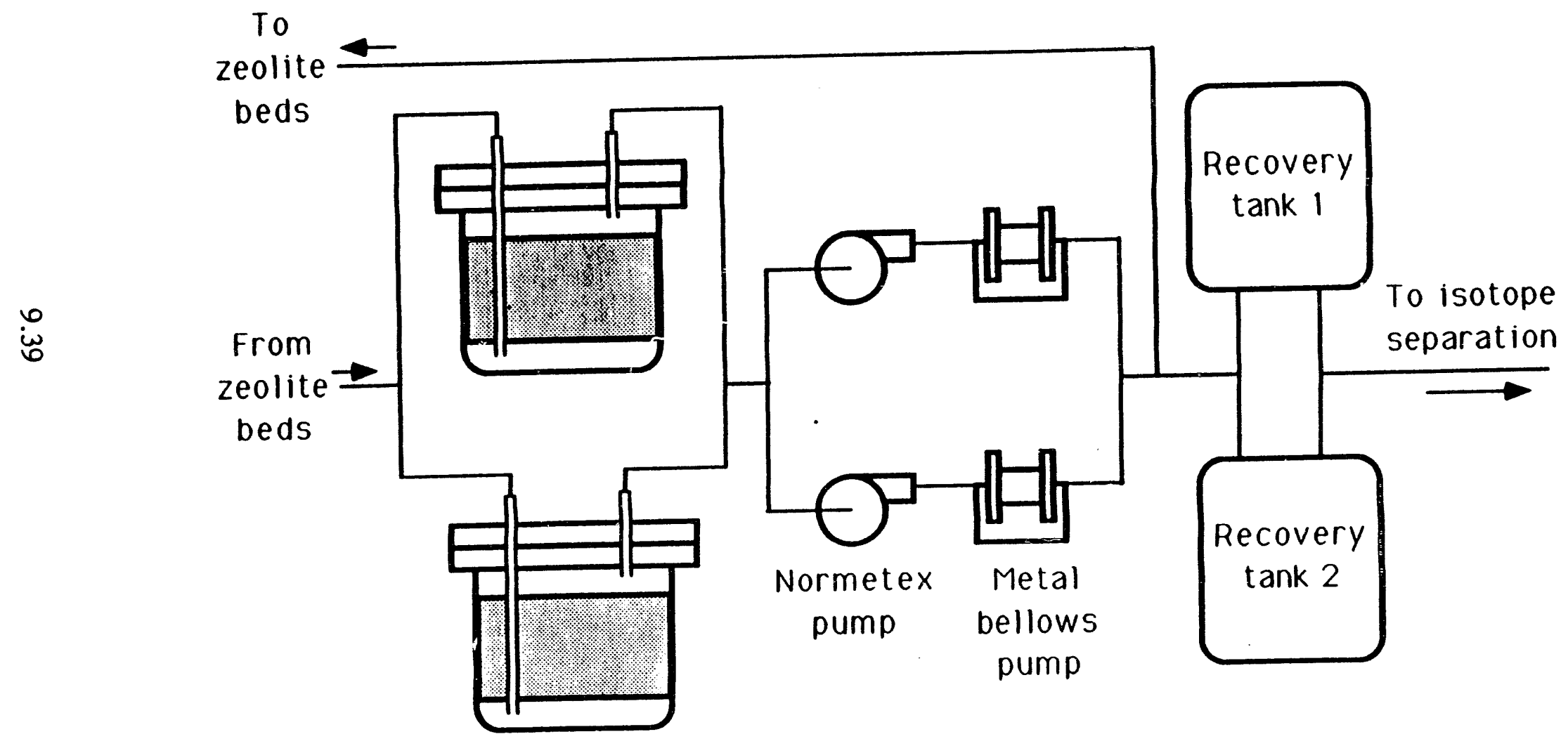

Hot uranium

bed 
Appendix 9A

Tritium Release Estimate For

Accelerator Production of Tritium (U) 
¿SRTC

Date:

$7 / 19 / 93$

TO: $\quad$ R. Lewis Steinhoff, DP -42

Eena-Mai Franz, BNL

FROM: $\quad$ J. R. Knight, WSRC, 773-A

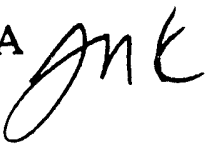

CC: T. Motyka, 773-A

L. K. Heung, 773-A !

D. D. Wilhelm, 235- $\mathrm{H}$

\section{TRITIUM RELEASE ESTIMATE FOR ACCELERATOR PRODUCTION OF TRITIUM (U)}

Attached is a memo addressing an action item on tritium release from the APT Tritium Processing Meeting on 6/30/93 at DP-42.

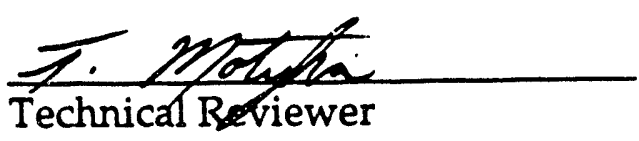

Derivative Classifier

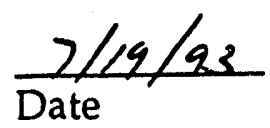

$\frac{7 / 19 / 63}{\text { Date }}$ 


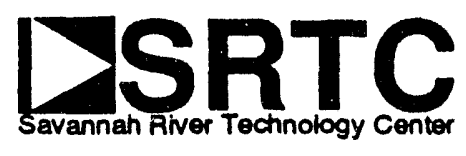

Date: $\quad 7 / 19 / 93$

TO: $\quad$ T. Motyka, 773-A

FROM: $\quad$ L. K. Heung, 773-A $\mathcal{L} K H$

\section{TRITIUM RELEASE ESTIMATE FOR ACCELERATOR PRODUCTION OF TRITIUM (U)}

This memo addresses an action item on tritium release from the APT Tritium Processing Meeting on $6 / 30 / 93$ at DP-421. An estimate of the maximum tritium release from the tritium extraction and purification operations of the APT is required for an upcoming PEIS.

Tritium release from a tritium extraction and purification facility can come from several sources:

- Extraction furnace if $\mathrm{Li}-\mathrm{Al}$ is usedas a blanket material. (Helium piping if helium gas is the blanket material)

- Isotope separation from protium and deuterium by-product.

- Purge stripper, which strips tritium from glovebox effluents before it is sent to the stack.

- Process stripper, which strips tritium from process waste gas before it is sent to the stack.

- Maintenance operations.

This estimate is based on the results of an earlier report which was prepared for a similar, but larger capacity, facility 2 . For those release sources which are dependent on the capacity, a factor of $3 / 8$ has been used to scale down the values. No scale-down factor is used for the other release sources which are not capacity dependent. The maximum total release is estimated to be $10,000 \mathrm{ci} /$ year. The values from individual sources are summarized below: 


\begin{tabular}{ccc}
\hline Source & $\begin{array}{c}\text { Goal Capacity } \\
\text { (ci/year) }\end{array}$ & $\begin{array}{c}3 / 8 \text { goal } \\
\text { (ci/year) }\end{array}$ \\
\hline Extraction furnace & 4000 & 1500 \\
Isotope Separation & 4380 & 1643 \\
Purge Stripper & 3941 & 3941 \\
Process Stripper & 1761 & 1761 \\
Maintenance & 300 & 300 \\
Total & & 9145 \\
& & (Called 10,000)
\end{tabular}

The values listed above are estimates based on SRS's past process history and current experience. The $10,000 \mathrm{ci} /$ year total should be considered an upper limit for conceptual design. The final design limit and the actual operating limits are expected to be less in keeping with ALARA goals.

\section{REFERENCES}

1. R. L. Steinhoff, DP-42, APT/070831I278.

2. J. E. Koonce, "Functional Design Criteria, Replacement Tritium Purification Facility, Building 231-H (U)", 9/23/91, WSRC-RP-91-942. 

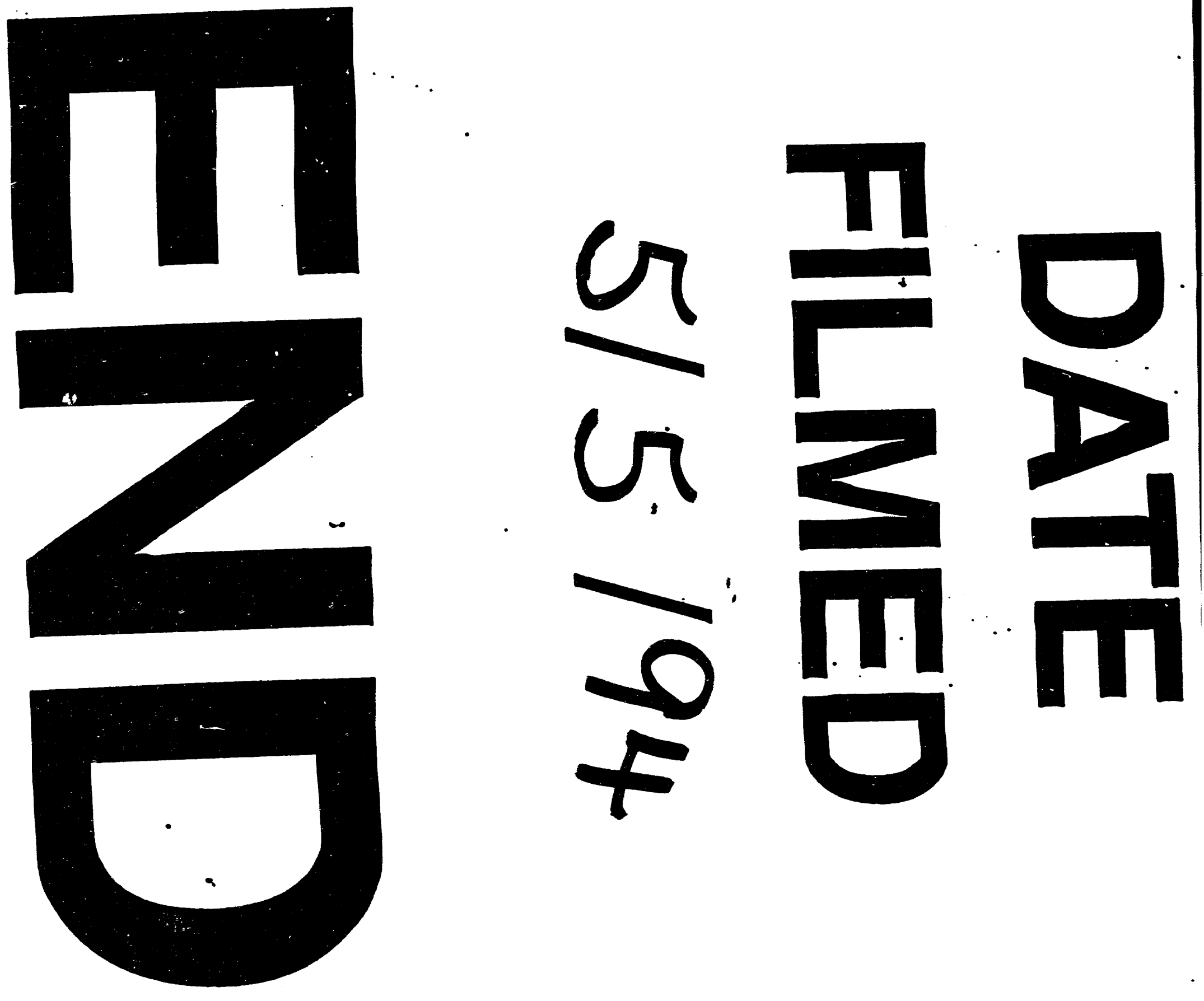


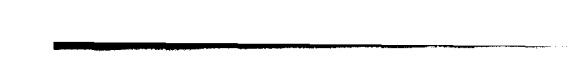

